\title{
Boring Formless Nonsense
}

(or, On The Aesthetics of Failure in Recent Experimental Composition)

by

eldritch Michael Priest

A thesis submitted to the Faculty of Graduate and Postdoctoral Affairs in partial fulfillment of the requirements for the degree of

\author{
Doctor of Philosophy \\ in \\ Cultural Mediations
}
Carleton University
Ottawa, Ontario

(C)2011

eldritch Priest 


$\begin{array}{ll}\begin{array}{l}\text { Library and Archives } \\ \text { Canada }\end{array} & \begin{array}{l}\text { Bibliotheque et } \\ \text { Archives Canada }\end{array} \\ \begin{array}{l}\text { Published Heritage } \\ \text { Branch }\end{array} & \begin{array}{l}\text { Direction du } \\ \text { Patrimoine de l'édition }\end{array} \\ 395 \text { Wellington Street } & \begin{array}{l}395, \text { rue Wellington } \\ \text { Ottawa ON K1A ON4 } \\ \text { Canada }\end{array} \\ \begin{array}{l}\text { Ottawa ON K1A ON4 } \\ \text { Canada }\end{array}\end{array}$

Your file Votre référence
ISBN: $978-0-494-81589-2$
Our file Notre référence
ISBN: $978-0-494-81589-2$

NOTICE:

AVIS:

The author has granted a nonexclusive license allowing Library and Archives Canada to reproduce, publish, archive, preserve, conserve, communicate to the public by telecommunication or on the Internet, loan, distribute and sell theses worldwide, for commercial or noncommercial purposes, in microform, paper, electronic and/or any other formats.

The author retains copyright ownership and moral rights in this thesis. Neither the thesis nor substantial extracts from it may be printed or otherwise reproduced without the author's permission.

L'auteur a accordé une licence non exclusive permettant à la Bibliothèque et Archives Canada de reproduire, publier, archiver, sauvegarder, conserver, transmettre au public par télécommunication ou par l'Internet, prêter, distribuer et vendre des thèses partout dans le monde, à des fins commerciales ou autres, sur support microforme, papier, électronique etlou autres formats.

L'auteur conserve la propriété du droit d'auteur et des droits moraux qui protège cette thèse. $\mathrm{Ni}$ la thèse ni des extraits substantiels de celle-ci ne doivent être imprimés ou autrement reproduits sans son autorisation.
In compliance with the Canadian Privacy Act some supporting forms may have been removed from this thesis.

While these forms may be included in the document page count, their removal does not represent any loss of content from the thesis.
Conformément à la loi canadienne sur la protection de la vie privée, quelques formulaires secondaires ont été enlevés de cette thèse.

Bien que ces formulaires aient inclus dans la pagination, il n'y aura aucun contenu manquant.

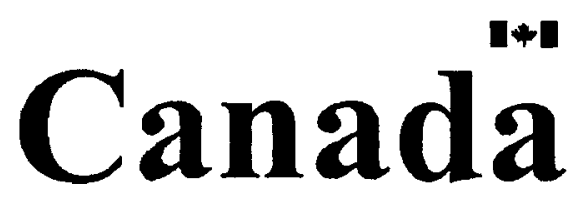




\section{Abstract}

Failure has been an implicit theme in the arts since at least the beginnings of the modernist era. More recently, cultural practices have made failure an explicit and positive theme whose expressions pivot on the contestation of both modernism's utopian bid for a master aesthetics and post-modernism's optimistic investment in difference. Yet failure, like so many avant-garde artistic strategies of the twentieth century, has become blunted by its own satisfaction, its critical edge dulled by a belief that the transgression of expectations is sufficiently productive. In a sense, failure has failed. Failure in art is expected and so short-circuits its ways to success, leaving the irregular elements of experience that it stands for to go to weed. What then can be made of this "weed garden" that failure remainders? Or, how might one imagine an aesthetics of failure wherein hesitation, lack of concentration, duplicity and other markers of insufficiency are not simply recuperated as a kind of inverted success but are permitted to breed and proliferate in the slow creep of their own boring formless nonsense? In this dissertation I try to answer that question by looking at failure through contemporary experimental composition that takes its cues from preoccupations other than those characterized by the normative avant-garde gesture of (self)reproach. Drawing on theoretical approaches to contemporary culture including Sianne Ngai's concept of the aesthetic "stuplime," Rei Terada's theory of "phenomenophilia," and Gilles Deleuze's theory of sense, I suggest that an aesthetics of failure resonates with a broader set of cultural logics that revolve around the mechanics of depression, distraction, and prevarication. I conclude that recent experimental compositions engage with failure not as a celebratory phenomenon but as a strategy for coping with the apparent horizonless vista of contemporary culture. 


\section{Acknowledgements}

I am extremely grateful to my advisor, Geraldine Finn, whose support and counsel as well as her commitment to the adventure of thought helped make the morass of my own thinking, if not entirely clear (to me), then at least (partially) interesting. I am also thankful to my other readers, Jill Carrick and Jesse Stewart, who have been generous in their time and their words. I would also like to thank the composers who spoke with me, and were kind enough to provide me with scores and recordings of their work as these, for the most part, are not commercially available. Thank you to Timothy Murray and The Society for the Humanities at Cornell University, and to Brian Massumi for allowing me to crash his course during my stay in Ithaca. Numerous friends and colleagues have supported this work, some by their camaraderie, including Rory Magill, Lindsey Wellman, David Brosco, and others through their interest in my study such as Michael Urbanski and David Cecchetto. But special thanks must be made to Marc Couroux for encouraging this dare and being part of its strange feedback loop, and John Mark Sherlock for his moments of therapeutic lucidity and staunch refusal to say "simulacrum" properly. My parents, of course, must be acknowledged, if not only for their boundless supply of emotional and financial support, then for having the courage to not completely understand what I've been up to all these years, yet love and encourage me anyways. Thank you also to Penelope whose wish is my command and unbridled success is my wish. And lastly, my immense gratitude to Claudette Lauzon who I shower with love and illimitable thanks for helping me edit and prepare this document, but most of all for the immeasurable gift of patience and love that I know I will spend my life failing to match. This work is dedicated to Aaron Granville-Martin and David Foster Wallace. 


\section{Contents}

Abstract $\quad$ ii

Acknowledgements $\quad$ iii

Table of contents

Introduction 1

One: Boring

Introduction $\quad 42$

A boring history $\quad 55$

Cage, Fluxus and Extendedness in the 1960s and 70s 67

The Aesthetics of Boredom and the Art of Waiting 83

The Premises/Promises of Aesthetic Boredom 91

A Less Promising Boredom 93

Uglier Feelings of the Stuplime 101

Post...Death... 115

$\begin{array}{ll}\text { Afterthought... } & 119\end{array}$

Two: Formless

Pretext 124

(Informe) 130

How to read this chapter $\quad 136$

$\begin{array}{ll}\text { Story } & 137\end{array}$

Becoming Formless 148

Music Noise 156

Recording Distraction 162

---Multitasking 171

$\begin{array}{lr}\text { Capture and Escape } & 174\end{array}$

Lull ))) ))) )))

$\begin{array}{ll}\text { Listening to SoS\#16's Lull }))))) & 188\end{array}$

$((((($ Listening Away $))))) \quad 190$

Muzak's Way of Dreaming Ubiquitously $)))) \quad 194$

---Notes on Muzak 194

--Quantum Modulation 194

We don't (((listen))) anymore 197

The (((Sound))) of Habits $\quad 200$

Sound-Effects $\quad 203$

))))) Charm and Dissatisfaction 208

$\begin{array}{lr}\text { Last))))) } & 219\end{array}$

Another Again 223

Three: Nonsense

(Voodoo 224

((Metareferentiality, Metamusic and Hypermusic $\quad 233$

(((Grúpat and Pseudonymity 238 
((((Symptoms, Syndromes and Hyperfiction $\quad 250$

((()(In a Sedimental Mood 255

(((()(Hyperstition, Magick and Nonsense 258

((( (((B)ecoming Karen et al, a Real-Time Hyperstition as of March
$\quad$ 30, 2007 By Karen Eliot

$\begin{array}{ll}((()(((O) \text { Lies } & 275\end{array}$

$((()(((($ What does music feel like? (or, 'on the refrain of pain and imagining'): Discursive Remainders from glossolalia (stress

positions) by Engram Knots

282

$\begin{array}{ll}(((()((((\text { glossolalia }(\text { stress positions }) & 288\end{array}$

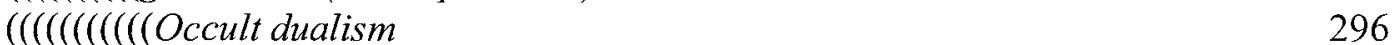

$\begin{array}{ll}((((()((((((\text { Illustrative Interlude: Practicing } & 299\end{array}$

$(((((((((((($ The sleep side of music and dream-work $)))))))))))))) \quad 302$

Inconclusion/This chapter is false $\quad 310$

$\begin{array}{ll}\text { ("Disclaimer") } & 318\end{array}$

$\begin{array}{ll}\text { Confabulation } & 319\end{array}$

$\begin{array}{ll}\text { Bibliography } & 326\end{array}$ 


\section{Introduction}

\section{Gamble}

This dissertation theorizes an aesthetics of failure in post-Cagean experimental composition. Failure here is approached as an ambivalent event — an approach that skews its more familiar reception in contemporary art as a form of resistance to, or critique of, aesthetic and social norms. In this study I suggest that failure is sounded out by recent compositions in their resonance with a set of affects and effects that characterize contemporary culture's efforts to cope with its own inconsistencies and contradictions.

Failure, of course, has been an implicit theme of the avant-garde since at least the beginnings of the modernist era. More recently, cultural practices have made failure an explicit theme whose expressions pivot on creative practices and artworks that contest modernism's utopian bid for a master aesthetics and complicate post-modernism's optimistic investment in difference. Yet failure, like so many avant-garde artistic strategies of the past century, has become blunted by its own satisfaction, its critical edge dulled by a belief that transgression of expectations is sufficiently productive. In a sense, failure has failed. Failure in art is expected and so short-circuits its way to success, leaving the irregular elements of experience that it stands for to go to weed. What then can be made of this "weed garden" that failure remainders? Or, how can one imagine an aesthetics of failure wherein hesitation, lack of concentration, and duplicity are not simply recuperated as a kind of inverted success but are permitted to breed and proliferate in the slow creep of their own boring formless nonsense? In this dissertation I try to answer that question by looking at failure through contemporary experimental 
composition that takes its cues from preoccupations other than those characterized by the normative avant-garde gesture of (self)reproach. As such, the sense of failure that I draw from this music is one whose weave is slack and uneven as it touches upon several areas of contemporary culture's current expressions of disease including depression, distraction and, disinformation. I conclude that contemporary experimental composition points to failure not in its forms of error or insufficiency, but in its expression as a risk, or wager, a pure potentiality.

But right off I will reveal that there won't be any fussing over the way failure and success spiral around each other. While it can be momentarily amusing to occupy oneself with the semantic loop that arises if one intends to fail and does so, whereupon one succeeds and therefore fails to fail, but in failing to fail one fails and therefore succeeds, and so fails again and succeeds again...I prefer not to. I don't suggest by this declination, this "Bartlebyism," that there are better things to do than ride this corkscrew of thought. I do however contend that there are fewer words to play with and fewer hands to play if all we want to do is "solve" this paradox. We can play a game of tag or we can play poker. While poker is probably not superior to tag when it comes to the point(lessness) of games, at least it has "straights" and "flushes," "flops" and "pocket kings," "folds" and "bluffs" by which the difference among the ranks of royals and suits is more variedly expressed. Failure, in other words, figures in what follows not as a paradox but as a gamble.

But let me also say that I have no intention of defining failure. Not only is the work of defining failure exactly the kind of thing that is not going on in the musical practices that comprise this study, but failure is itself a radically relational term that, despite its seeming finality and veiled fatalism, is easily overturned or inverted with the 
simplest change of context or relevance. Consider how easily Thelonious Monk's (relatively) awkward and somewhat clumsy playing style was reimagined as "inventive" and "imaginative," and how often film flops become cult favorites (like current rep cinema darling Tommy Wiseau's The Room of 2003). ${ }^{1}$ In fact, the history of twentiethcentury art can be seen as a continuous reversal of failures: from fascist lunatic "noise" to visionary sound art (Luigi Russolo's Gran Concerto Futuristico), and from an ordinary pisser to an acute conceptual vector (Marcel Duchamp's Fountain). ${ }^{2}$

Secondly, failure as a term of art becomes, like Roland Barthes' le neutre, George Bataille's informe, or Derrida's "différance," a fugitive concept—one that evades those structures of thought and expression that impose themselves as obligatory, but which at the same time is only conceivable and sensible through those same structures. For instance, Barthes concept of le neutre as an impossibly impartial position within discourse is undermined with every illustration of it, for as he himself notes, "to utter a word is immediately to affirm its referent."3 To affirm something is to determine its position and thereby to say something about this "something" debars it from both "the perfection (the respite) of the negative"4 and the indifference of the neutral. As such, Barthes can never unequivocally say what le neutre is. His only option is to confound language, to battle it. And Barthes does exaclty this: He battles language not by refusing to speak, but by distracting and baffling language with extemporizations on subjects that hinge on ambivalence such as "silence," Zen, negative theology, Pyrrhonic skepticism,

\footnotetext{
${ }^{1}$ See Tom Bissell, "Cinema Crudité The Mysterıous Appeal of the Post-Camp Cult Film," Harper's Magazme, August 2010, 60

${ }^{2}$ Both, perhaps coincidentally, from 1917

${ }^{3}$ Roland Barthes, The Neutral Lecture Course at the Collège De France, 1977-1978, trans. Rosalınd Krauss and Denıs Hollier (New York Columbia Unıversity Press, 2005), 42

${ }^{4}$ Ibıd , 43
} 
affect, and androgyny. Essentially, what Barthes practices is a form of discursivity that respects discourse's capacity for digression and drift. By "riffing" on a thematic ambivalence, Barthes illuminates the sense of the neutral in passing, his improvisations each producing a peculiar angle that allows us to register what he calls the "twinklings" of le neutre. While this generates the impression that Barthes is merely practicing a form of free association, he is in fact creating an anamorphoric discourse, a discourse whose distorted form appears intelligible only when viewed from particular gaze or at a particular angle. This kind of discourse is a way to "sidestep assertion,", which itself is an expression of the way that le neutre must work to evade the authority that of the "laws" that discourse generates by virtue of its habit of iteration.

The "sidestepping" of assertion can itself be understood as an expression of failure insofar as the implicit explication of le neutre can go easily unnoticed. That is, the obliquity of Barthes' disquisitions on the neutral - a technique that in-folds rather than un-folds the many ways in which le neutre's evasion (dis)locates a paradoxical (pro)position such that it asserts its own non-assertion-may fail to be perceived and appreciated. Failure rings through Barthres' notion of the neutral not so much as an analogous paradox of explicable inexplicability, but in the way that its figure, too, participates in the "implicarity" of its expression. If it's to avoid an explication that converts its dim twinklings into shining successes, the implication of failure must take a chance in not being registered or discerned. And it is in this respect, that failure begins to resemble a gamble, for there is no certainty that failure's significance as a virtual or implicit cipher for the relevant beliefs, expectations and goals of a culture or social group

\footnotetext{
${ }^{5}$ Ibid.
} 
will be perceived in such a warped discursive hand. Yet it is perhaps in mistaking failure's implication for the lack of an explication that failure fails to be even a gamble. So opaque are its insinuations and suggestions that the allusive risk of failure, the very capacity to be otherwise than what's expected, is lost to its own digressions. But then again, maybe that is its interest, for failure can only ever succeed, and this success is failure's failure.

With this in mind, and before I state my own thesis, I want to look at the different ways that failure has been theorized and thematized, and draw out some of the (in)felicities of these approaches. While the following commentary respects the digressive nature of discursive matter by surveying a broad range of failures, I nevertheless follow a certain drift that describes, somewhat circuitously, the arc of failure's increasing abstraction as it passes from the familiar halting of malfunction, through the wonder of naiveté and frustration of undecidability, to the sublimated ambivalence of absolute potential.

\section{Failure}

A country road. A tree. Evening. Estragon, sitting on a low mound, is trying to take off his boot. He pulls at it with both hands, panting. He gives up, exhausted, rests, tries again. As before. Enter Vladimir.

Estragon: (giving up again).

Nothing to be done.

Vladimir: (advancing with short, stiff strides, legs wide apart).

I'm beginning to come round to that opinion. All my life I've tried to put it from me, saying Vladimir, be reasonable, you haven't yet tried everything. And I resumed the struggle.

(He broods, musing on the struggle. Turning to Estragon.)

So there you are again. 
Though as tıred and worn as Estragon's boot, the opening lines of Watting for Godot are the archetypal image of modern fallure a struggle, a meditation, and nothing to be done The passion of the mystic and the clown, where holy resignation is a practical joke Most accounts that take fallure as an explıcit theme revolve around just this kind of dialectrcal recuperation, where a conflicted existentiale spins and stalls on the coincidence of futility and stubborn persistence Take, for instance, a recent edited volume on failure in contemporary art, several of the collected writings, from artist statements to critical essays, represent faılure in relation to terms that fixate on the way mutual negations paradoxıcally affirm each other, from Søren Kıerkegaard's take on rony ("1t can be just as 1 ronic to pretend to know when one knows that one does not know as to pretend not to know when one knows that one knows") ${ }^{6}$ to Julian Schnabel's description of his own art as "a bouquet of mistakes" ("I am makıng a synonym for the truth with all its falsehoods") ${ }^{7}$ But perhaps the most prevalent image of fallure, in this volume and in contemporary culture at large, is the myth of Sisyphus A king punished by the gods for his impudence is infected with an interminable compulsion to repeatedly push, carry, or roll an immense stone up a hill and then watch it tumble down What the expression "Sisyphean" captures is nothing less than the sentıment and affection of an "eternal involvement"- existentialism's code for "life" Hence Beckett's equally resonant and affecting, "All of old Nothing else ever Ever tıred Ever falled No matter Try again Fall again Fall better "8 But there is something queer about these words whose rhythm

\footnotetext{
${ }^{6}$ Søren Kierkegaard, "The Concept of Irony," in Lisa Le Feuvre, Fallure (Cambridge, MA MIT Press, 2010), 73

7 Julıan Schnabel, Statement," in ıbıd, 131

${ }^{8}$ Samuel Beckett, Worstward Ho (London John Calder, 1983), 7
} 
extracts a sense of life from their own entropic despair to suggest that something productıve or generatıve lıes withın the downward spıral of miscarrıages And indeed, as writer-artist Emma Cocker contends, the Sisyphean task is "more than a model of endless or uninterrupted contınuation of action it is a punctuated performance " ${ }^{\circ 9}$ While the sense of the "task" remains the same across every tteration of the "un-deed"-a goal, an action, an insufficient attempt-the Sisyphean gesture itself has the potential to be endlessly individuated or actualized And this potential is in its punctuation, in the interval where the task rests and difference slips in, creatıng "a pause for thought, a space for thinking $" 10$

The pause, what Camus, in his Le Mythe de Stsyphe (1942) called a "breathingspace," is nestled in the circuit of fallure as a splinter of heightened awareness that carries a potentıal for a difference that "produces an unexpected surplus, the residue or demonstration of wasted energy "11 Surplus is where fallure's specificity abides, a specificity that exposes a culture's limits and absurdities, its structures of desire and orders of the real Much of the conceptual and post-conceptual art that emerged from the experiments of the 1960 s and 70 s can be seen as attempts to 1solate and express this surplus For instance, John Baldessari's Throwing four balls in the alr to get a square (best of 36 tries) (1974) - a sequence of eight photographs that capture a hand throwing four balls into the air, almost but not quite forming a square-expresses a ocular surplus in the way an initially narrow demonstration of repeated fallures can become seen as ınadvertent jugglıng act More recently, Belgian artıst Francis Alys' video work, The

\footnotetext{
${ }^{9}$ Emma Cocker, 'Over and over, Again and Again," in ıb1d , 154

${ }^{10}$ Ib1d , 155

${ }^{11}$ Ib1d, 156
} 

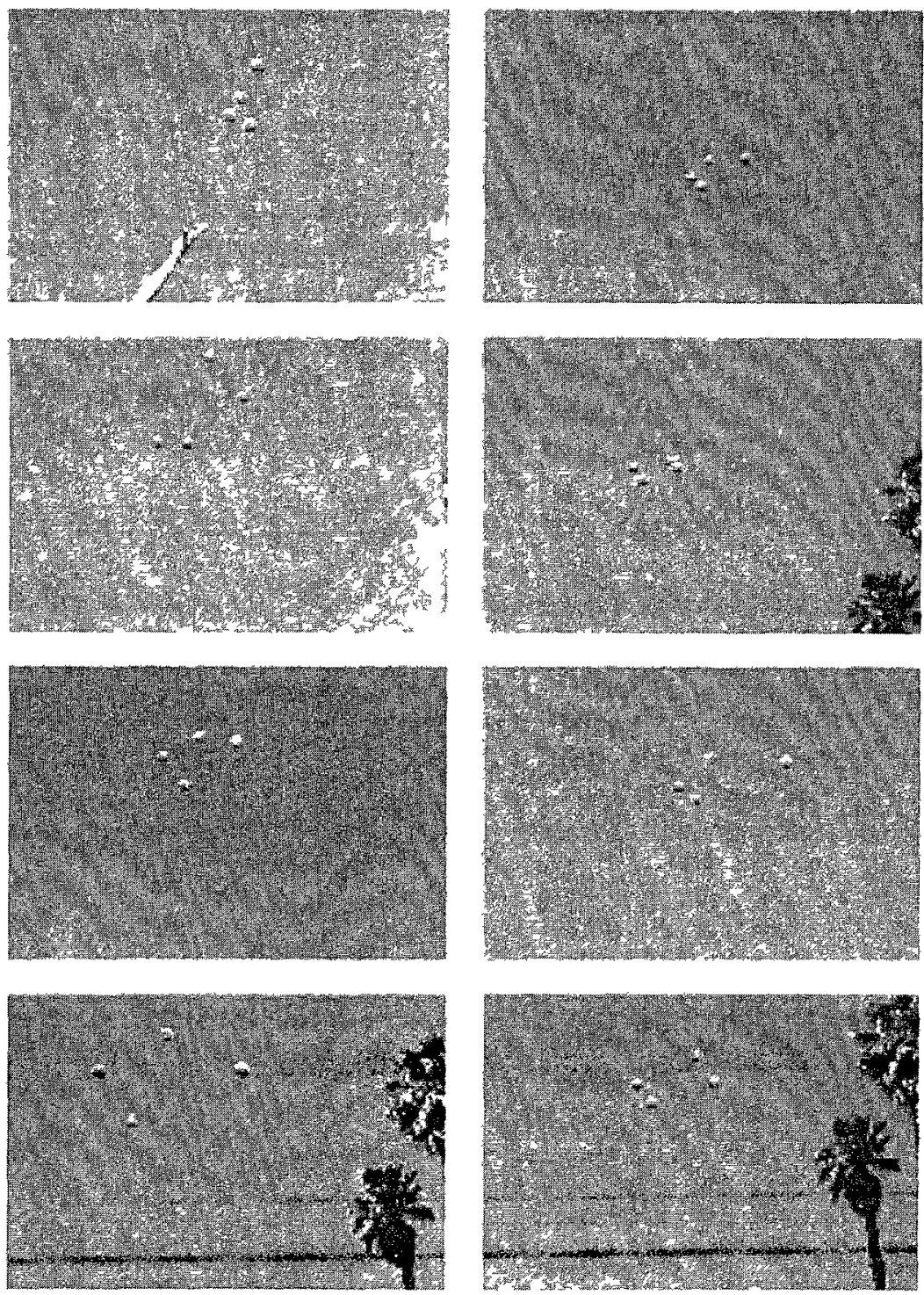

Throwing four balls in the air to get a square (best of 36 tries) (1974) John Baldessari 
Rehearsal (II) (2001), which shows a burlesque dancer practicing her routine in parallel to a musical rehearsal on the soundtrack, expands the ordinary flow of desire by extending its feeling into the the typically occulted time of production instead of limiting it to the time of the product. The rehearsal is Sisyphean insofar as its intended results-i.e. a swifter removal of the bra, a smoother transition from verse to chorus - can never be anything but "good enough," which is to say that practice has no end: it is excessive. Practice skews the concluding perfection of the perfect. To open practice to desire is to scar the verisimilitude of all performances, whether performances of gender, ownership, race, or even art, music, and thought, with the sense of their own ongoing imperfection. In chasing failure and its factious breathing space, these works, and presumably those who experience them, are led to new events, new ways of expressing the sense, or the nonsense as it were, of failing.

It is the expression of an incidental and immanent excess, the "silver-lining" to Sisyphus's plight, that is the hidden grace of failure, and it is the most common way that art is thought to engage with it. In fact, I would suggest that Cocker's view of failure as "a device for deferring closure or completion, or... a mode of resistance through which to challenge or even refuse the pressures of dominant goal-oriented doctrines," ${ }^{12}$ can be taken as a general definition of an aesthetics of failure. The problem with this definition, however, is not only that it's too broad, but it's also too satisfying, too sufficient. It suggests that the aesthetic practices it applies to are certain of their own project and their own effects, that power is so clear a target and its agents so feeble that a well-aimed failure can safely and securely "rupture or destabilize the authority of the rule while

${ }^{12}$ Ibid. 


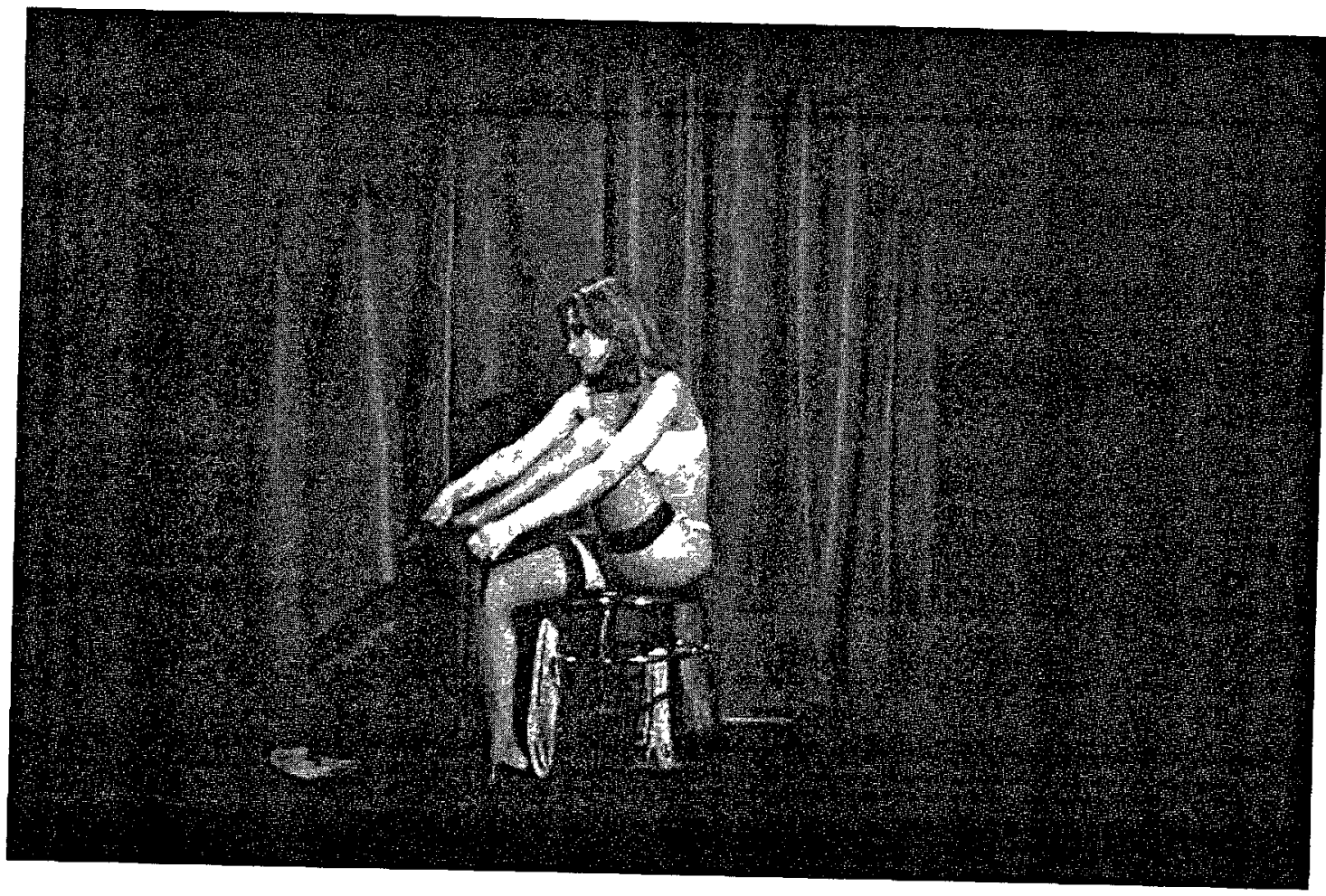

The Rehearsal (II) (2001) Francis Alÿs 
keeping it in place."13 As such, this "aesthetics of failure" misses the point, which is my point and thesis: that failure has no particular point, that it is radically perspectival and, ultimately, despite the regularities that restrict its measure, radically indeterminate.

The obvious way to explain this indeterminacy is that failure is essentially an assertion of "judgement relative to certain norms."14 But as historian of science and philosophy Koen Vermeir notes, norms are often vague, multiple, and part of a "broader framework of beliefs, expectations and goals"15 such that the judgement made in their regard is subject to perpetual revision. For instance, musician Kim Cascone's widely circulated essay about the aesthetics of failure in electronic music judges failure according to the conventional uses of digital technologies. ${ }^{16}$ Vermeir calls this convention a "function on which the characterisation or meaning of the artefact crucially depends," such as the ability for a bicycle, whether fast, slow, safe, or stylish, to "go," or an Mp3 player, whether an iPod or some cheap knock-off from China, to "play music." Cascone's expressions of failure--“"glitches, bugs, application errors, system crashes, clipping, aliasing, distortion, quantization noise, and even the noise floor of computer sound cards"18 — are judgements made according to the way they skew the assumed functionality of the digitally instrumentalized artefact, a functionality that in contemporary industrial cultures revolves around expressions of speed, connectivity (to other digital technologies), and simulation. Yet these "failures" are not naked failures.

\footnotetext{
13 Ibid.

${ }^{14}$ Koen Vermeir, "The Reality of Faılure. On the Interpretaion of Success and Failure in (the History and Philosophy of) Science and Technology," in Variantology 2 On Deep Time Relations of Arts, Sciences and Technologles ed. Siegfried Zielınskı and Davıd Lınk (Kỏln Buchhandlung Walther Konıg, 2006), 343

${ }^{15}$ Ibid, 344

${ }^{16}$ See Kim Cascone, "The Aesthetıcs of Farlure 'Post-Digital' Tendencies in Contemporary Computer Music," Computer Music Journal 24, no 4 (2000).

${ }^{17}$ Vermerr, "The Realıty of Fatlure," 350.

${ }^{18}$ Cascone, "The Aesthetics of Fallure," 13
} 
They are dressed in in scare-quotes, which directs judgement towards something nonfunctional, something that creates an irresistible alliance with a network of significations that do not necessarily interfere with the "positivist and functionalist paradigm [of] our technological society." ${ }^{\prime 19}$ From this perspective, a "glitch" is a dialectical attribute of digital technology's core function and is at once a technological failure and an aesthetic success.

This example of "failure" suggests that judgements which shift from assessing functional to non-functional norms, lets call these "aesthetic," entails a shift from the distinct to the indistinct. Said another way, failure's passage from a digital field--“it works 'this' way or it does not"- to an analogue field- "it works well 'this' way, less well 'that' way, but if you do 'that' over and over again and again, something wonderful happens"- - turns its event inside out. The discrete event of the glitch as a break in an artefact's practicable relays becomes a continuous event when the evaluation of its occasion is caught up in its own duration, in its temporization. A point of fault becomes a fault-line when its evaluation is prolonged, for the process of assessment, in effect, suffers a hitch serially and ongoingly such that it cannot help but accumulate expressive correspondences that intensify the abstract potential of the "error" by giving the derivative meanings that cling to its barb the chance to tell another story. Aesthetic norms, besides being vague and multifarious, encourage this kind of serial or intensive engagement because their measure is an abstraction of how one relates to things rather than how one uses things. And this kind of measure is largely feeling-based, for feelings are embodied gauges of how organisms "abstractly see [or hear] potential."20 As Brian

\footnotetext{
${ }^{19}$ Vermeir, "The Reality of Falure," 348

${ }^{20}$ Brian Massumı, "The Thinkıng-Feelıng of What Happens," Inflexıons 1, no 1 (2008) 5
} 
Massumi argues, perception is not simply a matter of registering what is actually before us but a way of sensing the virtuality or event-uality that is implicated in an encounter between our body and objects. Every actual sight or sound is set off against an auratic flow of virtual movements or actions that poise the body for what may come. The feeling of beauty, for example, is not a registering of the harmony of parts to a whole, but a process of dwelling in the intensity or principle of a promise that what-may-come will be apt and satisfying. While this latter point suggests that aesthetic norms house a dimension of "use" or purpose, such as Darwin's theory that music functions as an erotic lure, ${ }^{21}$ this is largely eclipsed by the way certain forms, like a "song" or even a simple arabesque, for instance, foreground the abstract dynamics that inhere in perception. Aesthetic assessment is a continuous affair whose findings are persistently self-modulating such that aesthetic success and failure play out their indeterminacy as degrees of satisfaction.

The emphasis that aesthetic judgements place on relative satisfaction is what makes failure in terms of music so dodgy and disputable. Because a melody not only solicits comparison with a tradition of song or a convention of thematic development, but also proposes the contemplation of and/or identification with a type of mood that in turn plugs into the micro-politics of social affiliation, its satisfaction, even though polyvalent, is always more or less failing in one sense and succeeding in another. While common to all aesthetic judgement, this ambiguity of satisfactions is made particularly evident when considering the category of "outsider music." For example, The Shaggs. Hailing from Freemont, New Hampshire, The Shaggs (Dot, Betty, and Helen Wiggins) represent a

\footnotetext{
${ }^{21}$ Darwin's take on the origin of music reflects what he sees as an order of sexual selection based on sensation, on the way that vibration passes from a material phenomenon to an immaterial effect- desire See Elızabeth Grosz's essay "Vibration Anımal, Sex, Music" for an unpackıng of Darwin's theory of music as it is filtered through Deleuze and Guattarı's concept of "the refram "Elizabeth Grosz, Chaos, Territory, Art Deleuze and the Framing of the Earth (New York Columbia University Press, 2008), 25-62
} 
wider field of musical culture that is "outside" by virtue of its originating beyond the pale of official culture. ${ }^{22}$ Characterized as outsider art is by a stunning absence of selfconsciousness, whose piercing sincerity makes the non-outsider feel like a voyeur, the music of The Shaggs is pure incompetence. To the unprepared listener, The Shaggs' 1969 studio album, Philosophy of the World, comes off as what music critic Irwin Chusid's describes as a spectacle of "hacked-at chords, missed downbeats, out-of-socket transitions, blown accents, and accidental convergences." ${ }^{23}$ Yet despite The Shaggs' excessive ineptitude and botched musicality, there is an irresistible charm that radiates from their performance. Chusid suggests that this is because Philosophy is " 100 percent authenticity and refreshingly guileless. ${ }^{24}$ That is to say, the album's paroxysmal and convulsive grooves embody a kind of sincerity that official musical culture is incapable of achieving, and as such, accesses an unaffectedness that, like all forms of sincerity, comically exposes the routine workings of what should be supple and elastic-like our definitions of "art" or "music." Because Philosophy of the World is presented as an unabashed album of pop songs, it sets up certain expectations and activates assumptions about musical phenomena that are utterly disappointed. But in failing to satisfy these, it remainders a certain bathos that reflects on the artificially stable categories of aesthetic success. By most accounts the songs on Philosophy this should fail as "music," especially as "pop" music which conforms to an especially rigid formulae. Although while the Wiggins sisters clearly fail with respect to the conventional norms of practicing an instrument, performing in a band, and writing songs, the impossible consistency of their

\footnotetext{
${ }^{22}$ In general, this means culture whose expressions are affiliated with some kind of social institution, whether conservatory, museum, gallery, record company, university, or even social club

${ }^{23}$ Irwin Chusid, Songs in the Key of Z The Curious Universe of Outsider Music (Chicago A Cappella, 2000), $1-2$

${ }^{24} \mathrm{Ib}$ id , 2
} 
gormless performance on Philosophy of the World has a way of mystifying expectations and subverting the usual set of expressive correspondences such that anyone who listens to this music for anything greater than the time it takes to dismiss it cannot help but feel a qualitative realignment in how things like competence and originality are satisfied. In this regard the aesthetics of outsider music, which revolves around a logic wherein the absolute failure to satisfy an already determined purpose coincides with the success to satisfy an unintentional objective, draws explicit attention to the ultimately indeterminate nature of failure.

In addition then to intensifying the perceptual convolutions of evaluation, aesthetic judgements stress how failure's thematic representation is often oxymoronic. Despite being represented as a phenomenon constituent to progress and achievement, failure's entanglement with "success" is not so much essential as it is structural and expressive. To represent failure, which is to abstract its occasion from a wider event, is to articulate expressions of unintentionality with expressions that affirm intentionality, as for instance Bruce Nauman's double exposed photograph, Failing to Levitate in the Studio (1966), in which the artist's body is shown suspended and collapsed between two folding chairs, and Jonathan Monk's Searching for the Centre of a Sheet of Paper (White on Black/Black on White) (2003), an animated video depicting two people trying to place a dot in the centre of a sheet of paper, do. Both works thematize failure and so couple an involuntary event - not levitating, missing the centre of the paper-with a voluntary activity such that the outcome cannot but express itself as a negative event. Like Lewis Carroll's "snark," the expressions of failure in these works say their own sense, which is to say that "failure" (in scare-quotes or in the genitive case "aesthetics of failure" (also in 
thematizing scare-quotes)) is an " $x$ " that radiates sense but is itself "never where it is sought and always where it cannot be found $" 25$ A thematic fallure is a structural effect, an oxymoronic expression that resembles any other aesthetic expression to the extent that its expression foregrounds the way one always perceive relationally and processually, the way one feels an abstract potential for more or otherwise in every occasion of hearing or seeing, etcetera However, the "failure effect" isolates the abstract potential of an event so thoroughly that unlıke Mona Lisa's enıgmatıc smırk that actually satısfies some its possible expressions of being amused, beguiled, or charmed, it obscures itself with the virtual satısfaction of everything that it is not Thus, the singularity of fallure is concealed by the coincidence of a purposeful mistake Makıng a theme of fatlure is therefore an oxymoronic expression

But so what if a thematic failure is oxymoronic? An oxymoron is not impassive, for its conjoined contraries are a hermetic expression whose form enjoins "a definite mode and shadıng of association ",26 In Infidel Poetıcs (2009), Daniel Tiffany argues that puzzling or cryptic expressions such as embodied by a riddle "does not imply the absence of disclosure or sociability" but that its deliberate obscurity "serve[s] as the impetus and object of a guessing game - a social configuration which converts the sound bite of the oracle into a literary toy, improvised in contests of wit on convivial occasions "27 More specifically, Tiffany contends that "lyric obscurity," the seemingly alienated and alienatıng effects of certain types of expressions, ${ }^{28}$ stages a fallure of meaning but

\footnotetext{
${ }^{25}$ Ronald Bogue, Deleuze and Guattart (London, New York Routledge, 1989), 75

${ }^{26}$ Daniel Tiffany, Infidel Poetıcs Riddles Nightlufe Substance (Chicago Unıversity of Chicago Press, 2009), 5

${ }^{27}$ Ibid , 4

28 of which he suggests poetry is the most representative
} 
nevertheless functions "as an expressive medium, or substance, harmonizing disparate phenomena, just as sociological obscurity defines the basic condition of countless subcultures and historical underworlds." ${ }^{29}$ The failure of meaning does not then necessarily annul the relational power of obscurity. Instead, much like the counterfeit relations that sustain various social underworlds, obscurity facilitates "transactions...in the absence of ostensible relations, ${ }^{, 30}$ and so enjoys the status of what Tiffany, borrowing from Leibniz, calls a "courtesy substance": obscurity is "a "semi-being" straddling the divide between sensible and insensible orders of existence." 31 Obscurity's failure to make its form transparent is, in this sense, a transversal medium that catalyzes the "expressive and reciprocal correspondences" 32 between hermetic forms.

Susan Stewart maps a similar kind of underground relationship in her 1979 work on the mutually contingent nature of sense and nonsense, suggesting that nonsense, a substance parallel to obscurity, has various pragmatic and social effects that extend its forms of failure into the domain of the real. For Stewart, sense and nonsense are byproducts of the interpretive procedures that a social group employs to compose and accomplish the horizon of relevance of a shared situation. What is established as either sense or nonsense, and by extension as real or unreal, is not fixed or entirely opposed to modification or manipulation, for as Stewart writes, it is only "an assumption of consensus" that makes either profile effective. ${ }^{33}$ However, a consensus does not have to revolve around positives: "it may be that this consensus is assumed through a pattern of

\footnotetext{
${ }^{29}$ Tiffany, Infidel Poetics, 10

${ }^{30}$ Ibid, 9.

${ }^{31}$ Ibıd, 10.

${ }^{32}$ Ibid, 12

${ }^{33}$ Susan Stewart, Nonsense Aspects of Intertextuality in Folklore and Literature (Baltımore Johns Hopkins Unıversity Press, 1979), 49
} 
acknowledged misunderstandings,",34 which is to say that things like obscurity, error, peccadillos, false impressions, and fiascos, too, can provide a certain (if only a negative) definition to consensual reality.

But perhaps a more radical and much less assenting model of the oxymoronicthe openly obscure - and one that aligns more with the sentiment of this work, is Paul Mann's notion of contemporary sub-cultures that he names "stupid undergrounds." Unlike either Tiffany's or Stewart's analysis of the largely hidden structures that organize a culture's social sphere, Mann argues that the members of various "Apocalyptic cults and youth gangs, colleges and phalansteries, espionage networks trading in vaporous facts and networks of home shoppers for illicit goods; monastic, penological, mutantbiomorphic, and anarcho-terrorist cells..."35 are hyper-aware of the complicity and indirect collusion that is endemic to modern society's structures of centre/margin, power/resistance. Whereas Tiffany and Stewart's "infidels" and interpreters, whose membership in a community relies on a form of willful ignorance, Mann's undergrounders are not so much ignorant as they are willfully indifferent to their ineluctable participation in the cultural power/knowledge structures that they antagonize. This indifference is further marked by a brazen apathy or morbid fascination that does not pretend to enact a higher ethics, redouble the critical gesture, or produce a greater kind of

\footnotetext{
34 Ibid

35 .quasiscientific research units, paranoid think tanks, unregistered political parties, subemployed workers' councils, endo-exıle colonıes, glossolalıac fan clubs, acned anorexic primal hordes; zombıe revenants, neo-fakırs, defrocked priests and detoxing prophets, psychedelic snake-oil shılls, masseurs of overdiagnosed symptoms, bitter excommunicants, faceless narcissists, ideological drag queens, mystical technophiles, subentrepreneurial dealers, derivatıve dérivistes, tureless archivists of phantom conspıracies, alıen abductees, dupe factota, tardy primitives, vermın of abandoned factories, hermits, cranks, opportunists, users, connections, outriders, outpatients, wanna-bes, wanna-not-bes, hackers, thieves, squatters, parasites, saboteurs, wings, wards, warehouses, arcades, hells, hives, dens, burrows, lofts, flocks, swamis, viruses, tribes, movements, groupuscules, cenacles, $1 \mathrm{sms}$, and the endlessly multıplied hybridization of variant combinations of all these, and more Paul Mann, Masocntıcısm (Albany State Unıversity of New York Press, 1999), 127
} 
novelty, instead, it is simply a way to "get off" on the difference that contemporary culture's pathological need to organıze (commodify) experience produces As Mann writes,

The energy released by the stupid underground is never anything more than an effect of its very morbidity It is marketed as novelty, but that is not its truth Nor will it ever constitute a base for opposition it cannot be yoked to any program of reform, nor serve any longer the heroic myth of transgression It is merely a symptom of order 1tself ${ }^{36}$

Importantly for Mann, because his is a post-Baudrillard reality of simulation, the delightful misery of the stupid undergrounds belongs not only to the marginal and disenfranchised but is shared by the cultural critic who feels driven to examine the simulacral cadavers that festoon the desert of the real Mann suggests that like the undergrounds themselves, there is justification for this critıcal drive besides "an unendurable habit of attention, a meager fascination [that is] no more or less commanding than that hypnosis one enters in the face of television ",37 In this regard, the stupid undergrounds and cultural criticism are both masochistic gestures that reflect a selffulfilling trend in contemporary culture to manage its addiction to difference by intensifying the expression of that difference In this model then, the stupid intelligence of both critic and undergrounder draw out the oxymoronic as a way to "complicate cultural space for a moment or two to thicken it and slow one's passage through it to render critıcism [and expression] itself as painful and difficult as possıble ${ }^{, 38}$

Except perhaps for Mann's analytical suicides, what all these figures of fallure and the oxymoronic seem to construe are the mechanics of an unacknowledged potentiality,

\footnotetext{
${ }^{36} \mathrm{IbId}, 139$

${ }^{37}$ lbid , 128

${ }^{38}$ Ibld , 129
} 
what might be characterized as the potential of potentiality. But while this is doubleness of potential is merely implicit in the preceding figures, it is something that Giorgio Agamben attempts to foreground in his essay on contingency with respect to Herman Melville's Bartleby, the Scrivener. For Agamben, Bartleby's formula--'I prefer not to"-is an expression of absolute potentiality that "destroys all possibility of constructing a relation between being able and being willing. ${ }^{, 39}$ It is potentiality's capture by what Agamben calls our "ethical tradition" and its emphasis on expressions of the will--"what you want to do or must do"--that elides capacity with necessity and so exempts from potentiality the concurrence of "to do" and "not to do." What "I prefer not to" expresses is an experimental event in the sense that its utterance, which suspends negation, doubt, and contradiction to expresses the full potential of potentiality, designates "an experience characterized by the disappearance of all relation to truth." to" questions what is possible; it "call[s] into question Being itself, before or beyond its determination as true or false" so that "whoever submits himself to these experiments jeopardizes not so much the truth of his own statements as the very mode of his existence. ${ }^{, 41}$ Here, Agamben's tone reveals that Bartleby's formula is not only an experiment but also a kind of existential analytic, and that the failure in which it is always implicated is an affair of being, of Being-in-the-world.

From the perspective of potentiality, the mechanics of failure have little to do with actual cases of malfunction or deficiency and more to do with the contours of existence. The paradox that failure articulates in this respect is not a dialectical conundrum as much

\footnotetext{
${ }^{39}$ Giorgio Agamben, "Bartleby, or on Contingency," in Potentralittes Collected Essays in Philosophy, ed Daniel Heller-Roazen (Stanford Stanford University Press, 1993), 255

${ }^{40} \mathrm{Ibld}$, 259-60

${ }^{41}$ Ibid, 260
} 
as a category of being, a category that while no less real than, say, "minds," "classes," "properties," "events," or "relations," cannot be lived out but only lived in its selfabstraction In other words, paradox characterizes a mode of being that 1s virtual Michael Marder draws this line of thought out with regard to Martin Heidegger's analysis of experience in Being and Time, suggestıng that from falure springs forth, "Both too much and too little not things in their actuality, but being in its possibility, in the futurity of its future ${ }^{, 42}$ For Marder, Heidegger's existential analytıc divorces the question of fallure from "the 1deals of actuality and actualization" 43 because his phenomenological method emphasizes the "possibilization of Dasein" over the essentialization of being Being (Dasein), in this analytıc, is nothing but "ecstatı" - standing out But Dasein is not a standing-out-from-some-thing, which would make it just another thing among things, but the movement 1tself of standing out, the "standing out of-" whose expressions are essentially expressions of involvement, concern, and fascination To be more precise, the ecstatic nature of Being is its potential to stand out and this can only be expressed in terms of what Heidegger calls Daseın's "fallıng" (Verfallen), its way of carıng for and belonging to the everyday As such, the ecstasies that express Being are also the ecstasies that perplex it, ın Heidegger's terms, standıng out artıculates the "authentıc" stıllness or virtuality of Dasein with the "inauthent1c" turbulence or noise of "being-with" (MitDasein) What this amounts to is that Dasein can only express 1tself, its potential to stand out, by failıng to be itself, to be only and fully this potential (to stand out) It is here, in the existential comportment where Dasein dis/articulates itself from its own potential, that Marder argues fallure is uncoupled from actuality and comes "to be associated with

\footnotetext{
${ }^{42}$ Michael Marder, "Heidegger's 'Phenomenology of Farlure' in Sein Und Zeit," Phillosophy Today 51, no $1(2007) 77$

${ }^{43}$ Ibid 70
} 
the realm of possibility, if not the very possibility of possibility." 44 The virtual fissure that cleaves Dasein is a structural necessity of the existential analytic that elaborates a convoluted awakening wherein Dasein (loses and $)^{45}$ finds itself, first in the din of its sociality where it "fails to hear [überhört] its own self in listening to the they-self," and then as "something which failed to hear itself, and which fails to hear that it listens away to the they." ${ }^{46}$ Or as Marder writes,

The ecstatic constitution of Dasein renders failure itself ecstatic, given that the failure of hearing the call of conscience is measured against the "success" of placing the call by "one's own Dasein" who fails. Failure fails ecstatically.

Dasein's ekstasis, which is its "authentic potentiality-for-being" that by necessity is "always already [socially] inflected or convolute" is, in a sense, the "modalization of failure. ${ }^{, 47}$ In other words, how one finds oneself feeling about the type of situation that one (already) finds oneself in is always a mood of Dasein's originary failure. Strictly speaking then, existence is a series of moody failures.

\section{Music}

From the outset, I said that I would refrain from defining failure and instead said that I would try to illuminate its "twinklings." By far the brightest twinkle is that failure is not a point as much as it is a potential or an intensive measure of relative satisfaction. And "Music," too, insofar as it is as a place holder for the potential to "compose," "perform," or "listen," yet also a potential to "practice," to "study," "dance," "shop to," "protest or

\footnotetext{
44 Ibid

${ }^{45}$ This has to be placed in parentheses, for the matter of Being's being "lost" is a matter that is retrojected in how it finds itself (Befindlichkeit)

${ }^{46}$ Martın Heıdegger, BeIng and Time, trans John Macquarne and Edward Robınson (Oxford Blackwell, 1978), 315-16

${ }^{47}$ Marder, "Heıdegger's 'Phenomenology of Fallure' in Sein Und Zeıt," 73
} 
pray with," and most especially, "to feel (to)," resembles failure in its elusive satisfaction. As such, "music," like failure, is point-less. "Music's" productive inconstancy models the kind of polymorphous perversity that makes "failure" so supple and multivalent, so evasive and so frustrating.

Of course, not all musical expressions reflect on or exploit the way music's own polymorphism untidies a culture's sense of reality and itself. Pop and film music, for example, function on an industry myth that music's social and emotional cues are reducible to a set of formulae and therefore representative of a well-ordered system of cause and effect. India's classical music, which classifies its rāgas (melodic formula) according to their appropriateness to a particular time of a day or season, and the traditional work songs of Sub-Saharan Africa whose rhythms are used to coordinate the body's movement with the timings of a task, explicitly emphasize music as an organizing force. However, when music's ambiguous or indeterminate nature is emphasized, even though its forms may still be embedded in distinct social practices with their own set of norms and conventions, it loses its status as an existential appliance and tends to fall into the category of the "experimental," a category like nonsense "that gives us a place to store any mysterious gaps in our systems of order." 48 For this study, however, I will use "experimental" in a more precise way to refer to music that takes the self-conscious and deliberate confusion which is characteristic of post-Cagean aesthetics as an expressive norm.

"How and what shall I listen to?" "Why is this music?" "What am I supposed to do with these sounds?" These are expressions that register the experimental's ambiguity and

\footnotetext{
${ }^{48}$ Stewart, Nonsense, 5.
} 
refer to musical works that fail to affirm a ready-to-hand reality, for what is foregrounded by such an "experimental comportment" is music's event-hood. Rather than affirm a world whose terms and relations are fixed, the experimental designates the way and the degree to which a musical occasion traces an adventure through time and space, bringing disparate phenomena to interaction and invention. Thus, what makes music experimental and truly pointless - a failure of sorts - is not how it ruptures the totality of our involvements (i.e. everyday reality) so as to be mutely present-at-hand, but how it emphasizes the way multiple and incompatible views and demands can subsist indeterminately in its event as a vague fringe or aura of potential aesthetic effects.

This sense of indeterminacy would seem to suggest that the experimental overlaps with some of the more daring practices of improvised music. While there is little doubt that Anthony Braxton's Composition No. 247 (2000), with its unspecified instrumentation playing a stream of eight notes notated on a staff with an undefined clef ${ }^{49}$ that also carries the instruction for performers to play other Braxton works while playing 247 , shares a sensibility with the priorities of Harris Wulfson's Livescore (2006), a work that converts the twiddling of a knob-device by audience members into real-time notation that is sight read by individual performers, ${ }^{50}$ I want to suggest that the latter has a slightly higher degree of failure than the former owing to the contradiction that inheres in its "intentional unintentionality." To act on this contradiction, which is what soi-disant "experimental" composers do, is to add a measure of internal inconsistency to the process(es) that composition embodies. And for the most part, because the musical results of an

\footnotetext{
${ }^{49}$ Braxton often use what he calls a "diamond" clef that indicates its music may be read in any clef (treble, alto, tenor, bass)

${ }^{50}$ For a discussion of Livescore and its composer see G Douglas Barrett and Michael Winter, "Livescore Real-Time Notation in the Music of Harris Wulfson," Contemporary Music Review 29, no. 1 (2010)
} 
improvisation so closely align with an improviser's will as to make his/her meaningful profiles indistinguishable from each other, improvisation is exempt from this inconsistency. This of course does not mean that improvised music can't be experimental or can't fail; it just means that composed music's discrepant dealings with intention and inadvertence makes its failure shine a little brighter.

If this dissertation has a point (which, if it's faithful to its thesis that failure has no particular point, then it shouldn't), it is this: Experimental composition has no point, or at least its post-Cagean variety has no particular point. But having no particular point doesn't exempt this music's expressions from having an effect. Music that swerves towards the experimental comportment of intentional unintentionality still affects us. As Aden Evens writes,

Stripped of intention, sound no longer triggers responses from the standard catalog of emotions, no longer refers to the human activities of manufacture, performance, etc... [but] one still hears difference, sound is still pointed, but now out-of-joint, no longer pointing along a two-dimensional line with a universal history and a determinate future. ${ }^{51}$

Having no particular point is having too many points, just as that which opposes the absence of sense is not no-sense but too much sense - a presence opposing the lack of presence. Yet, as Sartre illustrated in Nausea, the revelation of this excess or superfluity does not necessarily come across as entirely pleasant when illuminated, which is why Roquentin, sitting by the Masqueret Fountain with its bubbling sound in his ears, a putrid odour in his nose, and the image of a chestnut tree's black and swollen bark in his eyes, declares, "Existence is a deflection," the displacement of cloying abundance-dépenses.

\footnotetext{
${ }^{51}$ Aden Evens, Sound Ideas Music, Machines, and Expenence (Minneapolıs Unıversity of Minnesota Press, 2005), 49
} 
Sounds stripped of intention do not cease to signify, but neither do they say anything in particular. Instead, they imply or connote so much about so little, much in the way affections like "sadness" or "love" radiate indistinct impressions of extremely complex sensations. A "de-intended" musical event like the kind that Cage tried to manage has an excessively charged vagueness to it by virtue of the way its "accidental" advent expands the margin of uncertainty to one hundred percent. This is why such formally remote works like Cornelius Cardew's Treatise (1963-67) or Christian Wolff's Burdocks (197071), both examples of what is called an "open work," give the sense of being swarmed by unarticulated signifiers and incipient movements: they are infused with an absolute vagueness that is "the way in which potential presents itself in the unfolding of experience." ${ }^{52}$ It is what sheer relation sounds like in action, but with nowhere to go, no cynosure to guide it or transcendental signified to conduct it. As such, experimental composition tends to be boring, formless, and nonsensical (and sometimes nauseating). To that end, this dissertation considers recent compositions that express failure in these terms, and in the way they articulate an unintentional im-particularity by evoking aspects of waiting, insufficiency, distraction, dissatisfaction, bullshit, and pain in contemporary culture.

\section{Parameters}

While this study appears to be composed of three distinct and autonomous chapters, they are, in fact, linked by more than simply how the consecution of their titles reads like a dopplering judgement. As modes of failure, boredom, formlessness and nonsense have an

\footnotetext{
${ }^{52}$ Brian Massumı, Parables for the Virtual Movement, Affect, Sensatıon (Durham, NC Duke University Press, 2002), 232.
} 


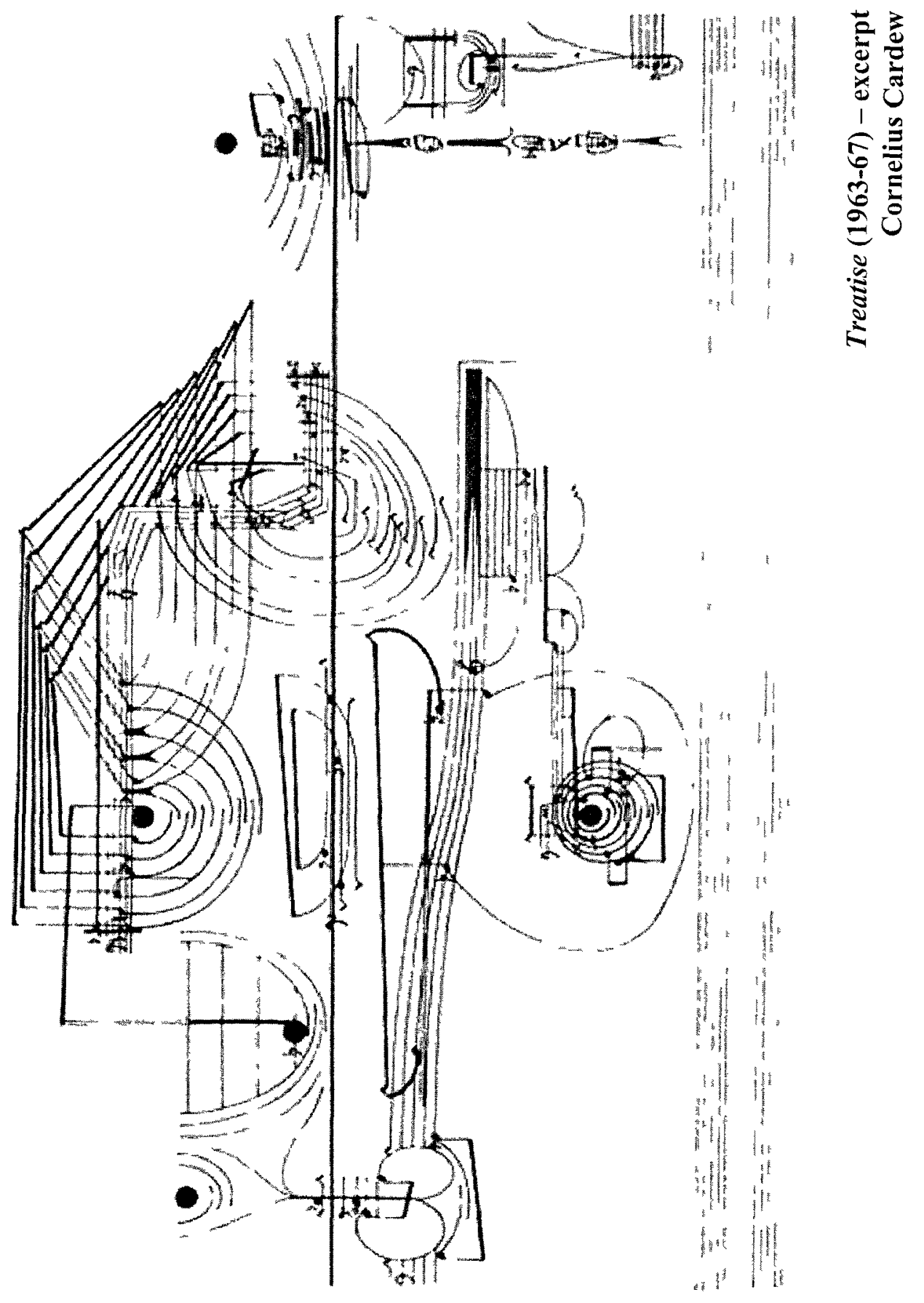




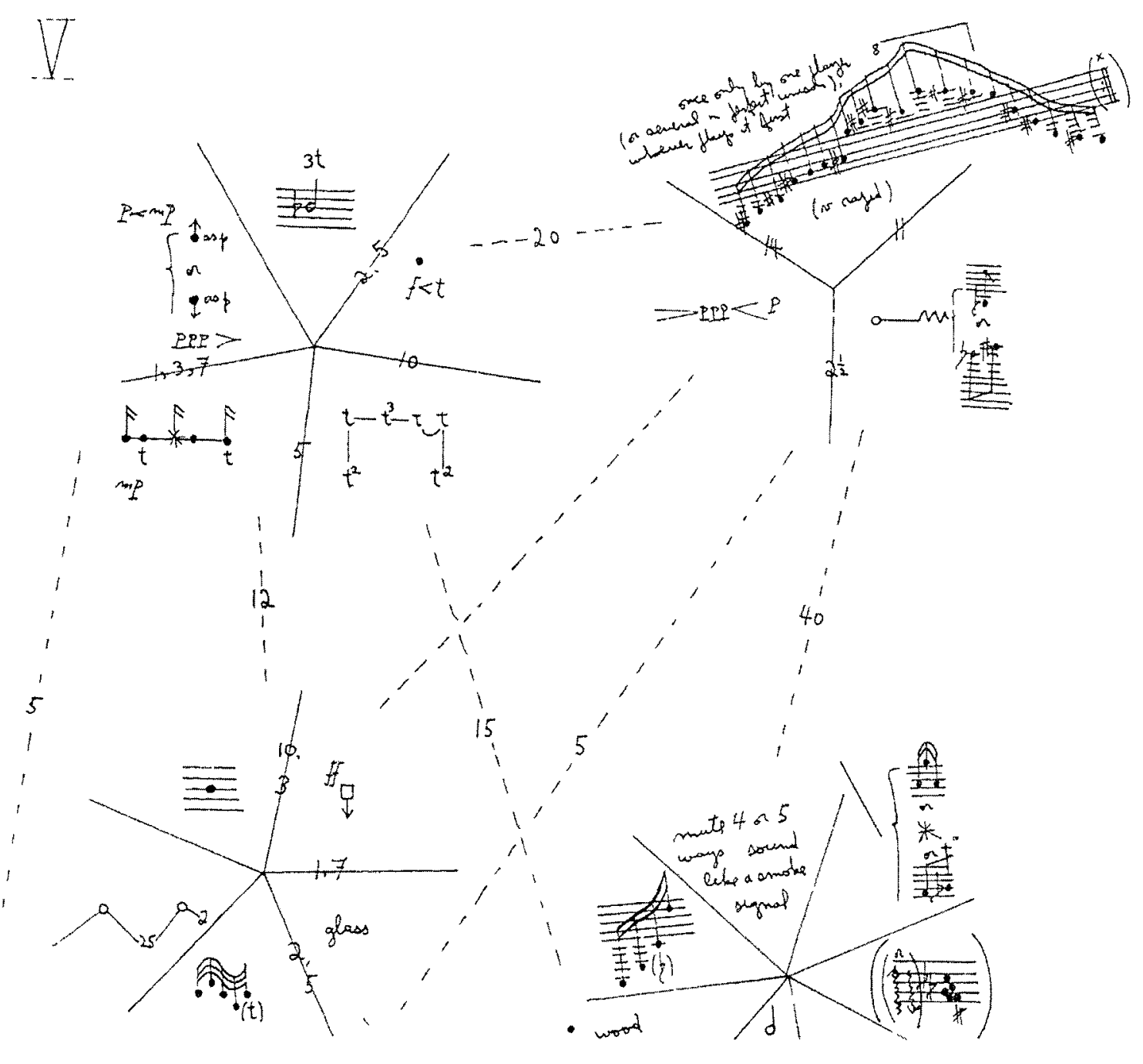

Burdocks (1970-71) - excerpt Christian Wolff 
internal correspondence in which the sense of each echoes within the others as a potential line of expression. Thus, boredom can be expressed by encounters with formless and senseless phenomena, and similarly, nonsense can be characterized by the tedious deformation of what passes for sense. This, however, is not made explicit in any of the chapters; rather, it is implied by the way many of the works that illustrate the expressions of one mode can be used to illuminate another, albeit from a different angle that emphasizes different properties and qualities of the musical work. Yet, despite this interpenetrability, I have retained the order of the chapters precisely because of the effect that their being read one after the other generates.

I begin this study by considering what is perhaps the most common trope of aesthetically fashioned failure: boredom. In this chapter I challenge the received sense that boredom is an inchoate form of interest and suggest instead that the mood no longer affects the contemporary subject in a way that compels attention to the overlooked, where a splendor of intensities lay concealed in the folds of infra-ordinary awareness.

Considering first how boredom has become an ordinary affect of contemporary art and then examining the history of the malaise as a specifically modern mood, I contend that aesthetically articulated boredom is now more ambivalent in its effects in that it is more difficult to distinguish its hollowing sink from the low-level dullness that pervades activities such as watching television, continually checking one's email, or monitoring various twitter feeds. Drawing on Sianne Ngai's notion of the "stuplime," a stilted and undecidable response to expressions of an infinitely iterated finitude, and evoking alternative ways of suffering the passion of waiting, I use recent compositions to focus the scattered rays of monotony on a wider set of logics that can be found in numerous 
other aspects of contemporary culture. While heir to a well-defined tradition of anti-art represented in music primarily by the so called "New York School" and Fluxus, I argue that many composers, who are now writing long, quiet, repetitive, and slow-moving music of the kind that is intended to be experienced without (external) interruption, express a sense of boredom that articulates with contemporary culture's dimensions of depression and simulation in a way that connects the ambient feelings of uncertainty and being unjustified with neoliberal norms of independence that insist on a responsibility for the initiation of one's own identity.

While my intentions in this chapter are directed primarily at adjusting the terms and stakes of what I see as boredom's standardized justification in art and music as a way to delegate a work's meaning or value to the recipient-a gesture that is not without its merits - it is also a first attempt to baffle or outplay (déjouer) the discursive paradigm that frames so much criticism and analysis of avant-garde music. This means that I draw my argument crookedly, which entails making conceptual detours, drifting in and out of remote subjects, and, occasionally, running into a dead-end. Basically, in this chapter I try to enact an essayistic kind of "shunpiking," a way of writing that avoids major paths and toll roads for more "bucolic" and "scenic" interludes. Admittedly, this is only my initial attempt, and the roads only get windier from here.

In the second chapter, the focus shifts from the simulated and depressing refrains of having to choose one's "self" for oneself, to the conundrum that contemporary culture's norms of self-invention are enforced in a field of continuous distraction. Whereas boredom's disaffection expresses the poverty of our culture's curiosity, formlessness characterizes how this same culture has developed habits of inattention in 
response to ubiquitous media forms (i.e. records, television, internet, etcetera). Audio technology, which not only historically leads the way in the escalation of mechanical reproduction's tendency to become smaller, more portable, and increasingly invisible, disarticulates sound from its site of production in a way that gives the listener permission to disregard the material cradle of sound. Music, which survives its own "live" death by becoming a recording (which is arguably less a death than a reincarnation of sorts), has been indirectly affected by this capacity for dis-articulation in that individuals in modern industrial societies have effectively learned how to listen away from or "unlisten" to musical sounds that are always, to some degree, drifting in the background. I suggest that this performs a kind of aural anamorphosis in that "listening away" alters the direction of ingress by, paradoxically, emphasizing msuic's backgrounded dimensions, which, in the tradition of Western concert music turn out to be the sloppy and imprecise qualitiesaffective and social qualities - that inhere in and surround the physical manifestations of sound which its emphasis on structure has exiled to unconscious registers of perception.

From the perspective of this art music tradition, the unconsciously acquired habits of listening away and underhearing music offend its defining principle of "structural listening" not by overturning its purview but by turning it inside out. Whereas structural listening is based upon a set of historically developed techniques for immobilizing the body and sequestering its faculty of hearing in order to restrict perception to the active reception-interpretation of a work's immanent formal relations, the unintentional cultivation of distraction, in a sense, reverses this process and expands the field of immanence indefinitely, opening the body to respond to everything that is not structurally significant, even to things that it cannot hear. But listening away is ultimately a soft 
offense, for it is expressed not in a confrontational manner that characterizes the antiaesthetics of Fluxus or the abject aesthetics of bands like Throbbing Gristle and Cabaret Voltaire, but in the incidental way that slipping on ice offends the balance of the body or that puns offend language as a fixed set of correspondences. In this respect, I enlist Georges Bataille's idea of informe as a culture's to address how certain contemporary experimental compositions exploit the drifts and digressions of distraction in a way that paradoxically draws attention to the "black noise" and "allure" raditing from musical sounds that have become something to be "unfocused on." Arguing that this allure elicits a strangely inaccessible sincerity, one that seduces the piqued listener into peculiar hermetic or "toy involvements," I conclude this chapter by suggesting certain composers suffer from what Rei Terada calls "phenomenophilia," an attraction to "off-beat perceptions" that deals with cultures of distraction by converting fragmented in/attention into a series of incipits to keep one's interests in-going rather than ongoing.

The final chapter, "Nonsense," can be considered a response to the speculations of the two previous chapters. Taking its cues from chapter one's discussion of norms of selfinvention and chapter two's discovery of a charm in distraction and a desire for outré perceptions, this phase of the study literally creates a metaphor that speaks to the way that music cannot speak for itself. This perhaps makes chapter three the most challenging section, for it requires a dual awareness to follow the constant double-speak that allows one to say two things at once. "Nonsense" therefore requires more explanation than the other two chapters, for its form of address, by virtue of its topic, is highly reflexive and self-divided. You might expect then that a chapter on musical nonsense would take the kind of modernist twaddle of Kurt Schwitters' Ursonata or the virtuosic bilge of Frank 
Zappa's Gregory Peccary as its exemplary cases. And if not these, then perhaps something seemingly less mannered or refined such as the cochlear threshing of Lou Reed's Metal Machine Music or the electric squawk of Belgian musician Wim van Gelder (aka Portable Noise Kremator)'s cracklebox album. You might think that, but then you would be thinking about a chapter that is not this one.

To treat nonsense as simply a matter of non-understanding or unintelligible gobbledygook betrays a presupposition that nonsense is "simply." As Susan Stewart notes, nonsense is anything but "simply." "The nature of nonsense," she writes, "will always be contingent upon the nature of its corresponding common sense, and since common sense is always emergent in social processes, including nonsense activities, that category "nonsense" will never have a stable content." will always be "determined by the generic system available to the given set of members" $" 54$ so that its expression, its manifestation as a type of failure, is dependent on how a situation is given a unique orientation with respect to some seemingly transcendental operator such as "God," "society," "truth," or even "use." Nonsense is not merely a relational term that is conterminous with sense, but, as I will explain, like sense, something to creatively move on. Nonsense is in fact closer in form and effect to what we may identify as "indirection," or more slangy-like, as "bullshit." Like these forms of expression, nonsense is characterized by a failure to respect the firmity and transcendence of "truth" and/or "meaning" and thereby shows reality to be a plastic and inventive realm.

I try in this final part of the study to demonstrate this sense of nonsense in a manner that doesn't just enumerate the familiar operations of reversal, inversion,

\footnotetext{
${ }^{53}$ Stewart, Nonsense, 51.

54 lbid.
} 
simultaneity, infinity, and boundary blurring that characterize how nonsense is made. ${ }^{55}$ Instead, I attempt to create a situation that is problematic in the sense that a problem is not something to be solved so much as it is something to be creatively accosted. Specifically, I target a paradox that John Shepherd identifies in the way symbolic processes allow us to manipulate our environment while exhibiting a certain independence form it. ${ }^{56}$ Out of this paradox, around which the practice and discourse of "music" revolves, I invent a fictional line of enquiry that loses itself in the deictic quagmire in which the non/sense of music is constituted, developing the idea of "music" as an effect that has a peculiar capacity to migrate between bodies- -virtual and actual. I do this by exploiting the indirection inherent to the kinds of words that music's discursive constitution relies on, words such as "it," "this, "that," "I," "he," "then," "now." These terms, which Roman Jakobson calls "shifters," have a duplex structure that allows them to express both a conventional and existential relationship to the object(s) they represent. ${ }^{57}$ Insofar as music is an inherently ambiguous quasi-object where, as theorist Ian Cross suggests, "one and the same musical activity might, at one and the same time, be about the trajectory of a body in space, the dynamic emergence or signification of an affective state, the achievement of a goal and the unfolding of an embodied

\footnotetext{
55 A host of other studies explicitly interrogate this anatomy of nonsense See, for instance, Elizabeth Sewell, The Field of Nonsense (London· Chatto and Windus, 1952), Wim Tigges, Explorations in the Field of Nonsense (Amsterdam Rodopi, 1987), and Jean-Jacques Lecercle, Phlosophy of Nonsense The Intuttons of Victorlan Nonsense Literature (London. Routledge, 1994).

${ }^{56}$ See John Shepherd, "Difference and Power in Music," in Musicology and Difference, ed. Ruth A Solse (Berkeley, Los Angeles• Unıversity of Calıfornı Press, 1993)

${ }^{57}$ Jakobson actually borrows the term "shifter" from the Danısh linguist Otto Jespersen who introduced the term in 1923, but it was Jakobson who instigated its common use in linguistics with his 1956 essay "Shifters, Verbal Categories, and the Russian Verb "For the portion of his essay on shifters see Roman Jakobson, "Shifters and Verbal Categories," in On Language, ed Linda Waugh and Monıque MonvilleBurston (Cambridge, MA Harvard University Press, 1990), 386-92
} 
perspective," 58 it can be said to be duplicitous, double dealing, for "it" always refers both to a material and a set of relations whose correspondence, as Shepherd notes, is selfconflicted.

Like the "I" that associates with myself by convention, yet also stands existentially contiguous to my I, I am trying to say two things at once. This can be confusing at the best of times, and, considering that I exploit this feature of shifters throughout the chapter to move between voices who not only take up the issue of nonsense in different ways, but do so in a reflexive manner that replicates the already duplicated structure of shifters and the free indirect style that I use here less than sparingly, it can be downright mystifying. In this chapter I not only consider pseudonymic and "meta" practices as ways in which a duplicitous nonsense circulates in art music, I also employ them. As such, this essay should be read with the understanding that the surtext (the main body) is metaphorical while the subtext (footnotes) is literal. This of course does not make the "sur" is any less real than the "sub." It just makes the former less direct than the latter. The form of the chapter thereby reflects the kind of duplicity (duplexity) that is at work in the music I examine (invent) by transposing it to a meta- level where the bond between symbol and material that the construct of "Music" problematizes starts to unravel in the face of its own artifice, its own bullshit. In this chapter then, I play my hand at making nonsense, not by being absurd but in making a theoretical straight from a fictional suit that will justify the gambit I have now made in telling you that I am going to bluff.

\footnotetext{
${ }^{58}$ Ian Cross, "Music, Cognition, Culture, and Evolution," Annals of the New York Academy of Sctences 930 (2001) 38
} 
To address an immi/anent concern...

What matter who's speaking? I would answer that it matters, for example, to women who have lost and still routinely lose their proper name in marriage, and whose signature - not merely their voice - has not been worth the paper it was written on; women for whom the signature-by virtue of its power in the world of circulation-is not immaterial. Only those who have it can play with not having it. $^{59}$

With a few exceptions, almost all of the examples that I have drawn on to illuminate contemporary aesthetic failure are works produced by men. Not all these men are straight however, but they are all university educated, middle class, and white-a predictable homogeneity that undoubtedly generates a feeling of disquiet around the tacit assumption that "anyone" can play with failure. True, everybody can fail, but not anybody can play with failing. The above passage by Nancy Miller speaks to what I would call the "anybody-fallacy" that is remaindered by post-structuralism's discursively contrived decentring of "man." Miller argues that the "metalogically 'correct' position" advocated by post-structuralist theories - that signification of gender is an archaic practice - is "too confident that non-discursive practices will respond correctly to the correct theory of discursive practice." ${ }^{60}$ For example, the "indifference" towards the origin of a text that Michel Foucault imagines he hears in a world after the death of the author is, "one of the masks... behind which phallocentrism hides its fiction." ${ }^{61}$ In other words, practice lags behind theory, or, theory exceeds the social and institutional structures that make its claims effective.

While Foucault can imagine an authorial indifference and rationalize the

\footnotetext{
${ }^{59}$ Nancy K Miller, “The Text's Herome· A Feminist Critıc and Her Fictions," Diacritics 12, no. 2 (1982) 53

${ }^{60}$ Ibid . 49, 50 .

${ }^{61}$ Peggy Kampf quoted in ıbid 50 See also Michel Foucault, "What Is an Author?," in The Foucault Reader ed Paul Rabinow (New York Pantheon Books, 1984), 101-20
} 
conditions under which it would be immaterial whether the producer of a text is a man or women, in practice it is anything but immaterial. In fact, his capacity to think this results from a privilege that he has not to have to account for or justify his own voice. The "sovereign indifference" $" 62$ of the theoretically impersonal text is something that can only be thought by one whose own voice already assumes its sovereignty, and advocating for the death of the author is a privilege of a suicidal "man" who has always had a life to lose and the right to end it. That is to say, only a subject whose agency is always (already) secure can put the potential of its own annulment into practice. Likewise, while in theory "everybody" has the potential to fail, in practice only those who have (always) already succeeded as social agents can play with failing, and in Western culture this has traditionally been the prerogative of men, particularly white, straight and university educated men. To practice failure and play with its potential is not for "anyone," it is for some. And this study is itself evidence of that. As a white, university educated, heterosexual male, I am not only permitted to produce a study on the aesthetics of failure I am permitted to write something that is aware of its privilege but does not have to question how this contributes to its production. That I chose here to suspend the interrogation of this text's privilege does not, however, cleanse it but in fact makes it more apparent in the way that an ambivalence circulates in the form of discursive figures which are never wholly certain of their assertions. But I submit that the sense of ambivalence is itself an affection of the failure that informs and animates this study, and as such embodies or enacts the concurrence of "to do" and "not to do" that, as Agamben

\footnotetext{
${ }^{62}$ Miller, "The Text's Heroine," 53
} 
notes, is typically exempted from potentiality ${ }^{63}$

It should be kept in mind throughout the study that the privilege I give to those impressions of failure that emphasize the ambivalence of failure is a tension that drives its propositions and owes as much to what it excludes as to what it includes. And it is perhaps for this reason that my attempt to scrutinıze fallure may prove to be too big a wager and that it may end up becoming just another successful expression of the discourse that it is trying not to be, which will make it the fatlure that was all along. I propose then that this document advances awkwardly in its own ambivalence towards a failure, a failure cognizant of it own limits and blind spots, that it will never be. If this sounds a little too utopian, then allow me to appropriate a line from the poet and theorist Craig Dworkin who believes a fierce politics lies behind seemingly impossible tasks: "I would rather maroon myself nowhere than surrender to a status quo with which I am not content."

\footnotetext{
${ }^{63}$ This gendered politics of aesthetic fallure is something that remains to be explored and as far as I can tell, its interrogation revolves around the issue of a right to fail or to be indifferent to expectations, whether they are articulated as normative structures or relational standards At stake in this right to fall then is the value of aesthetic negativity, the value to pursue practices that seek an intensity rather than a purpose in experience As Christopher Menke argues, this value translates in into art as a matter of sovereignty and a concern for forms of "non-understanding," a concern for a mode of experience that is not satisfied by realızıng specified aims For Menke, where "understandıng" entails conventional and automatıc processes of perception "that selectıvely transform undefined material into interrelated and meaning-related signifiers," non-understanding is a way of suspending the habits of interpretation by continually returning perception and thought to the process of selection where each taking account of the undefined is backgrounded with more unselected material And access to the right (but also the political and economic fortıtude) to not be understood, access, that is, to what Jean-Françors Lyotard identıfies as the "libıdinal" or "figural" over the discursive dimensions of art, ${ }^{\ddagger}$ is my no means equal Further to this point then is the very validity of the right to the sovereignty of fatlure as it is premised on a discourse that not only favours certain expressions of aesthetic expenence that presuppose the universality of the imagination, but one whose notion of sovereignty has gendered implications

$\uparrow$ Christoph Menke, The Sovereignty of Art Aesthetic Negattvity in Adorno and Derrida, trans by Ne1l Solomon (Cambridge, MA MIT Press,1999) 43

$\$$ See Jean-Françoıs Lyotard, Lıbıdınal Economy, trans Iaın Hamılton Grant (Bloomıngton Indıana University Press, 1993) and Discourse, Figure, trans Antony Hudek and Mary Lydon (Minneapolıs, Unıversity of Minnesota Press, 2011)

${ }^{64}$ Cratg Dworkin, Reading the Illegible (Evanston, IL Northwestern Unıversity Press, 2003), xx1
} 
Lastly, experimental music, my ostensible subject, finds its way into this failing scheme through tactics of duration, distraction, and deceit, devices of (dis)engagement that characterize the operational purview of a post-Cagean experimental music community whose members have the peculiar privilege to toy with the intensity of failure, and as such, to draw insights and observations about failure from "failure." In this sense, as a member of this same community, the failure ascribed to the music that I discuss here is a failure that describes my own discussion of the music. Its failure is my failure, a strange loop that lets me be both knight and knave, right and wrong, sincere and full of shit. It is a way to show how failure lives out the way one lives in contradictions: the way one finds interest in boredom, form in formlessness, and sense in nonsense.

But before moving on to the study proper, I want to consider the risk of this last point regarding living in failure's contradictions. Living in contradiction is exceptional. Basically, to live in contradiction is to enjoy an abnormal disconnect between knowledge and action. This is how Melville's scrivener, Bartelby, lives when he dwells in the prorogating effects of his formula: "I prefer not to." However, only ascetics and sybarites have either the spiritual mettle or the material convenience to "prefer not to." These are extreme positions and would seem to be beyond the ken of most individuals. Yet, as political and social critic Chris Hedges argues, contemporary Western liberalism has shown that it, too, "prefers not to." As a response to the authority of feudalism and religion, classical liberalism is defines itself by a conviction to the rule of law. However, only the myth of liberalism remains and, as Hedges writes, this myth "is used by corporate power elites and their apologists to justify the subjugation and manipulation of 
other nations in the name of national self-interest and democratıc values "65 The liberal class has ignored the fact that the legal system, which manages the law that they appeal to as guarantor of equality and individual autonomy, has been influenced by corporate powers as much as electoral politics and legislative debate has The consequence is thus

The inability of the liberal class to acknowledge that corporations have wrested power from the hands of citızens, that the [US] Constitution and its guarantees of personal liberty have become irrelevant, and that the phrase consent of the governed is meanıngless, has left it speaking and acting in ways that no longer correspond to reality ${ }^{66}$

The failure of the liberal class to act on its ideals of reasoned betterment and individual egalitarianısm has effected a disconnect from knowledge and action, which has made the workıng and middle class that it purports to speak for vulnerable to a virulent strain of what Hedges calls "magıcal thinking"

The message that one can make things happen by thinking about the desired results rather than the steps required to accomplish these results is a message, writes Hedges, that is "peddled to us by all aspects of culture, from Oprah to the Christian Right " ${ }^{67}$ Magical thinking essentially encourages faith in the preposterous and "permits societies to transfer their emotional allegiance to the absurd," ${ }^{, 68}$ which in turn converts portions of society's dispossessed into a lunatic fringe who also "prefer not to" face real problems

Both the liberal class and the lunatic fringe of society "prefer not to," and so both are living out the effects of living in contradictions The liberal class's staunch belief in the ideals of reason makes it increasingly irrelevant in a world that is made by design and

\footnotetext{
${ }^{65}$ Chris Hedges, Death of the Liberal Class (New York Nation Books, 2010), 8

${ }^{66}$ Ibid, 9

${ }^{67} \mathrm{lbld}, 200$

${ }^{68} \mathrm{Ibid}$
} 
fabrication, while the lunatic fringe's reasons for belief in the direction that its anger and rage take it make it like a child with a loaded revolver And because the way that I approach fa1lure in this study is "trans-rational," its "preferring not to" threatens to correspond with the liberal class's ineffectual fulminations and the lunatic fringe's absurd investment in the "reality" of pseudo-events (1 e simulations of celebrity and sports culture)

The indulgence of living in failure's contradictions is a gamble that risks both exile into its own emptiness and annihilation by tts own excesses Like Dostoevsky's "Underground Man," whose vain attachment to reasonable ideals sends him into utter obscurity, those who "prefer not to," who prefer to play with fallure, risk living life in a corner, taunting themselves "with the spiteful and useless consolation that an intelligent man cannot seriously become anything seriously, and it is only a fool who becomes anything "69 But "preferring not to" also hazards the intemperance of Michel Houellebecq's character in the 2001 novel Platform, who aspires to a state of permanent tourism where leisure tactics and morning blow-jobs substitute for the edification of the self and the wellbeing of society This study of fallure, too, insofar as it plays with emptiness and annihilation, entails its own risks and is therefore partly an examination and document of its own fallure

\footnotetext{
${ }^{69}$ Fyodor Dostoyoevsky, Notes from Underground, trans Constance Gamett (New York UK Dover Publications, 1992), 3
} 


\section{One: Boring}

Bliss-a second-by-second joy and gratitude at the gift of being alive...lies on the other side of crushing, crushing boredom. Pay close attention to the most tedious thing you can find...and, in waves, a boredom like you've never known will wash over you and just about kill you. Ride these out, and it's like stepping from black and white into color. Like water after days in the desert. Instant bliss in every atom.

David Foster Wallace

"Wiggle Room"

\section{Introduction}

I heard a string quartet a while ago by Los Angeles composer Art Jarvinen titled 100 cadences with four melodies, a chorale, and coda ("with bells on!"). As the title suggests, the piece keeps ending, over and over again, each time promising to conclude a musical adventure that never was. Over forty-eight minutes, the consecution of endings, punctuated by solos and glimmering silences, draw out an irritatingly radiant array of mock-perorations. And I am always more or less aware of this: More aware when the sheer materiality of these several endings intrude upon my sense of contemplation, and less aware when, like Proust's madeleine, I am taken away by time passed. I am alternately with the music, my attention buoyed by a precession of simulated extinctions and untimely non-events, and beside the music, dreaming counterfactuals, shifting backward, forward, side to side in fantasies of otherwise. Buoyed in the messy immanence of a perpetual conclusion, my attention floats on nothing in particular, nothing but a series of loose intensities that are now and again interesting, or boring, or both. 

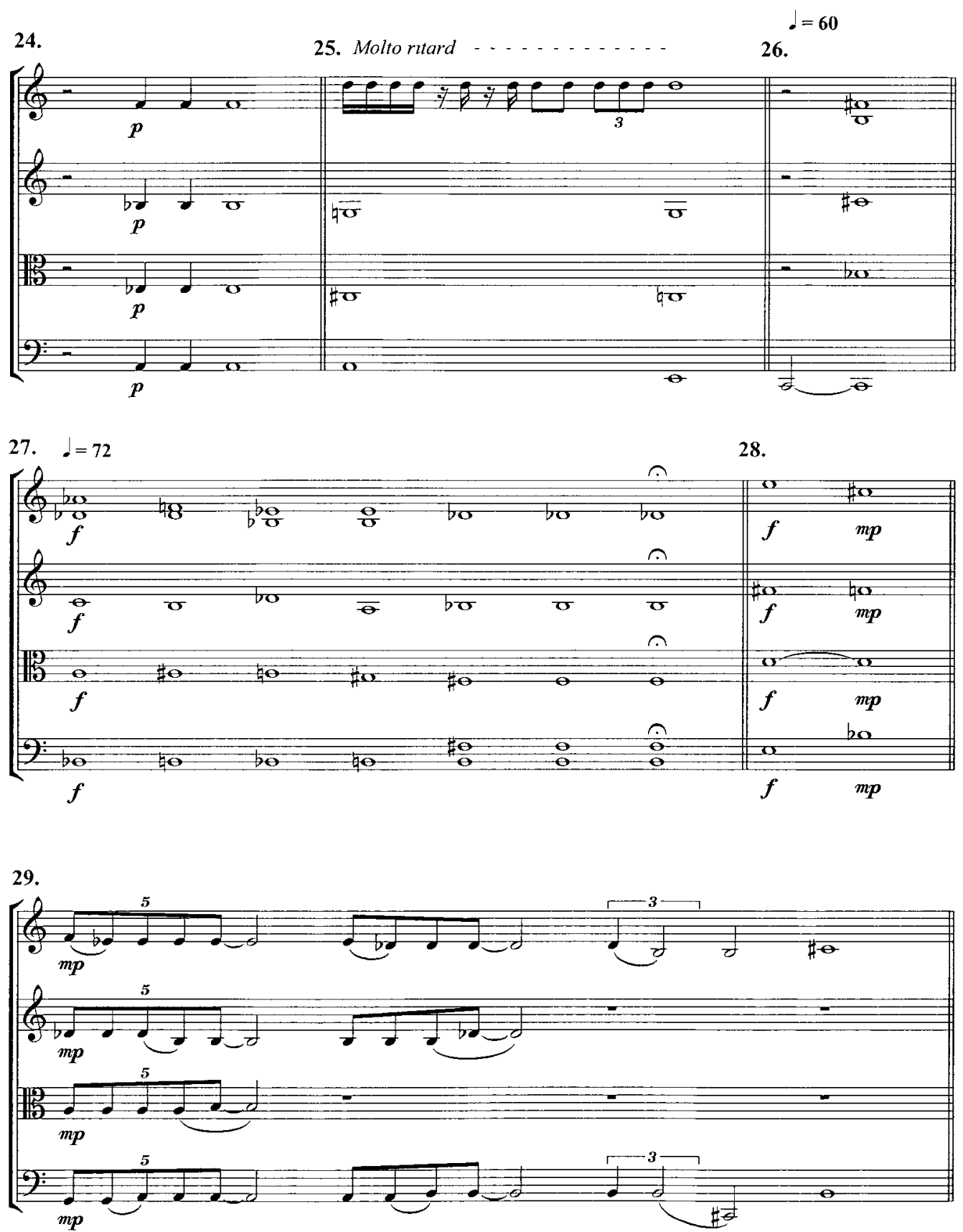
Listening to Jarvinen's prece, I hear David

Foster Wallace's summons: Ride out the waves of boredom, Wallace insists, and “it's like stepping from black and white into color." Maybe once upon a time, when there was a patience to let the swells and breaks slowly teach us to ride its current, one could learn to surf the waves of boredom. But being bored is not the ride it once was. Through the second half of the twentieth century, boredom bored so many holes in the body of every genre, every medium, every performance, and every criticism, that it bled its promise of blıss into ever-narrower furrows of distraction. The problem with boredom now is that the rituals of bloodletting that go by the name "boring art" are largely indistinguishable from the practices of everyday life such that our interests have, in a sense, hemorrhaged. Bored to death, the "we" of Western
The "sensuous infinity" that I refer to in this chapter is the sense one has of a perpetually receding end-point, or inversely, of a continually dividing mid-point This can be represented in two ways using the famıliar example of a number series ( $m, n, o)$ The former is what's called an extenstve infinitude whereın along a real number senes one can always count one more term beyond the last This is represented by the formula $(\mathrm{m}, \mathrm{n}$, o $)+1$ The latter however, is called an intensive infinitude, wherem between two terms of this series lies a third The formula for this sense of infinitude is $1 / 2(m+n)$

FYI Infinity has a curnously rich conceptual history that extends from the ancient Greek notion of apeiron (roughly translated as "primordıal chaos"), to Arıstotle's ontologically ambiguous "potential infinity," to the nıneteenth-century mathematician Georg Cantor's mind-bendıngly bizarre theory of "transfinite numbers" which introduces the 1dea of cardinality - a number of elements in a set-and the hypothesis that infinite sets can have different sizes, represented by the nifty symbol (Hebrew letter) Aleph $\aleph_{0} \aleph_{1} \aleph_{2}$

industrial culture is dying by a thousand little interests. Boredom no longer compresses into a tight bundle of bliss; now it just splays out - the pullulatıng temper of postmodernity's bad or "sensuous infinity." While characterizıng the nihilısm of the postmodern, this sensuous infinity (a term I borrow from Hegel, who used th to describe a situation of perpetual alternation between the determination of $x$ and not-x $)^{1}$ is more

\footnotetext{
'Hegel elaborates the notion of a "bad infinity" in his critıque of Johann Gottlieb Fichte's account of subjectıvity (ego) For Hegel,
} 
accurately capturing something of the affective scope of what it's like to endure the pressure of finding oneself a finite subject addressed by seemingly infinite demands. Boredom in this sense is a coping mechanism that cradles us from the madness of the infinite, but, insofar as there is no end to being bored, its cradle reduplicates the summons of infinity. Boredom's sprawl is therefore the propagation of an ambivalent event that shelters the subject from the loss of its practicable horizon with a homeless mood.

It is this ambivalence that I want to consider in the pages that follow in order to update the capacity, or incapacity as it were, of boredom (1n music) to articulate the feeling of being a subject in contemporary culture. While experimental composition is the primary aesthetıc medium that I use to explore this concern, ${ }^{2}$ I deploy it more as a lens by which to focus the scattered rays of monotony on a wider set of logics that can be found in numerous other aspects of contemporary culture. I suggest that many composers who are now writing long, quiet, repetitive, and slow moving music of the kind that is intended to be experienced without (external) interruption, express a sense of boredom that characterizes a more general feeling of being unjustified that is engine to a neoliberal injunction which demands constant self-definition. In other words, the transcendental satisfaction promised by a work like Charlemagne Palestine's Strumming Musıc (1974), a fulfillment that discriminates aesthetic boredom from mundane ennui, is no longer

Fichte does not attain to the idea of Reason as the perfected, real unity of subject and object, or of ego and non-ego, it is only, as with Kant, represented as the thought of a union in belief or faith, and with this Fichte likewise concludes For because the ego is fixed in its opposition to the non-ego, and is only as being opposed, it becomes lost in that unity The attainment of this aim is hence sent further and further back into the false, sensuous infinitude $-\mathrm{G}$ W F Hegel, Lectures on the History of Phllosophy, trans E S Haldane and Frances H Simson, vol 3 (Lincoln University of Nebraska Press, 1995), 499

${ }^{2}$ While repetition, slowness and suspension are not exclusive to experimental composition, 1 emphasize the Cagean tradition here, for a certain conviction and celebration of boredom is fundamental to the aesthetics of post-Cagean composition in a way that sets it apart from the droney doom metal of SunnO)) ) or the numbingly pensıve groove of Britısh dubstep 
operative. There is no water in the desert, but only a parallel series of fatigue and regeneration that split infinity in two: "I can't go on, I'll go on." In contrast to the certitudes of artists like Dick Higgins, who gives boredom a euphoric aura, and Andy Warhol, whose banal repetitions suggest that boredom is the logical conclusion of commodity culture's delight in novelty, the contemporary musical practices that I identify and analyze in this chapter effect what theorist Sianne Ngai identifies as an affective response exemplifying a more stilted and undecided type of boredom. She calls this aesthetic category the "stuplime" and contends that it is a more accurate depiction of the alternately astounding and stupefying experience of "processing the finite but iterated.",3

The significant difference expressed by stuplimity introduces into contemporary aesthetic figurations of boredom an important acknowledgement of what Marx and Engels referred to as the "everlasting uncertainty and agitation" of modernity.

As expressions of this insufferable situation, I argue that new musical complexes of stuplimity can be understood to condition the practice of waiting - an art of witnessing events in their eventness. In short, waiting is a vanity, a talent for tedium whose passive enactment is one of the only spaces left for a cultural practice--in this case, "art music" - whose hyperreflexive proclivities and suicidal tendencies estrange it from both popular and academic appreciation. This, however, is precisely not to attribute to the art of waiting a subversive intent but to suggest that waiting is a way of "acting out" the circumstances of being disposed towards the delirium of postmodernism's promise of multiplicity but lacking the tools to build the rafts that would float its drifts. As such, contemporary boredom performs a new role, not to rupture habit but to madden desire's

\footnotetext{
${ }^{3}$ Sianne Ngai, Ugly Feelıngs (Cambridge, MA. Harvard Unıversity Press, 2005), 277

${ }^{4}$ Ibid See Karl Marx and Friedrich Engels, The Communıst Manifesto, trans Samuel Moore (London Penguin Classics, 2002), 223
} 
clichéd attachments by simply failing to be interesting, a failure that puts these practices perilously close to what Paul Mann calls "stupid undergrounds"-contemporary vanguards that "feign stupidity" or adopt a "posture of indifference" in order to get off on the symptoms of difference excreted by our culture's pathological need to organize (commodify) experience. To the extent that contemporary boredom avoids its own proximity to the sheer stupidity that grows around it, it does so at the cost of denying itself even a modest fit of "inane energy" earned by the blazon of its dumb insistence and critical paucity. Thus, the uncertainty of contemporary aesthetic expressions of boredom reveals the affective perplexity attached to a post-avant-garde swagger that $I$ trace and theorize in the present chapter through the lens of contemporary art music's boring solecisms.

Traditionally, boredom is understood in relation to a lack of meaning. But I would propose instead to describe it as a lessening of one's capacity to affect and be affected-a diminishing of our potential engagement with the world. If we follow Brian Massumi in thinking of affect as the intensive measure of what "escapes confinement in the particular body whose vitality, or potential for interaction, it is," ${ }^{6}$ then boredom is rightly a disaffection, for it reveals a certain corporeal engulfment that, by virtue of its strange underlying tension, borders on the neighbourhood of pain. Too much body and not enough imagination becomes an affliction. ${ }^{7}$ This is perhaps why our culture has

\footnotetext{
${ }^{5}$ Paul Mann, Masocriticism (Albany. State University of New York Press, 1999), 139

${ }^{6}$ Brian Massumi, Parables for the Virtual Movement, Affect, Sensation (Durham, NC Duke University Press, 2002), 35

${ }^{7}$ Elaine Scarry's influentıal work The Body in Pain detarls an elegant theory of how sentience can be represented as a spectrum hemmed by complementary extremes at one end is the imagination wherein the act of imagining coincides with the object imagined, and at the other end is pain in which the act of perception takes itself as its object Arguing that these two ends form each other's act and object-pain
} 
developed so many ways to live beyond its fleshy limits - to reduce the burden of embodiment and relieve the labour of existence. I'm not, however, speaking only about the virtual realm of cyberspace, but about everything that capitalizes on the terror of our finitude: Television, film and the Internet relieve us (to a certain degree) of our fleshy burden, but so do art galleries and concert halls, where bodıes are incarcerated and the senses mortified in order to dispose our being not towards nothing, or death as Heidegger would have 1 t, but towards anything but nothing. ${ }^{8}$ But boredom is not "nothing." It is something in the way that a hole is something, and as such, it fulfills its etymological destiny: it "bores a hole" in us.

Now, why would artists want to intentionally bore? To diminish our affect, which is the very thing that an organism lives through, seems, if not cruel, then somehow callous, bordering even on a kind of torture. ${ }^{9}$ Isn't art's purpose to enliven, to vitalize, and thus to increase and multiply our ways of connecting and interacting with things? For example, one usually goes to a concert or listens to a CD in order to be affected, to be

\footnotetext{
becomes imagination's intentional act and the imagination pain's intentional object(1ve)-Scarry posits that sentience is the dynamic elaboration of their infinitesimal interstices Thus, for Scarry, pain is the condition of absolute embodiment whose unbearable intensity compels a movement away from the sensuous burn of sheer incarnation towards the dis-embodied state of imagining This theoretical scheme underpins (hence its placement in this footnote) much of my thinkıng about the relationship between the erratic imaginings that seem to radiate from and compose the fidgety state of being bored See Elaine Scarry, The Body in Pain The Making and Unmaking of the World (Oxford Oxford University Press, 1985)

8 "Death is a way to be, which Daseın takes over as soon as it is "Martın Heidegger, Being and Time, trans John Macquarrie and Edward Robinson (Oxford Blackwell, 1978), \46-53

${ }^{9}$ I don't mean to equate the compositional practices considered here with the employment of music as an actual torture device, as for instance the US government's 1990 invasion of Panama during which loud rock music was used to force Manuel Noriega from refuge in the Holy See's embassy, or the FBI siege of the Branch Davidian compound in Waco, Texas, in 1993 More recent cases of music as an instrument of torture have been documented in an FBI report which indicates that loud music was used at the US army's detention centre in Guantanamo Bay as an "enhanced interrogation" technıque (See Guantanamo Bay Inquiry at http //fola fbi gov/guantanamo/122106 htm) On this subject see also Suzanne G Cusıck, "Musıc as Torture/Music as Weapon," Transcultural Music Review 10 (2006), Suzanne G Cusick, "You Are in a Place That Is out of the World ' Music in the Detention Camps of the 'Global War on Terror'," Journal of the Society for American Music 2, no 1 (2008), Jonathan Pieslak, Sound Targets American Soldiers and Music in the Iraq War (Bloomıngton Indiana Unıversity Press, 2009), Suzanne G Cusick and Branden Joseph, "Across an Invisible Line A Conversation About Music and Torture," Grey Room 42 (2011)
} 
moved from one state to another and thus, in a sense, to embody the affirmation of our capacity to change, to become something otherwise. Typically, as Tia de Nora has argued, people listen to music in order to model their own vicissitudes on the music's highs and lows, to put themselves in another mood that hopefully makes their light shine brighter, makes them swell with a sense of well-being. ${ }^{10}$ Musical sounds have a way of enveloping and folding us within an intensive field such that, particularly in its everyday use, music is treated as a modulation device, an affective simulacra if you will.

But consider a piece like Canadian composer Joshua Giesbrecht's Pandaemonium's Abyss: The Final Throes of the Dead (2001), an hour-long composition for solo violin consisting solely of vacillating glissandi-hardly a work that choreographs an escape from the refrains of boredom. In fact, it seems to do the opposite; its repetitive sighs holds the listener in a state of impassivity. Keeping the mood consistently monotonous and gloomy, the work radiates little of the intensity commonly expected from the emotional experience of music. You can hear within the first five seconds of the work the virtual totality of its gestural language, its tempo, its volume, and the range of its intensive sweep. This is similar to many of James Tenney's compositions of the $1960 \mathrm{~s}$ and 70s. For Ann (rising) (1969), an electronic piece whose entire duration is percelved as a continuously rising tone - the "barber pole-effect"- and the solo violin piece Koan (1970) in which the performer executes a continuous tremolo between adjacent strings

\footnotetext{
${ }^{10}$ DeNora proposes that music in everyday hife functions as an "affordance structure," defined as "a resource or template against which styles and temporal patterns of feeling, moving, and being come to be organızed and produced in real tıme" See Tia DeNora, Musıc in Everyday Life (Cambridge and New York Cambridge University Press, 2000), 111 John Shepherd and Peter Wicke argue that music is an effective device for modulating our moods because its process of semiosis articulates the "inherently structural character of sounds" with states of awareness that are "fundamentally corporeal and affective in character" (119) See John Shepherd and Peter Wicke, Music and Cultural Theory (Cambndge Polity Press, 1997) William Benzon on the other hand draws on recent models of cognition to suggest that musical sounds enact a neurological resonance that puts individual cognitive processes into sympathy with one another Willam Benzon, Beethoven's Anvil Music in Mind and Culture (New York Basic Books, 2001)
} 
Pandaemonum ' Abyss. The Final Thoes of the Dead

$d=52$

Joshua Giesbrecht

2001

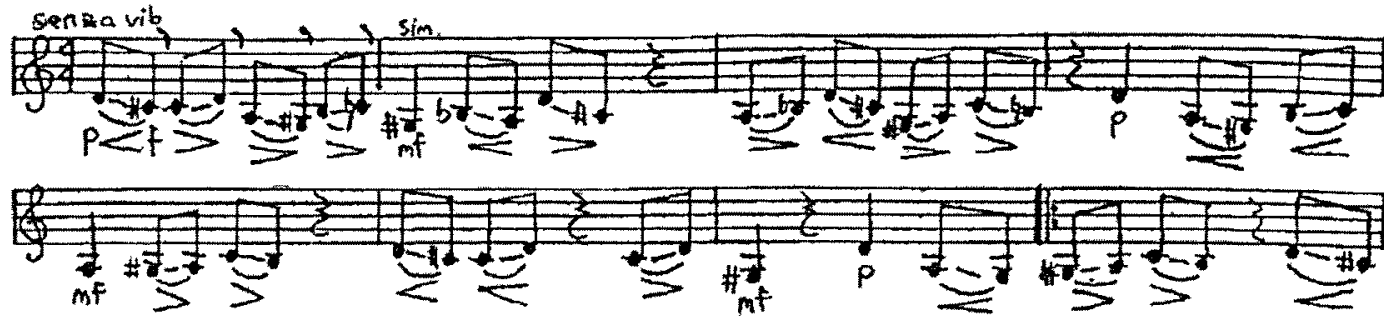

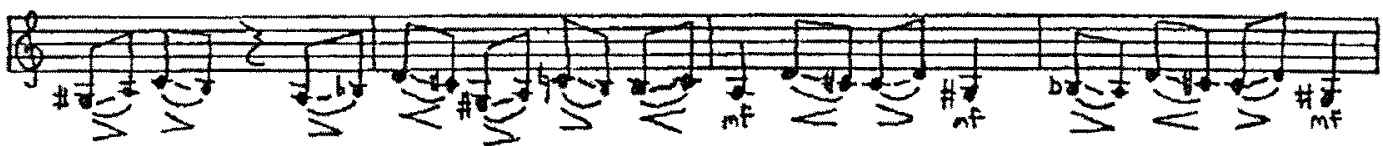

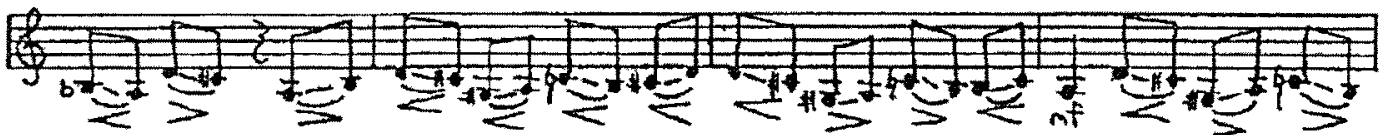

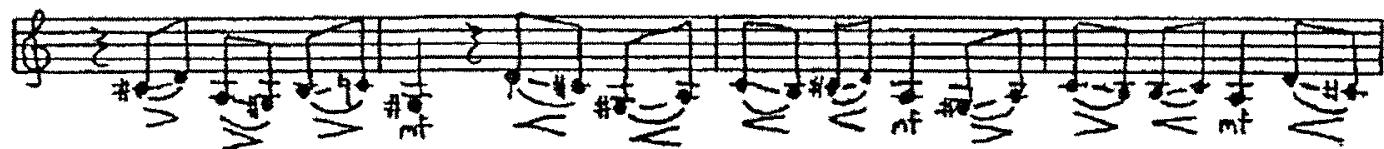

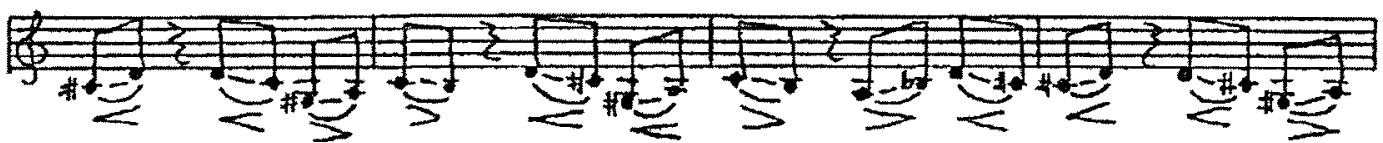

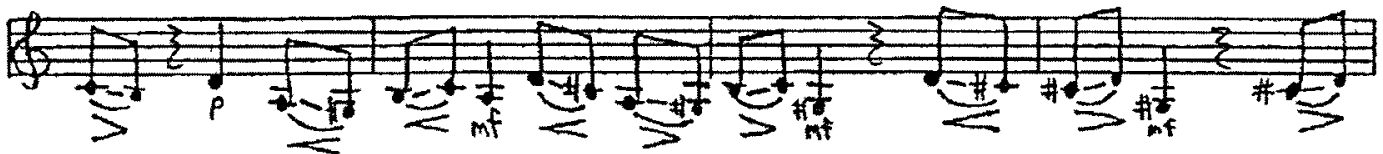

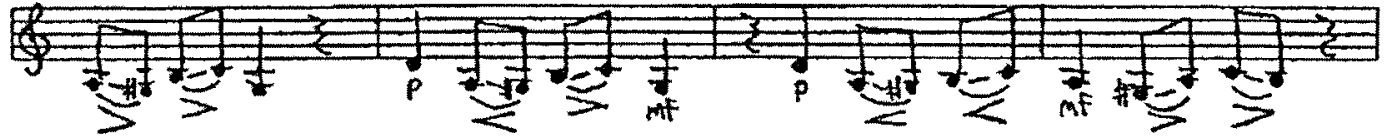

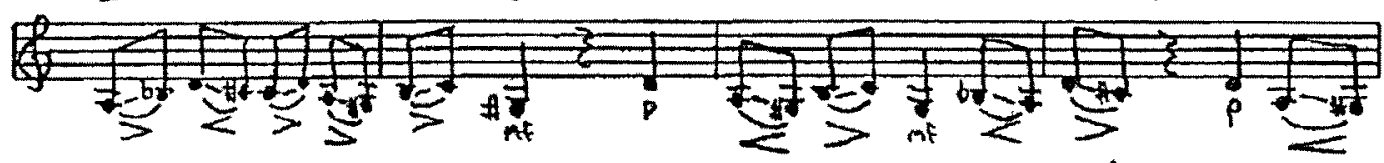

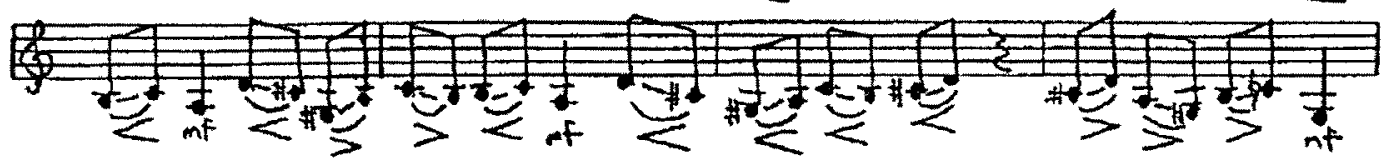

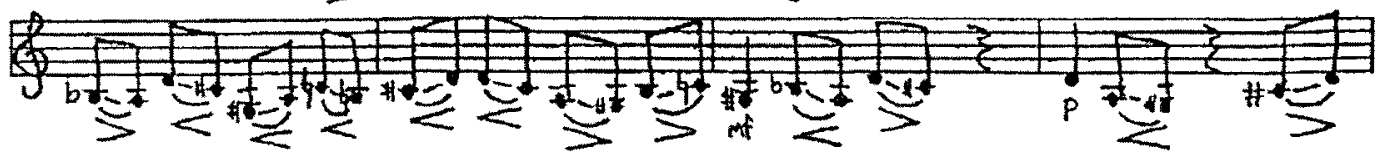

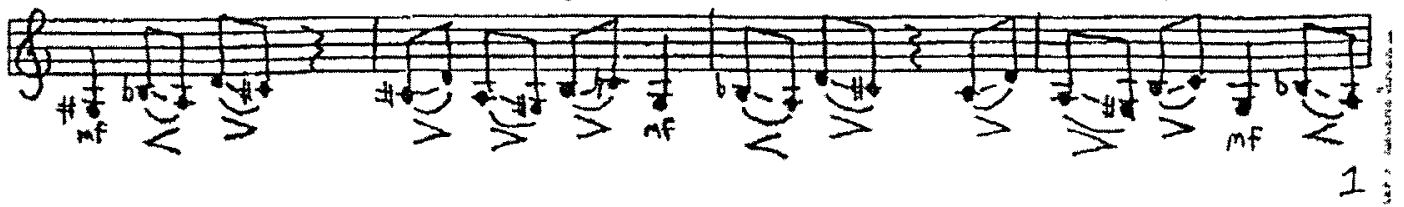


while slowly sliding one finger along one of these strings, are compositions where everything about the piece's formal properties is spelled out at the beginning so as to undermine the conventions of dramatic narrative and allow the listener to get on with listening to their listening. ${ }^{11}$ Pandaemonium's Abyss, too, charts a slow and inconspicuous progression of minor variations of its extremely constrained form of movement. But like all refrains, Pandaemonium's Abyss is no less territorial in the way that it conscripts the intensities that course through the listener to bring attention to its immanent order. However, the refrain of Pandaemonium's Abyss does not easily modulate the negative valence of its insistence in the way that other forms and uses of music are conventionally intended to do. As an aesthetic expression of the repetition of the difference that is each glissando, there is no formal way of "escaping" the kind of gloomy mood its tedium engenders. Such a slow and persistently constrained set of movements is so allied to enervated forms of being that it's not a matter of whether this work is tedious, but rather of how the intensity of the affect of this tedium is valenced. In other words, Pandaemonium's Abyss does not pretend to be un-tedious the way Wagner's fifteen-hour Der Ring des Nibelungen does, and therefore it does not afford the listener a way of being (or at least pretending to be) unbored. Instead, for reasons that I examine below, Pandaemonium's Abyss is a work that articulates a contemporary neurosis regarding the incapacity of post-vanguard aesthetics to transfigure the homogenizing indifference of being bored into, at minimum, the condition of being interesting.

The twentieth century, of course, has seen and heard a vast number of artworks that

\footnotetext{
1 Tenney coined the phrase "Ergodic music" to describe a type of musical-statistical form wherein every part of a system or process, given enough time, will exhibit statıstical equivalency with every other part. Tenney's works were concelved as phenomenological processes that would play out all the elements of "a piece clearly at the start, leaving the listener to contemplate their permutations "Ann Midgette, "Pioneer Composer Psychoacoustıcian?" New York Times, 8 May 2005.
} 
use forms of slowness, tedium, and repetition as aesthetic strategies to explore the strangely multivalent effects of aesthetic distortion, but because the contemporary expression of these forms occurs in a cultural space that has become self-evidently untotalizable, there is much less concern today with boredom's being interesting. This departs from John Cage's aphorism that if you attend long enough to what is boring you will find that what is boring is not boring at all. ${ }^{12}$ This oft repeated saying suggests that within the spins and stalls of boredom is an occulted interest that promises a sublimation of Hegelian proportions. However, neither the stakes nor the forms of attention that would bring boredom to such awareness are the same now as they were in the $1960 \mathrm{~s}$. After so many works like Satie's Vexations (1893), Gertrude Stein's The Making of Americans (1925), Andy Warhol's Sleep (1963) and Empire (1964), and recently Douglas Gordon's 24 Hour Psycho (1993) and Kenneth Goldsmith's Day (2003), it's hard to imagine that the desert of boredom holds any more water. But the redoubling of tedium in contemporary art and music might suggest something other than a redundancy. In contemporary Western culture, which is arguably characterized by excessive expressions of irony and multiple layers of metareferential discourse, the mood takes on a different life, a life that in fact resembles a kind of death, a stillborn death.

If this is the case, then the continued use of tedium in art and music can be viewed in a number of different ways. One way, and perhaps the easiest to conceptualize, is that aesthetic boredom has become redundant-that an hour-long presentation of all the 8178 possible chords within an octave, for instance (this is the conceit behind American

\footnotetext{
${ }^{12}$ This advice refers to an oft-cited sayıng attributed to Cage (which he ascribes to Zen Buddhism). "If something is boring after two minutes, try it for four If stıll boring, then eight Then sixteen. Then thirtytwo Eventually one discovers that it is not boring at all John Cage, Silence Lectures and Writings (Middletown, CT Wesleyan University Press, 1961), 93
} 
composer Tom Johnson's The Chord Catalogue of 1986, discussed below), is no longer an anti-music, but, as Baudrillard says, an "art of simulation" that aims to efface the scene of reality while at the same time preserving the image of its disappearance. ${ }^{13}$ Another way to consider contemporary tedium is to treat it as symptomatic of the postmodern habit to transpose the banalities of life into aesthetic fetishes that dazzle with the vertigo of their de- and re-natured appearance. A stronger view might be that boredom is being articulated to show the withering of its productive potential. This resembles a thesis advanced by art historian Christine Ross, who argues that the traditional models of melancholy and other despondent tempers as productive forms of subjectivity are being subsumed by the clinical discourse of depression that figures the individual as a more or less insufficient subject whose capacities are measured according to models of optımal cognitive-perceptual capacities and neoliberal norms of selfdefinition. ${ }^{14}$ A contemporary aesthetic of boredom in this case would signal the present insufficiency for tedium to perform the role of anti-art that, at least since Cage, tried to smuggle the acsthetic expectations and Mehrwert-"pay-off"- - of its contrary in through the backdoor. ${ }^{15}$ Boredom as an artistic device doesn't affect a postmodern culture that has, in words that echo Jameson's, ${ }^{16}$ forgotten that there ever was a history of beauty to

\footnotetext{
${ }^{13}$ See Jean Baudrullard, The Consprracy of Art Manifestos, Interviews, Essays, trans Sylvère Lotringer (New York: Semiotext(e), 2005).

${ }^{14}$ Christme Ross, The Aesthetics of Disengagement Contemporary Art and Depression (Minneapolis: University of Minnesota Press, 2006). Below I discuss how boredom relates to what Ross sees as a depressive paradigm that characterizes recent art practices represented by artısts like Ugo Rondinone, Vanessa Beecroft and Rosemane Trockel

${ }^{15}$ Diedrich Diederichsen applies the German "Mehrwert" (literally "surplus value") to contemporary attitudes towards art to indicate "an additional value that can be realized in return for a special effort or in connection with an exceptional situation" Diederich Diederichshen, On (Surplus) Value in Art (Rotterdam Witte de With, 2008), 21

${ }^{16}$ For Jameson, a major theme of postmodernism revolves around what he calls "historical amnesia":

The disappearance of a sense of history, the way in which our entire contemporary social system has little by little begun to lose its capacity to retain its own past, has begun to live in a perpetual
} 
be lost, challenged, defied, or conserved. Boredom is now just one more mode/mood among any number of existential motifs. Another interesting, though not necessarily truer perspective, would be to see the current use of tedium as an expression of contemporary culture's chronic incantation of the same difference; that is, the desire for desire.

Boredom is often described as a disaffection, an inability to form attachments or affection for the things of life. To desire desire is to experience and suffer the extreme success of our distractions, which is another way to say that it has become difficult to focus on the task of being oneself, of being maddeningly attentive to "a fundamental need to do something." 17 The affective torsion of wanting nothing in particular that seems to paradoxically "charge" acute states of boredom, characterized by Ngai as the "stuplime," distinguishes itself from Lyotard's postmodern sublime, which retains its Kantian sense of a rational subject's recovery in the face of being overwhelmed. ${ }^{18}$ The stuplime instead evokes a hobbled or lame astonishment to describe the affective response that captures the ambiguity of being drawn to nothing in particular.

Each of these points are addressed in different ways throughout the chapter, though neither in order nor in isolation from one another, for it's the nature of boredom to be multiply expressed: as alternately shocking and exhausting, as a long-term investment with eventual pay-off, as commenting on our insipid fascination with ourselves, and revealing our general lack of imagination. I contextualize the contemporary interest in

present and in a perpetual change that obliterates traditions of the kind which all earljer social formations have had in one way or another to preserve. - Fredric Jameson, "Theories of the Postmodern," in The Cultural Turn Selected Writings on the Postmodern, 1983-1998 (London* Verso, 1998), 20

${ }^{17}$ Gabor Csepreg1, The Clever Body (Calgary University of Calgary Press, 2006), 14

${ }^{18}$ See Jean Françoıs Lyotard, The Postmodern Conditıon A Report on Knowledge, trans Geoff Bennıngton and Brian Massumı (Minneapolis. Unıversity of Minnesota Press, 1984), 77-82, and Lyotard, Perigrinations Law, Form, Event (New York Columbıa Unıversity Press, 1988), 92-101. 
musical boredom, which I also refer to provisionally in terms of musical "extendedness," by considering antecedents in the experimental art and music of the 1960s and ' 70 s. Drawing on Ngai's theory of the stuplime and employing discursive tactics that take me from boredom avoidance training in office culture, to Michel de Certeau's polemological theory of the everyday, to the psychodynamics of absent object relations, to the libidinal flows of Lyotard's meaningless "events," I argue that contemporary boredom is a way of paying attention to our culture's fixation on nothing in particular $(=$ everything in general) and that contemporary music engineers this by staging an encounter with a sensuous infinity. I begin, however, with a survey of the philosophical dimensions of boredom as it has been theorized since the eighteenth century, in order to construct a narrative that supports the idea that ours is not merely a bored culture, but a culture in waiting. I will then be in a position to unravel the ways in which contemporary musical tedium and monotony, through its own studied failure to separate itself from the spins and stalls of everyday life, becomes, to cite Paul Mann, something occasional that "complicate[s] cultural space, for a moment or two, for a reader or two, to thicken it and slow one's passage through it, and, as always, to render criticism itsclf as painful and difficult as possible." ${ }^{19}$

\section{A boring history}

The major studies of boredom trace the appearance of the mood to the mid-eighteenth century and attribute its emergence and proliferation to a modern crisis of meaning wrought by the metaphysical ambiguity and social anomie ushered in by the material

\footnotetext{
${ }^{19}$ Mann, Masocriticism, 129.
} 
processes of modernization and the egalitarian distribution of enlightened scepticism's paradoxical epistemological claims that render subjective experience in objective terms and categories. The effects and theories of boredom as a symptom of modernity began to appear in the nineteenth century with writers like Søren Kierkegaard, Charles Baudelaire and Friedrich Nietzsche. Though not the first to address the emergence of the mood in modern Western culture, Kierkegaard articulated what he perceived to be a void consuming modernity's increasingly self-aware and self-affected sense of reality. Positing that "Boredom depends on the nothingness that pervades reality; it causes a dizziness like that produced by looking down into a yawning chasm, ${ }^{, 20}$ he imagines that a mode of existence organized around the growing aesthetic affectation of human interests leads to an immoral and ultimately bankrupt existence. Baudelaire, writing around the same time as Kierkegaard, gives boredom a lyrical figure in his work Les Fleurs du mal. In the poem he describes "l'ennui moderne" as a distinctly modern malaise-_"spleen"-whose mercurial pathos is expressed by an individual's alternation of disaffection and exasperation. ${ }^{21}$ Echoing Baudelaire's diagnosis of modern life, Friedrich Nietzsche bestows the nihilism of boredom, what he calls its "calm wind," with an eschatological function, seeing humankind end not with the fiery judgment of absolute self-knowledge but the stupefying irony that humanity's essence is ultimately an elaborate performance of fleeing from boredom. ${ }^{22}$

\footnotetext{
${ }^{20}$ Soren Kterkegaard, Elther/Or, trans. Howard V Hong and Edna H Hong (Princeton Princeton University Press, 1988), 287

${ }^{21}$ Charles Baudelaıre, Les Fleurs Du Mal, trans. Richard Howard (Boston David R. Godıne, 1985)

${ }^{22}$ Freidrich Nietzsche, Human, All Too Human, trans R J Hollingdale (Cambridge Cambridge University Press, 1996)
} 
Boredom has also been represented discursively in the twentieth-century existentialist fiction of Albert Camus (L'Etranger), Jean-Paul Sartre (Nausea), and Samuel Beckett (Waiting for Godot, Happy Days), where the mood is depicted as an expression of life's finitude and contingency, and by extension, its insignificance. Sociological studies of boredom are represented in the works of George Simmel, Walter Benjamin and Siegfried Kracauer, who each examined the malaise as symptomatic of an experiential atrophy due to processes of industrialization and urbanızation, ${ }^{23}$ while boredom's philosophical profile is perhaps best known by Heidegger's examination of the phenomenon as a fundamental human mood capable of providing direct insight into the nature of being and time. ${ }^{24}$ For He1degger, boredom, like anxiety, awakens us to the radically contingent and therefore inessential nature of being, provided, that is, that one can withstand (or submit to?) the crushing force of being awakened to being-as-a-

\footnotetext{
${ }^{23}$ See Georg Simmel, "The Metropolis and Mental Life," in The Socılogy of Georg Simmel (New York Free Press, 1964), 409-17, Walter Benjamin, Arcades Project, ed Rolf Tiedemann, trans Kevin McLaughlın Howard Elland (Cambridge, MA Belknap Press of Harvard Unıversity Press, 2002), Walter Benjamın, The Writer of Modern Life Essays on Charles Baudelatre, ed Michael W Jennıngs, trans Rodney Livingstone, Edmund Jephcott, and Harry Zohn (Cambridge, MA Belknap Press of Harvard University Press 2006), Siegfred Kracauer, "Boredom," in The Mass Ornament Weimar Essays, ed Thomas Y Levin (Cambridge, MA Harvard University Press, 1995)

${ }^{24}$ Heidegger treats the malaise as a disposition that reveals the way human being finds itself embedded in a world that matters to it Boredom (as well as anxiety) is what Heidegger calls an "authentic mood" and is distinguished from "inauthentıc" moods insofar as the former reveals the ontological strangeness of our radically contıngent and provisional nature rather than the familiar forms of attachment that play out in everyday situations For Heidegger, these moods are important for the way they attune us directly and forcefully to the enigma of being-namely, to the nothingness that underwrites being While both anxiety and boredom compel us to face the groundlessness of being, their distinctive tones mark the way in which this matters differently to being anxiety shows a way of being hyper-concerned at the prospect of having to perpetually secure onself in the world, while boredom, on the other hand, reveals an utter indifference to Dasein's finding itself in the world's theatre of being Heidegger's investigation into boredom is complex and comprehensive, however, because his project focuses largely on the mood's manifestation in the everyday, I'll only grapple with his theory to the extent that it helps articulates the connection between the way artists and everyday practices express the sense of the infinite by iterations of the finite For Heidegger's analysis of moods and boredom see The Fundamental Concepts of Metaphysics World, Finitude, Solitude, trans Willıam McNeıll and Nicholas Walker (Indianapolıs Indiana Unıversity Press, 2001), and "What Is Metaphysics?" in Basic Writıngs, ed David Farrell Krell (New York Harper Perennial Modern Classics, 2008)
} 
whole. ${ }^{25}$ However, the humanistic traits of existentialism that were targeted and surpassed by (post)structuralism's critique of self-authored being, ${ }^{26}$ and the increasingly central role that neuroscience and clinical discourse have come to play in defining human experience, have converted boredom into an epiphenomenon of the socio-psychic dynamics of contemporary information culture. Orin Klapp's Overload and Boredom (1986), for example, contends that the excessive amount of information in contemporary culture functions as a site of excessive redundancy that increases semantic entropy, and thereby ushers in the onset of boredom. ${ }^{27}$ Though each of these works look at the mood slightly differently, they all embrace the common themes of modern meaninglessness and temporal homogeneity as factors contributing to the transformation of the present into an absolute, but empty, value.

Beginning with an outline of the history of diminishing affects that predate the category of boredom's somewhat sudden appearance in the mid-eighteenth century, Seán Desmond Healy's Boredom, Self, and Culture (1984) draws on each of the above authors' observations to argue that the malaise is a consequence of a "growing metaphysical void at the centre of Western civilization. ${ }^{28}$ Healy suggests that boredom developed from a minor to a major affliction through the gradual de-centring of tradition, culture, and ultimately self--historical structures that enabled one to organize behaviour and experience into meaningful events. Though the feeling of being bored was not

\footnotetext{
25 "Profound boredom, drifting here and there in the abysses of our existence like a muffling fog, removes all things and men and oneself along with it into a remarkable indifference This boredom reveals being as a whole" Heidegger, "What Is Metaphysics?" 99

${ }^{26}$ (arising, curiously, at the same moment when the femınıst and civil rights movements began to assert the agency of marginal identitıes)

${ }^{27}$ See Orrın Klapp, Overload and Boredom (New York Greenwood Press, 1986)

${ }^{28}$ Seán Desmond Healy, Boredom, Self, and Culture (Rutherford, London Fairleıgh Dickınson Unıversity Press, 1984), 87
} 
without its antecedent afflictions--daemon meridanus ("noonday devil"), accedia, tristitia, melancholia, ennui--Healy contends that these were regarded as unusual maladies and "largely a theological concern, confined in its secular form to a mere handful of intellectuals." 29 Existing in some vague way before the term "boredom" appeared, it was not until the conditions and effects of the malaise "increased in such degree, incidence, and reflective awareness" ${ }^{, 30}$ that a term was required to describe what seemed an indefinite indifference to things, an "affect without effectiveness in locating the source of trouble. ${ }^{31}$ What Healy refers to as a waning sense of transcendence, an escape from the appetites of being, corresponds to the foundering idealism of Western European culture in the eighteenth century, spurred on by the advance of enlightened scepticism and its expression in the natural and physical sciences. ${ }^{32}$ As the rhetoric of reflection on modern experience began to organize around these materialist and rationalist explanations of experience, the idealization of meaning, "if by that is meant the urgent desire to search out and to pursue what is excellent and what is true," says Healy, "becomes increasingly incapable of being satisfied, or even of finding a credible object or direction, in a culture where Truth has been reduced to truth, or even more damagingly, to truths, or even to 'truths', ,33

The ideologies, the "truths" of myth, religion, and tradition that canalized the flow of desire and made sense of existence according to their modes of satisfaction, become

\footnotetext{
${ }^{29} \mathrm{Ibld}, 19$.

${ }^{30}$ Ibld , 24

${ }^{31}$ Ibid., 44 Healy notes the unknown etymology of the term but cites a philological study by Logan Pearsall Smith which "Identifies 'bore' as an eighteenth-century neologism" (44) Curously, this study also shows that "bore" was preceded two years earler by the term "interesting"

${ }^{32}$ Ibid , 25

${ }^{33}$ Ibld, 89.
} 
largely ineffective in the wake of post-Enlightenment scepticism. Healy writes, "Boredom is the inevitable accompaniment of the absence, or even serious uncertainty about the stability and reliability of values, purposes, meanings and commitments." ${ }^{34}$ If meaning can be understood as "the sense of a centre [that is not necessarily oneself but a "God" or a code which] endows [one's] existence with...a sense of the necessity of things, ${ }^{, 35}$ then what erodes the sense of a centre erodes also the necessity of things. To become unnecessary is to become contingent. Sartre, exploiting the French sense of sense (sens) to convey both meaning and direction, depicts this contingency viscerally when Roquentin, the protagonist of his 1938 novel Nausea, encounters a world that is radically indifferent to his existence. Perceiving the sheer un-necessity of any of his deeds or desires, Roquentin finds that he lives without sense, without meaning:

It is the reflection of my face. Often in these lost days I study it. I can understand nothing of this face. The faces of others have some sense, some direction. Not mine. $^{36}$

The death of God is only partially the concern here. For as Healy suggests, boredom concerns the withering organizing principles of a society and its individuals. Whether it is God, tradition, myth, culture, or "self" that serves as the measure of meaning, the sense (sens) of things matters little. It is the discrediting of all centring or grounding principles that establishes the condition of boredom.

Lars Svendsen gives a postmodern reading to this situation, what may be called the "disenchantment thesis," in his work A Philosophy of Boredom (2005). More acute and insidious than simply the death of God or a diminishing sense of transcendence is

\footnotetext{
${ }^{34}$ Ibid, 91

35 Ibid, 99

${ }^{36}$ Jean-Paul Sartre, Nausea, trans Lloyd Alexander (New York New Directions Publishing Corporation, 1969), 16
} 
what Svendson suggests is the growing inability for "us" postmoderns to fulfill "our" Romantic inheritance as "world-forming being[s]." 37 Drawing on Horkheimer and Adorno's critique of the culture industry and alluding to the logic of simulation explained In Baudrillard's analysis of contemporary culture, Svendsen argues that "as descendants of Romanticism [who] insist on a personal meaning,"38 our culture requires not a sense of transcendence but an immanent sense of mystique or opacity in order to make meaning. The human subject, Svendsen writes, is "a being that actıvely constitutes his own world, but when everything is always already fully coded, the active constitution of the world is made superfluous" 39 - de trop in Sartre's terms. In a world where "events, no matter how unimportant they may be...can be blown up to enormous proportions," 40 everything becomes "potentially visible" and virtually transparent. ${ }^{41}$ Nothing is hidden from me, and my life- to the extent that I can stıll call what I experience "my life"-is, in all its splendid shortcomings and virtues, laid out before I become them.

The transparency of contemporary culture's obsessive surveillance and transcription of itself, in aesthetic as well as epistemological forms, gives the impression that the world lacks secrets. Though this transparency is in a sense unreal, because it pertains more to the circulation of its own mediated forms of knowledge than any actual world existing apart from its representations, the postmodern subject is confronted with

\footnotetext{
${ }^{37}$ Lars Svendsen, A Phllosophy of Boredom, trans John Irons (London Reaktion Books, 2005), 32 Svendsen never clarifies who exacly belongs to this category of the "postmodern "While it wouldn't completely undermine his thesis, considering the actual make up of this population would problematize it in many critical ways Admittedly, I do not clear this up in this study, although I as point out in the introduction, I intimate that those in a position to examine their insufficiency or sense of privation inevitably do so from a position of privilege

${ }^{38}$ Ibid , 31

39 Ibrd , 32

${ }^{40}$ Ibid, 37 Svendsen is alluding specifically to technologies that can archive and treat virtually any dimension of experience as a specimen to be studied and thereby "interpreted"

${ }^{41}$ Ibid , 38
} 
"a world" that appears not to require interpretation. Accordingly, "The world becomes boring when everything is transparent. ${ }^{, 42}$ The Portuguese poet Fernando Pessoa expresses this sensibility at the beginning of the twentieth century, writing: "Tedium is not the disease of being bored because there is nothing to do, but the more serious disease of feeling that there is nothing worth doing." ${ }^{, 43}$ Nearly fifty years later, this sentiment is echoed in 1968 by the conceptual artist Douglas Huebler, who based his practice on the observation that "The world is full of objects, more or less interesting," and a resolve not to add to them: "I prefer, simply, to state the existence of things in terms of time and/or place. ${ }^{, 44}$ As if in dırect response to Huebler's aesthetic strategy of (dis)engagement, Svendsen argues that the source of boredom is not a "growing metaphysical void", but instead an excessive reflexivity, attributable to the Romantic neurosis that the self is "constantly in danger of acquirıng a meaning deficıency." 45 This hyper-reflexivity, Svendson concludes, is responsible for re-presenting the world as something already had, something exhausted of all its potential becomings.

Svendsen's philosophy of boredom updates Healy's thesis that the malaise ensues from a loss of meaning by showing how an essentially anthropocentric "dis-ease," incubated in early modern scepticism and pathologized within the philosophical individualism of Romanticism, spread throughout the Western world during the twentieth

\footnotetext{
42 Ibid

${ }^{43}$ Fernando Pessoa, The Book of Disquiet, trans Richard Zenith (London Pengum Classics, 2002), 365

${ }^{44}$ Huebler's aim is to merely document elements of the world through a motley assemblage of maps, drawings, photographs, and descriptive writıngs However, he overlooks the fact that his very act of assembly is not simply stating the existence of things but changing the nature of the "things" that he is assembling Thus, despite the sentiment, Huebler's practice is an enactment of the very processes of transcription that paradoxically show culture to itself by inventing new aesthetic configurations of its objects See Douglas Huebler, "Untitled Statement," in Theorles and Documents of Contemporary Art, ed Kristıne Stıles and Peter Selz (Berkeley Unıversity of Calıfornı Press, 1996), 840

${ }^{45}$ Svendsen, A Philosophy of Boredom, 33
} 
century as a result of an insidious aestheticization — "transcription"- - of the real. ${ }^{46}$ Aided by an emergent technocentrism that dissolved the things of the world into a system of functional and instrumental relays, ${ }^{47}$ the loss of traditional ways of reflecting on subjective experience, initially felt as a threat to personal meaning (Romanticism), gradually evolved into the modernist impossibility of personal meaning (Beckett), and culminated in the postmodern renunciation of personal meaning (Warhol).

While Svendsen's post-Baudrillardıan vision of a radically mediated world extends Healy's premise that boredom emerges from the withering of traditional meaning structures, Elizabeth Goodstein's study of the discourse of boredom, in her work Experience Without Qualities (2005), suggests that the experience of boredom is "a lived metaphor for the dilemma of the modern subject." ${ }^{48}$ She argues that the metaphorics of boredom, the way in which its expressions characterize the uniquely modern sense of disaffection, delineate an ambiguous experience that arises from the contest between a withering paradigm of faith and the reflexive proclivities of modern epistemological skepticism. The rhetoric of this experience, "centered on [an] embodied subject struggling with the meaning and purpose of existence in a world increasingly bereft of both religious and worldly certainties, ${ }^{, 49}$ addresses the malaise as a property of the world rather than an attribute of the self, while at the same time implying a "self" with no empırical purchase in the world it supposedly constitutes. ${ }^{50}$ Reflecting the reflexive

\footnotetext{
${ }^{46}$ Again, this "real" is only the real that the transcriptions express One's knowledge of reality is what one know it as

${ }^{47}$ Svendsen, A Phlosophy of Boredom, 88

${ }^{48}$ Elizabeth S Goodstem, Experlence without Qualttes Boredom and Modernity (Stanford Stanford Unuversity Press, 2005), 420

${ }^{49}$ Ibld

${ }^{50}$ This is the quandary that Kant faced and which he tried to reduce to a set of four antinomies that anse as byproducts of the faculty of reason's conflict with other faculties See Immanuel Kant, Critique of Pure
} 
capacities of (post)Kantian thought, the rhetoric of modern experience naturalizes this metaphysical ambiguity and "evoke[s] the fatalistic generalization that life itself is a senseless series of momentary encounters with irrelevant objects." ${ }^{., 1}$ Thus the discourse of boredom masquerades as a fundamental human mood because the rhetoric of modern experience, which draws its tropes from an "epistemological and ethical skepticism" regarding ways of "understanding and dwelling in the world," to boredom in such a way that the existential or practical insufficiency felt in being bored "eclipses the socio-critical dimension of the discourse." ${ }^{, 53}$ Goodstein's argument is that the metaphorics of boredom undercut its own ability to comment on the conditions that express what might be called the sense of senselessness.

Unlike Svendsen who sees a possible melioration, if not cessation, of boredom's urgency by accepting that life holds no great "Meaning" but only a series of fleeting "meanings," 54 Goodstein sees no hope for boredom. Where Svendsen shines a melancholic light on boredom, Goodstein drapes it in depression. Boredom for Goodstein has no redemption; the nihilistic dynamic that composes its lived experience cannot reflect on the historical specificity of its felt sense of senselessness. That is why she is able to speak of an "experience without qualities," for without a language of reflection, experience remains unqualified and, in a sense, unjustified, unnecessary — de trop. As a "lived metaphor for the dilemma of the modern subject" who is unable to say or convey what ails him/her, the experience of boredom can only circulate in modern discourse on

Reason, trans Paul Guyer and Allen Wood (Cambridge Cambridge Unıversity Press, 1999); and Victoria Wike, Kant's Antinomies of Reason (Lanham, MD· University Press of America, 1982)

${ }^{51}$ Goodstem, Experience without Qualtties, 408

${ }^{52}$ Ibid , 413

${ }^{53}$ Ibid , 408

${ }^{54}$ Svendsen, A Phulosophy of Boredom, 154 
subjective experience as a mute performative, a paradoxically expressive non-expression of the dumb and unqualified way of being present to an objectified world that has lost its capacity to defer-to God, to tradition, to culture. In other words, boredom expresses the failure of modern reflexive discourse to account for its own culturally and historically determined conditions; as a lived metaphor that compares certain corporeal manners (weariness, fatigue, sloth) with a proliferating array of anomie, boredom entails a forgetting not only of its own metaphorics but of the general role that metaphorunderstanding one thing in terms of another-plays in the discursive construction of experience and the expression of that experience.

Though Goodstein's study is focused primarily on boredom as a self-defeating discourse of reflection on the subjective experience of modernization, I want to concentrate on the way in which boredom's failed metaphorics open the way to the felt sense of senselessness, and how contemporary boring music enacts the way of "beingunjustified" by making us wait. These considerations are significant for at least two reasons: First, seen through the lens of failure, "boredom as a metaphor for the experiential predicament of the modern subject" ${ }^{\text {55 }}$ characterizes the plight of an ambivalent subject. This subject, in addition to coping with its "essential ambiguity" bestowed by modern scepticism, must manufacture its own interests or, following Felix Guattari's notion of subjectivity, "produce assemblages of enunciation capable of capturing the points of singularity of a situation." ${ }^{, 56}$ Although boredom's metaphoricity is incapable of grasping its own historical contingency, the interruption in the habitual and

\footnotetext{
${ }^{55}$ Goodstem, Experience without Qualities, 420

${ }^{56}$ Felix Guattar1, Chaosmosis An Ethico-Aesthetic Paradigm, trans Paul Bames and Jullian Penfais (Indıanapolıs Indiana Unıversity Press, 1995), 128
} 
therefore a-singular attachments to things, places, times, can be read through Guattari's onto-aesthetic paradigm as "an activity of rupturing sense, of baroque proliferation or extreme impoverishment, which leads...to a recreation and a reinvention of the subject itself." ${ }^{, 57}$ Boredom divests the contemporary subject of its certainties and at the same moment it grants this "larval subject," or subject in waiting, the power (the illusion?), if not the form, of self-invention. There are, however, a number of consequences that follow from this and I'll take them up in what follows, but first I want to address the second aspect of boredom's failure.

The forgetting of boredom's metaphorics, though it sacrifices meaning, can be understood to occasion a productive situation in which, as Guattari's counterpart Gilles Deleuze argues in his work on time in cinema, "a different type of image can appear." 58 This "image" — whether a work of art or an everyday perception-is one whose capacity to stand for something else is impeded such that it "brings out the thing in itself, literally, in its excess of horror or beauty, in its radical or unjustifiable character." 59 Boredom has a way of unbinding expectations and responsive habits from their conventional assembly and customary valence; however, it does not give a superior view of being in the sense promoted by Sartre or Heidegger. ${ }^{60}$ Instead, the inability to reflect meaningfully on subjective experience that characterizes the metaphorics of boredom elaborates a situation-an "image"- that is both excessive and deficient, a situation whose

\footnotetext{
${ }^{57}$ Ibrd, 131

${ }^{58}$ Gilles Deleuze, Cinema 2 The Time-Image, trans. Hugh Tomlınson (Minneapolıs Unıversity of Minnesota, 1989), 20

59 Ib1d

${ }^{60}$ Sartre's position is that being is given enturely-without remainder - in its appearance. Thus the appearance of being bored is the ontology of the phenomenon of being as it manifests itself See Jean-Paul Sartre, Being and Nothingness, trans Hazel Estella Barnes (New York Washınton Square Press, 1984) For Heldegger's position see note 24
} 
senselessness (non-sens) expresses not the "thing itself," but the dumb refrains of nonsense. The "thing itself" is revealed in being bored as something that is essentially unjustified in itself, something radically supplemental, and, ironically, something that is perpetually interesting.

NB I'm not trying to resuscitate the aura that boredom has earned over the past forty years of canonizing Cage's pithy maxims. I think that what still intrigues artists about boredom concerns the low-level intensity that accompanies its onset and the way this engenders a feeling of senselessness which conveys something about "being in the world" without its being qualified as "you," "me," "artworks," "news specials," "sporting events"

\section{Cage, Fluxus and Extendedness in the 1960s and $70 \mathrm{~s}$}

The predictable place to look for precedents to today's enactments of tedium is musical minimalism, particularly in the process pieces of minimalist composers such as Steve Reich, Phillip Glass, and Terry Riley. However, unlike the more contemporary mode of boredom that is constituted by an evident ambivalence, Glass, Reich, and Riley's music is unabashedly affirmative in the positive effects of extended time. The pulsating hypnotic sameness of Reich's Four Organs (1970) or Riley's In C (1964) harness the perceptual and somatic effects of prolonged exposure to repetition in a way that hypnotizes the listener and keeps boredom out of mind. In this sense, musical minimalism escapes more than it articulates the sensuous infinity that I hear waiting in contemporary musical boredom. ${ }^{61}$ A more ambivalent form of boredom may, however, be traced through the less frenetic and rhythmical declaimed work of composers such as La Monte Young,

\footnotetext{
${ }^{61}$ Robert Fink's recent study on minimalism of this sort resonates with my thesis to the extent that he sees it tied up with the larger cultural repetition of desires under the guise of novel art. See Robert Fink, Repeating Ourselves American Minimal Music as Cultural Practice (Berkeley: University of Calıforma Press, 2005)
} 
Morton Feldman, Christian Wolff, and members of the 1970s British experimental scene including Cornelius Cardew, Gavin Bryars, and Howard Skempton.

The music of these composers can be immediately distinguished from that of minimalism by its mensural or "floating" surfaces on which boredom is cultivated like the green patina that grows to tarnish and passivate bronze metals. La Monte Young's early piece Trio for Strings (1958), for instance, is a five-hour work in which long sustained tones alternate with spans of silence to create a static field of sounds whose timbral characteristics overtake the formal dimensions of the experience. ${ }^{62}$ From the late seventies to his death in 1987 , Morton Feldman began to extend his characteristically asyndetic refrains (refrains that follow one from the other with no coordination but the momentum and contiguity of their appearance) beyond the hour mark to include the occasional six or seven hour piece such as his string quartet II (1982) and For Philip Guston (1983). Unlike the excited throbbing of minimalism, the slow and mannered unspooling of Young and Feldman's works never gather up the energies of attention enough to launch the imagination into the clutches of a higher interest; instead, they allow attention to leak and settle into its own contemplation. The British experiments, too, took boredom in a route that did not necessarily lead to its dissipation. Gavin Bryars' work Jesus' Blood Never Failed Me Yet (1971), a treacley orchestration of a loop of a homeless man's rendition of the English Hymn, though repetitive and drawn out, never quite drives boredom away, for its sentimental text and schmaltzy arrangement invoke

\footnotetext{
${ }^{62}$ But five hours is very little when compared to Young's later work, the numerous versions of which he captures under the rubric of The Tortolse Hls Dreams And Journeys (1964-present), are presented sometimes as days long performances but also, as in Dream House located at the Mela Foundation in New York City, as sound installations Dream House, which is actually a collaborative project between Young and visual artist Marian Zazeela, is described as "a tıme installation measured by a settıng of contınuous frequencies in sound and light"
} 
the referential tendencies of musical sound to mire the listener in the nostalgia of $1950 \mathrm{~s}$ Hollywood optimism. And the music of Cornelius Cardew, Michael Parsons, and Howard Skempton (the Scratch Orchestra) used duration not to access a utopian dimension into which the energies of dissatisfaction would be sublimated, but to realize the principles of socialism in musical terms.

But even these studies in extendedness tend to avoid the rhetoric of boredom as an aesthetic category that attaches to contemporary experiments in tedium. To understand how boredom itself comes to organize aesthetic experience we must turn to visual and performance art practices of the 1960 s and 70 s, particularly those associated with Conceptualism, Fluxus, and the immersive principles of John Cage's non-intentionality. This trajectory shows that while audiences were being blissed-out on Glass's four-hour Music in Twelve Parts (1970-74) and politicized by the Scratch Orchestra's collective compositions, video artists like Nam June Paik, Bruce Nauman and Vito Acconci were examining the dullness of a time made available through the continuous feed of video streaming, and conceptual artists like Dick Higgins, George Brecht and Yoko Ono were producing works that deconstructed the terms of not only music but also poetry and theatre. Paik's TV Buddha (1974), for example, which consists of a Buddha statue facing and peering at its own televised projection, introduces a form of narcissistic repetition whose difference is obscured by the mechanical precision of the ongoing video transmission. ${ }^{63}$ Bruce Nauman's Violin tuned D.E.A.D (1969) or Vito Acconci's Waterways: 4 Saliva Studies (1971) can likewise be seen, as art historian Christine Ross

\footnotetext{
${ }^{63}$ Rosalind Krauss defined early video art as an inherently narcıssıstıc medium She sees the "sımultaneous reception and projection of the image" as situating bodies, whether the artist's or the viewer's, in an instantaneous feedback loop that turns the subject into a conduit such that "the body and psyche are its own surround "One 1s, as it were, "self-encapsulated "See Rosalınd E Krauss, "Video The Aesthetics of Narcissism," October 1 (1976) 50-64
} 
has suggested, as means of studying what she calls "the waning of time," partıcularly the assimilation and abstraction of time into space that accompanies modernity's progressivist ethos ${ }^{64}$ Then, George Brecht and Yoko Ono, two figures who represent the loosely organızed art movement known as Fluxus, were instrumental in developing the "event-score"- a concise set of verbal (sometimes absurd) instructions that simulate the

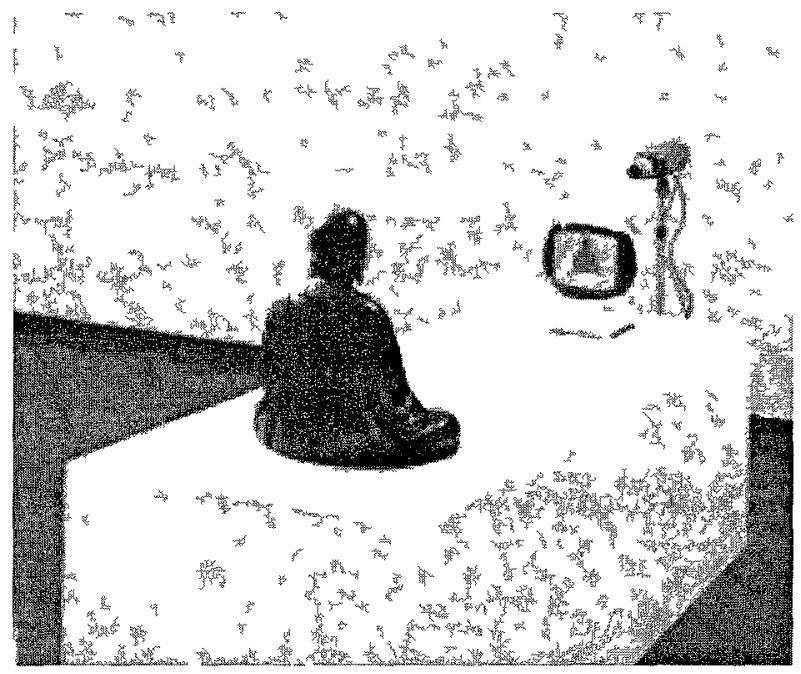

TV Buddha (1974)

Nam June Paık

address of a traditional musical score yet direct the performer (or reader as it were) towards the act (thought) of mundane actions In many ways, these artists were indebted to the aesthetic experimentation of John Cage, particularly the principles/practice of ego-extınction garnered from numerous sources of Eastern mysticism, particularly Zen Buddhism I don't want to spend too much time wrestling with the contradictions and latent imperialism in Cage's music and thought, but since his work often stands as a synecdoche for an aesthetıc vanguardism that touts its expressions and practices as radically inclusive (while at the same time disavowing its esoteric faith in the a-referential ideals of "absolute" music), ${ }^{65}$ it needs to be addressed not only for its

\footnotetext{
${ }^{64}$ Christine Ross, "The Temporalities of Video Extendedness Revisited," Art Journal 65, no 3 (2006) 82 99

${ }^{65}$ This contested term has its ongms in the late nineteenth century and revolves around the theorization of instrumental music (contrasted with vocal music) in relation to the emerging notion of autonomous art (l art pour $l$ art) See Carl Dahlhaus Nineteenth Century Music (Berkeley Unıversity of Calıfornı Press, 1989), Janet Wolff, "The Ideology of Autonomous Art, in Music and Society The Polutics of Composition Performance and Reception, ed Richard Leppert and Susan McClary (Cambridge Cambridge University Press, 1987)
} 
contribution to the development of an aesthetics of boredom in composition but also, and relatedly, for the complexity of ideas of spectatorial co-creation that pivot around its axis. Although somewhat overextended, the axiom, derived from Zen Buddhism, that if you stay with something long enough you'll find that it's not boring at all, has come to represent Cage's attitude towards music, art and life in general. How much Cage believed this wisdom is beside the point that it clearly served him as inspiration (justification?) for a way to broaden the terms of what can count as aesthetic material. Since the composers that I associate with contemporary "boring" music are themselves inheritors of this type of post-Cagean aesthetic, Cage's neo-dada praxis (and theorization of that praxis which takes for granted the implication of the addressee in the constitution of an artwork) is not only salient, but indeed, crucial to the present study. To be fair to Cage, he wasn't interested in being bored, or boring, per se-at least not in the way that Andy Warhol made boredom both a career and an alibi for his career. ${ }^{66}$ Cage's project was more generous and sincere in its intentional non-intentionality than I think our inherited rronic reflex will permit, a consequence of which is the obfuscation of both the radicalism and crypto-conservativism of his ideas. ${ }^{67}$ Whereas Warhol's boredom can be understood as a

\footnotetext{
${ }^{66}$ Warhol's notorious reputation for "being bored" can be illustrated in many ways, but perhaps, owing to their time-based expression, his films Sleep and Empire are most representative of his aesthetic tedium Both Sleep (1963) and Empire (1964) are eight-hour films that fixate on the passage of time by focusing the camera on a single event. In the case of the former, the film is a partially looped shot of a sleeping John Giomo, whle the later is a contmuous shot of the Empire State building as late afternoon dusk passes into evenıng darkness

${ }^{67}$ Much of the debate about the aesthetic and ideological effects of Cage's thought is being carried out in the relatively recent practices and studies constituting the fields of sound art and auditory culture. See for instance Jonathan Sterne, The Audible Past Cultural Origins of Sound Reproduction (Durham, NC Duke Unversity Press, 2003), Paul Théberge, Any Sound You Can Imagine Making Music/Consuming Technology (Hanover, NH Wesleyan University Press, University Press of New England, 1997), Douglas Kahn, Nolse, Water, Meat A History of Sound in the Arts (Cambridge, MA MIT Press, 1999), Alan Licht, Sound Art Beyond Music, between Categorles (New York, NY Rizzoh International Publications, 2007), Brandon LaBelle, Background Notse Perspectives on Sound Art (New York Contınuum International, 2006), Paul Hegarty, Nolse/Music A History (New York Contınuum, 2007), R Murray Schafer, The Soundscape Our Sonic Environment and the Tuning of the World (Rochester, VT Destiny Books, 1993),
} 
cynical embodiment of art and consumer culture's mutual implosion (itself arguably indebted to Cage's own aesthetic liberalism), Cage's boredom can be construed more honestly as the expression of a veiled ideology that assumes a continuity between the natural realm (the "real") and art.

For Cage, a sprawling "nothing" 68 stood in the way of his project to appropriate the totality of sounds to the category of music. But "nothing" can be seen here as a convenient 1deological construct that allowed Cage to extend his notions of chance to the domain of the real. Art historian Ina Blom argues that Cage's perspective on chance as the expression of an "infinitely heterogeneous reality where all things interpenetrate" 69 makes it appear as though his chance operations are not simply a compositional means, but a way of expressing the reality that they presume. Blom contends that chance functions within Cage's project "both as an ideology - a view of the world (or nature) as

Velt Erlmann, Hearing Cultures Essays on Sound, Listening, and Modernity (Oxford, New York Berg, 2004), Michael Bull and Les Back, The Audtory Culture Reader (Oxford, New York· Berg, 2003); Christoph Cox and Daniel Warner, Audio Culture Readings in Modern Music (New York Contınuum, 2004)

${ }^{68}$ This "nothıng" was for Cage not a mihılıstıc "nothıng" but a creatıve nothing that resembles the vold of numerous eastern mystical traditions But Cage validates this sense of nothing in a way that makes art servile to science His argument, which draws its first premise from Ananda K Coomaraswamy's assertion that "the traditional function of the artist is to imitate nature in her manner of operation," and poses its second premise that "changes in science give artısts different understandings of how nature works," concludes that "art changes because science changes " ${ }^{67 a}$ For Cage, quantum mechanscs' model of a fundamentally indeterminate reality sanctions the reality of his chance-based art The problem is not the logic of the argument but the way Cage obscures the fact that "nature" is a representation of, in this case, a scientıfic model. This is a fact that Cage himself introduces in his second premise, and one that he ignores when he admits to finding "nature far more interesting than any of man's control of nature "67b "Nature" as he infers it is no more natural than is his musical portrayal of its indeterminacy, and as I show above, this elision of an "indetermınate nature" as itself a representation leads Cage to mistakenly hypostatize his very artificial "chance operations "I don't actually have a problem with this circularity, for it generates all manner of fugitive phenomena that mess with the integrity of the musical field In fact, chapter two and three of this study examine the power and the effects that this type of thinking has for art

${ }^{67 a}$ Cage, Silence Lectures and Writings, 194 Cage attributes this sayıng to Coomaraswamy, however, Douglas Kahn notes that Coomaraswamy himself borrowed the notion from St Thomas Aquinas who wrote Ars imitatur naturam in sua See Kahn, Nolse, Water, Meat, 170

${ }^{67 \mathrm{~b}}$ Cage, Silence Lectures and Writtngs, 194

${ }^{69}$ See Ina Blom, forthcoming manuscript awatting publication based on pages 5-70 of Blom, "A Cut Though Time A Version of the Dada/Neo-Dada Repetition (Oslo Acta Humaniora/UnıPub, 1999) 
an indeterminate a-causal sphere of infinite changes - and a method through which to produce the work of art as reality. "70 Cage's belief in an indeterminate reality and his practice of an indeterminate music thus make sense of each other: the real as a purposeless domain coincides perfectly with its chance expressions.

Cage imagined a radically inclusive world of sound where any "audible, potentially audible, or mythically audible sounds" could be materialized as music." However, nestled within this fantasy was, as Douglas Kahn argues, a strategy borrowed indrectly from Luig1 Russolo's 1912 Art of Noise, which can be cited as the first treatise on musical inclusiveness, ${ }^{72}$ and directly (though in a distorted way) from Edgard Varèse, ${ }^{73}$ that would "let sounds be themselves" so long as they were interpolated within the purview of a very narrow musical sensibility (a sensıbility that Kahn sees allied to the stipulations of absolute music-a-referentiality). ${ }^{74}$ Though Cage's effort to open musical experience to a wider materiality was premised on a phenomenological account - - the sound of silence (I'm referring here to the oft-cited story of his experience in an anechoic

\footnotetext{
${ }^{70}$ Ib1d

${ }^{71}$ Kahn, Notse, Water, Meat, 164

${ }^{72}$ Kahn suggests that Russolo's work enacts a policy of music's worldliness both in practice and in rhetoric, but largely as a means to reinvigorate the discipline of music rather than exceed it. Ibid.

${ }^{73}$ Gerard Pape contends that Varèse's project, which also aimed to expand the musical palette of sound, was unsympathetic to Cage's wildly inclusive principles He writes
}

The methods of Cage were too fortuitous and under-controlled for Varèse's tastes Varese was not advocating, as was Cage, to let the sounds be themselves What was at stake for Varèse was to liberate the imagination of the composer, not to liberate the sounds themselves While Varèse was fascinated by the physics and acoustics of sound as such, that did not imply for him that sound in its raw form already had sufficient physical structure to give a satisfying musical structure or form to a composition - Gerard Pape, "Varese the Visionary," Contemporary Music Review 23, no 2 (2004) 20

${ }^{74}$ Kahn's critique is decisive here He contends that Cage's musicalization of sound-in-itself is carried out along the lines of a radically exclusive principle embodied in the nineteenth century as "absolute music" which predicated its terms on musical areferentiality See Kahn, Nolse, Water, Meat, 164-65 
chamber $)^{75}$ - it could only be made effective through a rhetorical manoeuvre that ciphered the semiotic remainders of sound first through the measure of duration and then through the supposed paradoxical intentionality of silence. Silence, as Cage conceptualized it, was "all the sounds that we don't intend;" "76 therefore, its experience is a matter of intentionally in-attending to the sounds that populate the field of hearing. Any sound was musical so long as it was intentionally heard as music and un-heard in its worldliness. That is, sounds are musical to the extent that their being-heard articulates the intentions that constitute the traditional horizon of listening musically while at the same tıme seemıng to disartıculate those intentions that tradition places on the composer.

This rhetorical sleight of hand, aided perhaps by the schizophrenic condition inherent to modernism's hyper-reflexive discourses, ${ }^{77}$ and the procedural interventions of his "chance" operations, allowed Cage to shift the act of intentionality from composer onto the listener in such a way that the composer's ego-culpability would become, if not extinguished, then at least scattered in a hall of mirrors. ${ }^{78}$ Cage is quoted as saying: "If

\footnotetext{
${ }^{75} \mathrm{An}$ anechoic chamber is a specially engıneered room designed to elımınate echoes and ambient reverberations such that it is, in principle, a room of absolute silence Cage, wanting to hear what silence sounds like, entered an anechoic chamber and discovered two distınct sounds one high pitched, the other low He was told that these were the sounds of his nervous system and blood crrculation From this Cage concluded that there could never be absolute silence but only degrees of attention See Cage, Sllence Lectures and Writıngs, 8 For an examination of how Cage's "silence" is an expression of technological medıatıon see Frank X Maucerı, "From Experımental Musıc to Musical Experıment," Perspectives of New Music 35, no 1 (1997)

${ }^{76}$ Michael Zerwin in Kahn, Noise, Water, Meat, 163

${ }^{77}$ Louss Sass discusses the parallels between the psychology of schizophrenı and modern self-awareness in his work Madness and Modernism Insanity in the Light of Modern Art, Literature, and Thought (New York Basic Books, 1992)

${ }^{78}$ Cage's investment in the discursively constructed aptitude of a creative "nature" afforded him the conscience to colonize a broader territory for (absolute) music by proposing that sounds which appeared to self-manifest by means of chance could be intended, or attended to, as though free of semiotic impurities By rolling dice, in other words, Cage could keep his hands clean What should be gleaned from this foray into Cage's aesthetics is the way he divests composition of its intentionality yet leaves the intentionality of listenıng, with all its appurtenant investments and interests, firmly in place The sentiment was perhaps right but the way it relies on a hyper-reflexive approach makes its expression self-conscious, by which I mean awkward and insecure Mainly this is because intentionality was never really extınguished in this
} 
you're non-intentional, then everything is permitted. If you're intentional, for instance if you want to murder someone, then it's not permitted." ${ }^{79}$ For him it seems that what lies outside of intention is a nothingness that is in itself, if not beautifully harmonious, then effectively innocuous. But this m.o. was challenged by a group of artists, associated with Cage, known as Fluxus (initiated by George Maciunus and including Nam June Paik, Dick Higgins, George Brecht, Yoko Ono, and Sol Le Witt). In her 1998 essay "Boredom and Oblivion," Blom contends that Fluxus submitted Cage's structurally and formally neutral "field of endless heterogeneity and multiplicity" to the "kinds of marks that it would - in principle--be immune to: the marks of ownership, of singularities, of different subjectivities, intentions, and representations." 80 That is, Fluxus introduced the body and all its concrete relationships into Cage's abstract model of inclusivity. Dick Higgins' serıes of works titled Danger Music (1962), for example, represent an attempt to draw out the implications of these corporeal "marks" that Cage's inclusive system expels. Danger Music \#17, with its instructions: "Scream! Scream! Scream! Scream! Scream! Scream!" or Danger Music \#9 that simply reads: "Volunteer to have your spine removed," pierce the conceptualized veil of a theory that purports to embrace everything, not to deflate its claims but to disclose its limits and tolerances. Taking Cage's hypothesis for granted, Fluxus found that "the space of immersion could not be formulated without an engagement with, and through, borders and limits."

Whereas Cage's inclusıve gesture posits "an empty framework waiting to be

scheme but simply reallocated, by chance, to a subject traditionally considered marginal to the production of musical sounds

${ }^{79}$ Cage in Richard Kostelanetz, Conversing with Cage (New York Routledge, 2003), 213

${ }^{80}$ Ina Blom, "Boredom and Oblivion," in The Fluxus Reader, ed Ken Friedman (West Sussex Academy Editions, 1998), 64

${ }^{81}$ Ibid, 65 
filled, precluding any actual relation between the structure and its filling material, Fluxus showed that this inclusion could only be accomplished by making the elements traditionally disowned or "exscribed" by music proper-i.e. a concert performance's start-time, the exchange of money for entrance to the hall, coughing, sniffling, waiting coincide with the processes of semiosis that delineate the structure. Boredom was instrumental for Fluxus in this respect for the way that its metaphysical ambiguity blurs distinctions between subjective and objective experience and thereby implicates the environment, the sensible milieu, in its expression. Dick Higgins' account of a piece by George Brecht that was performed in the utter darkness such that it became impossible to discern when the work had ended, exemplifies the way in which, as Blom notes, "boring art involves the surroundings in ways not apparent when stimuli appear as exciting along certain lines of expectation." ${ }^{, 83}$ Unlike Cage, who gathers all sounds under the postulates of absolute music (a-referentiality), Fluxus' "event-scores" articulate the abstract propositions used in conventional musical performances and compositions with ordinary items and mundane actions in a way that opens a space between the purview of "music" and the domain of the everyday.

This "between" Higgins termed "Intermedia." 84 Not to be confused with an unmediated event, Intermedia describes how a Fluxus event-score effects Cage's inclusive gesture using elements of the world in which the performer and listener are embedded to enframe how he or she is always already included or "immersed" in a

\footnotetext{
${ }^{82}$ Ibid, 76

${ }^{83}$ Ibid, 65

${ }^{84}$ See Higgins' "Intermedia," orıgmally publıshed in Something Else Newsletter 1, no 1 (Something Else Press, 1966) Republıshed as Dick Higgins and Hannah Hıggins, "Synesthesıa and Intersenses. Intermedia," Leonardo 34, no 1 (2001)
} 
universal embrace. The Fluxus event doesn't divest these mundane elements of their signification the way Cage's formalism does; rather than try to efface the ego and transcend to a universal-immersive position outside the realm of discursive reality, Fluxus shows that the act of radical inclusion entails the matter of subjectivity, a matter of being continuously positioned within an intensively plastic world. Inclusion therefore cannot take place beyond the lineaments of subjectivity (and its implicit politics, its "will to power') but only within them; one is included in a world or event by enacting, more and less intensively, a subject position. Fluxus can be understood then to adjust Cage's inclusion ideal by inverting its transcendentalism, by attaching "art affects" to the particular intensities of (everyday) life rather than banishing the difference between them: "the semiotic remainders that [are] generally placed at [art and] music's margins" become the components of the frame within which a listener can actually "get lost" by getting bored.

\footnotetext{
${ }^{85}$ Blom, "Boredom and Oblıvion," 76.
} 


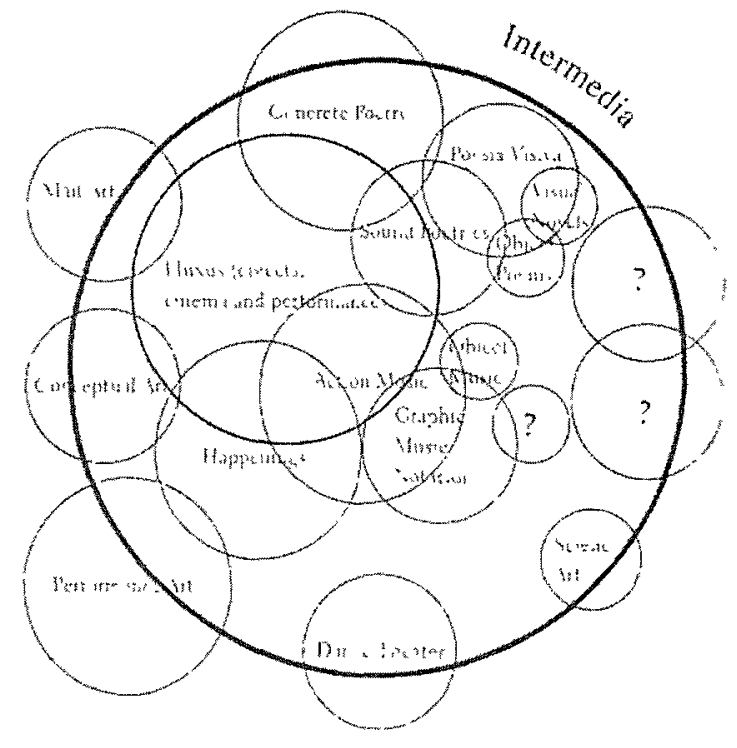

By disrupting the familiar lines of expectation in a

way that allowed attention to light upon the

discursive and intensive regularities that constitute

that "residual category into which can be jettisoned

all the irritating bits and pieces which do no fit into

the orderly thought ${ }^{\prime 86}$ - i.e., the everyday-Fluxus'

"aesthetics of boredom" marks the emergence of two

significant developments in composition. One thing

that boredom's articulation of art with the everyday
NB: A case could be made for all of this music that repetition, not duration, is the salient factor in these works. In a sense this is true, but the dominant trope of repetition that characterizes these musics has to be understood to function not merely as a formal element but an ideological gesture whose execution serves as a type of aesthetic transgression, a sign of disobedience aimed at the prohibitions of high modernism. Moreover, repetition is not opposed to duration so much as each of these terms is an expression of change as such. For this essay I prefer to focus on the figure of "duration" for two reasons: one, I find that "repetition" is still overburdened by its ideological function that keeps it shackled to an historical opposition; and two, despite disrupting teleological figures of time, repetition's affirmation of the eternal return of the same-difference (depending on your Nietzsche-Deleuze tastes) does not express the sense of a "bad" or "sensuous" infinity that is symbolized by the sheer extendedness and slowness of the contemporary works which I consider in this chapter.

Though much of the same phenomena that emerge in musical repetition apply to recent boring music's sense of infinity (such as a slackening of ego constancy and the replacement of tonal order for moments of varying intensity), the context in which these appear changes their expression such that the experience of "ego death" and "process" characteristic of repetitive music are refigured in light of boredom and as "insufficiency" and "waiting."

\footnotetext{
${ }^{86}$ Mike Featherstone, Undoing Culture: Globalization, Postmoderism and Identtty (London; Thousand Oaks, CA: Sage Publications, 1995), 55.
} 
did was to suggest a certain libertarian socialist ${ }^{87}$ politics that presaged the DIY sensibility of 70s punk culture, but within the floundering category of "art" music as represented by Christian Wolff and Cornelius Cardew's pseudo-socialist schemes that would both define music by and use music to create a collective "situation in which sounds may occur." ${ }^{88}$ The other direction in which boredom moved music was in relation to the nature of musical time. Corresponding to the temporal sprawl that expresses the time of being bored was the change in musical time from being merely a metronomic quantity to a chrononomic quality. That is, duration becomes something more than a measurable parameter, aligning itself with various vital processes whose powers or intensities wax and wane. It is this shift towards duration and its corresponding affects that I want to focus on in the next section in order to draw attention to the way in which boredom's aesthetic expression becomes an occasion for us to witness the time of events and practice the art of waiting.

Expressed in Steve Reich's essay on music as a gradual process, ${ }^{89}$ in Feldman's interest in the sublime effects of scale, ${ }^{90}$ and in Brian Eno's development of open or generative musical systems, ${ }^{91}$ duration began to resemble Henri Bergson's notion of dureé, an

\footnotetext{
${ }^{87}$ Also called "socialıst anarchısm" (Geoffrey Ostergaard, "Anarchısm," in A Dichonary of Marxist Thought, ed. Tom Bottomore, et al [Oxford Blackwell Publishıng, 1991]), or just good old "anarchism."

${ }^{88}$ Michael Nyman, Experimental Music Cage and Beyond (Cambridge, New York Cambridge University Press, 1999), 62

${ }^{89}$ Steve Reich, "Music as Gradual Process," in Writıngs on Musıc, 1965-2000, ed Paul Hillier (Oxford; New York. Oxford University Press, 2002).

${ }^{90}$ For example, the irldescent patternıng of his six-hour string quartet 2 (1982)

${ }^{91}$ The newest and perhaps most commercially accessıble of Eno's generative music systems is the 1 Phone application "Bloom," which was developed in collaboration with software designer Peter Chilvers Bloom is in essence a twenty-first-century music-box that allows the user to set slowly evolving patterns of sound in motion by tapping the screen in vanous places The generic term for Eno's particular brand of mınımalısm, a minımalısm that despite its formal differences functions much like Muzak, is "ambient music"
} 
experienced time that dilates and therefore changes as it passes. ${ }^{92}$ Writing about his experience listening to Steve Reich's It's Gonna Rain (1964), Brian Eno describes the very concrete effect that duration has on perception.

What happens when you listen to it is that your listening brain becomes habituated in the same way that your eye does if you stare at something for a very long time. If you stare at something for a very long time your eye very quickly cancels the common information, stops seeing it, and only notices the differences. ${ }^{93}$

Though couched in psychological terms, the way in which the expressive elements are compounded with the elongated form of the work reveals how Eno is recountıng how one perceives difference as that substance which impresses on our senses over time. Eno's observation, that you only "notice the differences," in a way describes the sentiment of composers in the 1970 s that time is not an "empty hopper" but essentially a matter (material) of difference.

At this point it might be suggested that the variety conveyed by these works has nothing to do with being bored, and that boredom is articulated only as an un-perceived expression of difference. To an extent I think this is true. All of these composers, except perhaps for Tom Johnson, whose accompanying text to his An Hour for Piano (1971) actually describes the difficulty of listening to the hour-long precession of vagrant semiquaver melodic patterns around a $\mathrm{G}$ pedal, ${ }^{94}$ address the issue of tedium and extendedness by getting rid of it: Reich and Glass by effectively hypnotizing the listener and performer, Cardew by incorporating the messiness and inchoate droll of

\footnotetext{
92 Bergson discusses his notion of dureé and its knowing through what he called "intuitıon" in Henrı Bergson, The Creative Mind, trans Mabelle L Andison (New York· Phılosophical Lıbrary, 1946)

${ }^{93}$ Brian Eno, "Evolving Metaphors, in my Opinion, is What Artısts Do," In Motion Magazine, 7 July 1996 , http //WwW inmotionmagazıne com/enol html (my emphasıs)

${ }^{94}$ (a prece that wouldn't be out of place as the score to Willam Friedkın's 1973 film, The Exorcist)
} 
undisciplined activities into the artwork, and Feldman by restating of form as a matter of scale, thus changing the stakes of a musical experience in a clever way that supplants the potential boredom of listening to his extended pieces with less judgmental responses like "fatigue" and "weariness." In this way, boredom is displaced onto the listener and becomes an alibi for the disaffections that the composer's negative aesthetics elict. In other words, faith in an experience irreducible to anything other than what the "autonomous" work of art evokes is sheltered from the vulgar moods and tempers of the society that structures its occasion. Boredom's indifference is saved here from its sympathies with the tedium of the everyday.

In a sense, these composers' works recuperate the affect that boredom's temporal stall introduces. Consider how each of Feldman's chords is presented as an exquisitely cut gem, or how Glass's repetitions conjure a sargasso of hallucinated melodies, ${ }^{95}$ reinvesting the monotonous field of minimally changing forms with a value whose aesthetic import is re-cast along the familiar lines of the sublime. Subordinating its lowlevel and indeterminate intensity to these recognizable aesthetic categories, boredom's sluggardly torsion and slow burn is elided by the thrill of its relief, in moments of diversion or the work's end. Furthermore, boredom's recently acquired aura (witness 2009's highly lauded and well attended revival of Beckett's Waiting for Godot on Broadway and West London ${ }^{96}$ or the cynical entertainment value of the proliferation of

\footnotetext{
${ }^{95}$ (...l'm refernng to the charming way that Music in Twelve Parts exploits the emergence of certain auditory illusions - usually sum or difference tones-that are remaindered by the way our listening system works .)

${ }^{96}$ Globe and Mal contributors Elizabeth Renzett1 and Simon Houpt discuss the conversion of Beckett's disconcerting play into a Broadway success and "star-magnet" as well as the curious transposition of its bleak despair reflecting initially the fear of imminent nuclear holocaust to the alarm of a global economic melt-down Elizabeth Renzettı and Simon Houpt, "The All-Stars of Absurdism Face Off," The Globe and Mall, 16 May 2009.
} 
reality television) suggests that the mood has been made an experience in and of itselfso long as it has been enframed in one way or another. Under these conditions, boredom keeps us waiting by holding its transports within itself and offering only sporadic wonders whose Cartesian poetics give way to a Spinozan paralysis ${ }^{97}$ in momentary reflections on the ludicrous nature of how we individually and collectively submit ourselves to ever more subtle forms of suffering in the hope of either opening a vein of new amusements, or bleeding-out the last of desire. In short, by considering the multitude of devices and strategies that have been invented to keep individuals and communitıes amused, let's say, un-bored, then we can suppose that boredom is not the exception to, but instead the very principle of contemporary culture. Assuming this, we can also see its expression in contemporary musical practices as forming another "image" of boredom that interferes with or unsettles its common currency in art as "a station on the way to other experiences." 98 Having little access to the institutional endorsements that would give it Godot's modernist aura, and lacking even the sensuous appeal by which a mass market could grant it the alibi of being entertainment, the image of boredom enacted in certain contemporary musical practices eschews the earlier "successes" of musical minimalism by simply practicing the art of wating.

\footnotetext{
${ }^{97}$ Wonder is conceived by Descartes as the 'first passion' that leads to a senes of thoughts and expenences that end in the knowledge or explanation of the initial spark Spinoza on the other hand conceptualized wonder as a paralysis of the essentrally active mind in the presence of an inassociable novelty (object, event) Because for Spmoza the mind is its movement between thoughts or sensation, wonder in this case indexes a defective mind In contrast to the stalled mind Spinoza pars with wonder the opposite passion, disdain, by which a novelty's inassociable characteristics keep the mind from engaging the contemptible event in an association of thoughts, continuing instead to think of everything else but it For an account of the varied history of wonder see Lorrane Daston and Katherıne Park, Wonder and the Order of Nature (New York Zone Books, 1998), Philı Fisher, Wonder, the Rambow, and the Aesthetics of Rare Experiences (Cambndge, MA Harvard Unıversity Press, 1998), Dennıs Quinn, Iris Exaled A Synoptic History of Wonder (Lanham, MD University Press of America, 2002)

${ }^{98}$ Dick Higgins, "Boredom and Danger," in Breaking the Sound Barrier A Critical Anthology of the New Music, ed Gregory Battcock (New Yolk Dutton, 1982), 22
} 
The Aesthetics of Boredom and the Art of Waiting

Go back to David Foster Wallace's thoughts on boredom. Though crushing, he imagines that boredom can be a nostrum to what he perceives as America's addiction to entertainment. Wallace, who hanged himself in the fall of 2008, was working on a novel about boredom, provisionally titled The Pale King. In this work, his stated aim was to interrogate the merits and powers of concentration and mindfulness. But, from the portions of the work that have already been published, it's clear that Wallace wanted to catechize the full breadth of a malaise whose emotional burn feeds quietly off the everexpanding patina of diversion. For Wallace, media culture disables an individual's ability to decide how and what he or she pays attention to. Imagining for a moment that one could actually pay attention to nothing, the saturation of media makes it impossible. Thus, to the extent that an individual could slow the dizzying flows of media imagery and "find itself" in the fog of boredom it would seem to occasion something other than mindfulness and something more like what psychoanalyst Adam Phillips has suggested is a confrontation with "the poverty of our curiosity." 99

In a portion of The Pale King published in an April 2009 issue of The New Yorker, Wallace fictionalizes the tactics available to US Internal Revenue Service (IRS) agents to combat the threat to curiosity that the job of processing tax returns cultivates:

Lane Dean, Jr., with his green rubber pinkie finger, sat at his Tingle table in his chalk's row in the rotes group's wiggle room and did two more returns, then another one, then flexed his buttocks and held to a count of ten and imagined a warm pretty beach with mellow surf, as instructed in orientation the previous month. Then he did two more returns, checked the clock real quick, then two more, then bore down and did three in a row, then flexed and visualized and bore way down and did four without looking up once, except to put the completed files

\footnotetext{
${ }^{99}$ Adam Phillips, On Kissing, Tickling, and Being Bored Psychoanalytıc Essays on the Unexamined Life (Cambridge, MA Harvard Unıversity Press, 1993), 75.
} 
and memos in the two Out trays side by side up in the top tier of trays, where the cart boys could get them when they came by. ${ }^{100}$

Though Wallace never concluded his diagnosis of the pale king, I wouldn't claim that being bored is an antidote to either entertainment or information overload, for the effects of boredom are much too diffuse and uneven to counteract the disturbingly focused and systematic distractions and amusements that contemporary culture contrives to keep the loose threads of desire in tow. That is to say, while boredom may be ubiquitous, its effects are local and unpredictable. As such, I would suggest that the boredom Wallace was after is a tactical one, a downtime in the sense of "la perruque," which Michel de Certeau conceptualizes as kınd of subterfuge whereby one poaches time for other ends that are "free, creative, and precisely not directed toward[s] profit." 101 The difficulty, however, in seeing boredom in this way is that the time it takes is structured by no apparent "ends," creative or otherwise.

This guerrilla or banditry boredom is carried out in the work of Brooklyn-based composer Devin Maxwell. In his piece $P H-4$ (2004), for bass clarinet, contrabass and marimba, the listener is made simply to wait, not for something but to something. Over 13 '41" is unfolded a series of slow permutations on what Maxwell calls a "crippled gesture," in this case expressed as two short notes and one long tone distributed among the three instruments (with an occasional tremolo for variety). This crippling is used, as Maxwell says, to "build momentum which can or cannot lead to something interesting." ${ }^{102}$ Reminiscent of Morton Feldman's early work, but also of the British

\footnotetext{
${ }^{100}$ David Foster Wallace, "Wiggle Room," The New Yorker, March 2009, 63

${ }^{101}$ Michel de Certeau, The Practice of Everyday Life, trans Steven Rendall (Berkeley University of California Press, 1984), 24

${ }^{102}$ Devin Maxwell, Personal communication, 2009
} 

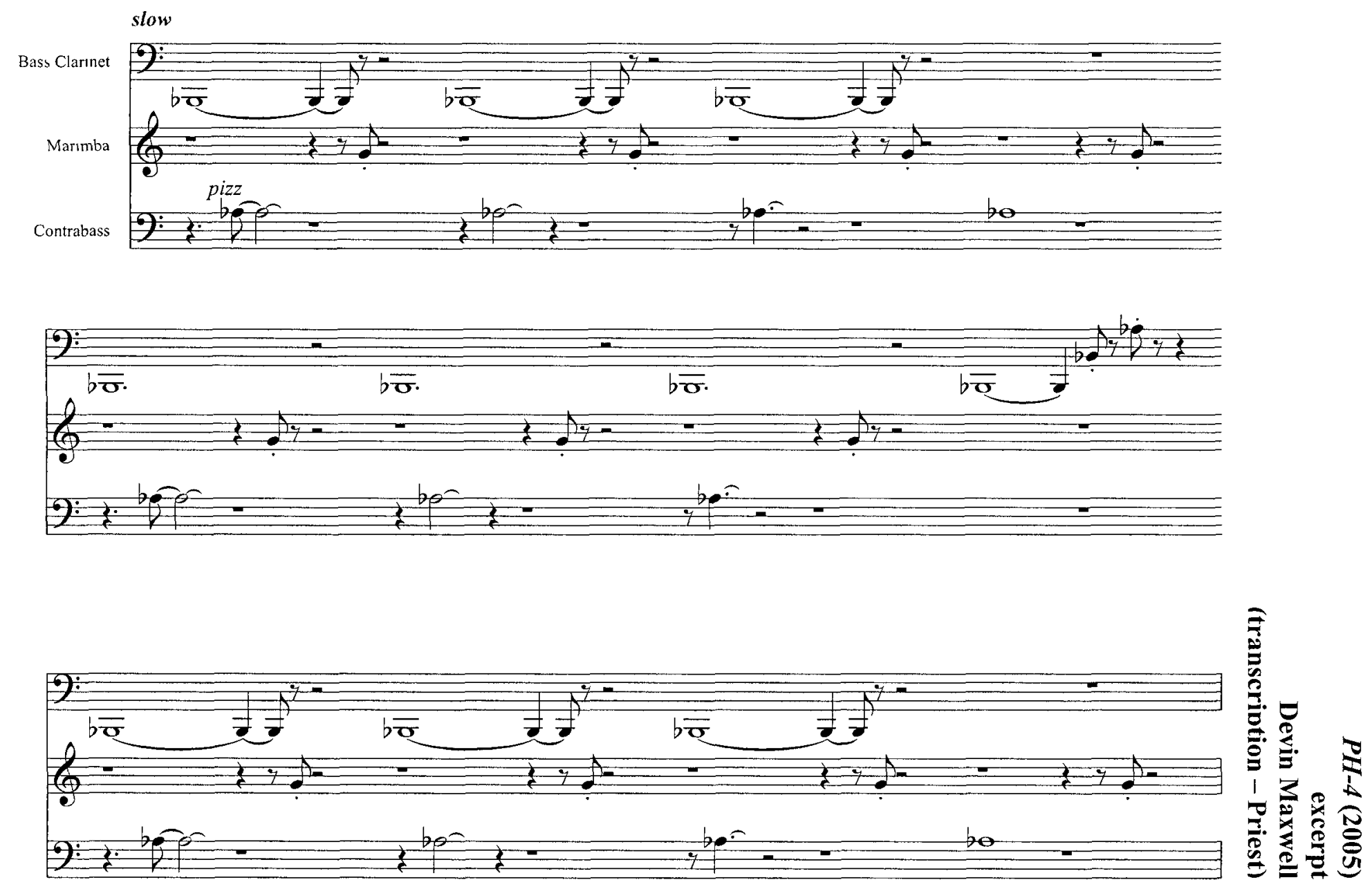
composer John White's "machine music" pieces of the 1970s, ${ }^{103} \mathrm{PH}-4$ develops a form of wa1ting from within its refrain that shifts attention to the event of the moment's happening, taking time away from the meaning of our expectations and giving it to the feeling, the intensity, of anticipation. In $\mathrm{PH}-4$ the listener is made to wait and to listen out for waiting, not for what follows waiting but for the event that (rather like dying) is both something we do and something that happens to us. The listener is encouraged to witness $P H-4$ 's event not as an occasion of attention but as an occasion for attention, where watıng is what happens while it happens.

Summoning de Certeau again, we can understand the waiting encouraged by $\mathrm{PH}-$ 4's evocation of a musicological downtime as a "“remainder' constituted by the part of human experience [in this case, being bored] that has not been tamed and symbolized in language." "104 Though one can speak of "waitıng" in the infinitive form, it's known best in its specific expressions of "waiting for" somethıng—waiting for the subway...for the movie to begin...for a song to end. But in terms of de Certeau's analysis of everyday practices, watting falls into a species of lived art or tactical know-how that is "composed of multiple but untamed operatıvities," 105 which is to say that waiting is a non-discursive art of organizing human experience without a proper time or place outside of its own occurrence. ${ }^{106}$ Waiting can happen anywhere, anywhen. How one waits is mandated by

\footnotetext{
${ }^{103}$ John White wrote what he calls "machine music" during the period 1967-72 For White, the "machine" describes "a consistent process governing a series of musical actions within a particualr sound world, and, by extension, the listencr's perception thereof "John White, Notes to Machine Music John White and Gavin Bryars, LP Obscure One of White's better known machine preces is Drinking and Hootıng Machine (1971), a set of mstructions indicating types of drinkıng actıons and the number of "hoots" that are to ensue after these

${ }^{104}$ Certeau, The Practice of Everyday Life, 61

${ }^{105}$ Ibid , 65

106 "Event," in the sense that I am using it here, draws on Gilles Deleuze's idea of an event as unactualized potentral that underlies whatever has occurred or will evidently occur An event refers then not to the
} 
circumstances, but the capacity to wait is independent of any variation it may take. As

such, "to wait" characterizes a bizarre in-activity that "operates outside of the enlightened discourse which it lacks." ${ }^{107}$ What makes the waiting strange in $P H-4$ is that it brings out its infintive quality in a similar way that we might say Samuel Barber's Adagio for Strings (1938) brings out the "essence" of mourning, or Sergio Ortega's iEl pueblo unido, jamás será vencido! (The People United Will Never Be Defeated!) captures the spirit of a mobilized working class. Boredom in $\mathrm{PH}-4$ brings something of the extradiscursive operativity of waiting-let's call it the art of waiting--to attention. Or, to put this into another perspective, recall Wallace's IRS agent, who, confined to his “tingle table," enacts a virtuosic display of the art of waiting:

Then he looked up, despite all best prior intentions. In four minutes, it would be another hour; a half hour after that was the ten-minute break. Lane Dean imagined himself running around on the break, waving his arms and shouting gibberish and holding ten cigarettes at once in his mouth, like a panpipe... Coffee wasn't allowed because of spills on the files, but on the break he'd have a big cup of coffee in each hand while he pictured himself running around the outside grounds, shouting. He knew what he'd really do on the break was sit facing the wall clock in the lounge and, despite prayers and effort, count the seconds tick off until he had to come back and do this again.... He thought of a circus strongman tearing a phone book; he was bald and had a handlebar mustache and wore a stripy all-body swimsuit like people wore in the distant past. Lane Dean summoned all his will and bore down and did three returns in a row, and began imagining different high places to jump off of. ${ }^{108}$

It's in the last line of this passage that we see how boredom introduces the inarticulate, yet highly effective, "know-how" or capacity of waiting into the logos and "productivist

interruption of a contınuous state, but, as Cliff Stagoll succinctly puts it, to "the potential immanent withın a particular confluence of forces " Cliff Stagoll, "Event," in The Deleuze Dictionary, ed Adrian Parr (Edinburgh. Edınburgh University Press, 2005), 87 The event of "watıng" is therefore something like the event of the event, an event in its paradoxically manifest suspension

${ }^{107}$ Certeau, The Practice of Everyday Life, 66

${ }^{108}$ Wallace, "Wiggle Room," 63-64 
ideal" of the tax return. ${ }^{109}$ And from this example we can extrapolate that boredom is expressing the sense of waiting apart from its varying occasions.

While the boredom of this IRS rote examiner brings to suicidal attention the range of his vocational and existential deprivation, we might suggest that the aesthetically conjured boredom of $\mathrm{PH}-4$ exercises a capacity to imagine at all by making us wait, "return[ing] us to the scene of inquiry" where the individual comes to experience the conditions for "what makes desire possible." 110 What expressions of boredom in works like $\mathrm{PH}-4$ specify are the protocols of desire. Waiting to find new desires, to find ways of becoming what one hasn't already become, describes an art of becoming-otherwise, becoming wise to the ubiquity of unimagined possibilities. As such, "the paradox of waiting that goes on in boredom is that the individual does not know what he was waiting for until he finds it, and that often he does not know that he is waiting." 111 It is this paradox of waiting for nothing - the uneventful event of waiting - that characterizes the contemporary sense of boredom. If, as we've heard so many times, the world is already coded by multiple layers of simulation, including the repertory of our desires and responses, then to be bored is not to wait for some-thing (we already have those "things") but to wait for no-thing. And to wait for no-thing is to risk waiting for nothing, a risk that is itself charged with an ambivalent mixture of wonder and contempt, fixation and flight.

Perhaps it's the intensity of the risk of boredom that Cage is connoting when he suggests, "If something is boring after two minutes, try it for four. If still boring, then eight. Then sixteen. Then thirty-two. Eventually one discovers that it is not boring at all."

\footnotetext{
${ }^{109}$ Certeau, The Practice of Everyday Life, 67

${ }^{110}$ Phillips, On Kissing, Tickling, and Being Bored, 75, 74

${ }^{111}$ Ibid, 77
} 
What Cage implies is that boredom's "hedonic tone,"112 the positive or negative feeling of waiting internal to a state, must be practiced, rehearsed, and therefore "perfected."113 Lane Dean's effort to imagine himself elsewhere than the returns office is an exercise that resists the practice of waiting by refusing him permission to adopt the refrains of boredom that lay within his constrained and routinized existence. However, to the extent that boredom can be seen as a kind of Spinozan wonder, a wonder that stalls in the face of an inassociable novelty, it offers the opportunity to practice the art of waiting but does so only under the condition that one wait for the novelty of a "nothing" that must be brought to attention and allowed to flourish in inattention. What, for example, is Cage's 4'33" but a model of attention, refined under the sign of concert culture, that performs a sacrament whereby the object(ive) of attention is inattention? Traditionally construed in terms that suggest some kind of aesthetic pay-off (Mehrwert), the contemporary expression of boredom in $4^{\prime} 33^{\prime \prime}$ encourages the listener to practice a type of waiting that relies on the failed promise of its so-called "musical" form so that in this failure the listener might experiment with his/her appetites in the presence of no-thing and, as Phillips suggests, "by doing so commit himself, or rather, entrust himself, to the inevitable elusiveness of that object." 114

\footnotetext{
${ }^{112}$ Hedonic tone belongs to the nomenclature of emotion studies and defines the pleasure-displeasure axis along which emotional experience fluctuates For an overview of the distinctions and elisions between affect, valence, and hedonic tone see Lous $\mathrm{C}$ Charland, "Emotion, Experience and the Indeterminacy of Valance," in Emotion and Consciousness, ed. Lisa Feldman Barrett, Paula M Niedenthal, and Piotr Winkielman (New York The Gulford Press, 2005)

${ }^{113}$ This sense of "perfection" alludes to eighteenth-century German aesthetician Georg Frnednch Meier's notion of beautıful thınkıng (ars pulchre cogitand $)$ which he borrowed from his mentor Alexander Gottlieb Baumgarten

${ }^{114}$ Phillips, On Kissing, Tickling, and Being Bored, 78
} 
So, is this really the virtue that Wallace wants to put us in mind of, a concentration on "the principally open field of endless heterogeneity and multiplicity" "15 imagined by Cage as interestingly boring? Having ultimately chosen oblivion, I'm inclined to think that this is not exactly what Wallace was after. Judging by the way Wallace often represented his fragmented thinking through a sophisticated use of footnotes, and later, a deft handling of stream-of-thought prose, he was likely advancing an immanent form of concentration and mindfulness rather than the kind that adorns itself in the esoteric trappings of perennial wisdom-cum-aesthetic insight. Like the patient variations of $P H-4$, which conjure an implacable scene of waitıng (for nothing) that strands us in the desert of wall-towall delay, Wallace leads us to speculate that it is more productive to imagine contemporary aesthetic tedum as a means of coping with the felt sense of senselessness that inheres in contemporary culture's poverty of curiosity.

A benevolent description would call compositions like Maxwell's PH-4 or Giesbrecht's Pandaemonium's Abyss "meditative" in aims of characterizing what seems an artless march through a forest of placid variations whose only goal is to peacefully exhaust itself But as anyone who has meditated knows, meditation is anything but placid Meditation is full of turbulence it is a wave of thoughts and impulses that break on shores of doubt, fear, desire, aches, itches, wearıness, anger, lust, indifference, and occasionally, tranquility The energies at play in meditation are not merely a byproduct of sitting still, they are always there, coursing through us, fugitive until captured by our discursive interests Meditation doesn't quell these signs of life so much as it is a way to cultuvate disinterest That is, meditation is a practiced disposition to refrain from chasing and capturing these fugitive energies, of qualifying and channeling their force towards specific ends, ends that tend towards sustaining the apparatus of capture Thus, as the Zen Buddhist says, by "sitting as you are," meditation attunes us to the underlying condition of being alıve, of being vital organisms chaos I can admit the characterization of these works as "meditative" so long as the meditative experience is understood as a turbulent affair

Like it or not, there is literally nothing to wait for because everything is already at hand. The proliferation of boredom shows us to be a culture in waiting, a culture more attuned to the singular and pure time of its own happenıng - its event-hood-than to the

\footnotetext{
ll Blom, "Boredom and Oblivion," 64
} 
mixed and impure time of an immediacy mediated by a deferred desire. However, without recourse to overarching narrative complexes that supplement the singularity of waiting, one can only deal with the dumb insistence of an event that attunes us to its virtual infinity. The question then is not whether $P H-4$ 's musicalized boredom allows the listener's "feelings to develop in the absence of an object," "16 but rather, how does being bored these days take the time of its happening, its waiting, as something it does and undergoes? In short, it can't take it. It is a deponent force, which is to say that boredom is active in form but passive in meaning. The boredom of waiting does not describe but instead witnesses its happening. It, and those who wait, become, in Lyotard's lovely words, "good intensity-conducting bodies," 117 bodies whose alternating expression of wonder and fatigue are testament to the radical ambi-valence of events.

\section{The Premises/Promises of Aesthetic Boredom}

The kind of emotional or affective illegibility that typifies the experience of the aesthetically induced boredom that I've been outlining over the last several pages is consistent with the reports by its champions who tend to depict a committed engagement with mood as expressing a concealed virtue. While boredom's relationship with art has a rich history that extends back at least to Baudelaire, the history that I'm really dealing with here is the increasing appearance of boredom in art from the 1950s onward. Cage's 4 '33" is paradigmatic of a certain unacknowledged articulation of boredom (as are Robert Rauschenberg's 1951 White Paintings that Cage supposedly drew insight from), but looking a little afterwards we see more explicit and unequivocal expressions of

\footnotetext{
${ }^{116}$ Phillips, On Kissing, Tickling, and Being Bored, 78

${ }^{117}$ Jean-Françoıs Lyotard, Lıbıdınal Economy (Bloomıngton Indıana Unıversıty Press, 1993), 262
} 
boredom in Warhol's Sleep (1963) and Empire (1964) and in the procedural poetry of Jackson Mac Low, ${ }^{118}$ and in 1968, Dick Higgins published his essay "Boredom and Danger" in which he considers post-war art's increasing interest in boredom. In this work Higgins draws a line backwards from Fluxus' mid-century experiments to Erik Satie's turn-of-the-century iconoclasm suggesting that the latter's outlandish use of repetition in pieces like Vexations (1893) and Vieux Sequins at Vieilles Cuirasses (1913) reflects a modern concern and response to actually having to live with the possibility of an endless future promised by the multiplying wonders of technological innovation and scientific knowledge. Recounting his own experience of Vexations, Higgins writes that, after the initial offense wears off, one has "a very strange, euphoric acceptance" and an eventual insight into the "dialectic [relationship] between boredom and intensity." 119 From this Higgins suggests that the fascination with boredom in art lies in the way it functions as "an opposite to excitement and as a means of bringing emphasis to what it interrupts.",20 As such, boredom, for Higgins, dialectically affirms the intensities that frame its occasion making it "a station on the way to other experiences."

But after nearly fifty years of sincere, ironic, and iconoclastic elaborations of aesthetic boredom, this has the ring of a cliché. Furthermore, calling it a station obscures a metaphysical ambiguity that is expressed in boredom's way of being both a property of the objective world ("That song is boring") and a subjective state ("I' $m$ bored"). That is, qualifying boredom as a dialectical passage between intensities obscures the mood's

\footnotetext{
${ }^{118}$ On Mac Low's poetry, which is noted for its use of chance operations and the application of arbitrary systems for selectıng and assembling new text from pre-exıstıng source material, see Jackson Mac Low, Thing of Beauty, ed Anne Tardos (Berkely University of Californı Press, 2009)

${ }^{119}$ Higgins, "Boredom and Danger," 21, 22

${ }^{120}$ Ibid , 22

${ }^{12 \mathrm{I}}$ Ibid , 22
} 
stranger way of being both objective and subjectıve, dull and interesting - ambivalent However, as I suggested in the last section, boredom is less dialectically operatıve and more tactically effective There is no time of waitıng for an event, there is only a syncopated time of watting as event And furthermore, as I will argue in the next section, the event of waiting has been absorbed by another paradigm that allies the premise of boredom's potential to be interestıng with an individual's capacity and responsibility to realize their "self" My point then is that aesthetıc boredom no longer has the same dialectical leverage it did for Higgins et al Whereas the outlandish repetition of Vexations once invoked boredom as a negative "structural factor,"122 the contemporary simulation of 1ts refrain, one that can be automated and more importantly, one can be 1gnored, evokes a response that is less certain, less transcendent and more perplexed In short, boredom is less promising these days

\section{A Less Promising Boredom}

But if boredom has less to offer, if its disaffection fails to bore into blissful indifference, what's the point of art's being boring anymore? For contemporary art historian Christine Ross, boredom is one of the conditions that conveys what she 1dentıfies as a "depressıve" paradigm in recent art practıces In The Aesthetıcs of Disengagement (2006), Ross argues that recent art works stage symptoms of depression such as slow time, perceptual insufficiency, and the dementalization of subjectivity to show how art, while filching from science's varied portrayals of depression, works to challenge and alter these as it generates its own expressions of the condition Ross

${ }^{122}$ Ibid , 22 
suggests that these renderings of depressive symptoms are productive insofar as they map their own affective sense of the disorder, particularly by showing a concern for the depressed subject in a way that is exempted from clinical definitions of the illness. Challenging and enriching the classification of depression as a form of insufficiency, art, says Ross, addresses depressed subjectivity at the level of sensory appreciation (aesthesis), which expands the sense of insufficiency as primarily a cognitive or hermeneutical deficiency to include somatic and affective failures, failures that are no less expressive in their representation of depressed subjectivity than impaired thinking is.

Ross details a number of ways in which the symptoms of depression are dealt with by contemporary artists. In a series of video works by Ugo Rondinone, featuring clowns engulfed by a torpor of unknown origin, Ross sees the "withering of melancholia" in art as it has become subsumed by a contemporary depressive paradigm. However, in Douglas Gordon's 24 hour Psycho (1993) and Rosemarie Trockel's Sleepingpill (1999), two video pieces that depict an illegible form of (slow) motion, she sees how slow time in art suggests the way depression interrupts the hermeneutic impulse of perception and revalorizes the domain of sensory appreciation. Here Ross construes the staging of depressed behaviour in these and other cases to show that they "are not the symptoms of a disease but 'normal' configurations of contemporary subjectivity." ${ }^{23}$ And insofar as boredom's disaffection signals a diminishment in one's capacity to do something, it too articulates the feeling of insufficiency that dominates the subject of "a society founded on

\footnotetext{
${ }^{123}$ Ross, The Aesthetics of Disengagement, 61
} 
individualıstıc independence and self-realization," a subject whose "self is always on the threshold of being inadequately itself "124

In this view, boredom no longer forms a dialectical relationship with intensity that Higgins took its contrast with exc1tement to mean Where boredom once served "as a means of bringing emphasis to what it interrupts,"125 1t now functions in this "culture of individualized independence" where individuals have the "right" (or the duty) to choose their own identity and interests, as a symptom reflectıng the individual's fa1lure "to meet the neo-liberal demand for speed, flexibility, responsibility, motıvation, communication, and initiative ${ }^{1126}$ Drawing on Alain Ehrenberg's study of depression, ${ }^{127}$ Ross argues that since the 1970s, Western culture has experienced a "decline of norms of socialization based on discipline, obedience, and prohibition and the concomitant rise on norms of independence based on generalızed individual initiatıve and pluralısm of values "128 Depression might be seen then as the psychic fallout of postmodernism's discursive execution of ideological and normatıve prescriptıons whose celebratıon of difference, while directing "the individual to be the sole agent of his or her subjectıvity," established at the same time the perpetual risk of "fa1lure to perform the self"129 As such, I suggest that Ross' reading of depression as symptomatic of neo-liberal 1deals and its expanded field of potential faılure shows how depression has taken over where boredom left off modernity's trope of anomic distress has been replaced with postmodernity's "pathology

\footnotetext{
${ }^{124}$ Ibid , 160

${ }^{125}$ Higgins, "Boredom and Danger," 22

${ }^{126}$ Ross, The Aesthetics of Disengagement, 92, 178

${ }^{127}$ Alain Ehrenberg, The Weariness of the Self Diagnosing the Historv of Depression in the Contemporarv Age (Montreal, Kingston McGill-Queen's University Press, 2010)

${ }^{128}$ Ross, The Aesthetics of Disengagement, $91-92$

129 Ibid, 92
} 
of insufficiency." $" 130$ Boredom, I contend, appears now as a failure for the (neo-liberal) individual to secure a sufficient self, a view that contrasts markedly with the Cagean directive of "losing one's self" in the dissolution of the life-art divide. Failure here is a potential gained while depression is a state earned by the injunction "to be oneself," an optimal functioning self in a world that expects and prohibits nothing but that you demonstrate your right, and/or your (in)capacity, to create/perform your "self."

The curious thing about this paradigm is that failure comes to serve a major role in the expression of contemporary subjectivity. To the extent that the contemporary self must continually perform and reiterate its independence (ironically, on already coded models of performance), its failure to obtain the perfection of the idealized performances of this independence along the lines of adaptability, ingenuity, or initiative figures the contemporary subject as what Ross calls a "coping machine." Borrowing the term from cognitive science studies of depression, Ross cites artist Vanessa Beecroft's performance installations as exemplifying the dynamics of coping that express the failed self. Crudely put, Beecroft's works can be seen to stage a confrontation with the impossibilities of performing feminine ideals. Typically comprising a group of female models chosen for their svelte appearance and homogeneous features, features that can be easily appropriated to common clichés of femininity, Beecroft instructs these meagerly clad (or unclad) women, always in high-heeled shoes, to stand motionless or pose indifferently before an audience for a duration of two to four hours. Ross reads the flagging resolve and subsequent alterations that appear in the performers' attempt to fulfill this performance as behavioral actions, but actions that fail, actions that are "not merely

\footnotetext{
${ }^{130}$ Ibid., 61.
} 


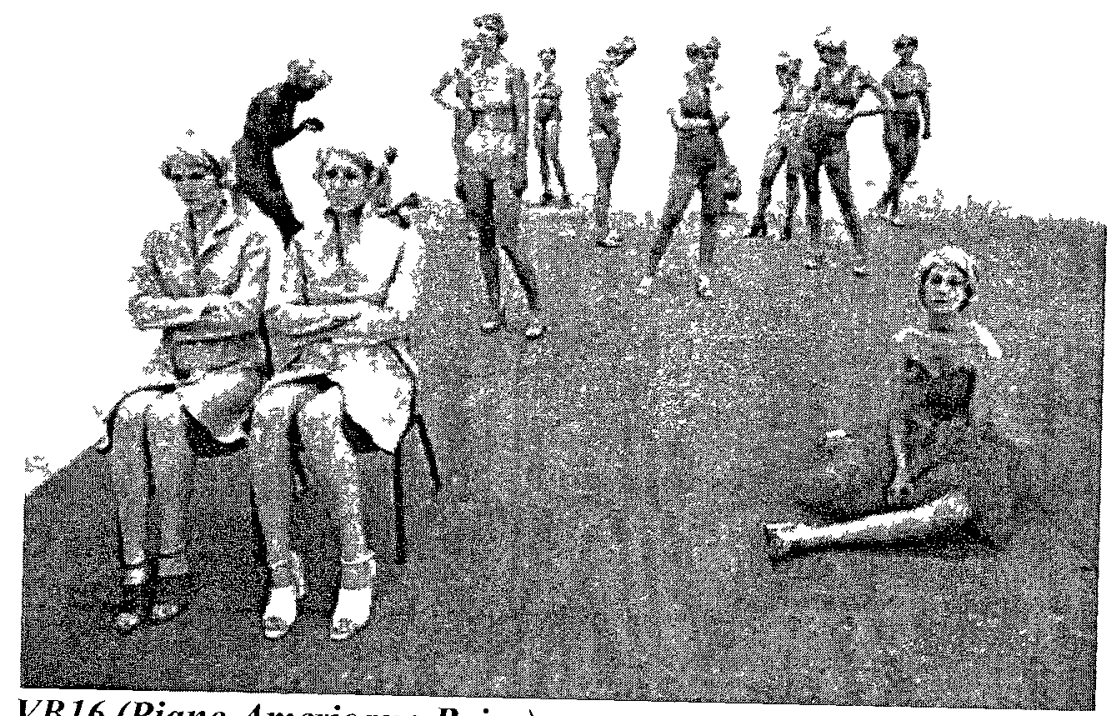

VB16 (Piano Americano Beige)

1996, New York

Vanessa Beecroft

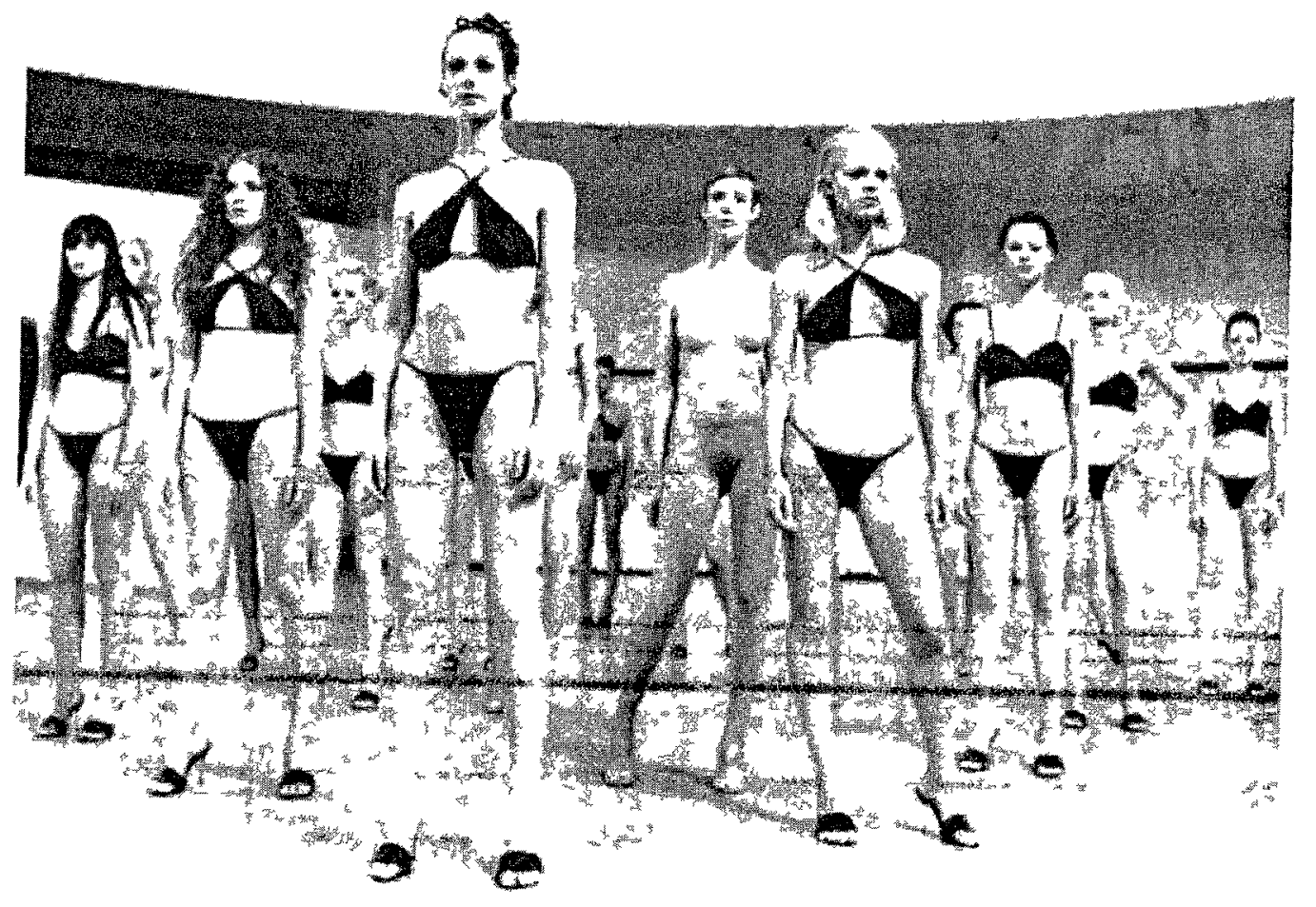

VB35

1998, New York Vanessa Beecroft 
failures but mostly modes of coping with failure."131 In failing to perform the feminine ideal that is aesthetically framed and exaggerated by the array of uniformly anonymous performers, Ross contends that a coping machine's exhibition of "depressive affects become a strategy by which one shapes one's individuality." 132 Beecroft's exemplary machines affirm then a mode of contemporary subjectivity whose "self" is differentiated and expressed not by mastery or affirmation of a prefigured quantity of, in this case, "femininity," but rather by its manner of coping, by the way it expresses an array of depressive affects that make the depressed/bored individual his/her own (positively flawed) subject.

Ross's take on the way depression articulates a mode of subjecthood along the lines of failure, or in her words, insufficiency, is instructive and helps to show how the "metaphysical ambiguity" at play in the discourse of boredom is being reworked in contemporary culture. We can see this attitude of neo-liberal self-responsibility reflected in the way composers who work with various forms of tedium insist that their music isn't boring — or at least that it doesn't set out to bore. Take this statement from Canadian composer John Abram, whose 68-minute composition Vinyl Mine (1996) catalogues the sound of a single pass from the play-off groove of each album comprising the (then) whole of his record collection:

It's a pet peeve of mine that people say "It's boring," when they really ought to say "I am bored by this." I really believe that anything at all can be engaging and fascinating if you examine it the right way, or for long enough. The viewer's

\footnotetext{
${ }^{131}$ Ibid, 76. Specifically, Ross positions this failıng individualısm as gendering a depressed subjectivity* these women-models - are required to perform the idealized and homogenızed feminınity that they perform as models, but in this case, they perform this performance far longer than they are usually asked to do so After about ten minutes of standing st11, the model's capacity to keep still wanes and she starts to adopt other poses in order to cope with the growing tension in her body and the boredom that gradually envelops her

132 Ibid, 83.
} 
inability or unwillingness to engage with the work is not the work's problem, nor its maker's. ${ }^{133}$

Or consider this, from Toronto-based American composer G. Douglas Barrett, who says of his piece Three Voices (a work that I address below):

As square and strict as this score is, there is always something unexpected which arises in performance-in this case having to do with the sheer concentration and endurance needed to repeat an action 169 times in strict coordination with two other performers. ${ }^{134}$

Both composers here give boredom no purchase on their work, either displacing it onto the listener or treating it as a surface effect of the piece's formal monotony that will (eventually) become marginalized by the appearance of the unexpected-provided that one is capable of perceiving it in this way. These comments, obviously taking for granted a Cagean faith in boredom's promise, inadvertently evoke the contemporary sensibility of insufficiency that requires the listener to be the agent of his/her own interests. Here again is have Adam Phillips' idea that boredom returns the individual to the scene of inquiry, only this time with the belief that one must “initiate one's own identity [desires] instead of being disciplined to do so."135

Yet as insightful as Ross's intervention into the construction of depressed subjectivity is, it overlooks that fact that the viewer is somehow expected to understand the hidden operativity of slowness, monotony, fatigue, without actually having to experience the lived reality of these corporeal states. Of course it's possible, to an extent, to understand depression without having suffered it; however, insofar as Ross contends that many of the works she discusses aim to revalue "the sensory and affective

\footnotetext{
133 John Abram, Personal communication, 2009

${ }^{134} \mathrm{G}$ Douglas Barrett, Personal communication, 2009

${ }^{135}$ Ross, The Aesthetics of Disengagement, 92
} 
dimensions of aesthetics, ${ }^{, 136}$ it bears noting that almost no one watches the entirety of Gordon's 24-hour Psycho, or stands for the duration of the performance with Beecroft's models. As such, the audience inevitably misses something of the somatic and intensive dimension of failure that is being staged by these works. In this respect, we can see how musical enactments of boredom actually make the time and space for the kind of sensory regeneration that is only symbolized by the sluggardly pace of these optically-based works. That 1s, the forms of embodiment that are only ever portrayed by Rondinone's and Gordon's work, and which are supposed to "create the beholder as depressed," are actually made effective by the concert and listening rituals of music that conjure a phantasmatic space-time which allows and indeed requires one to endure the intensities of insufficiency that take time to play out. ${ }^{137}$ Music's "concerted" expressions of boredom make the experience of suffering what literary theorist Sianne Ngai terms the "ugly feelings" that define contemporary subjectivity an effectively affective part of its aesthetic expression and reception.

\footnotetext{
${ }^{136}$ Ibid , 152

${ }^{137}$ Music has a long history of association with the phantasmatic Though the most common sense of this is inherited from religious and folk traditions that treat musıc hke an incantatory form which conjures a quasimystical spacetime into being, more obscure formulations include Susanne Langer's theory that musical morphology expresses the affective "semblance" of the "inner life" (a concept borrowed from Schiller's notion of Schein), Jacques Attalı's sense that the suppleness of music's medium simulates a hyper-fast economy of relations that presage political orders, and David Burrows' thesis which conjectures that music operates on a synthetıc plane of sensory immediacy that compensates for the abstractness of language. See Susanne Langer, Feeling and Form (New York Charles Scribner's Sons, 1953), Jacques Attalı, Noise The Political Economy of Music (Minneapolis University of Minnesota Press, 1985), David Burrows, Time and the Warm Body A Musical Perspective on the Construction of Time (Leiden, Boston Brill, 2007).
} 


\section{Uglier Feelings of the Stuplime}

How aesthetic expressions of boredom have affected us differently over time outlines something of the history of modernity's preoccupation with "ugly feelings." Along with envy, paranoia, and irritation, Ngai identifies a feeling of modernity that characterizes the kind of "syncretism of excitation and enervation"138 generated by encounters with mindbendingly vast and excessively dull art. Addressing and unpacking the under-theorized ambi-valence of aestheticised tedium, Ngai draws attention to the way it resembles the sublime insofar as a listener's "faculties become strained to their limits in their effort to comprehend the work as a whole," but differs from the sublime in that "the revelation of this failure is conspicuously less dramatic." ${ }^{139}$ Naming this feeling "stuplimity," Ngai argues that works like Beckett's Stirrings Still (1988) and Kenneth Goldsmith's American Trilogy (2005-08) ${ }^{140}$ (or even abstract systems like the one representing "justice" to K. in Kafka's The Trial) do not induce a properly (Kantian) sublime experience. While the vastness of the sublime that threatens to crush the finite individual "ultimately refer[s] the self back to its capacity for reason" and its ability to "transcend the deficiencies of its own imagination," 141 the excessive "agglutination" that comprise Stirrings Still and American Trilogy keep us mired in our insufficiency and in touch with the sensuous infinity intimated by these works. ${ }^{143}$

\footnotetext{
${ }^{138}$ Ngar, Ugly Feelings, 280.

${ }^{139}$ Ibid , 270.

${ }^{140}$ Three novels composed entirely of one year's worth of New York City weather, traffic and sports reports

${ }^{141}$ Ngat, Ugly Feelings, 266.

${ }^{142}$ Nga1 uses the term "agglutination" rather than accumulation to describe the holding together in perception or formal relations "the mass adhesion or coagulation of data particles or signifying units " Ibid , 263

${ }^{143}$ I think that Ngai ultimately relies too heavily on the formal elements of the works she uses as her studies to exemplify the affective response to 1terability Although her examples are persuasive, particularly as they
} 
The difference between the sublime and stuplime can be clarified and its affect examined by looking at a work like Piano Installation with Derangements (2004) by Canadian composer Chedomir Barone. There is nothing intimidating or overwhelming about its material in the sense suggested by the sublime. Essentially, it is a deliberately obtuse presentation of 750 coupled derangements ${ }^{144}$ of a $\mathrm{C}$ major scale that when performed (as it was in 2005 by the composer who spent three hours slowly [ca. $d=52$ ] and quietly playing each paired derangement while depressing the sostenuto pedal throughout and treating each quarter rest as an unmeasured fermata) invokes the vertigo of the sublime without eliciting the (Kantian) promise of reason that will rescue the affected mind from the failing of its imagination.

Staged as an "installation" so that listeners ("non-performers" in Barone's words) might come and go as they wish, the piece, says Barone, is actually intended for the performer, whose encounter with boredom, because he or she "must pay attention or the piece collapses," does not have the luxury of being carried away from its monotony. Like Beecroft's models, the performer must attempt to accomplish an ideal, which in this case is described by a slow, quiet and steady sounding of seriated C Major derangements. But of course, the performance is festooned with "errors" and slips, and these expressive failures are what usually pass as justification for the work's boredom. However, the

draw attention to the way the repetition of finite elements undermines the stability of formal concepts by mutılating the signifying relays of the system that grants them meanıng, she overlooks the detail that only now is our culture, after having suffered a century of aesthetic boredom, able to apprecrate the sense of being alternately bored and interested by the same experience It's not merely the individual work's linkıng of boredom and astonishment that expresses the stuplime, but the collective history of ways we've developed to aestheticize and thereby unsteadily elevate the mundane or picayune.

${ }^{144}$ A derangement refers to a permutational mode in combınatonal mathematıcs whereby no element of a given set (1e C major C D E F G A B) appears in its original place For example

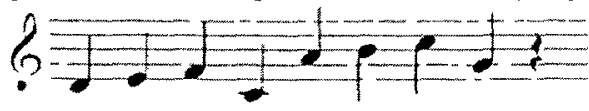



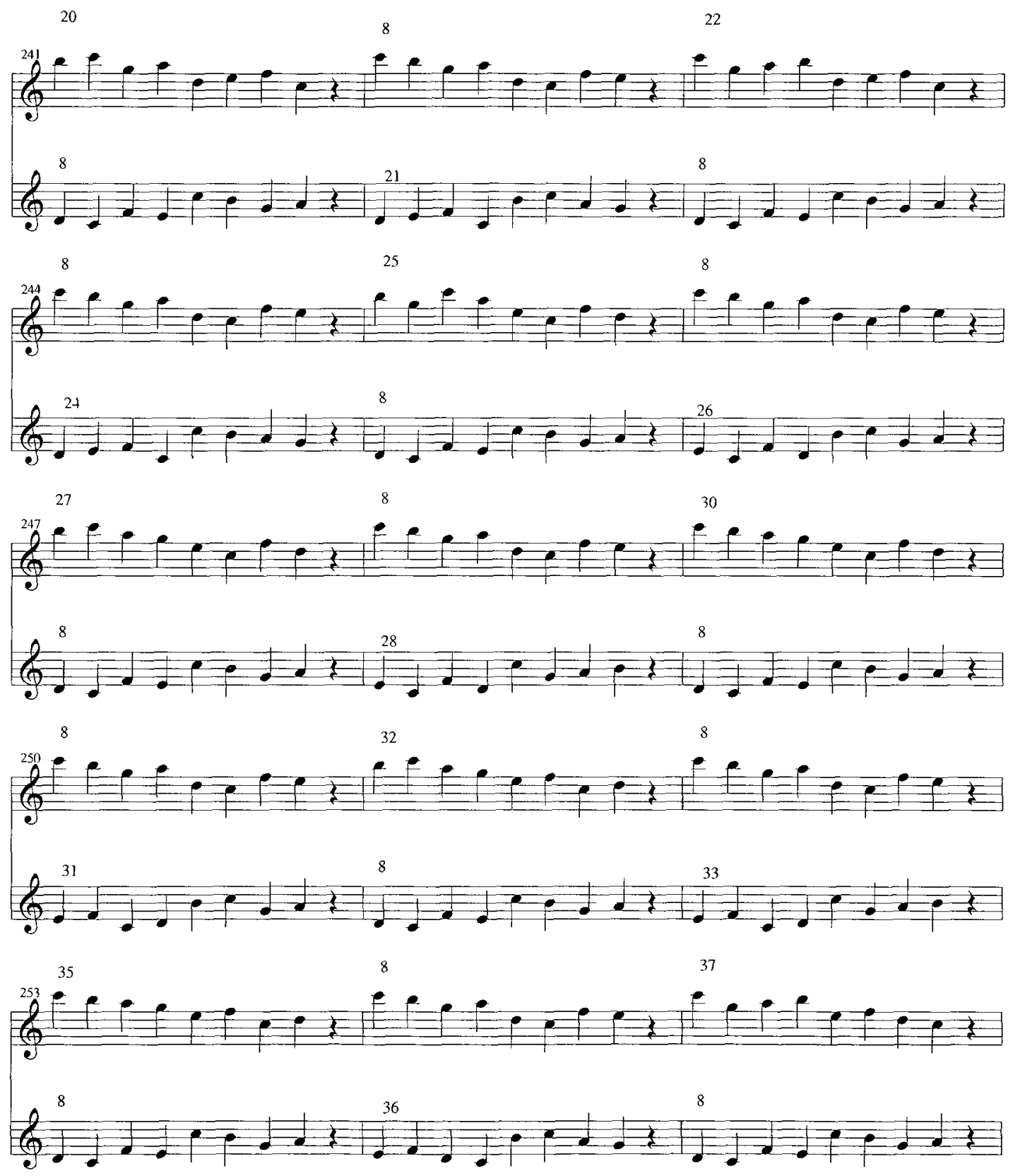

Piano Installation with Derangements (2004) 
discourse of musical experimentalism that converts these "failures" into aesthetic successes - a discourse premised on the idea that "An error is simply a failure to adjust immediately from a preconception to an actuality" "145 — has the effect of obscuring the affective conditions that engendered their expression. Here's how Barone describes his experience of performing Piano Installations:

I was perhaps a little over half way through the piece when I had a series of revelations. First, I realized that I was no longer consciously controlling my hands, or even reading the music. It seemed at the time that I was only looking at the pages, and my hands were somehow working by their own accord. Next, it occurred to me that I didn't even know "how" to play the piano. (I started to feel the sort of giggly panic at this point that you get when you've taken magic mushrooms and are strolling about town trying not to look/act high). Finally, I realized that nothing much made sense. I was smacking some wooden box with my hands for reasons unknown, and somehow sounds were happening as a result of my actions. Everything- the music, the piano, the concert, the people sitting there-seemed utterly foreign and utterly ludicrous. ${ }^{146}$

Note, Barone never says that the monotonous refrains of the piece transported him to some transcendent plateau or endowed his sense of self with some agreeable estimation of itself. The expressions of sublime transduction are clearly absent from his description. Instead, Barone recounts a senseless mixing of bodies and fugitive intensities whose familiar semantic crust and affective attachments have corroded — not exploded—under the slow decay of his capacity to sustain a focused attention. Throughout this performance, Barone is neither elated nor self-secure. He simply finds himself enduring a slow burn that alternately sears and numbs attention as his body encounters the sensuous infinity of the finite's iterability. Although Barone is relating a performer's experience of the work, its presentation as "music" (despite its title and the invitation to exit) solicits a kind of attention that condemns one to suffer the duration (durée) of the performance and

\footnotetext{
145 John Cage qtd in Nyman, Experimental Music Cage and Beyond, 62

${ }^{146}$ Chedomir Barone, Personal communication, 2009
} 
so to cope with a "series of fatigues or minor exhaustions, rather than a single, major blow to the imagination." describes an experience of Barone's work, expresses a paradox in a way that both recalls and challenges Cage's immersive ideal. It does this insofar as the concerted stuplime articulates the Cagean conceit that displaces intentionality onto the listener who is at the same time created as, in Ross's terms, an insufficient subject. That is, the musicalized stuplime solicits a subject who is expected to be responsible for witnessing his/her incapacity to adequately intend to nothing in particular. The ambivalence infusing this paradox, which in the 1960 s was managed and qualified discursively by appealing to the rhetoric of Zen and other traditions of coincidentia oppositorum, ${ }^{148}$ is in this case expressed in the affective terms of "coping" and "striving," terms that embody a contemporary "form of living related to a loss of self but inextricably tied to the development of the self."149 Thus, whereas something like author Kenneth Goldsmith's work Fidget (2000), which is nothing/everything but a transcription of his bodily movements over a single day, simply represents the array of corporeal techniques that he suffered over twenty-four hours, the audience captured by the musical address of Barone's much more modest three-hour performance is given its own occasion to yawn, to loll, to ache and so to shape the individuality of its members through their alternately flagging/rebounding capacity to cope with the stuplimity of its derangements.

What differentiates the boredom of this situation from its Romantic expression is the articulation of a neoliberal and cognitivist model of subjectivity in which

\footnotetext{
${ }^{147}$ Ngar, Ugly Feelings, 272.

${ }^{148}$ (. . which include not only Eastern mystical traditıons but modern Western esotericisms like psychoanalysis, relativity theory, and quantum uncertainty )

${ }^{149}$ Ross, The Aesthetrcs of Disengagement, 68
} 
individuality is constituted, expressed, and strangely empowered by the transitive banalities, rogue affects, and uneven fatigues that assail him-her-it. In other words, whereas Romantic boredom promised an ecstatic, eventual, and indubitable (if inexpressible) self-presence, contemporary boredom makes no such promise, leaving one, for better or worse, to carve a selfhood out of an apparently uniform tedium by showing how one is uniquely affected by the pressures of contemporary culture's norms of independence. In the context of an experimental music culture that has made it compulsory to flaunt an iconoclasm and an ostensibly catholic taste, this pressure is felt and manifested in the imperative to meet the strikingly neoliberal policy of required creativity, of the constant need to display not a mastery, for that is impossible, but capacity to creatively cope with the uncertain, the unforeseen, and the ultimately "unknown unknowns" of life. Thus, the extent to which the stuplime expresses a contemporary ambivalence to aestheticized boredom, one that contrasts with the rhetorically attractive refrains of its Romantic escapes, can be seen by the way it addresses a subject who is persuaded that it is both a right and a chore to wait for one's own interests.

The ambivalence of stuplimity plays out a little differently in the work of American composer G. Douglas Barrett. Barrett's interdisciplinary practice traverses the conventions of traditional composition and visual art and skews Barone's affectedly doltish (over)abundance of minor variations ${ }^{150}$ by its conceptually mannered conceit of

\footnotetext{
${ }^{150}$ Almost all of Barone's work consists of spelling out cycles or permutations of some element, whether that element is acoustical or kinetıc, or otherwise For example, his four-hour Progressions for String Quartet (2003) is a series of four movements each of which elaborates in quartet notes all possible combinations of the $\mathrm{C}$ scale with sharps, flats, and naturals, and his hour-and-a-half to two-hour piece Golden (2003) comprises simply the execution of two contrasting and alternating actions at a uniform
} 
simulation, or what Barrett calls "transcription." Transcription for Barrett turns less on the order of the real and the hyperreal than it does on the way of making expressive the distortions, the insufficiencies, and the overlooked in what Barrett says are "processes that have to do with documenting, replicating, recording and repeating." 151 These processes, of course, nevertheless participate in the general economy of simulation, for each instance is a type of image that cannot help but articulate the logic of models and copies that both generate and undermine the notion of the real or original. ${ }^{152}$ Barrett's practice of transcription, however, can be distinguished from the contemporary history of simulation by virtue of the way his work emphasizes rather than dissimulates the disfiguring properties intrinsic to its processes. ${ }^{153}$ Like the act of translation, transcription for Barrett entails a certain amount of interpretive activity that does not so much introduce as express the difference that occasions two or more instances of a thing-event. In other words, Barrett's transcriptions witness and delineate, in musical terms, the virtual multiplicity, or multivalence, of an event as it is figured in different mediums: audio recording, notated score, and live performance (and this discursive medium in which you're encountering it now). What makes Barrett's transcriptions and their exquisite tedium elicit a stuplime ambivalence has, however, less to do with the familiar

\footnotetext{
tempo and dynamic The performance Barone gave of this work 17 February 2003 consisted of the two actions "clımbing stairs" and "hitting a flower pot"

${ }^{151} \mathrm{G}$ Douglas Barrett, artıst statement, http //syntha caset buffalo edu/ gbarrett/bı html (accessed 21 May 2009)

${ }^{152}$ For example, in addition to using common audio recorders and transposing the captured sounds into musical notation, Barrett has designed a piece of software capable of performing a spectral analysis of a recording whose results are converted tones that are mapped onto an specified instrument or ensemble

${ }^{153}$ Baudrillard's theorization of simulation entals the historical development of a sign or image's nature of appearance and relation to a "real" This history charts an increasingly attenuated order between sign and referent that concludes with their being ultimate indistıngushable from each other See Jean Baudrillard, "The Precession of Simulacra," in Simulacra and Simulation, trans Sheila Glaser (Ann Arbor University of Michigan Press, 1995)
} 
dimensions of repetition and extendedness than it does with the way it treats every source as an insufficiently expressed event. Take for example his work Derivation XI, or

Derivation[Derivation \{Derivation(Derivation[Derivation \{Backyard [Music] - Vol. 4 (or Derivation IV.)\} (or Derivation VI.)] (or Derivation VII.)) (or Derivation VIII.)\} (or Derivation X.)] (or Derivation XI.)

The originary event for this "piece," or more accurately, the series of derivations executed by Barrett since 2006, is a recording of a performance of his piece Backyard [Music] (2006), which is itself the transcription of a recording made of the ambient sounds of a Hollywood street comer. Derivation XI can be thought of as the eighth generation of Backyard [Music]-as the collective expression of the recording, transcription and performance-or, if you want to discriminate a performance, from a recording from a transcription, then Derivation $X I$ will be the twenty-second iteration of Backyard [Music]. In Barrett's terms:

Derivation XI is a transcription of a recording of a performance of a transcription of a recording of a performance of a transcription of a recording of a performance of a transcription of a recording of a performance of a transcription of a recording of a transcription of a recording (of a performance). ${ }^{\text {i54 }}$

What each subsequent occasion (recording, transcription, performance) of this process implies is that the previous iteration is, in a sense, in-attentive to something that can only be attended to in the following iteration, paradoxically showing that the finitude of each event is composed of an excess that escapes its specificity. Brian Massumi describes the ingressive potential that informs each instance of a thing or event as the "autonomy of affect," a potential that gives things their sense of "life." "Actually existing, structured

\footnotetext{
${ }^{154}$ Barrett, from score.
} 

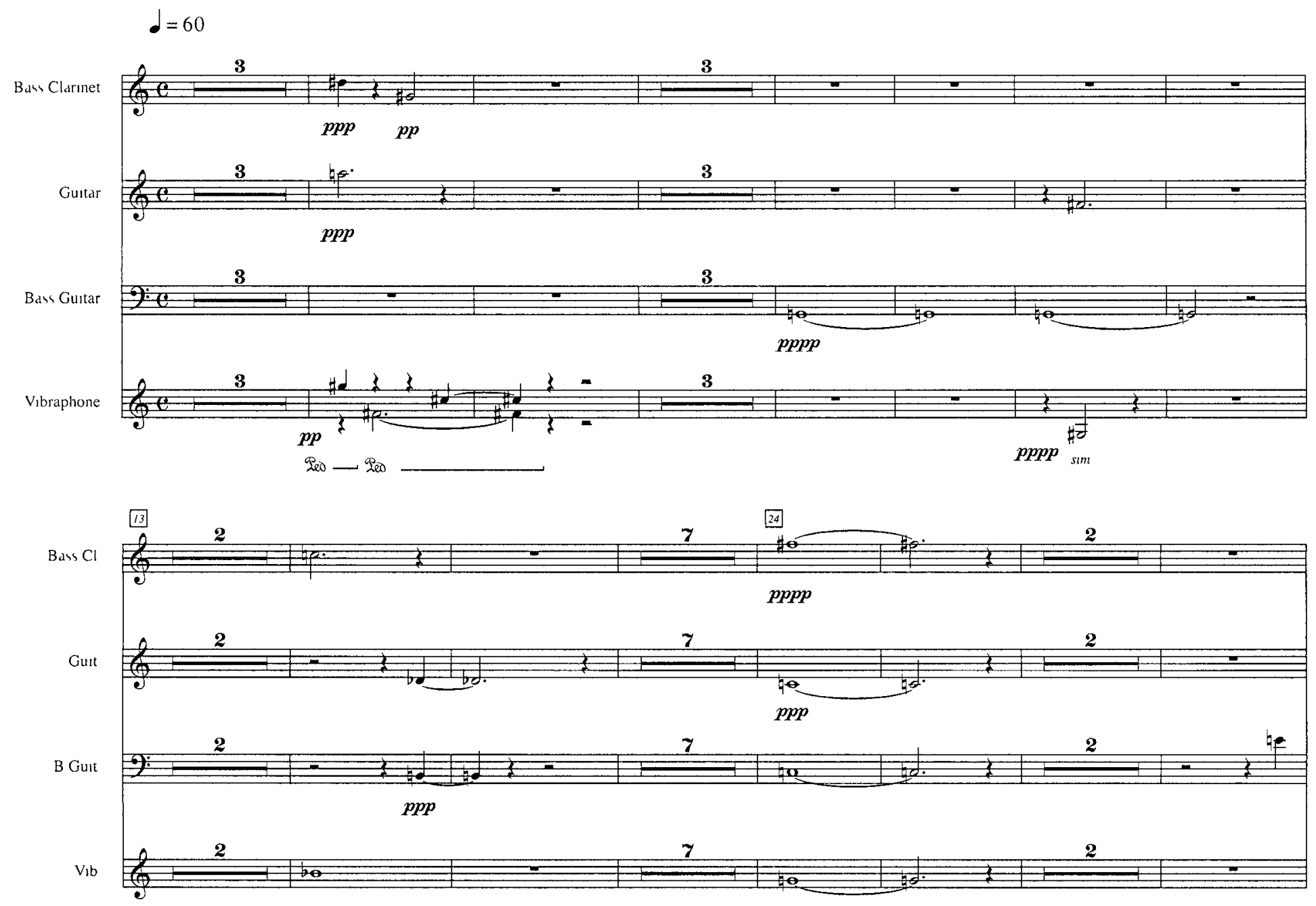

Derivation XI (2008) - excerpt G. Douglas Barrett 
things," he writes, "live in and through that which escapes them."155 This "escape" is what Barrett transcribes and reiterates, each time expressing again the same potential difference, or as Massumi says "a fade out to infinity." 156 The ambivalence of the tedium that Barrett crafts derives from the kind of charged uncertainty that gives life its feeling, its sense of open-endedness, which reminds us of what Cage averred as a heterogeneous field of multiplicity. However, because of the way that Barrett's transcriptions still participate in a logic of simulation, a logic that dislodges all signs from their relation to a "real" referent and which, argues Baudrillard, is the dominant economy of our age, they also remind us that there is no outside or founding model, no tradition or central edict that shows us how or who to be--except for the model of individual independence, a model joyfully embodied in the 1960 s and 70 s, but tediously, and often insufficiently, performed by today's bored subject.

While the seriality of Derivations takes on the impressive but ultimately impossible task of actualizing the totality of its difference, Barrett's piece Three Voices (2008) composes another series of simulations through the description of "every possible ordering of entrances and cut-offs of sounds or actions for three performers." ${ }^{\text {157 }}$ From left to right, three lines, three performers, each playing a single tone, sound, or action corresponding to the 169 graphic portrayals of relative beginnings and endings, Barrett composes an exhaustive picture of a particular form of time, of time written sideways. An hour-long performance from 2008 features two violins and flute articulating the diversity

\footnotetext{
${ }^{155}$ Massum1, Parables for the Virtual, 35

156 Ibid

${ }^{157}$ Barrett, Personal communication.
} 

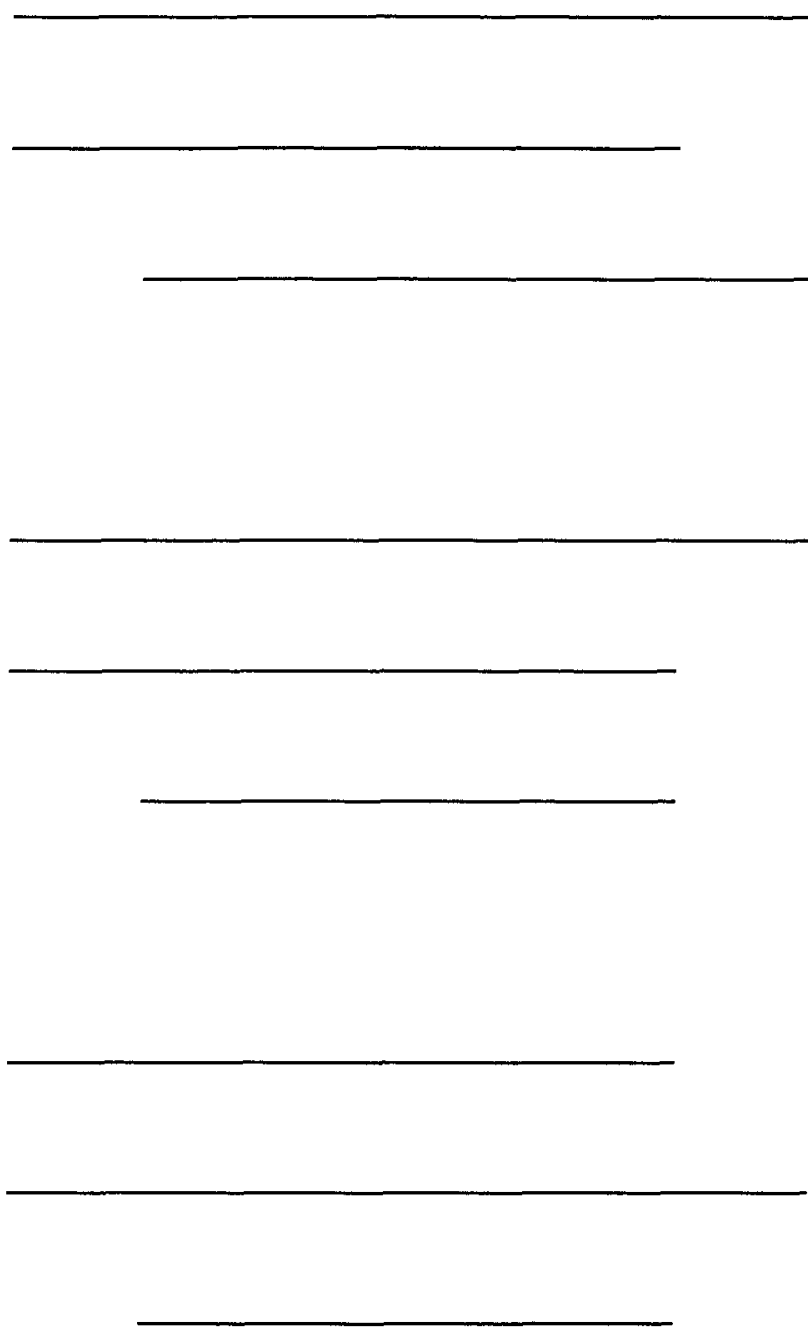

Three Voices (2008)

G. Douglas Barrett (excerpt) 
of entrances and cut-offs through a series of soft iterations of the sonority:

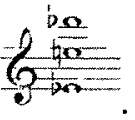

On one level, Three Voices resembles the fetishization of presence associated with

the compositions of Morton Feldman. Like Feldman's works, which elaborate a

succession of varied instrumental events, Barrett's piece stages a uniform flow of

variations of the same event. However, to the extent that it aims to elaborate a kind of

action, Three Voices is more usefully compared to Gertrude Stein's The Making of

Americans: Being a History of a Family's Progress ${ }^{158}$ in the way that it attempts to

exhaust the telling of its "kind," its "list[ing] of every ordering of starts and stops of three

elements." 159 Like Stein's psychedelic taxonimıation of "kinds" of Americans, Three

Voices enacts a totalizing project that engenders a stuplime encounter with the singular

"kind" of beginnings and endings. The labour involved in this sort of "inventory art,"

from writing, performing and listening to it, summons affects that force the subject back

upon itself, not in a recuperative gesture of the sublime that Kant sees as reason's triumph

over the imagination's insufficiency, but in the sense that the imagination is made to

continually reflect upon its paucity and in a way that forces the listener to take

responsibility for developing new ways and manners of listening.

Certainly one can imagine slips in intonation or uneven bowing and breathing as

\footnotetext{
158 "There must now then be more description of the way each one is made of a substance common to their kind of them, thicker, thinner, harder, softer, all of one consistency, all of one lump, or little lumps stuck together to make a whole one cemented together sometımes by the same kind of being sometimes by the other kind of being in them, some with a lump hard at the centre liquid at the surface, some with the lump vegetablish or wooden or metallic in them. Always then the kind of substance, the kind of way when it is a mediumly flund solid fructifyıng reacting substance, the way it acts makes one kind of them of the resisting kind of them, the way another substance acts makes another kınd of them the attacking way of them. It and the state it is in each kind of them, the mixing of it with the other way of being that makes many kinds of these two kinds of them, sometıme all this will have meaning" - Gertrude Stein, The Making of Americans Being a History of a Family's Progress (New York. Something Else Press, 1966)

${ }^{159}$ Barrett, Personal communication It's interesting to note the Steinean quality of Barrett's prose here
} 
moments of "excitement" in the unfolding of Three Voices. But Ngai's description of The Making of Americans as a "labor of enumeration, differentiating, describing, dividing, sorting" tells us that this making involves very little excitement but instead "generally takes place as a painstakingly slow, tiring, seemingly endless 'puzzling' over differences and resemblances." 160 The instruction that Three Voices be played "soft, concentrated, for its own sake ${ }^{, I 6]}$ indicates a making of kinds of beginnings and endings that are neither euphoric nor ironic, but unjustified multiples of kinds (of beginnings and endings) whose repetitions "elevate and absurdify"162 their way of being an assembly of singular kinds whose strangeness breaks upon the familiar of their kinds. Works such as these extract an affective response that is decidedly un-sublime. Both Barrett's and Barone's neo-dada interrogations of the shockingly obtuse drift perilously close to the un-musical refrains of the everyday by unintentionally choreographing the contingencies and inexactitudes that inhere in and inform any programme of embodied actions. While lacking the intensive magnitude of the sublime, like the buzz of everyday life, both Three Voices and Piano Installation with derangements are rich with hiccups that, because of their aesthetic making, lie on just this side of being boring.

As an affective category the stuplime easily addresses itself to kinds of affective engagement that one tends to form with objects given definition using a severely constrained set of rules and material. Barone's work is a clear example of a work generated using an extreme constraint, but other examples include George Perec's $L a$

\footnotetext{
${ }^{160}$ Ngai, Ugly Feelıngs, 292

${ }^{161}$ Barrett, from score

162 Ngai, Ugly Feelings, 280.
} 
Disparition (1969), a lipogram written as a novel entirely without the letter "e," and many of the films made under the rubric of Scandinavian directors Lars von Trier and Thomas Vinterberg's Dogme 95, which stipulates that filmmakers must, for example, film sound and visuals together, use only hand-held cameras, use only the items, spaces and lighting available at the filming location, and refrain from invoking genre tropes. However, the presence of constraints does not a stuplime experience make. Musical serialism, which may be classified as an art of constraints, does not invoke the stuplime because its works, such as Boulez's Le marteau sans maitre (1955), though rigorously committed to their own constraints, tend to be carried out within the very self-aware context of European concert music whose expressive norms compel composers to qualify their work by recycling the history of musical affect. ${ }^{163}$ The works that I've described here, however, put constraints to ends that let loose the intensive side of difference, an unjustified difference that escapes yet empowers every actual event. Thus, neither Barone's Piano Installation nor Barrett's Three Voices is beholden to the regime of difference that has historically and traditionally constituted and policed "Music" (and its uses) as a formalized array of tonal, rhythmical, and affective relations. Instead these works express the difference by which the regulated attributes of "Music" - a C major scale or a notational convention for instance--may be assembled, sounded, performed, and felt or not felt. Barone's work, for instance, contests the nature of neither the tonal scale nor the piano. These elements remain relatively intact; however, the manner in which these elements slowly and monotonously sound forth a series of scalar derangements tells a different story about "Music," not about what it should be, but about

\footnotetext{
${ }^{163}$ The exception to this may be La Monte Young's Trio for Strings, which is exactingly serial But you can also spy glımmers of stuplimity in serıalıst works like Jean Barraque's Prano Sonata (1950-52), which over its fifty contınuous minutes, disposes of much of its obligatory expressivism
} 
how it can be different--even by not being capital "M" music. Similarly, Barrett's Three Voices isn't concerned with its status as Music: “These pieces are about actions and their overlappings, whether those actions produce sound or not." 164 Its graphical allusion to the musicalized timing of events show how "the ability to perform a sustained action, noise, or tone coordinated among a group of three performers" $" 165$ can provoke a response that needn't be drawn from the archive of "Musical" feeling, by which I mean the archive of affective affectations developed throughout the nineteenth century to embody the "crypto-sacred" rhetoric of absolute music. ${ }^{166}$ It's in the way these particular composers "exaggeratedly submit to structural laws"167 and emphasize the senseless sense-making process of iterability subsisting within the most trivial "musical" parameter that folds the affect of contemporary art's sensuous infinity into a process of bearing witness to the stuplimity of its happening.

\section{Post...Death...}

Obviously, boredom today is not wholly distinct from the boredom of the sixties and seventies; the formal and conceptual similarities, as well as the discursive figures that are used by artists to describe and justify the boring things that they do are more than apparent. What is not so evident is the way in which the paradoxical "shock" of boredom now functions as a currency in what theorist Paul Mann calls the "white economy of

\footnotetext{
${ }^{164}$ Barrett, Personal communication

165 Ibid.

${ }^{166}$ See Susan McClary's essay "Narratıve Agendas in "Absolute Musıc" for a discussıon of how the narrative conventions and affective codes of eighteenth and nineteenth-century Europe informed the "standard sequence of dynamical events" of instrumental (art) music In Musicology and Difference Gender and Sexuality in Music Scholarship, ed Ruth A Solıe (Berkeley. Unıversity of Calıfornı Press 1995), 330

${ }^{167}$ Nga1, Ugly Feelings, 297
} 
discourse." In his 1991 book, Theory-Death of the Avant-Garde, Mann argues that the devices of avant-garde or "oppositional" art, of which boredom is just one device along with "shock," "juxtaposition," "collage," and most importantly for Mann, "critique," are forms of currency in an economy that trades on expressions of conformity/resistance. ${ }^{168}$ The avant-garde doesn't occupy the latter term of this binary so much as its expressions mark the differential drift by which this pair is made sayable in a system of exchange. In essence, Mann is suggesting that the avant-garde's perpetual effort to differ makes it a discursive agent insofar as its expressions of difference generate discourse. And as discourse is the scene of recuperation, the assimilation of difference to the same white economy of exchange, the avant-garde is less a site of resistance and more "a system for instrumentalizing contradiction."169 This insight into the avant-garde's complicity with a bourgeo1s culture of exchange is supposed to be the death of the avant-garde; however, as Mann notes in pointing to the proliferation of "obituaries"--like his book and even this dissertation- - the avant-garde's death makes it not less productive, but in many ways more productive:

The death of the avant-garde is the $n$-state of the recuperation of its critical potential by a narrative of failure. ${ }^{170}$

Here, Mann is saying that the avant-garde's critical posture is itself a commodity that can

\footnotetext{
${ }^{168}$ Mann argues that the avant-garde is essentially an expression of a system of radical recuperation, an expression wrought in aesthetic (artworks) and theoretical (manifestoes, essays) terms The art and ideas venerated as "avant-garde" are instruments for sımulatıng and expropriating difference (as it were) I speak more directly to this with respect to my own thesis at the end of the chapter See Paul Mann, The TheoryDeath of the Avant-Garde (Bloomington Indiana Unıversity Press, 1991), 46 Curiously, Mann's work was published the same year as Frednc Jameson's Postmodernism or, The Cultural Logtc of Late Capitalism In the latter, Jameson makes simılar arguments to Mann but does not direct his critique at the avant-garde per se, instead, he focuses his analysis on the systems of production that encourage "confidence" in a fragmented view of contemporary culture, such as pastiche and historical recycling See Fredric Jameson, Postmodernism, or, the Cultural Logic of Late Capitalism (Durham, NC Duke University Press, 1991)

${ }^{169}$ Mann, The Theory-Death of the Avant-Garde, 46

${ }^{170}$ Ibıd , 40
} 
be used for purposes of exchange While artworks contınue to be made and sold, their real value hes in being placeholders or ingredients for the essays, books, dissertations, conferences and symposia that are like grimorres and seances for reanımatıng the dead Within a discursive economy, every critical study of an avant-garde's death is like a type of necromancy From this perspective, the current interest in aesthetic boredom would seem to lie not in how it affects someone, but in how a work's senseless drifts and empty feints persuade someone to talk or write about it The catch here of course, one whose dialectical gesture is tautologically poised to collapse in an ever tightenıng spiral of immanence, is that art which is merely an interestıng thing to write about--to discourse on- $l s$ boring, and being boring is merely interestung to write about The bind for contemporary art and criticism is that they become unable to make a critical statement about their own situation without re-presenting the discursive mechanisms of its expressive distress The only way to escape this dilemma would be to dodge participation in the discursive economy by ımaginıng a place outside of discourse And this, writes Mann, is "a place that, one is assured, does not exist" "171

Or if "it" does exist, it exists in a way that cannot be articulated without being drawn into the wholly affirmative character of discourse, for "discourse has no negative force that is not reduced to dialectical systems-maintenance "172 This means that if I am to do what I am about to, to suggest how contemporary boredom intımates an "escape" from discourse without actually dying the death of absolute silence, I should really stop writing and let a little nihilism loose on my own words However, it is clear by this point

\footnotetext{
${ }^{171}$ Ibid, 91

${ }^{172}$ Ibıd, 88
} 
that I won't. I have to at least suggest a conclusion, one whose even modest inference or speculation will compromise the chance of aesthetic boredom to be unjustified.

Well...I can't go on, I'll go on.

Perhaps in losing the operational difference that distinguishes between aesthetic and mundane boredom, a loss diagnosed by Baudrillard as a consequence of media saturation that takes us beyond questions of representation, contemporary "aesthetic" boredom (which should by now be put under erasure), articulates the uncertainty of its own conundrum. Unlike earlier artworks that focused on boredom's capacity to disturb conventions, to drum up differences in which discourse could be invested, contemporary boredom, in its stuplimity, seems to address the metaphysical ambiguity that has always been evident in boredom's rhetoric. Boredom, as the phrases I wrote above-_That song is boring" and "I'm bored"-reveal, is a way of speaking about the felt sense of senselessness and the uncertainty affecting a subject caught between a withering paradigm of faith and the reflexive proclivities of modern epistemological scepticism. Thus, whereas a work like Steve Reich's Four Organs (1970) once promised to eliminate the uncertainty of being neither a faithful nor empirical "self" by annihilating this duality in an immersive gesture of extinction, Barrett's Derivation XIIIb transcribes and simulates the ambivalence that has allowed boredom to spread beyond the desert of art into the wasteland of the mundane, where the intensity of being unjustified becomes indistinguishable from a day at the office. But this is no hard-won insight. It is the simulation of an insight into the fact that our waiting no longer pays off in the revelation of hitherto unknown interests, an insight into the theory-death that waiting tries to infinitely postpone. Waiting is stuplime: It is an uncertain witnessing of the time of 
events in their infinite eventuality and a way of listening to nothing in particular in order to imagine the impossible possibility of disappearing into an event that always never takes place.

\section{Afterthought...}

In 1971, John Baldessari produced his now-famous work I Will Not Make Any More Boring Art. Initially an installation commissioned by the Nova Scotia College of Art and Design, Baldessari, who couldn't make the trip to Halifax to install the work, had students write the pledge on the walls of the gallery. However, the better-known version of the piece is the thirty-two minute video of Baldessari himself writing the phrase over and over again.

In several ways, the composers whose works I have analyzed in this chapter blow open the liar's paradox at the heart of Baldessari's conceit. Baldessari's work, which articulates and comments on the nature of self-reflexivity that characterized so much conceptual and (post)minimalist art of the $1960 \mathrm{~s}$, is able to enjoy or at least amuse itself with a clever cynicism and irony that has come to characterize a certain species of postmodern aesthetics. Nearly forty years later, however, this gesture lacks the critical edge it once had. As Robert Goldman and Stephen Papson argue in examining the way contemporary "advertising practices try to turn self-reflexive awareness of advertising codes into an object of consumption," ${ }^{173}$ consumer in Western cultures have become (relatively) savvy to the artifice of "the text" and the tricks of drawing attention to the meta-language that underwrites its codes and form of address. Perhaps what makes

\footnotetext{
${ }^{173}$ Robert Goldman and Stephen Papson, "Advertısing in the Age of Hypersignification," Theory, Culture \& Soclety 11, no 3 (1994) 43
} 


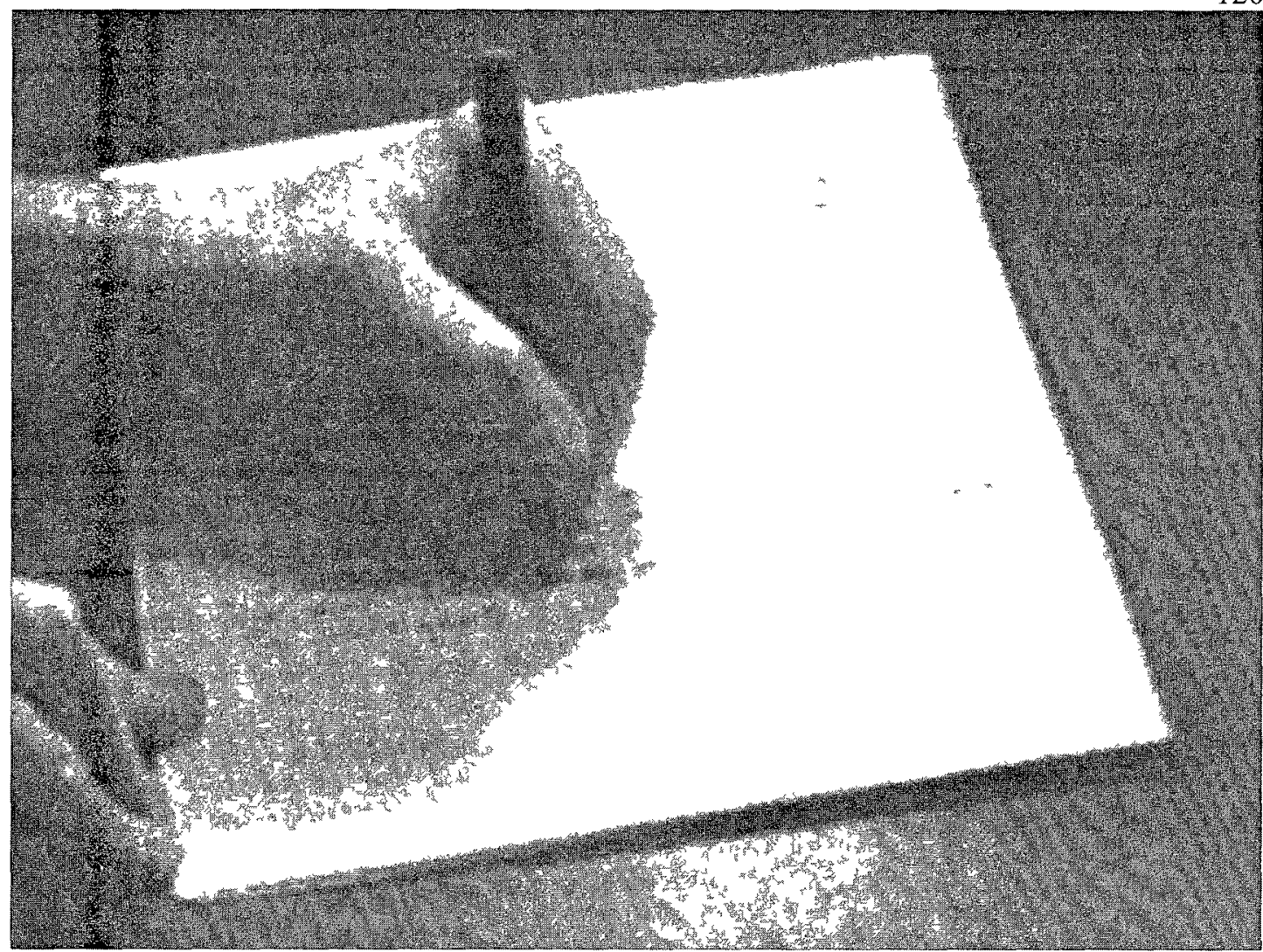

I Will Not Make Any More Boring Art (1971)

Video still

John Baldessari

ot wiel nut emake any mine foing ant. of wier not maxk any mune tosily ant. * wiv not mate any mone toming ant.

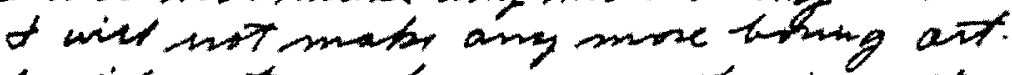
ot wier mot swates any mune bosing ant o will mot male any more trosing ant.

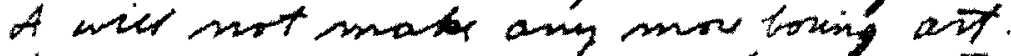

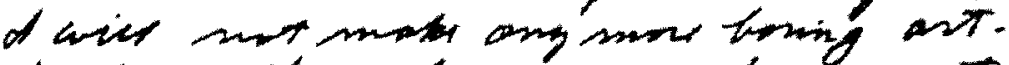

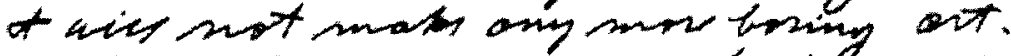

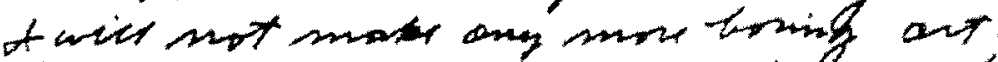
t wier not mate any mantioneg ant A wier mot mabr ong sumer troking ont

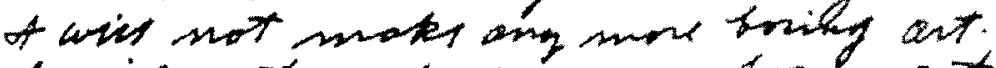
of wis mot mater any mon tormy ast.

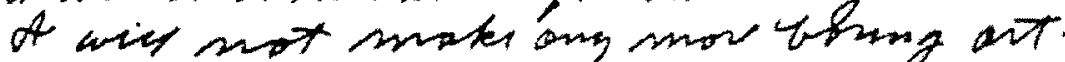

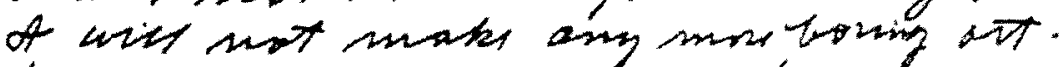

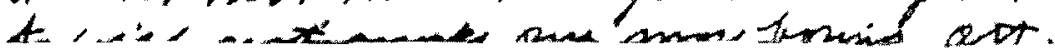


Baldessari's paradox still amusing is the way that it keeps its reflexivity quiet, so to speak.

But as it has become common practice in advertising (and so much contemporary art) "to create an empathetic relationship with the viewer by foregrounding the constructed nature of the text," continually shifting the viewer's attention between the aesthetic act and the place of meta-language, becomes another banal ploy to get us to buy something, be it a product, and image, or an idea of critique. This neutering of reflexivity as a critical tactic is precisely what Mann is referring to as the theory-death of the avant-garde when he points to how contemporary artists who work with boredom can make no such promises not to bore. I don't suggest, however, that these composers allege an ugly feeling that really is interesting, even if only from an ironic point of view, but that the reflexive gestures which conflate the tropes of advertising with aesthetic significance are distracting.

But distracting from what?...

... Ways of mattering.

The vertiginous experience of self-reflexive uncertainty, scepticism and depression that tend to caricaturize the malaise of postmodern anomie, seem in many ways to typify, if not a "real" breakdown (for the "real" has been exposed as just another "metaphor" and thus indistinguishable from a simulated or metaphorical breakdown), then a failure to form affective attachments to the task of sceptical reflection itself. Meditating on how one formulates values and how feeling and imagination play a role in this, philosopher Irving Singer suggests that above "inductive reasoning about the availability of

${ }^{174} \mathrm{Ibld}$ 
satisfaction," which revolves around our self-interested concerns, is an imaginative activity that bestows, or treats the object of our attention "as if some appraisal found it to be excellent, even perfect, though no such appraisal has been made or can occur.",175 What Singer contends is that as it concerns developing various bonds with the world and with others, appraisal, that is, reflection alone, is an insufficient mode of valuation. Ross' study is in a sense a study of the pathology of wholly determining our individual worth by appraising the efficacy of our actions and conduct. Affectivity, argues Singer, is not merely an expressive response to external threats or fortune, but an active agent in the "making of importance." ${ }^{176}$ For something to matter, "a person, thing or ideal must be treated as inherently meaningful, and not just instrumentally valuable."177 Attachment, and thereby value, cannot develop then under the strict regime of sceptical reflection.

Recent expressions of boredom, instead of persuading us that the world is really interesting after all (Cage), or that the expression of boredom as a cultural disposition is "un-boring" (Goldsmith), present its somniferous refrains as a curious form of detachment, of affective failure, that models, or more correctly, simulates a space of contemplation or composure from which the spectator can become sensitive to the minor intensities of everyday life and thereby reinvigorate his or her perception from within the vicissitudes of these (Ross). This is the redemptive ending that Ngai reserves for the ambivalence of the stuplime, an ending whose perplexing dysphoria entails the "slowing down of other emotional reactions" which leaves "a state of undifferentiated alertness or

\footnotetext{
${ }^{175}$ Irving Singer, Feeling and Imagination (Lanham, MD Rowman \& Littlefield, 2001), 14

${ }^{176}$ Ibid , 15

${ }^{177}$ Ibid
} 
responsiveness - a kind of affective static, or noise" in its wake. ${ }^{178}$ Ngai imagines that this "open feeling" makes possible an attention to a "kind of resistance," affective failure that Singer suggests "can result in a heightened and correlative reattachment to the very world from which one felt so painfully separated." 180

Although I appreciate how Ngai and Singer address the problem and stubborn insistence of negative affect, they both fail to see the quandary that besets this project of affective re-attachment. Besides the debatable efficacy of the necromancy that is the actual practice of contemporary avant-garde studies, the state of undifferentiated alertness that stuplime events are meant to model is in this culture already being practiced and performed by that other sly form of stupefying delight-television. More stupefying than three hours of $\mathrm{C}$ major scale derangements is a marathon of the programme C.S.I. (any of them: Vegas, Miami, New York), or better (worse?), one full day watching CNN repeat itself (and the multitudinous adverts by its host of pharmaceutical sponsors). Exceptional as these aesthetic crusades seem, they wage an ambivalent campaign, for the resistance or cool detachment they might conjure is no more or less interesting than the kind that watching Seinfeld stumble over nothing in particular simulates.

Or, as Paul Mann concludes,

No excuse, no justification: all one can put forward is an unendurable habit of attention, a meager fascination, no more or less commanding than that hypnosis one enters in the face of television; a rut that has always led downward and in the end always found itself stuck on the surface; a kind of drivenness, if not a drive. ${ }^{181}$

\footnotetext{
${ }^{178}$ Ngat, Ugly Feelings, 284, 83.

${ }^{179}$ Ibıd., 284.

${ }^{180}$ Singer, Feeling and Imagination, 186.

${ }^{181}$ Mann, Masocritıcism, 128
} 


\section{Two: Formless}

\section{Pretext}

This chapter is about shit. ${ }^{1}$ It's about what shit sounds like and how one listens to it. Of course I'm not talking about actual shit; I'm talking figuratively about syncopated elements, the off-beat of a homogenizing groove that is called "music." In other words, I'm interested in the excretory phase of the process of making "musıc," in "the difference that must be expelled" from this process "in order for the same to be the same" ${ }^{2}$ - for another melody to be a tune like any other tune is a tune. Specifically, this chapter is about how habits of mattention that have developed around the use of ubiquitous media forms (i.e. recordings, internet) have been implicated in recent experimental composition, and in turn, how this music replicates and warps the drifts and digressions that constitute those habits. That is, the essay takes an interest in the perceptual grotesqueries of distractıon, especially those remaindered by a "world whose defining boundaries have been deformed by electric signal."3 Thus, the kind of shit that I consider here is a shit that

\footnotetext{
'Self-indulgent note \#1 Scatology (aka coprology) 1s the study of shit Or more broadly, it's the study of shit that's happened But let's not get too figurative just yet Let's get our hands dirty Let's review the various kınds of shit there are (avoidıng for now that human kınd) For that which comes in bulk we say "dung," while individually it's "droppings" When it belongs to cattle there's "tath," cows it's "bodewash," and of course (though this is flirting with the figurative) there's the ubiquitous "bull shit " Deer get a more refined term - "fewmets"-but it's nothing like the "frass" of insects, or even better, an otter's "spraint" Undomesticated carnivores leave "scat," stony seashores gather the "guano" of seabirds, while foxes eject "billttting," hawks launch "mutes," and dogs, well they just "scumber" (It's worth mentioning here that playing with shit is the exclusive right of neither science nor lunacy but belongs, in addition to the realm of pure curiosity, to spatlomancy, a practice concerned less with things such as diet and behaviour than with divination ) For the names and other honorifics given to human shit and shitting I refer you to the exhaustıve (and alphabetızed) list provided at www poopnames com

${ }^{2}$ Andrew Wernick, "Batalle's Columbine The Sacred Space of Hate," ctheorv, 1999, Www ctheory net/artıcles aspx? $1 \mathrm{~d}=119$

${ }^{3}$ David Foster Wallace, A Supposedly Fun Thing I'll Never Do Again Essays and Arguments (Boston Little, Brown and Co, 1997), 51
} 
musical aesthetics took when recording technology became the veritable sewage system of sound.

As early as 1938, Theodor Adorno observed that the mechanical reproduction of music, via radio and phonograph, had fundamentally altered listening conditions by dissolving the intersubjective and absorptive space that allows the listener to focus on the structural relations exhibited by a work of music. In other words, the recording disarticulates the sticky matter, such as duration and concern, ${ }^{4}$ from its listening experience. Like water, whose vital intensity is obscured by an elaborate subterranean system of distribution and drainage that makes it effortless to access, the contemporary ubiquity of musical sound affects the way music affects; if you barely notice musical sounds it's because you don't need to. Audio technology is thus a kind of sewerage of the ears: A system of wires, speakers, volume knobs, and playback devices are so many pipes, tanks, and valves. Turn this switch, insert that plug, and a supply of sonorities circuit through social and economic conduits to pump refreshing vibrations through the cochlear labyrinth of our ears to our nervous system where they are "heard but not listened to." ${ }^{, 5}$ Like the toilet does to water, our listening has gone underground; musical ablutions that wash away the gooey residue of last night's mood and the film of everyday stress are performed unconsciously and without (intentionally) contemplating their sonic effluvium. As I will elaborate below, taking mechanically accomplished power over the emanation of musical sounds and making these managed expressions ubiquitous influences the way music is heard (or not) by converting a respect once paid to the restive

\footnotetext{
${ }^{4}$ See Adorno, "On the Fetısh-Character in Music" (1938) and "The Radio Symphony" (1941), both in Essays on Music, ed Richard Leppert, trans Susan H Gıllespıe (Berkeley Unıversity of Calıformı Press, 2002).

5 This was Muzak's semi-official slogan for many years
} 
effects of listening to music, particularly in the way Adorno recommends listening to "form," into a contempt or disgust. In this conversion, where process becomes product, as it does in a work like Alvin Lucier's I am Sitting in a Room (1969), where the accretion of a recorded text spoken by the composer transforms into an undulating mass of harmonic swells that express the acoustic resonance of the recording space, even the most recalcitrant music fails to express its "cultural negativity," a negativity that while expelled like shit acts more like the sacred.

But as I wrote above, this chapter is about shit, and so considers how, in becoming ubiquitous and generally "disposable" (a condition encouraged largely by the mediations introduced by audio technology and an industry built around it), listening to music has become a disjointed and trivial affair. Specifically, I look at how certain contemporary experimental compositions respond to and exploit the strange effects of distraction that promotes the simultaneous escape and capture of attention in order to carry out their own sort of "conversion," one that draws expressive potential from the way in which musical sounds have become increasingly something to be "unfocused on," and, as a result, perceptually indistinct phenomena. To this end, I consider how certain kinds of cultural shit--shit like Muzak, the public shame of good taste--fertilize the wider field of listening with a farrago of attentional spores that sprout gnarled shoots of interest that grow into new aesthetic sensibilities. Focusing on the unfocused, the picayune, and the dreamy qualities of listening as it takes place through distraction, I draw observations about and speculate on the way the formless appearance, that is, the

\footnotetext{
6 "A sense of form means listening for the music and following it to where it wants to go, stayıng as far away from an imposed will, an imposed architecture, as an ahen necessity in which for the most part an arbitrary subjectıvity that has gone blınd has become entrenched "Theodor Adorno, "Form in the New Music," Music Analysis 27, no 2-3 (2008) 215
} 
amorphousness of particular experimental compositions, reflect and at the same time deform the depreciative and soporific effects generated by our culture's habit of putting listening aside. I'm suggesting then music that is "heard but not listened to"-a lovely catchphrase that with the right inflexion or sense of innuendo can evoke the cosseting qualities of luxury toilet paper--characterizes the aural and sensory shit-field ${ }^{7}$ in which contemporary notions of composition are left to go wild.

This talk about shit and sewerage, in addition to being generally provocative, is mobilized in order to focus my methodological lens, which despite the overtones, is not strictly scatological. "Shit" is evoked here largely to draw attention to the way music sluices certain expressions from its concept, whether this concept derives from specific theoretical assumptions, traditions, or is invented to "express states of affairs in terms of the contingent circumstances and dynamics that lead to and follow from them."8 Something is always ejected in order to homogenize, or at least to harmonize wayward sonic events with its standard expression, even if that means simply prohibiting or debasing those fugitive sounds. However, and this is what my study aims at, in order for a (musical) concept to consolidate its expressions, which its users (us) are compelled to do in order to validate its particular efficacy, it has to extend itself. But in doing so the concept encroaches upon the same "non-things," or the renegade expressions that it precludes in order to constitute itself. In the same way that the concept of hygiene has to cope with the variations of filth and varieties of shit that it creates, the concept of what is Musical has to deal with the noise, the "not musical" that it remainders. This constant

\footnotetext{
7 "Shit-field" a colloquialısm for a grassy field in which munıcipal wastewater is irrigated

${ }^{8}$ Cliff Stagoll, "Concepts," in The Deleuze Dictionary, ed Adrian Parr (Edinburgh Edınburgh University Press, 2005), 50
} 
process of excretion, which never finally ejects or sublimates its inassimilable element but circuits it through a proliferating (as opposed to progressive) series of successes and failures, seems to address what I hear happening in the way composers like Martin Arnold, Warren Burt and Christian Wolff are able to keep certain of Western music's normative niceties-melody, harmonic variation, rhythm, etcetera--in play, while at the same time letting its proscriptions flourish behind its back. Harmlessly schizophrenic and generally addled in character, this ambidextrous music is, I suggest, symptomatic of the way contemporary culture's condition of distraction imposes its addiction to "the now" (which is actually an addiction to "the next" that signifies the now (again)) upon a tradition of effortful control that in turn develops expressive tactics for coping with an economy of intermittent attention. So in addition to the familiar strategy of defamiliarization that converts recognizably functional musical elements into deviant figures, a larger condition of distraction is at work in dividing attention between composition's practice(s) of reflection and its habit of indulging in the sensory gratification of aural hallucinations that flicker and sweep over/alongside/about/around musical form.

To speak to the ambivalence of this divided aesthetic and to frame it within the context of failure's contortions, I've conscripted the commeasurably shifty notion of informe, or "formless," as imagined by the French writer Georges Bataille. As I'll explain, the idea of informe pivots on its own kind of conceptual ambivalence, one that matches the dithering of a music that tells us to take it as "art" music, yet, in its appearance, invites the kind of listening that tends to be brought to background music, or to music as it's heard (but not listened to in the structural sense) in everyday life. Informe, 
like the equivocal summons of this formless music, is self-defeatıng but strangely expressive of its own confoundedness. In effect, I'm poaching the conceptual valence of Bataille's informe in a way described by Brian Massumi, who writes, "A concept is by nature connectible to other concepts," and so "1s defined less by its semantic content than by the regularities of connection that have been established between it and other concepts." For Massumi, a concept is an expression of "the rhythm of arrival and departure in the flow of thought and language. ${ }^{\prime 10}$ In this case, the obscenity of informe that Batalle draws out in writings like Historre de l'oeil (1928) or the more abject The Solar Anus (1927), circuit into musical concepts such as "virtuosity" and "structure" a sense of offense that, rather than negating them, warps or "perverts" their network of relations with other concepts like "competence" and "interpretation," "form" and "artistry." More thematıcally then, the relay that I stage between the concepts of informe and distraction is one that expresses the non-confrontational creative offense that can be heard in pieces like Australian composer Warren Burt's Another Noisy Lullaby (2009) and Canadian composer Martin Arnold's Burrow Out; Burrow In; Burrow Music (1995), where attention, rather than compelled to gather its wanders around an omphaloskepsic negativity, is pulled in many directions at once by the formless charm of a multicephalous interest. ${ }^{11}$

\footnotetext{
${ }^{9}$ Brian Massumi, Parables for the Virtual Movement, Affect, Sensation (Durham, NC Duke University Press, 2002), 20

${ }^{10}$ Ibid

"It's important to note, however, that concepts, as concelved by Massumi-Deleuze-Guattarı, are defined by "the conjugations and connections that constitute its consistency" Gilles Deleuze and Felix Guattari, What Is Phllosophy?, trans Hugh Tomlınson and Graham Burchell (New York Columbra University Press, 1994), 90

As such, concepts, while internally consistent in their rules of "conjugation and connection," are mutually transforming and inventive in that the "bridges thrown from one concept to another" change the nature of other connections to create new concepts Thus, in connecting inform and distraction, another concept emerges that expresses a new composition whose components are inflexions of its progenitors (1bid)
} 
(Informe)

Before explaining how this chapter is land out and how I think it works, I want to spend a

few moments on the intellectual history of informe in order to tease out some of the

relevant details that inform my thinking on both the concept and my own writing

practice. Bataille introduced informe when he was editing the French journal Documents,

a kınd of alter-Surrealist periodical featuring a motley collection of essays on art and

ethnography, as well as critical essays by folk such as Michel Leiris, André Masson, Carl

Einstein, and himself, of course. In a number of issues there was a section titled "Critıcal

Dictionary." This part of the journal essentially comprised a series of short articles that

were less definitions than quasi-literary interventions into the received ideas of things.

Specifically, these entries were designed to disrupt the more conventional essays in the

journal, but their blend of critique and creative irreverence, as well as their prescient

interdisciplinary pseudo-methodology, has given them an intellectual purchase that

extends well beyond the journal's original time of publication. The kind of works

included in the "dictionary" were those that promoted Bataille's notion of "heterology"12

\footnotetext{
${ }^{12}$ Batalle describes his notion of "heterology" as the study of what any homogenizing system of knowledge "excretes." The latter is defined by Batalle as an instrument of approprration in that it works to make the sundry profiles of experience practicable that consequently renders human (and inhuman) being a servile species "fit only for the fabrication, rational consumption, and conservation of products" However, because the practicablization of experience automatically limits its process of appropriation it produces "of its own accord its own waste product, thus liberating $i n$ a disordered way the heterogeneous excremental element "Importantly though, heterology is only a pseudo-science, it doesn't describe an organized and formal study of the heterogeneous for that would make it the kind of homogenizing endeavour that it opposes Instead Batalle sees heterology as a process of "conscrously and resolutely drawing attention to what is expelled This, however, can only be a provisional task for its "method" entals a series of transitional moments which pass from noticing a "process of limitation" and then the "violently alternating reactions antagonism (expulsion) and love (reabsorption) obtained by positing [showing] the heterogeneous element "Heterology is therefore never concerned with the "objectivity of heterogeneous elements," for by definition their occasion is utterly conditional The objectivity of the heterogeneous is an abstraction derived from the same processes of limitation that makes the homogeneous an abstraction Interestingly then, "only the subjective heterogeneity of particular elements is, in practice concrete "Georges Batalle, Visions of Excess, ed Allan Stoekl, trans Allan Stoekl (Minneapolis University of Minnesota Press, 1985), 97-98
} 
and "base materialism," a non- or anti-philosophy that took the disgusting and repulsive as its subject with aims to disturb the assumed stability of reason's categories. Entries like "Factory Chimney," "Big Toe," and "Spittle" not only work to unsettle the terms of what counts as a proper subject of study, but has the additional effect of exposing the integral role that filth and waste play in the composition of society. For example, contrasting the low and ignoble status of toes to the high and supple grace of fingers, Bataille writes,

...fingers have come to signify useful action and firm character, the toes stupor and base idiocy. The vicissitudes of organs, the profusion of stomachs, larynxes, and brains traversing innumerable animal species and individuals, carries the imagination along in an ebb and flow it does not willingly follow, due to a hatred of the still painfully perceptible frenzy of the bloody palpitations of the body. ${ }^{13}$

While writing like this generates an obvious polemical and critical effect, it is Bataille's entry on "informe" that makes the most radical intervention into modernity's "knowledge project," the enterprise of reason that he contends is what condemns human being to servility. Taking his own project-the "Critical Dictionary"-to task, Bataille writes in the entry on informe that a dictionary should not give meanings but tasks, or what we might call the performative operation of words. As such, he describes the task of informe (formless) as that which "lowers" (déclasser) or invalidates the significance or relevance of the thing(s) it classifies, including (maddeningly) the classification of its own operation-performance. At the heart of informe then is a thoroughgoing intolerance for any systematic elaboration of ideas, including its own.

This is something that Rosalind Krauss and Yves-Alain Bois play with in their 1997 work Formless: A User's Guide, where they attempt, as they put it, to "redeal

\footnotetext{
${ }^{13}$ Ibid., 22.
} 
modernism's cards." 14 By "modernism," Bois and Krauss mean specifically Clement Greenberg's idea of modern art, which categorizes aesthetic modernism primarily in terms of a work's formal character, or more exactly, the way a work makes the display of its medium and the relations between its formal elements, its content. Though there are a host of theoretical problems with Krauss and Bois' project-particularly the charge that their re-dealing merely shuffles or switches the order of the same deck without changing the rules of the game- the way they go about putting informe to work, or rather, letting informe do its work by composing a book that enacts the non-systematic spirit of Bataille's dictionary, is enormously effective for it allows readers to make the same kind of erratic and informal moves between themes that characterize the inarticulate (disjointed) activity of informe. (That Formless: A User's Guide was so upbraided by critics speaks, I think, to the effect that expressions of informe have on thought. For Bataille, both form and formless are impure; each category is always mixed and operating in the other's field in a way that damns the distinctness and clarity of either term ((which means that my project, too, can already glimpse its immanent failure)). As such, the bind embodied by Krauss and Bois' work, whereby everything about mainstream aesthetic modernism they try to undo is haunted by the fact that their book, with its cover and pages-its "form"-performs its own unifying, formalizing effects, is itself an instance of the fundamental instability that Bataille means to expose and operationalize in his own writing.)

Reflecting on Krauss and Bois' approach, one that displays a respectful disrespect for Bataille's own asseverations on the topic, and considering that my own engagement

\footnotetext{
${ }^{14}$ Yve-Alain Bois and Rosalind Krauss, Formless A User's Gutde (Cambridge, MA. MIT Press, 1997), 21
} 
with the notion of formless/ness has been fragmented, frustrated, flitting, in short, distracted, it makes sense, conceptually and practıcally, for me to work in a similar manner While there are of course other studies on Batalle's informe that I could model my own work on, such as art historian Georges Did1-Huberman's 1995 La Ressemblance informe or perhaps more relevantly, Paul Hegarty's recent writıngs on no1se music, ${ }^{15}$ insofar as I am dealıng with a contemporary musical practice whose compositional posture invokes uneasıly the protocols of an avant-garde tradition that seeks to "justify its existence as the search for 1 ts own essence," its attempt to destabilize a dominant understanding of musical modernism that emphasizes formal invention and the kind of attentıve deference this demands But it also takes the insights and fallacies of some one like John Cage for granted While my invocation of informe has more modest aims than redealıng the whole deck of musical modernısm, or of overturnıng "Cageanısm," there is a spirit of experiment in Krauss and Bois' thought that not only resonates with my own prochvities towards theory and writıng, but actually animates my topic in a way that I think is faithful to the tactics of self-distraction employed by the music that I'm considering here And, because I'm examıning how cultures of distraction have come to inform the way music is listened to and the way music makers (specifically experimental composition) responds to this, it seems both productive and ironically fitting to perform this research in a way that puts its own claims under suspicion by trying to be both rigorous and slipshod

What I propose is for the reader to consider this chapter a hyphenation of thoughts

\footnotetext{
${ }^{15}$ See Georges Did1-Huberman, La Ressemblance informe ou le gal savoir visuel selon Georges Batalle (Paris Editions Macula, 1995), and Patrick Crowley and Paul Hegarty, Formless Ways in and out of Form (Bern Peter Lang, 2005) See also Hegarty's website at http //dotdotdot com

${ }^{16}$ Bois and Krauss, Formless A User s Gude, 25
} 
on how informe can be imagined to describe a distracted "form" of attention that develops musically expressive responses to the informational and affective atmospherics that characterize contemporary culture's "electric definition." That distraction is by nature an interruption in a felt continuity, the form|informe of this essay-comprising a series of interrogations on certain themes and practices of listening, scored with footnotes (notes that are in turn notched and scotched with their own set of asides)-reflects this situation. To this end I employ the "switchiness" that describes the mind of a multitasking subject and the bivalence of distraction's logic of escape and capture, not as a gimmick but as a way to simulate the effects that distraction has on listening habits and (to paraphrase what Hegarty wrote about the form of Formless in a review of Krauss and Bois' book) to illustrate informe working itself through the writing. ${ }^{17}$

I recognize that this task risks failing, that it may only succeed at being a series of surface impressions that simply skim the film off the way distraction and informe articulate with the kind of musical poetry that constructs a self-contradictory "background concert" music. Perhaps there's no getting around this. The "hypertext" that a series of episodes and a scatteration of notes become seems inevitably to promote a reading velocity that, while encouraging increasingly supple forms of connection that

\footnotetext{
${ }^{17}$ The subtext (which of course I place here in the footnotes) of this chapter's focus on distraction and its expression in contemporary composition is the relation between form and content, or more accurately, informe and content. In drawing attention to a certain type of inattention, i.e., distraction, I'm not suggesting that the form-content formula is bunk, but rather, I'm suggesting that the proliferation of musical singularities generated by the general condition of distraction, short-circuits the processes that make form "significant "In a sense, the "wholeless," or to use Paul Mann's phrase, the "fractal deformation" that distraction compels, amplifies the valence of musical fragments in a way that paradoxically gives them an abundance of (in)content ${ }^{17 \mathrm{a}, 17 \mathrm{~b}}$ Said another way, content becomes the effects of form's failure to serve as content Said in yet another way, "What the drive to unity anımatıng the process of propagation [distraction] achieves is less oneness than a controlled contagion of divergence "17c

${ }^{17 a}$ This addresses the badly formed concept of "musical abstraction" in which acoustic gestalts--perceptual effects - are conflated geometrical forms

$17 \mathrm{~b}$ its "infinitization" is also its disintegration, its evacuation

${ }^{17 \mathrm{c}}$ Bnan Massumı and Kenneth Dean, First and Last Emperois The Absolute State and the Body of the Despot (Brooklyn, NY Autonomedia, 1992), http//www anu edu au/hrc/first_and_last.
} 
multiply a text's associations, discourages a slower, more reflective engagement with the text. ${ }^{18}$ But, I submit that this is an effect which reflects the habits of inattention that we've contracted in response to the manifold and speedy summons that our mediasaturated environment generates. That is, a reading that "flits" over this chapter in a way that attention loses track of itself and the impression of a whole--a form-suffers the same kind of infinitization or "fractal deformation"19 that I contend affects how music is perceived. Thus, while the epistolary form of the essay creates the kind of effects that I argue make the music that I'm writing about interesting and informe, an effect that Adorno, in his famous essay "On the Fetısh-Character in Music" likens to a children's language "consist[ing] exclusively of fragments and distortions of the artistic language of music," ${ }^{20}$ it also makes this writing informe-fractally deformed. This means that the "dis-integratıon" of my chapter, by encouraging an intermittent reading, is expressing something of the lived economy of informe.

\footnotetext{
${ }^{18}$ Much of the difficulties of reading hypertext, whether it's expressed in HTML or in a more traditional format such as Laurence Sterne's Tristam Shandy, Jorge Luis Borges' Garden of Forking Paths, or Milorad Pavic's Dictionary of the Khazars, is the way that it encourages the reader to move rapidly between items and to forego assessment of relevance and/or gravity of the item For a detatled discussion of the difficulties and challenges of writng for and reading hypertext see Jeffery Conklin, "Hypertext. An Introduction and Survey," IEEE Computer 20 (1987) The online work The Electronic Labyrinth, which scrutinizes and evaluates the potential of hypertext in the context of non-linear literary tradition, is perhaps the best resource for understanding the possibilities and effects, good and bad, of this electronic text Christopher Keep, Tim McLaughlın, and Robın Parmar, "The Electronic Labyrınth," 2001, http //www2 ath virgınıa edu/elab/ For an extremely sophisticated renderıng of hypertext's potentıal for creating new writing and rhetoric see Gregory Ulmer, Heuretics The Logic of Invention (Baltimore, London The Johns Hopkıns University Press, 1994)

Note These works may seem rather dated, but this is telling of the way our sense of time and progress has been compressed so much by developments in intellectual technologies to the effect that ten years seems like a life tıme

${ }^{19}$ Paul Mann, Masocriticlsm (Albany State Unıversity of New York Press, 1999), 154

${ }^{20}$ Theodor Adorno, "On the Fetısh-Character in Music," in Essays on Music, ed Richard Leppert (Berkeley University of Calıforna Press, 2002), 307
} 
How to read this chapter.

Like Formless: A User's Guide this chapter is sectioned into a number of broad themes around which a musical notion of informe articulates with distraction. Unlike Formless, however, I don't perceive these sections as "key processes of informe/formless",21 but instead describe them as quasi-concepts which, following Deleuze and Guattari's view that concepts are inventions that draw forth an aspect of reality without these expressions being grounded in sense perception, articulate the effective relationships between variables that compose the circumstance of distracted listening and formless music. Thus my section headings are something like "probe-headings" in that they locate an escape from within the seductions of the "face," the white wall/blackhole of the text on/in which a reassuring meaning is inscribed/sunk. ${ }^{22}$ Here I suggest that while the organization is somewhat arbitrary, it's also necessary, but necessary only in the way that it reflects the kind of fragmented and ambient awareness that constitutes not only one's sense of distraction but the way that one listens to or away from music. As such, I recommend that you read through this chapter according to your own capacities, ${ }^{23}$ but ask that you be aware (as I am) of at least this:

The problem for all who seek to show, bring or let be the formless, is transposition. For something to stay outside the world of form requires that an object remain a process, disabling the imposition of form at all stages. Arguably

\footnotetext{
${ }^{21}$ Paul Hegarty, "Formal Insistence," The Semiotic Review of Books 13, no 2 (2003) 7

22 "Facıality" is Deleuze (and Guattari)'s concept for the way subjectivation and significance are composed by mechanisms which govern the way a subject sinks his/her affective energies into a space where signs are inscribed and reflected. "Probe-heads," on the other hand, is a term Deleuze uses to characterize the way Francis Bacon's melting faces (e g, his "Screamıng Popes") convey a disruption from within of the processes of facility, a disruption that leads out of the humanly organized face towards the animal and inhuman. On "Facialıty" see, Gilles Deleuze and Felıx Guattan, A Thousand Plateaus Capitalsm and Schizophrenia, trans Brian Massumı (Minneapolis Unıversity of Minnesota Press, 1987), 167-91, on "Probe-heads" see Gilles Deleuze, Francis Bacon The Logic of Sensatıon, trans Danıel W Smıth (London Contmuum, 2003)

23 which will always be modulated by the way past and future circumstances impinge on your present moment of reading
} 
this is impossible, and that is its interest: the attempt can only ever fail, and this failing is formless/informe (the same could be said of attempts to theorise or demonstrate the formless). ${ }^{24}$

\section{Story}

My wife was leaving for Seville early one morning. We were having coffee before she passed through security. I don't recall the details of our conversation, but I believe it revolved around the art exhibition she was going to see and the recent protests that had been staged against its inadequate but nevertheless self-congratulatory gesture of aesthetic transnationalism. I have a few photographs of that morning that I took with my cellphone: The two of us, bleary eyed, sitting at a table, paper coffee cups in hands hovering over emptied sugar packets. What's left out of these images (among other things) are the sounds from a speaker overhead, just below the volume of our conversation yet mingling nicely with the hissing espresso machine, the tolling cash register, and the pervasive airport murmur. Yet strangely, in being left out of the frame, these supernal sounds have virtually the same presence, or non-presence, as they did when I was drinking my coffee. That is, they hardly exist.

At some point during our conversation, I stopped hearing my wife and found myself drawn to the incessant pulsing of a saxophone and snare-drum duo playing a steady stream of staccato saxophone would accent a pulse or change pitch and thereby form an erratic series of irregular groupings. But, I couldn't quite hear everything that was going on. My attention was distributed among this beating, my wife's voice, the espresso machine, and other

\footnotetext{
${ }^{24}$ Hegarty, "Formal Insistence," 7.
} 
people's endless nattering. At 7 in the morning, unshowered and with a thin film of sleep clinging to me, I was dimly perceiving what I never expected to hear in a noisy airport coffee shop; yet there it was — kind of - dividing my attention — or maybe gathering it: some kind of experimental music. Bemused, I interrupted my wife. "Do you hear that?" I asked. "Who'd put music like this on in a coffee shop?" "Arg," she responded, "I wish they'd turn it off." "What? Why?" I balked. "It's great! When do you ever hear music in like that in a place like this?" To which she replied, "What are you talking about? That's not experimental music, the CD's just skipping; it's been going on like that since we got here."

For a moment I thought she had no idea what she was talking about, and I continued to hear this unforeseen minimalism for about another five seconds. But then, summoned from its wanders with susurrant coffee makers, the mild burn on my tongue of too-hot coffee, and the scatter of echoic boarding announcements, my full attention was given to the sounds coming through the speakers above me and I began to compose a new perception that was, indeed, the digital stutter of a CD passing glacially through a glitch on its surface. At this instant, a threshold was crossed and the illusion dispelled. I was no longer listening to the industral resolve of American minimalism but the cloying sweet talk of Dave Koz, or something equally vapid.

The shock of this two-fold astonishment still sticks with me. First, hearing "experimental music" anywhere besides a concert hall, where its insult to taste can be easily corralled and halter-broken, was in itself thrilling. ${ }^{25}$ But even more mind-bendingly

\footnotetext{
${ }^{25}$ It should be sard, however, that the offense, or criticality, of experimental music is itself a bit of a concelt The concert hall, or art gallery, or small "underground" club are so far under the radar of larger cultural trends that their expressions of the "cuttıng edge" are less than irrelevant In other words, the
} 
delightful was realizing that my perception was so wrong, so mistaken and wholly persuasive that I'm compelled to treat it as nothing less than pure sorcery. Call it an illusion if you will, but understand that I WAS CONVINCED. Skipping CD or not, my experience of a saxophone and drum duet was a sonic reality. That the sounds turned out to be the result of a malfunctioning CD doesn't negate this "reality" so much as it says something about the formless and plastic nature of perception.

This vignette is meant to draw attention not so much to the way that listening can be "fooled" or in error, but that listening, like other sensations, has "reality-effects" insofar as what emerges from the mingling of vibrating matter organizes actions and behaviours around it. In this case, while the skipping $\mathrm{CD}$ was not actually a recording of an experimental saxophone and drum duet, the perception not of its malfunction but of its dysfunction-its functioning otherwise than intended — organized my sensibility in a way that seems almost magical or mesmeric. Clearly, the partial obscurity of the sounds and my diffused attention contributed to this mis|perception. However, the effect that these conditions had on the way I mis|took the sounds was not incidental, but absolutely integral to its effect. Though my perception was ultimately corrected, "normalized," in relation to the din of so-called extra-musical sounds and non-sounds, this mis-take illustrates the weirdly creative effects that distraction has on perception. That distraction could be at all inspired may be contentious, but to the extent that its chronic expression can be thought to "harmonize" the scattered perceptions in a way that a skipping CD becomes an experimental composition, there is something unpredictably inventive and even charming.

concert hall is itself a pretense that conjures its own illusion of an offense, one that hardly registers even among its own under-class. 
A similar observation is made by Theodor Adorno in an essay about how cafés function as environmental transducers by which music becomes "wholly appearance." Though referring specifically to salon orchestras and not "piped" music, he argues that café arrangements of (formerly) celebrated works tend to dissolve the structural autonomy that allowed the original version of the music to express its nature as "art." However, rather than completely liquefy the work, Adorno writes that the "splendidly shabby" sounds acquire "a second, strangely transparent form," a "netherworldly glow" that doesn't go unnoticed so much as act like "an acoustic light source." 26 Though he lays too much stress on the formal alterations exacted by café arrangements, that Adorno recognizes something "splendid" or "shiny" in the appearance of this backgrounded music points to the way the field of distraction, constituted by the multifaceted demands of café milleu, modulates a "passionate appearance into the cold comfort of reality.",27 Notwithstanding the backhanded compliment he pays to composers like Greig and Puccini, whose "true mastery" is revealed when their music finds itself perfectly suited to café listening, or the claim that a café arrangement falsifies a musical work, Adorno sees that without an insulating stillness surrounding them, musical sounds become a "thing" among others objects: the too-hot coffee, the short bursts of laughter, a waiter's bad faith.

But maybe we should call these things "quasi-things," for in their mutual commotion none of these activities fully stands out as a complete object, its form wholly open to scrutiny. ${ }^{28}$ Instead they withhold the full range of their expressive profiles,

\footnotetext{
${ }^{26}$ Theodor Adorno, "Music in the Background," in Essays on Muslc, ed Richard Leppert (Berkeley University of California Press, 2002), 508-09

${ }^{27}$ Ibid, 509

${ }^{28}$ I'm drawing on Graham Harman's work here, but substitutıng the term "thing" for his more specific notıon of "object," because I think it effectively captures more of the relational-functional way in which our perception is composed of how one makes limited use of matter and circumstances Basically, this is an
} 
insinuating only certain aspects of the force that animates their qualities. In fact, this is how most "things" appear to "ordinary" plurivalent awareness that constitutes our everyday scatted mind. But despite the fact that these things withhold dimensions of themselves from us, they continue to solicit our attention, asking us to participate, more or less insistently, in the regional ontology of their apparitıon. A rhapsodic violin melody or a jangling teaspoon are, especially where their profiles are distributed among several sensuous objects that compete for our attention, grasped not by the matter of their form or structure, but by the style of their occasion, by the way their expressive signs entice or command us to explore their animating principle that, as the metaphysıcian Graham Harman writes, "is never visibly present, but enters the world like a concealed emperor and dominates certain regions of our perception." 29 And as both my own and Adorno's example suggest, in the case of background music this principle is not negated so much as it is scrambled and distributed - obscured. Or as Harman puts it:

Any noise exceeding the object of our attention is structured to as great a degree as the object itself. It is not a white noise of screeching chaotic qualities demanding to be shaped by the human mind, but rather, a black noise of muffled objects hovering at the fringes of our attention. ${ }^{30}$

Idle chatter, stirring spoons, car horns and air conditioners are things with unifynng styles of being and a need to be loved as much as John Adman's Violin Concerto is, or aspires to be. Distraction, however, interferes with the unity of a thing's style and distributes its animating force throughout the field of sensible qualities that it shares with other objects.

extension of the traditional phenomenological notion of an intentional object with the added four-fold twist that these objects are not merely ideal principles of unity among a host of intentional acts, but real things whose unity is fissured by two strains of tensions in which an object is divided from the plurality of notes that express 1t, as well as by the relations that compose it See Graham Harman, Guerrilla Metaphysics Phenomenology and the Carpentry of Things (Chicago Open Court, 2005)

${ }^{29}$ Ibid, 55

${ }^{30}$ Ibıd, 183 
Thus, while the structuring style of a backgrounded music remains whether or not it's being listened to, it participates in the "flesh" of the world, ${ }^{31}$ through the expressive correspondences that resound between its sensuous qualities and the other sensuous elements that are not strictly musical.

As Adorno's weird tribute to backgrounded music insinuates, this regard, or rather this "dis-regard," suggests how the circumstances of listening to the side of music brings certain of its qualities to play on a wholly different level than if they were the sole object of attention. By withdrawing from the level of engagement defined as "foreground," one enters a sensory register whose style, or manner of drawing attention, hinges on the way sounds interact with other not necessarily musical qualities. Music's proper "object"-its unity and coherence_-is absent at this distracted level; however, all of its sensual qualities are nevertheless aglow here. ${ }^{32}$ Indeed, this is the source of Adorno's fascination with café music: the background is a medium or obscure substance that interferes with what he sees as the customary relationship that obtains between a musical thing and its qualities. For Adorno, this relationship concerns the way a work's structural logic is its own aesthetic object to the extent that it expresses something of the historical relation it bears to past customary relationships. Here, a work's sensuous qualities are said to fuse with its formal objectivity. Thus, when the unity between a work's unifying style and its multitude of qualities is severed or interrupted, as they are when listening is diverted from the cues that are meant to capture attention in this way,

\footnotetext{
${ }^{31}$ I'm alluding here to Merleau-Ponty's idea of "flesh" as the point of contact between our body and the world across which the current of our person flows As said another way, the flesh designates a metaphysical surface that divides the spontaneous activity of being into its objective and subjective correlates See Maurice Merleau-Ponty, The Visible and the Invisible, trans. Alfonso Lingis (Evanston, IL Northwestern University Press, 1968).

${ }^{32}$ See Harman, Guernlla Metaphysics, 55-70
} 
musical sounds become free-floating lures that attract and bind with other qualities to form new and unintended perceptions.

This idea of musical sound as a "lure" has some resonance with Cage's notion of letting sounds be themselves, but is more familiar in the everyday way that attention draws somatic and psychic energies into carnal relations with a "shower of [musical] qualities freed from the elusive substances to which they presumably belong." ${ }^{33} \mathrm{I} \mathrm{m}$ referring here to the way a body find itself involuntarily tapping its toes or bobbing its head to a sound that it didn't know it was hearing, the body interacting with the qualities of rhythm, tone, and timbre apart from their relationship to any (formal) whole that exceeds their sensuous gratification. But this can also be expressed inversely, as for instance, when one scans the radio dial. In this case one isn't listening for the way a sound points to a moment beyond itself but for a fleeting sensory note loosed from its formal obligations so that it can commingle with the proprioceptive and kinetic tones of driving. For ears trained to listen disinterestedly and to value the way sounds relay attractions and repulsions between one another, the carnal satisfaction of sound seems to caricaturize the sincerity of the musical object. And I would agree; however, I would contend that this "caricaturization" is an expression of allure, of how one is lured into the style of a thing by an irrational slackness that arises between this weird object-which for this study is a "composition"--and its familiar qualities. For Harman, allure is an effect of the way the sincerity of a thing is skewed by its encounter with other things. And phenomena such as humour and charm are expressive profiles of allure that attune the observer "to the inner ingenuousness of things," somehow managing "to put the very

\footnotetext{
${ }^{33}$ Ibid., 66.
} 
sincerity of a thing at issue." "At issue in "art" music's prolapse, its falling out of place as "art" and into the sensuous commotion of the background, is the way that distraction interferes with its sincerity, a sincerity that in the shibboleth of Western art music is construed in terms of its historically evolved "form" or structure.

In short, I am saying that distraction does something to musical sounds. And what it does, I suggest, is to make them formless. But by this I don't mean that musical sounds become shapeless per se, so much as distraction interferes with the formal structure of music in a way that makes "form" irrelevant to perception. To make music's formal elements irrelevant is to tamper with its supposed sincerity, and this, paradoxically, is to give the music thing a charm. Specifically, distraction, which means simply to draw or drag something away from one thing to another, attenuates the capacity for one musical event (a tone, a chord, phrase, or a whole section) to point to and make us expect another musical event, what theorist Leonard Meyer calls their "embodied meaning."35 "Form," like all expressions of a thing's sincerity, has to do with the way something is "wrapped up right now in certain particular actions and no others. "36 Typically, form, musical or otherwise, is treated in perception studies as an emergent attribute, a "whole" of acoustic parts and dynamic patterns. But on a more philosophical level, a musical "thing" might be thought of as a measure of the degree to which its mannered and habitual routines of being remain concealed or unconscious, to it and to others. For someone like Adorno, this metaphysical principle of sincerity would be tied up with the complications of modern alienation that confound the capacity for a thing to simply be just what it is, a

\footnotetext{
${ }^{34} \mathrm{Ibld}, 141$

${ }^{35}$ See Leonard B Meyer, Emotion and Meaning in Music (Chicago University of Chicago Press, 1956)

${ }^{36}$ Harman, Guerrilla Metaphysıcs, 135
} 
complication that is especially gnarly for modern art, which, as Adorno puts it, is defined by its congress of contradictions ${ }^{37}$ As such, modern art's sincerity-which on Adorno's terms would refer to its sincere self-inconsistency (which at another level is selfconsistent) - can only be conveyed ironically, cynically, or in some other reflexive manner that can't but hurl the thing and its qualıties into a spiral of cascading negations However, in a sense, this $i s$ the sincerity of a modern, alienated art whose destiny to be just what it is is to be sincerely insincere What gives access to this ironic mode of sincerity is an awkward style that articulates the effects of art's affected occasion, a style that shows itself as a formal rather than casual ("natural") occasıon Under this scheme, it becomes the task of the discourse to discern the elements and relations that delineate art's existence as a fabricated form Adorno's notion of "structural listening" then would be reputed to access the (insincere) sincerity of a musical artwork by treating only those aspects of its appearing that attest to its alienated condition as relevant

Though relevant chiefly to a certain class of nineteenth-century music practices, "structural listenıng" has nevertheless become a normatıve model not only for academic disciplines and institutions of appreciation, but for a general population inculcated with the notion that "an art object alone determınes the qualities of aesthetic experience "38 Rose Rosengard Subotnick advances an argument that this sensibility is an extension of late nineteenth-century European aestheticism that regards music as an autonomous object, an object whose value lay within the active reception-1nterpretation of immanent

\footnotetext{
${ }^{37}$ See Adorno, "On the Fetish Character in Music"

${ }^{38}$ Ronald Michael Radano, "Interpreting Muzak Speculations on Musical Experience in Everyday Life," Amerlcan Musıc 7, no 4 (1989) 449
} 
relations that are supposed to express something beyond their immediate moment. ${ }^{39}$ She argues that the adequacy and the rectitude for structural listening is grounded in the Enlightenment ideal of "a supposedly universal rational capacity" to a (cognitive) level where only those elements which disclose the internal necessity of the thing's structure are relevant. ${ }^{41}$ In this view, which requires a concerted and sustained attention that presumes the existence of a contınuous and rational awareness, structural listening remainders a host of fugitive auditory phenomena that interfere with the formal access to a work's supposed sincerity by siphonıng off some of the attention demanded for its satisfaction. But we only have to recall Adorno's fascination with the "shabbiness" of café music, and my own enchanting encounter with a dysfunctional $\mathrm{CD}$, to note that listening is rarely drawn in structural terms and that contemporary conditions have made listening radically partial and precarıously coherent. As such "the landscape of sincerity has changed." 42 The musical "object" has been liquefied and its swarm of sensual notes flung into "the drunken alchemy" ${ }^{43}$ of contemporary attention-or lack thereof.

Now, there are a number of ways to address how the deliquescence of musical form in contemporary listening, brings to awareness features that while insincere in the

\footnotetext{
${ }^{39}$ The philosopher Lydia Goehr has also contributed to this discourse in her study on the ontology of music In The Imaginary Museum of Musical Works (1992), Goehr charts the development of a specifically post-1800 European sensibility that emerged during music's classical period to crystallize around what she calls the "work-concept," a concept that borrows its ontological scope from the plastic arts which emphasized the product and object-onented end of a practice over its processual and performative dimensions See Lydia Goehr, The Imaginary Museum of Musical Works An Essay in the Philosophy of Music (Oxford, New York Clarendon Press, Oxford Unıversity Press, 1992)

${ }^{40}$ Rose Rosengard Subotnık, "On Deconstructing Structural Listening," in Music, Culture, and Society A Reader, ed Derek B Scott (Oxford, New York Oxford Unıversity Press, 2000), 170

4) Adorno's most sustained exposition of structural listening is found in the essay "Types of Musical Conduct " Here Adorno outhnes eight different types of listener the expert listener, the good listener, the culture consumer, the emotional listener, the resentment listener, the jazz expert, the entertainment listener and the indifferent or anti-musical listener See Theodor Adorno, Introduction to the Sociology of Music, trans E B Ashton (New York Seabury Press, 1976)

${ }^{42}$ Harman, Guestrlla Metaphysics, 178

${ }^{43}$ Ibid , 170
} 
formalist sense are nevertheless argents in their own right. Anahid Kassabian has approached the intermittent listening cultivated by a technologically produced musical omnipresence through the notion of ubiquitous listening, whereby audition's being "always on" composes us as ambient subjects, nodes of transfer in the din of perpetual information exchange. More recently, Suzanne G. Cusick has written about the US military's use of music as a torture device wherein the emphasis on the materiality of sound-i.e. volume, timbral quality, and its affective grasp—renders the role of music's form utterly irrelevant. Steve Goodman has extended this premise to show how sound, including music's intimacy with noise, participates in the general field of warfare and the wider ecology of dread. ${ }^{44}$ But I'm more interested in the way contemporary (un)listening practices have been smuggled into the concert hall by certain experimental musics that demand the attention typical of the concert ritual, but proliferate glitches in this attention by inviting distraction into its to encourage what Rei Terada calls "phenomenophilia"--a love for "particularly ephemeral perceptual experiences." 45 This attraction to "irregular, unstable, and very transient phenomena [over] the possible objects of aesthetic reflective judgments, ${ }^{, 46}$ I examine more closely later on in this essay. But for now I simply want to suggest that phenomenophilia is a way to performatively scrutinize the rickety intimacy between attention and distraction, as well as articulate something of the latter's overlooked charm.

\footnotetext{
${ }^{44}$ See Anahid Kassabian, "Ubiquitous Listenıng and Networked Subjectivity," Echo 3, no 2 (2001), http //www echo ucla edu/volume3-ıssue2/kassabıan/ındex.html; Suzanne G Cusick, "Music as Torture/Music as Weapon," Transcultural Music Review 10 (2006); Steve Goodman, Sonic Warfare Sound, Affect, and the Ecology of Fear (Cambridge, MA The MIT Press, 2010)

${ }^{45}$ Reı Terada, Looking Away Phenomenality and Dissatisfaction, Kant to Adorno (Cambridge, MA Harvard University Press, 2009), 3

${ }^{46}$ Ibld , 23
} 
How distraction can be charming and how certain experimental musics reflect this in a way that articulates with contemporary cultures of distraction are matters that I now want to turn to by looking first at what it might mean for music to be formless as a consequence of how we've come to listen inattentively-i.e., distractedly-and then consider the ways in which this makes the complementary sense of musical autonomy shared by concert and background music a hinge on which the familiar elements of "melody," "harmony," and "mood" pivot to become heard as radical agents with regard to the way they put the sincerity of the music they evoke at issue.

\section{Becoming Formless}

So, let's agree right now that there's no such thing as "formless music" per se, or for that matter, a formless "thing" as such. In the broadest sense, even the most amorphous "thing" has a minimum of form insofar as it expresses a limit-i.e., as it appears as "thing." A colour, for example, is bound to the contours of the surface it stains and the ambient light that modulates its hue. Even something as intangible as a mood has form in that it expresses a particular composition of the localized effects of being situated-in history, a culture, a crowd, etc. Practically speaking, formlessness in musical terms refers to a conspicuous lack or absence of the structural and/or semiotic cues given by the familiar elements of metre, cadence, harmony, theme/variation, melody, etc. Typically, "music" 47 that is deficient in these cues is perceived somehow as failing to be musical, to be either aesthetically significant, ${ }^{48}$ or, except to the extent that it annoys, affectively

\footnotetext{
47 here of course is where classification begins to come apart, for how can we still call somethıng music if by definition it lacks those salient attributes that distınguish music from sound, from noise?

${ }^{48}$ They don't possess what aesthetıcian Clıve Bell calls "sıgnificant form" See Clive Bell, Art (London Chatto and Windus, 1949)
} 
moving. Generally speaking then, "formless" is not a good thing for music to be- to "unbe."

But of course, within the so-called "vanguard" or "experimental," or even socalled "outsider" music communities, formless has had a less derogatory currency, functioning almost like a genre characteristic, a quality, or, paradoxically, a form--an "un-form." For instance, reflecting on his first encounter with La Monte Young's music, Tony Conrad describes Young's work as “formless, expostulatory, meandering; vaguely modal, a-rhythmic, and very unusual; I found it exquisite."49 John Cage's works, too, are obviously contemporary touchstones for the revaluation of what are considered musical criteria, as is the performance-project/lifestyle of the reclusive Texas musician/concept "Jandek" who for thirty years has been producing recordings of structureless sounding songs sung with a frail voice and accompanied only by distrait plucking on a guitar that seems tuned to no particular way. ${ }^{50}$ But this sentiment towards the formally obscure can be extended back further to Nietzsche's claim that Wagner's music, owing to what to our twenty-first century ears seems a rather quaint attack on very culturally and historically narrow conventions of structure and tonal harmony, is formless in its drunken or delirious affects. ${ }^{51}$ But "formlessness" in these cases is structurally reliant on a notion of "form," a particular sense of form that the Italian composer Ferruccio Busoni, in his 1907 work Sketch of a New Aesthetic of Music, asserts is in most cases an "architectonic," "symmetric," or "sectional" style that characterizes a particular historical approach to

\footnotetext{
${ }^{49}$ Tony Conrad, "LYssophobra On FOUR VIOLINS," notes to Early Minimalsm Volume One Volume One (Table of the Elements, 1997)

${ }^{50}$ In 2004 Jandek emerged (partially) from reclusion to begin collaboratıng with other musicians in live performances For a guide to "Jandek" see Seth Tisue's website http //tisue net/jandek.

${ }^{51}$ See Freidrich Nietzsche, The Birth of Tragedy and the Case of Wagner, trans Walter Kaufman (New York Vintage, 1967)
} 
composition. While relevant and germane to the expressive problems and aesthetic values of a past era-chiefly nineteenth-century Western instrumental music--what can be called an architectonic or structural representation of "form" has over time become an apparently "objective" and necessary expression of music. ${ }^{52}$ In this received sense of form, formless/ness is taken as a negative attribute remaindered by the art music tradition's fixation (fetishization) on past conventions. For Busoni, this obscures the real "truth" of music, which is to wrest expressıon-what Deleuze calls "percepts and affects"- from reified or too consistent a plane of composition. In other words, Busoni's truth of music entails an ongoing realization of the inherently plastic nature of music. ${ }^{53}$ From a certain perspective, the history of aesthetic modernism and its "logic of offense" appears to have relieved formlessness of its pejorative quality, ultimately meliorating ${ }^{54}$ its reputation to the effect that, as the example of Conrad's encounter with Young's music shows, a work's obscurity is no longer percelved as a shortcoming but a virtue. Hence Schönberg's wonderfully obtuse comment: "How the music sounds is not the point."

\footnotetext{
${ }^{52}$ Ferruccio Busonı, Sketch of a New Esthetıc of Music, trans T H Baker (New York G Schrmer, 1911), 6-7

${ }^{53}$ The idea of music as an expressive escape-act is taken up by Deleuze and Guattari in their work "Of the Refrain " Here they posit music as a force of "deterntorialization," a tendency to break apart or away from the regularity of expression - a refram - that makes things (sound) relate predictably through patterns of rhythmic intensity. See Deleuze and Guattan, A Thousand Plateaus, 310-50, and Ronald Bogue, Deleuze on Music, Painting, and the Arts (London Routledge, 2003)
}

This reads as something of an inversion of Jacques Attalı's notion that music is a domesticating power, one that specifically cultivates the irrational wilderness of noise See Jacques Attal, Norse The Pollttcal Economy of Music (Minneapolıs University of Minnesota Press, 1985)

${ }^{54}$ This "improvement" of formlessness is interestingly resonant with aesthetic modernism's ideology of progress, an ideology whose metaphysical premises are capture by the doctrine of, tellingly, Melionsm For an overview of how melıorısm is articulated by American Pragmatısm see Colın Koopman, "Pragmatısm as a Philosophy of Hope Emerson, James, Dewey, Rorty," The Journal of Speculative Philosophy 20, no 2 (2006), and for its implication in bioethics see Arthur Caplan and Carl Ellott, "Should We Use Technology to Be Better Than Well?," PLoS Medicine 1, no 3 (2004)

${ }^{55}$ Arnold Schoenberg qtd in Stephen Toulmin, Cosmopolss The Hidden Agenda of Modernity (Chicago University of Chicago Press, 1992), 185 But it is the point insofar as the sound of a work can supersede any rationalization of its occurrence or reason for being 
However, despite the revaluation of formlessness, the above expressions are still given in terms bound to traditional protocols that see formlessness as merely an absence. Because something, no matter its incoherence, is still being given and had as "musical," and is still having an effect on us, it cannot be rendered in wholly negative terms. In other words, formless is positive. Busoni hints at how we might understand this within the domain of music when he writes, "all composers have drawn nearest the true nature of music in preparatory and intermediary passages (preludes and transitions), where they felt at liberty to disregard symmetrical proportions, and unconsciously drew free breath." $" 56$ Though delivered with a touch of gooey Romanticism that bedims its utter sublunary nature, Busoni is simply directing our attention to the overlooked occasions in music, particularly as it's heard, where the telic draw of a piece hesitates, where its unfurling gathers potential in the ongoingness-of-being-in-the-middle-of-itself. Busoni's "true nature of music" refers then to moments of suspense, moments in which, to take a traditional example, a sequence of notes have not yet crossed the threshold wherein they become a melody. We can think of this kind of suspension between one experiential series and another-i.e., notes and melody - in a more contemporary sense as a becoming or an "event," which Deleuze describes as what "eludes the present" and "does not tolerate the separation or the distinction of before and after, or of past and future." 57 Considered from this perspective, "formless" not only clinches a little wiggle room from its historical and structural reliance on "form," but it begins to have its own sense that follows a logic rife with paradoxes, a sense that goes in many directions at once to

\footnotetext{
${ }^{56}$ Buson1, Sketch of a New Esthetic of Musıc, 8, my emphasis

${ }^{57}$ Gilles Deleuze, The Logic of Sense (New York. Columbia University Press, 1990), 3
} 
express a loss that is lost, a lostness that finds itself fully present to its ability "of being in uncertainty and mystery.",58

Toronto artist-composer Josh Thorpe's musical "ready-mades" are exemplary of formlessness as becoming, for their conceptual character, more than any actual sounding transition, isolates and embellishes the strange logic of becoming and the paradoxes of its eventuation that in ordinary circumstances are obscured by a determined emphasis on only one end of its occurrence. Openly signaling their debt to Marcel Duchamp, Thorpe's Ready-made Aided \#2 and \#3, both for solo instrument that take works of J.S Bach as source material, exhibit the bi-directionality of becoming by interfering in the customary relationship between an object's use and its ideas (its "sincerity"). These musical readymades have the effect of simultaneously pointing to and expressing the sense of what they are and what they are not. Ready-made Aided \#2 (2000), for example, takes Bach's first sonata for solo violin as its found object, its "found form," and scores (wounds) its traditional expression by asking the performer to a) play the work slowly, and b) do so wearing stiff, preferably suede gardening gloves on both hands. When performed, the work divides in two, becoming more of what it is not (a mash of inarticulate notes, rhythms, and textures-a "platypus" as Thorpe calls it) and less of what it was (Bach's first violin sonata). In other words, the expression wrested from Ready-made Aided $\# 2$ is formless in the sense that it is neither Bach nor a platypus but an event, a "pinch point" through which two musical series (i.e. notes $\mid$ melody; Bach|platypus) divide from one another. Similarly, Ready-made Aided \#3 (for piano or harpsichord) (2000) takes another piece by Bach, this time the Goldberg Variations, and

\footnotetext{
${ }^{58}$ Rebecca Solnıt, A Field Guide to Getting Lost (New York Viking, 2005), 6
} 
Josh Thorpe, Ready-made Aided \#2 (violin) (2000)

$$
\begin{gathered}
\text { READY MADE A WEO } \# 2 \\
\text { O2000 josh thorpe }
\end{gathered}
$$
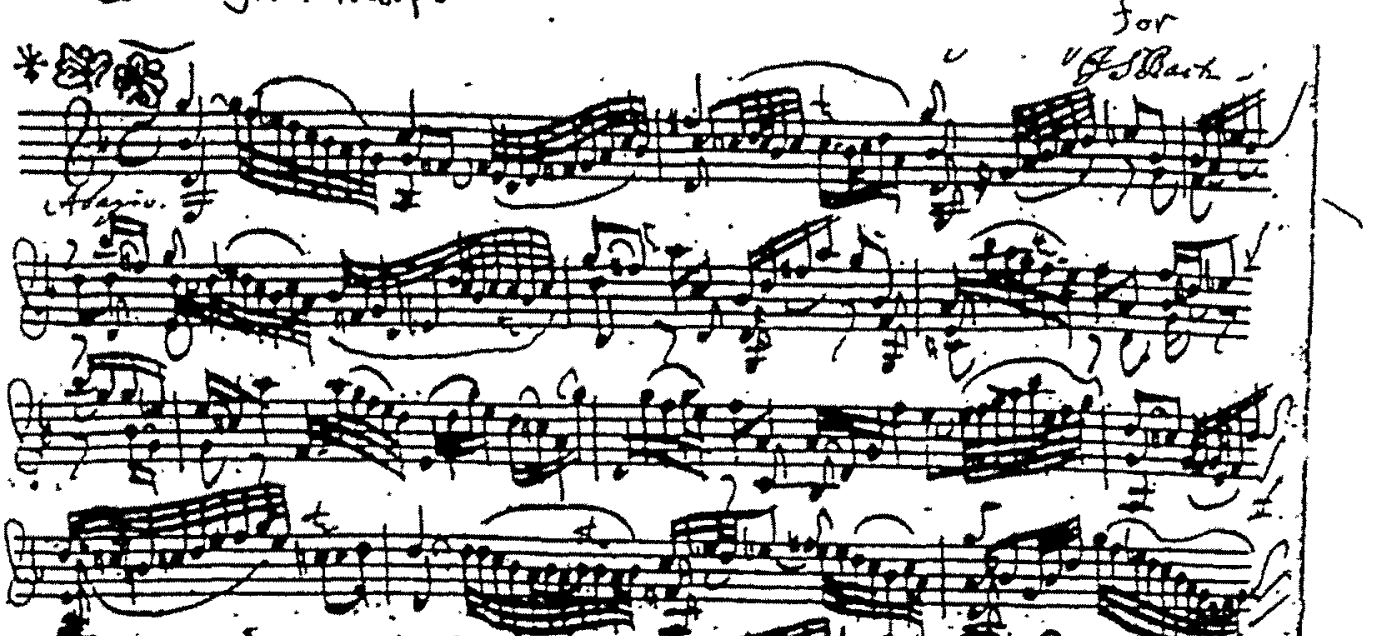

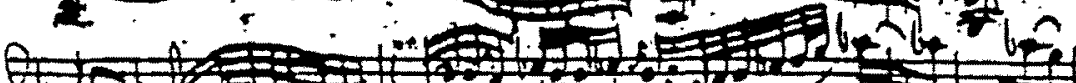
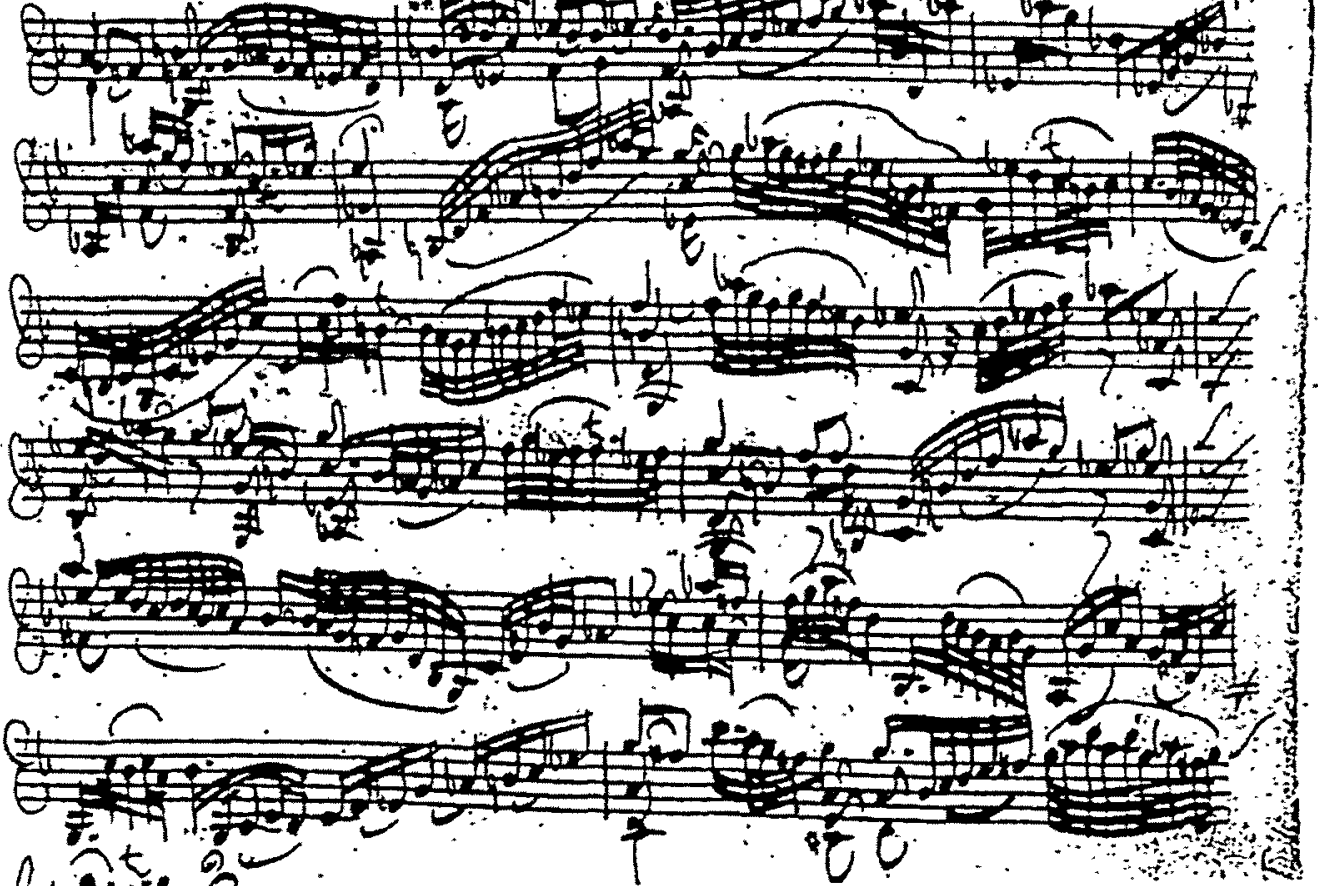

25
+21

$\frac{2}{2}$

$\because \quad y$
* Performance note: weor stiff, heary, lenther t cloth garderim gloves on both hands.
Sordor. 
Josh Thorpe, Ready-made Aided \#3 (for piano or harpsichord) (2000)

TABLE DES ORNEMENTS DE J. S. BACH avec terminologie française courante
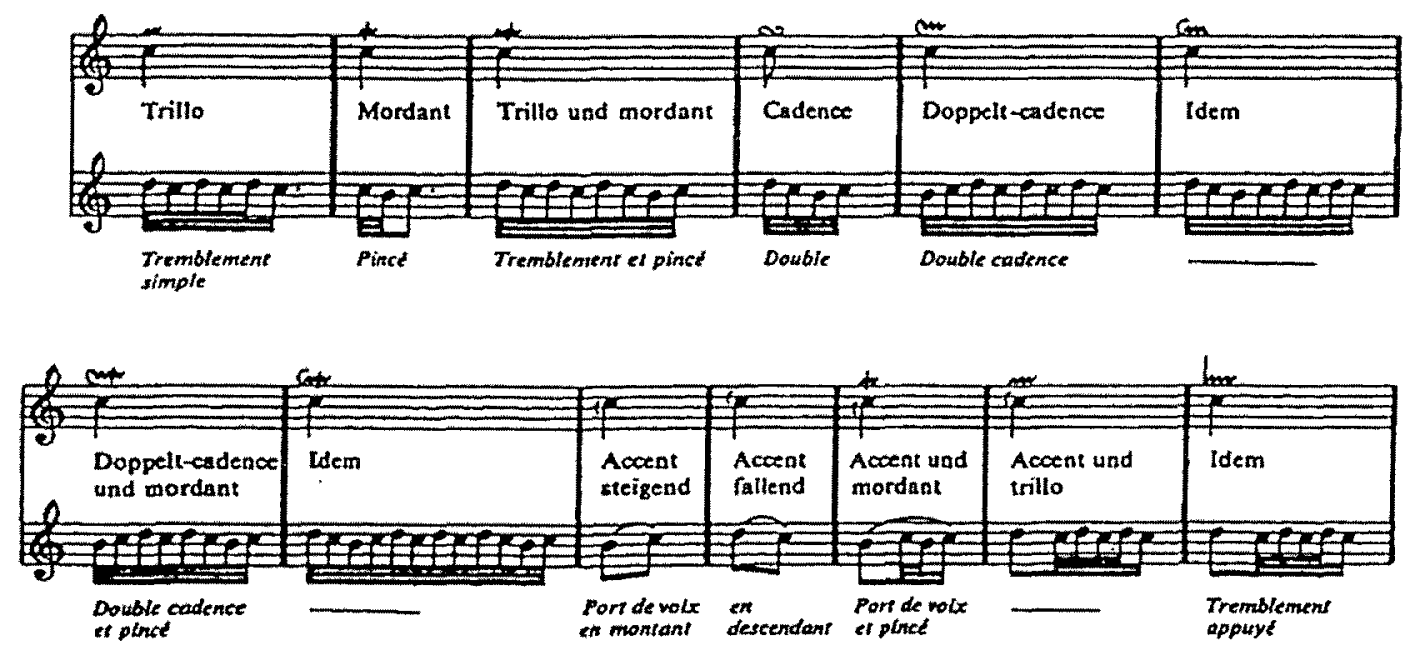

- (Ready-made Aided \#3 p. 6)

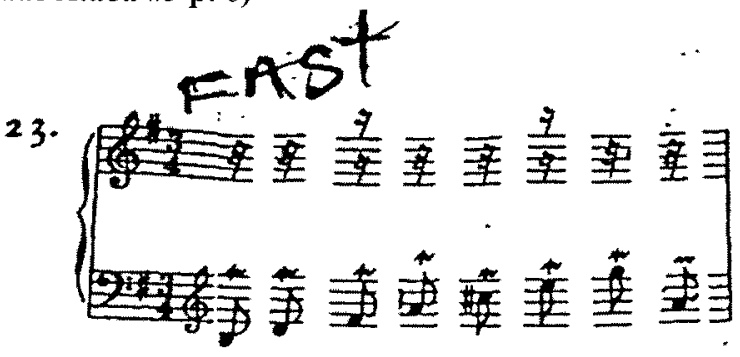
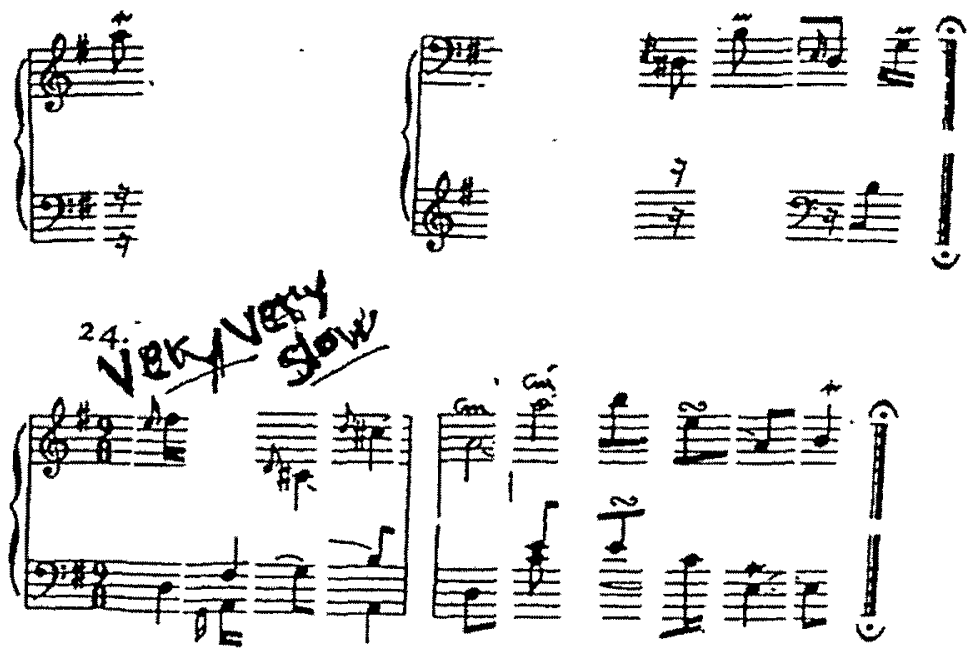
- (Ready-made Aided \#3 p. 7)

25. Notlce key chonge

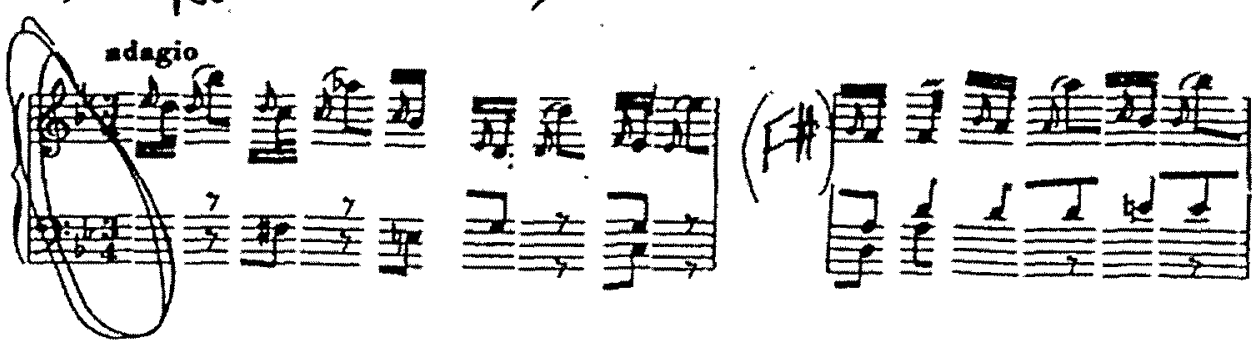
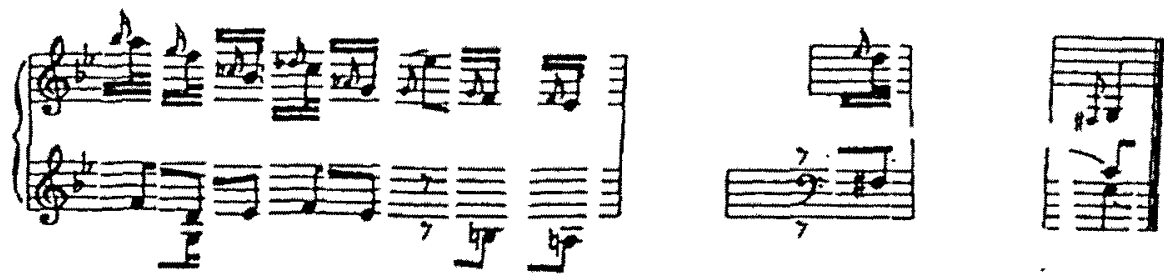

I.

26.

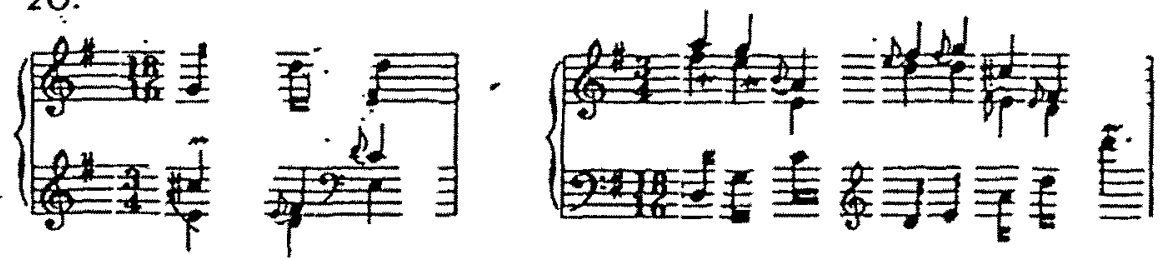

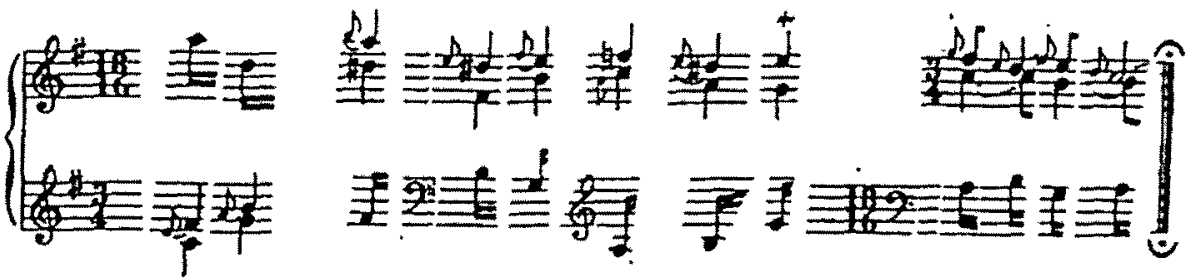

(1) 
intercedes in its form by literally cutting out every ornament from the score and pasting them, one after the other, in the order in which they appeared in the original Additionally, Thorpe intuitıvely inserts silences between these naked ornaments and deletes any implying a cadence In this piece, formless/ness is articulated in the way ornaments, which are by definition "superfluous, non-components to the actual material of the music," become the "actual material of the music "59 Ornaments here lose their decorative necessity (an internal contradiction that itself is already an expression of formless) and become a kind of almost-melody However, the floridness of an ornament is such that it inclines to be heard as incomplete or partial so that in stringing these "rough pearls" 60 together, one ends up with an ersatz melody, which in a way is maybe closer to the more common sense of "baroque" as grotesque or whimsical As such, Ready-made Atded \#3 oscillates, or better yet hesitates, between becoming ornament and/or structure

\section{Music Noise}

While I won't submit this as the "true nature of music," I will leverage the sense of "becoming" in order to address how we might take the duplicity of Thorpe's readymades to articulate the way "formless" can designate a suspension of, or better yet, a hesitation in the traditional sense of music as a succession of "felt probabilitıes"

\footnotetext{
${ }^{59}$ Josh Thorpe, "Here Hear My Recent Compositions in a Context of Philosophy and $20^{\text {th }}$-Century Experimental Music' (MA, York Unıversity, 2000), 72

${ }^{60}$ The onginal sense of the term (Fr baroque, $\mathrm{Pg}$ barroco, Sp Barrueco) was literally "rough or imperfect pearl " OED http //dictionary oed com/cg1/entry/50017799? single-1\&query_type-word\&queryword=baroque\&first ${ }^{-}$l\& max to_show -10

61 of satisfied or frustrated expectations See Leonard Meyer, Emotion and Meaning in Mustc (Chicago University of Chicago Press, 1956)
} 
I want to recruit the idea of "noise," for like becoming, its expression as something that one is (un)hearing at the same time one is listening to music--where each term modulates the sense of the other-involves the kind of paradoxes that set both it and music off in a mutually reinforcing infinite regress. Noise is for me more of a conceptual lever that when paired with its negative attendant - "music"-brings what I mean by the hesitation of becoming into (the) ear. And it's Paul Hegarty's work on "noise music" that offers the greatest insight into the way noise functions with respect to music as informe. In Noise|Music, Hegarty writes about the precession of noise and music as having two principle vectors: an imperial one figured forth by various musical avant-gardes commanded first by Russolo's Art of Noises and then by John Cage's cry to "let sound be!"; and an ethical or para-aesthetic vector that works to keep all expressions of either "music" or "noise" in suspension. Whereas the former charts the flight of music's empire across the entire spectrum of sound (one that maps nicely onto Western culture's expansionist economies), the latter is where the paradoxes multiply, for noise is only noise-a disturbance - as both it and music "dwell" within each other's field where they constitute on another's threshold(s), and mutually contaminate and modulate the limits of their respective affects. ${ }^{62}$ Noise in this sense is not opposed to music but is the other side of the same process that patterns both profiles of the event. Noise here is the becoming of the excluded, or what gets left out of the becoming of music. In a way this fixes a region of disordered remainders that take on the function of an anti-style. But as Hegarty notes, "When noise is put to use," such as it is when it serves expressive ends, "it can no longer

\footnotetext{
62 "Dwelling inherently involves adding on, replacing, and altering" Bruce Ellıs Benson, The Improvisation of Musical Dialogue A Phenomenology of Music (Cambridge; New York Cambridge Unıversity Press, 2003), 150
} 
be fully noise. Noise can never fully be - it is a transitional or temporary state. ${ }^{, 63}$ In other words, noise is something that never "is" but ever becomes. The passage or transition that hasn't yet happened qua "transition" or "passage," but is still-forming, still working-out a potential to become what it will have been, is the noise of formless. ${ }^{64}$

The effects of noise, of becoming, Hegarty draws out in terms of Bataille's notion of informe, which is itself a kind of "noisy" concept in that it denotes expressions of interference immanent to our desire to make sense of things. Treating noise as a form of informe invokes the kinds of paradoxes that characterize a logic of becoming such that in referring to forms of Japanese noise music as represented by the likes of Merzbow and Koji Tano's MSBR (“Molten Salt Breeder Reactor"), Hegarty writes,

These forms of noise are informe, not free of form, not deconstructing it, not in a dialectical relationship to it, not against, but worked through, despite and outside, moving from inside (music) to out (sound) with the noise the movement itselfthis is the 'besogne' of noise - the enforced labour of noise - which neither wants to work, nor be merely noise, but becomes it through exclusion - an exclusion it reclaims, and through this, becomes music, which it fails to be. ${ }^{65}$

However, despite the paradoxical gyrations that noise elicits from informe, and which thereby ally noise to becoming, as a character of musical formlessness informe-noise is limited in the way it invokes themes of abjection and excess. For Hegarty, whose object is "noise music," there's an accommodation of the abject by virtue of the way noise emphasizes the "outside" or excreted side of a differential relation, but also in the way its

\footnotetext{
${ }^{63}$ Paul Hegarty, "Residue - Margin - Other Noise as Ethics of Excess," in Argosfestival 2003, ed Paul Willemsen and Fre Depraetere (Brussels. Argo, 2003), http //www dotdotdotmusic com/seminars.html.

${ }^{64}$ Again you'll notice that even here, we're evokıng aspects of form This is a problem of dealing with becoming you have to talk about both profiles at once, which is something exceedingly difficult to do with language and make explicit in perception The best way to represent this is perhaps with an optical illusion where you have to try to see the chalice and both faces at once

${ }^{65}$ Paul Hegarty, "General Ecology of Sound Japanese Noise Music as Low Form," in Le travall de l'informelfunctions of formless (Cork University College Cork, 2002), http //www dotdotdotmusic com/hegarty7
} 
affect plays out across bodily systems more obviously than, say, the quiet rustling of

Australian composer Warren Burt's Another Noisy Lullaby (2009).

Burt describes this piece as a reposte to Julian Knowles' (another Australian composer) objection over Burt's being included in an essay on noise music. According to Knowles (and this is Burt in an interview recounting Knowles' objection):

I was too old, I didn't have a buzz cut, I didn't wear black leather, I didn't play in clubs in Europe, and the pub wasn't my main venue of thinking... and I didn't have a bad attitude towards the audience. ${ }^{66}$

In Another Noisy Lullaby, noise is reconsidered in light of the question: "If noise music is supposed to have an element of aggression and confrontation to it, how tender, how delicate, how nurturing can we make something, and still have it be noise?" ${ }^{67}$ Burt's response to this question was to write a piece using different hissing sounds ${ }^{68}$ whose complexion of whispers would evoke a mood that hovered somewhere between a tentative confidence and an insistent humility. Written for the Australian ensemble Decibel, and is scored for chamber ensemble ${ }^{69}$ and "boomboxes," Another Noisy Lullaby is based on transformations of nonsense anagrammes whose letters Burt uses to generate three categories of sound: simple diatonic melodies, whispered texts, and "noise bands",70 (contoured white noise). Immediately the work differs from a number of genre conventions in the way it sustains a wrinkly atmosphere of frail susurrations rather than

\footnotetext{
${ }^{66}$ Warren Burt, "DECIBEL02 Warren Burt - Another Noisy Lullaby,” Interview with Julhan Day, Australıan Music, Australian Broadcastıng Corporatıon, http //www abc net au/classic/australianmusic/stories/s2835399 htm.

${ }^{67}$ Decibel Ensemble, “Tape It "’ Programme notes Warren Burt, Another Nolsy Lullaby, http //decıbel waapamusic com/concert-1-tape-1t/tape-1t-program-notes/

${ }^{68}$ The impulse to write "noises" at first instead of "sounds" here is tremendous and is suggestrve of how the term is already loaded with judgement about a sound's non-musical character ${ }^{69}$-n the recording I have been listening to these are flute, bass clarmet, violın, and cello--

${ }^{70}$ You can get a sense of what these "noise bands" sound like by trying to make the following sounds. Trying sayıng the letter " $K$ " but prolong the windy part of the phoneme and then change the shape of your mouth to shift the vowel sound to "k(o)----" then "k(u)---." "k(aw)---." etcetera
} 
Warren Burt, Another Noisy Lullaby (2009) excerpt

The players are spread widely in space. Next to each player is a boom box with the same CD on it. Each player selects a different section of the score to begin at (numbered 1-8) and treats the score as a loop. Each player plays melodies and whispers at a very soft level. The boomboxes are also played at a very soft level, such that they balance the player's volume. The noteheads with no stems indicate relatively short melodic notes. The notes with arrowheads extending from them are sustained notes. Each instrument should sustain the notes in a way that's native to them. Each player plays independently of the other players, but with an awareness of balancing overall volumes with them.

\section{Another Noisy Lullaby}

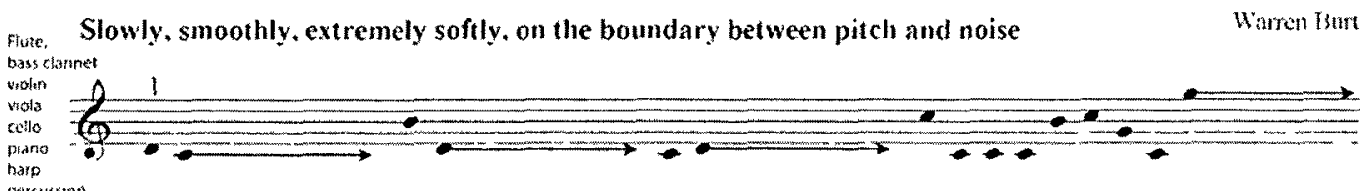

Whisper itl tents drimaticallh

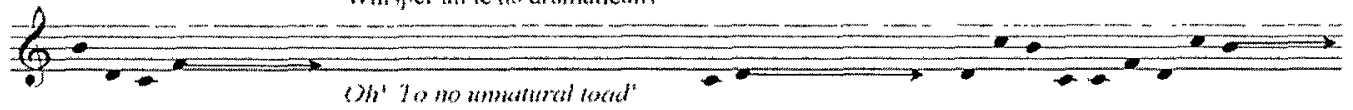

(3)' To no umbaturat toct
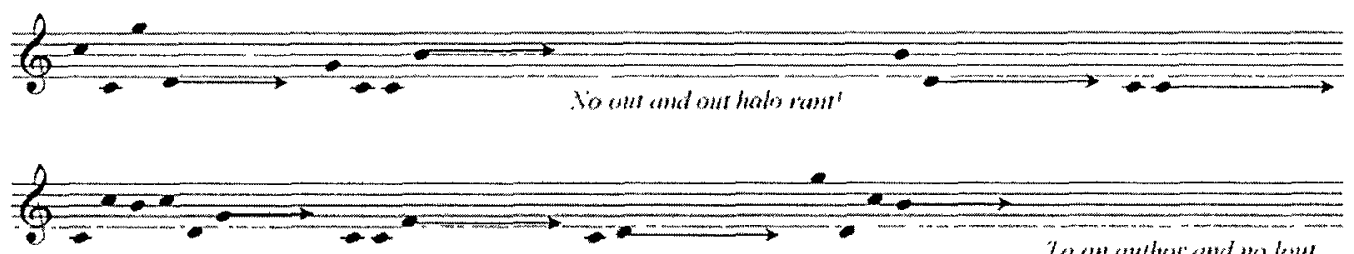

Jes an auther and no lom
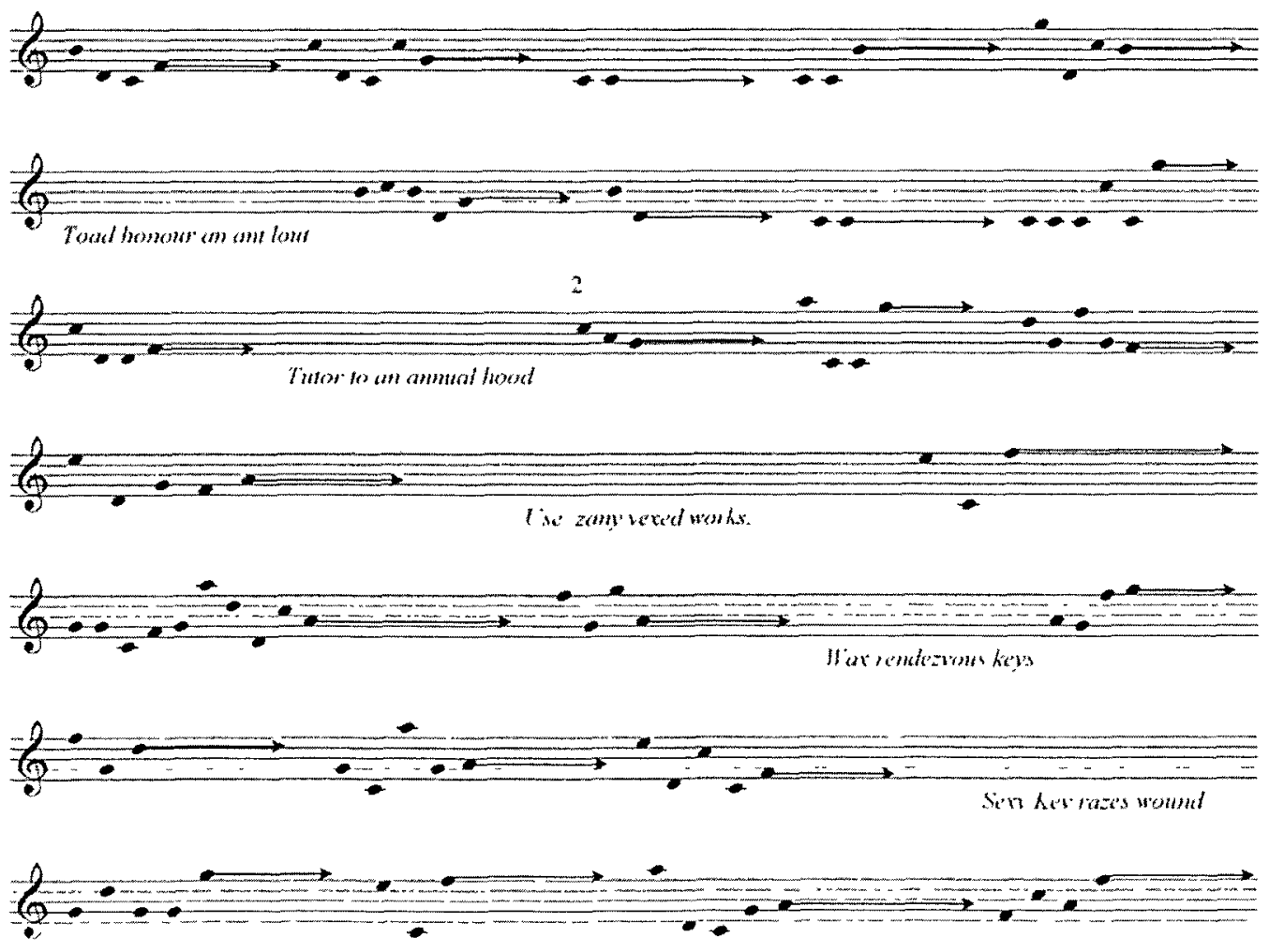
the pressing viscerality typical of noise music Here, the text is whispered "dramatically" rather than shouted, the volume of the boomboxes playing the noise bands is set extremely low, and the instruments, particularly wind and strings, play in such a slight way "that compete control of the purity of sound 1s impossible" "71 Additionally, the element of immersion that is often taken for granted by noise music is in this work achieved spatıally rather than by sheer volume The boomboxes playıng noise-bands, which are widely spaced so as to surround the audience, and the extreme softness of the instruments and volces, interact so as to "merge into a sort of grey blur",72 that in one sense captures the common sense of formlessness as amorphousness, but in a more interestıng way deforms noise's repulsıve force into a lullıng power In both cases, either through sheer might or moony drifts, listenıng struggles with the nonsense of noise and oscillates between listening to it and away from it

Strangely, Another Notsy Lullaby's softness becomes informe (becomes but never is formless) in two ways at once one is by the way its gentleness offends the more obstreperous conventions that are often taken as facts of "norse music," and the second is by the way this same softness interferes with our ability to discern those structural relations-art music's "facts"- - that would constitute the work as a proper "aesthetic" object What Burt achieves with Another Notsy Lullaby is a hesitation that not only stalls the more militantly defined conventions of "noise music" and frustrates both the formal and expressive expectations of art music, but invites one to linger in a sensuous haze without feeling the pressure to form a judgement on it

And it is here that my project departs from Hegarty's While Hegarty is after the

\footnotetext{
${ }^{71}$ Warren Burt, Another No1sy Lullaby," 2009, score notes

72 Warren Burt, personal communication, 2009
} 
elusiveness of a noise that tries to keep from being music, or at least keeps its effectsdisturbance effects-from being arrogated to the objectives of music, I want to focus on music that participates differently in the grey economy of informe, a "music noise" that aims to keep its effects—what I'm calling its "charm"- - from sinking into the mud of mere sound. I suggest that like noise music, music noise needs to be understood in a way that keeps its failure in sight. That is, in the same way that "noise" music fails to be noise because the expulsion from music that makes noise "noise" also makes it "music," music noise has to divide itself from conventions that is cannot do without in order for its points of deformation to make non|sense. And this, I suggest below, is achieved in a number of ways. But for now, I want to focus only on how the habit of listening to music inattentively is exploited (often unintentionally) by a number of composers to scuttle the familiar vessels of music so that their expressive flotsam will either wash up on the shores of more remote aesthetic contexts or sink to murky depths of the everyday.

\section{Recording Distraction}

When a composition is made to elicit only partial attention or when it behaves like background music, it evokes on the logic of distraction to incite the kind of disturbance and hesitation that is characteristic of the becoming which I've described as formless(ness). To illustrate this process, let's consider the work of Toronto-based composer Martin Arnold whose music, characterized by its strange allusions to mediaeval polyphony and post-bop jazz, as well as an unusual approach to orchestration, engages with listening in a way that celebrates "all those things you can't control within what's 
sounding.,"73 A work like Arnold's Burrow Out; Burrow In; Burrow Music (1995), which as he explains, “doesn't do anything or go anywhere" but simply meanders along, indifferent to whether it is being listened to or not, rather than charging the sails of music's windmill temporizes the normative pressure to form judgments or endorse the musical reality of what's being heard. Burrow's quiet and good-natured perversity ${ }^{74}$ lingers in what philosopher Fred Dretske calls "object" or "sense" perception," the perception of things without knowing what they are or what they mean. ${ }^{75}$ This lingering, and what I'll refer to as the "charm" that it circulates, is sought by listening away to music and designates a kind of perceptual predilection that Rei Terada has named "phenomenophilia"-an attraction to "perceptions that seem below or marginal to normal appearance." ${ }^{.76}$ To the degree that Burrow is phenomenophilic it expresses a mode of musical informe that has only partially to do with the immanent character of its sounds and much to do with the contemporary subject's increasingly insufficient attentional powers that encourages musical sounds to be distracted, literally "drawn away," from the foreground of awareness towards what Brian Massumi describes as the "felt environment" of background sensations. ${ }^{77}$ This means that musical formless/ness, at least as I am thinking about how it manifests in a work like Burrow, concerns the way musicto-be-listened-to engages the kind of penumbral audition that characterizes how background music is hear and how the latter converts perceptual aberrations (noises) that

\footnotetext{
${ }^{73}$ Martın Arnold in Paul Steenhusen, Sonic Mosalcs Conversations with Composers (Edmonton. Universty of Alberta Press, 2009), 148

${ }^{74}$ Martm Arnold, "Observations About, around and Besıde "Burrow out; Burrow in; Burrow Music" (PhD, University of Victoria, 1995), 12

${ }^{75}$ See Fred Dretske, "Meaningful Perception," in An Invitation to Cognitlve Science Visual Cognition, ed. Daniel N Osherson, Stephen Michael Kosslyn, and Lila R Glettman (Cambridge, MA The MIT Press, 1995)

${ }^{76}$ Terada, Looking Away, 3

${ }^{77}$ Massumi, Parables for the Virtual, 139
} 
abound in subliminal listening into aesthetıc "wonders" that in turn transfigure the image of music-to-be-listened-to into something grotesque, something weird

Burrow Out, Burrow In, Burrow Music is a one-hour ten-minute piece in twomovements written by Martın Arnold in 1995 as part of his doctoral dissertation at the Unıversity of Victoria As Arnold describes 1t, the underlyıng impetus for this work derives from his realization that his "fundamental experience of listening to music was through recording ${ }^{, 78}$ His aim was to write a piece with a sense towards how it would sound as projected from a stereo, this would entatl an attention to the way "production technıques are sıgnificant, distınct, and actıve contributors to the resultant recorded music "79 Ultimately then, Burrow Out, Burrow In, Burrow Music was intended to be realızed and listened to only as a recordıng and not a live performance ${ }^{80}$ In essence, Burrow is a work that acknowledges and adopts the mediation introduced by recording technology and recording techniques as an essential part of recorded music's "material" Beyond traditional elements such as "pitches, rhythms, textures and sonorities (and their histories outside of the piece)" audıble" in final recordıng Thıngs like

the dimensions of the room (including sills, ledges, outcroppings, trim, smooth or angled corners), all the materials involved in the walls (plaster/stipple/paper/kind of paint), the amount of furnishing and the placement, shapes, and material make-up of the furnishing, the floor surface and covering, the number of windows, the number of curtains, and the number of curtains drawn or not, the difference between the street noise from the third floor, the second floor, and the ground floor, ${ }^{82}$

\footnotetext{
78 Arnold, "Observations," 18

${ }^{79}$ lbid

${ }^{80}$ Ibıd , 20

${ }^{81}$ Ib1d, 27

${ }^{82}$ Ib1d, 7
} 
as well as the kind of microphone used; the placement of said microphone relative to an instrument, the amount of gain applied to the microphone, and, as legions of informed and not-so-informed musicians will attest to, whether these sounds are recorded in a digital or analogue format For Arnold, "how a piece is recorded is a part of the music, as much as all the other aspects of interpretation-dynamics, phrasing, articulation, rubato, etc $" 83$

A host of other aspects make Burrow an extremely interesting composition, however, I want to draw attention to the way that its formal perplexity renders the kind of listening that is typically brought to bear on "compositions" as insufficient First I want to describe how Arnold thinks this is accomplished and then I want to propose what I think is happening But since I'm almost certain that you will have never heard this prece, a more detailed description of the work is in order Basically, one can hear Burrow as a tımbrally rich, extremely long, and very weird work of slow moving modal counterpoint As I noted above, the prece is in two movements The first movement, at sixty-eight minutes, is the longest and texturally speakıng, is essentıally three-part modal counterpoint with an accompanyıng punctuatıng line that actıvates (opens/closes) a gated tape part on which is recorded an improvised organ and string performance (both instruments being played by the composer) Each of the voices is recorded separately and independently of one another on a cassette four-track recorder, and throughout the prece, the melodic lines are performed at different times by one of twelve different instruments ${ }^{84}$ that have been recorded in different ambient spaces, using different recording technıques, creatıng in a sense a second and third order counterpoint based on

\footnotetext{
${ }^{83}$ Ibid , 18

${ }^{84}$ Which include melodica, sopranıno, alto, and bass recorders, Casıo D[1gital]-H[orn]-100, alto and baritone saxophones, trumpet, trombone, electronic panpipes
} 
instrument timbres and ambient resonance. The strategies that Arnold uses for ordering the parameters of pitch and rhythm are many and multilayered and require too much space (and patience) to detail in depth here except perhaps to note that much of the material was generated using different applications of Danish composer Per Nørgård's "Infinity Series," "wavelengths" or "refractions" are audibly related to the fundamental series that lends the constantly expanding row the impression of generatıng hierarchical structures. ${ }^{86}$ The second movement, which times at forty-two minutes, is a representation of the same scored material that comprises the first movement; however, this time a MIDIrealization ${ }^{87}$ of the score is made and recorded to cassettes that are then listened to through headphones by performers who either whistle or hum along with one of the three melodic lines. Additionally, the midi-recording of the score is gated (turned on and off) and projected through speakers by a feed coming from the microphone the whistler/hummer plays into so that an extremely murky blend of whistling, humming and midi piano is heard on the recording. As Arnold writes: "This movement celebrates the non-expert pastime of humming and whistling-along and all the sonic anomalies that go with this activity. $" 88$

Aside from his underlying taste in mediaeval polyphony, Scottish Piobaireachd, 70s prog-rock, and jazz-lounge, Arnold cites an interest in experimental film and video,

\footnotetext{
${ }^{85}$ See chapter three, fn 130, for a more detalled explication of Nørgård's infinity series

${ }^{86}$ For a detailed description of the infinity serıcs and Nørgârd's applıcatıon of it in his musıc see Erık Christensen, "Overt and Hidden Processes in 20 ${ }^{\text {th }}$-Century Music," Axiomathes 14, no 1-3 (2004)

${ }^{87}$ MIDI is the acronym for "Musical Instrument Digital Interface," and designates an industry-standard protocol for enablıng electronic musical instruments and computers or other devices to communicate by what is called "event messages" that convey information about pitch, intensity, and timing In Burrow Music, what Arnold is referring to by its "midi-realization" is a computer-generated performance of the notated pitches and rhythms that appear in the score

88 Arnold, "Observations," 13
} 
particularly those reflexive works that, as he writes, "take on some kind of investigation into various aspects of various kinds of apparatus set in motion for the[ir] production and consumption." 89 Though citing the work of Michael Snow, Ernie Gehr and Peter Gidal as influential, it's film-maker/theorist Trinh T. Minh-ha whose work Arnold feels more indebted to. In Trinh, Arnold discerns what he calls a "non-demonstrative" approach that differs from other experimental filmmakers in that her films do not index the implicit understanding or control that a work like Michael Snow's La Region Centrale (1979-71) suggests. For Arnold, the "creative strategies and artistic innovations in regard to the manipulatıons of the camera... are demonstrative and exemplary in their methodology and, as such, offer clear indices to aspects of the artists' intentions." 90 This, he contends, demonstrates an authority on the part of the artist, or a claim to possess an interpretive privilege that in Trinh's work is absent. Arnold points out that while the "unsettling [of] various conventions and preconditionings" at work in Snow, Gehr, and Gidal's film are present in Trinh's films, their "subversions are not lucid enough or consistent enough or pervasive enough or dramatic enough to take on another [alien] authority." 91 The expressive ambiguity Arnold sees in Trinh's Naked Spaces parallels his desire for Burrow to both exploit and subvert conventions, while never presuming mastery or control of the effects of these.

Like Trinh, Arnold seeks to keep the affects of convention and subversion in play without isolating or classifying which effect belongs to which affect. Martin describes this as "a condition where the dialectic line that can be cut between the two disappears

\footnotetext{
${ }^{89}$ Ibld , 20

${ }^{90}$ Ibid , 26, my emphasıs

${ }^{91}$ Ibid, 26
} 
and they become unknowable as categories." ${ }^{92}$ He continues:

I want the array of elements that make up my hybrid material to be as capable of being (mis)apprehended as all context and content... I want a situation in which any given element in any given moment might seem familiar (and maybe beautiful or sentimental or comfortable) but in which there is no real sense of what is going on; no solid indication or even implication of what my agenda or intent as a composer might be. ${ }^{93}$

Burrow can be considered a work that tries to prolong a hesitation, tries to become an ongoing "event," an event that in effect has no duration, no envelop of development or contour of growth that would advocate a way of taking account of what's going on. Ideally, Burrow lingers in the "eventness" of its event wherein things are only apprehended as a "quasi-this" or "quasi-that" because they are always in the process of becoming this or that. Citing John Cage's Cheap Imitation (1969), a reversioning expression of Erik Satie's Socrate, as an exemplary case of musical hesitation (and model for Burrow) Arnold writes:

It has an innocuous, generalized familiarity because of its diatonic ("white note mode") nature, and yet, specifically, it is unknowable. There is absolutely no sense of what should come next-largely a result of the chance procedures which generated it... and yet, because of its sweet, friendly melodicism, it does not adhere to any recognizable archetype for "randomness." And not only is there no way of guessing what comes next, because there is no recognizable tension within the piece, it supplies no motivation for one to wonder such a thing; it is completely without suspense. ${ }^{94}$

Arnold goes on to describe other details of what this piece does, followed always by another "and yet..." which gets at something of the way Cheap Imitation keeps the effects of its gestures and formal relations in abeyance, keeps them eventual, hesitant. For

\footnotetext{
92 Ibld, 27

${ }^{93}$ Ibid

${ }^{94}$ Ibıd., 99-100.
} 
Arnold, this is indicative of how music, when organized in such a way, can,

paradoxically, appear to disorder itself, to give the impression of being formless, or in the Deleuze-Guattarian terms that Arnold uses, "faceless."

But much of what Arnold describes in Burrow (and Cheap Imitation) is its immanent details. While details such as the unusually long duration, the otiose melodic drifts, and a veritable absence of dynamic variety are necessary elements that help Burrow scramble expectations that mediate the way the listener takes account of a musical event, these alone are not sufficient conditions to render "the strangeness of its existence so disorienting." ${ }^{95}$ If they were, one should expect Burrow to relinquish some of its "unsettling" effects with successive hearings. Its being recorded would presumably give the listener a degree of control that would countervail Burrow's unsettling affect by giving one the opportunity to develop the kind of attention that evolves from multiple listenings, an attention that Warren Burt calls "exact attention":

First listening for (for example) melody (pitch), then maybe listening to harmony, then listening to form, then maybe a Schenkerian kind of listening, then concentrating on timbre, then concentrating on personal memories (why does this tune remind me of her? - or why does this tune remind me of tuna sandwiches?), then concentrating on semiotic aspects of the piece, etc. ${ }^{96}$

But the fact is that as many times as I've listened to Burrow, and as well as I understand the objectives of the piece that Arnold lays out in the text of his dissertation, I still have enormous difficulty grasping what's going on in the piece. To me this suggests that the capacity to listen, which Arnold insists is what he's addressing in Burrow, plays a key

\footnotetext{
${ }^{95}$ Ib1d, 100.

${ }^{96}$ Warren Burt, personal communication, 2010
} 
role in determining what Arnold says is Burrow's "insidiously disorienting instability." ${ }^{170}$ But Arnold's reading of his own intentions to thwart his intentions by elaborating the salient tactics he used, paradoxically, to control how the composition of Burrow might "escape" him, overlooks something about his own observation that recording introduces certain mediations that become part of the music.

While aiming to treat (in a non-demonstrative way) these mediations in a way that would address how "production techniques are significant, distinct, and active contributors to the resultant recorded music, ",98 Arnold neglects to consider how listening to recorded music affects the way one attends to it, that is, how attention-or lack of itbecomes an "active contributor" to the way the music sounds. Arnold is right that "there is nothing neutral about the recording process,"99 but there is also nothing neutral about the circumstances of listening, and certainly there is nothing neutral about what sound technology has done to these circumstances. Simon Frith puts it this way: "As we have taken power over music on records, as they have become ubiquitous... so the musical work has ceased to command respectful, structural attention." ${ }^{100}$ As a consequence, "All music," he contends, "is more often heard now in fragments than completely" and "because all our experiences of time are now fragmented and multilinear, fragmented music is also realistic music."101

Production techniques are therefore not the only "active contributors" to the way music is heard through recordings. For the majority of the population of industrialized

\footnotetext{
${ }^{97}$ Arnold, "Observations," 101.

${ }^{98}$ Ibid , 18

${ }^{99}$ Ibld

${ }^{100}$ Simon Frith, Performing Rites On the Value of Popular Music (Cambridge, MA Harvard University Press, 1996), 242

${ }^{101}$ Ibid , 242, 43
} 
cultures whose primary experience of music is circumscribed to that of listening (to recordings), the peculiarities of recording's mediations are no longer exceptional. Thus, in addition to affecting what is or is not audible, as, say, the way a microphone position alters the amount of finger noise made when playing a guitar, recordings have taught us how to listen in moments and thereby to orient "the listener's attention to 'sound' over 'music' such that "perception of the sound is more important than consideration of the 'composition' as an entity in and of itself.", 102 Pausing, turning down, rewinding, skipping ahead, stopping a song in the middle of playback, and simply forgetting about it are behaviours that develop around the way recordings allow one to affect music. But these behaviours also adjust the importance of the music downwards so that they become something grasped or appropriated unconsciously. As Walter Benjamin notes in "The Work of Art in the Age of Mechanical Reproduction," habits that develop around the way an individual uses things, or we could say, the way things mediate one's use of them, impinge on how these things figure into one's perception and influence the significance they can have. So as well as affording a separation of performer and audience, a separation that programmed music (what we refer to generically as "Muzak") relies upon, ${ }^{103}$ recordings encourage us to regard music as something that can be willfully tuned in and out of: ${ }^{104}$ the sound of music becomes something alternately neglected or cherished according to a nebulous set of continuously shifting priorities, priorities that are becoming increasingly multiple and superficial. ${ }^{105}$ Coupled with the fact of recorded

\footnotetext{
${ }^{102}$ Shuhe Hosokawa, The Aesthetıcs of Recorded Sound (Tokyo Keiso Shobo, 1990), 8, English Summary

103 See Jonathan Sterne, "Sounds Like the Mall of America Programmed Music and the Architectonics of Commercial Space," Ethnomusicology 41, no 1 (1997)

104 this is something that I address below

${ }^{105}$ Multitasking (over page)
} 
Studies on multitasking show that the brain does not work in parallel but processes serially, and so is limited to dealıng with tasks one after another While it's not clear if the shift from one task to another relies on a passıve bottleneckıng, or whether a central executive power actively coordınates the prioritıes of tasks, acting on multiple tasks entails switching between them This "switchiness," however, has costs Because the brain is limited to processing information in series, along separate channels devoted to visual, aural, proprioceptive signals, there's a certam amount of leakage in mental efficiency when switching between tasks "Brain leakage" is measured in time (fractions of a second) but it also entails a degree of energy depletion that when protracted makes perception and thought prone to error, to fallure Now what's interesting about this in terms of how it affects the way a spectator interacts with a time-based or "occurant" art like music, whose listened-to experience is constrtuted by the attention given its sounds, is that the perceptual habits we've contracted from living in a world of "electric definition" that encourages our senses to constantly commingle and inflect each other's expression, have conditioned us to rapidly alternate between different channels rather than to focus on any one sensory register in particular Next time you're in a concert hall, try to observe how often your awareness passes from one series of experience-the sensuous play of sounds-to another-the slow pressure bulding in your bladder-to another-the inevitable cough or cell phone ring And (though strictly speaking it's impossible to do this) try to notice how much of the music you're not paying attention to, by which I mean how much of the recognizably musical sounds are simply absent from your conscrous experience In a sense, you'll find that the acoustically contınuous phenomenon called a "prece of music" will be fractured and fragmented by the act of perception itself

But it's not as if perception was, before the mediatization of our environment, a continuous and unbroken flow William James points this out in his 1911 essay on attention when he asks us to locate a simple dot on a prece of paper or wall, and focus on it What's found here, says James, is one of two things "either your field of vision blurs to the extent that you see nothing distinct at all, or else you find that you've unintentionally quit lookıng at the dot and are now attending to something else "105a The subjectthe dot-1s in a sense "unchanging" and so "attention inevitably wanders away" $105 \mathrm{~b}$ However, the dot as an intentional object is anything but unchanging, or at least, our experience of it (which for a radical empincist is everything) is found to be teeming with all manner of wanders (e $g$ how big is the dot? how far from the edge of the paper is it? what's its shape? what color does it have? how does it set off the surface behind it? why does it look like a squashed bug?) What James' introspective cynosure reveals is twofold one, that attention is occasional, that "1t comes in beats" and pulsed quanta of effort, and two, as New York Magazine writer Sam Anderson put it, that attention is better described as an "ability to organize distractions around a central point " ${ }^{105 c}$ Distraction is, in a sense, the condition of attention Para-citing Deleuze, who makes an analogous observation about the "irrational," we can say that attention is something like a region carved out of distraction - not sheltered from it, but crossed by distraction and defined by a specific kind of relationship among distracted factors Attention can be thought of then as a type of gestalt, an afferent and centralızıng awareness hewn from a multıplicity of singular percepts In a sense, this makes attention a mode of distraction What distinguishes our contemporary situation then is not so much that our culture is "distracted," but that its highly reticular socio-economic base expresses another modality of distraction, one that flittungly decentralizes and ramifies awareness rather than gathering it around central point In other words, there's no "point" any more, but only a constellation of rhythmically and intensively conjoined moments of colours, flavours, odors, pressures, sounds, temperatures, excitements, and boredoms--Hume's pearls scattered over Deleuze and Guattarı's "smooth space" of bundled affects and symptomatıc matter No more huntıng gestalts, it's snark season

${ }^{105 a}$ Willıam James, Talks to Teachers on Psvchology, and to Students on Some of Life s Ideals (New York W W Norton, 1958), 80

105a Ibid , 79

${ }^{105 c}$ Sam Anderson, "In Defense of Distraction Twitter, Adderall, Lifehackıng, Mindful Jogging, Power Browsing, Obama's Blackberry, and the Benefits of Overstumulation," New York Magazme, 17 May 2009, my emphasıs

On the psychology of multitasking see Stephen Monsell and Jon Driver, eds, Control of Cognitive Processes Attention and Performance XVIII (Cambridge, MA MIT Press, 2000), Joshua S Rubınstein, David E Meyer, and Jeffrey E Evans, "Executıve Control of Cognitive Processes in Task Switching," Journal of Experimental Psychology Human Perception and Performance 27, no 4 (2001), Marlano 
music's ubiquity, the scission between performing and listening spaces gives musical

sounds an impropriety that allows them to circulate beyond their territory of expression to

become impersonal environmental qualities and something that one learns to listen away

from. ${ }^{106}$ Or, like architecture, which is rarely perceived apart from the lived economy of

the spatial array that it expresses, music (especially as tt has become increasingly

omnipresent) serves as a felt background from which one's attention can be detached

(i.e., be distracted) and given reign to drift towards more obscure perceptions and

sublimated tropes.

As such, Burrow's "insıdiously disorienting instability" is as much a function of

the way recorded music and a media-rich environment that it helps constitute invite us to

Sigman and Stanıslas Dehaene, "Dynamıcs of the Central Bottleneck Dual-Task and Task Uncertainty," PLoS Biology 4, no 7 (2006), American Psychological Associatıon, "Multıtaskıng - Switchıng Costs," March 20,2006, http //www apa org/research/action/multitask aspx

${ }^{106}$ Mechanization realızes the impersonal affective potential of music in two related respects First, recording technologies decouple music from its social pertinences (which by the way is what concert music has always aspired to) which grant it a form of autonomy that allows its sounds to be treated as a thing to be exchanged and circulated as any other thing Second, disarticulatıng the space of performance from the space of listening allows the affective profiles of a piece to circulate beyond the occasion $\mathrm{m}$ which their specificity was realızed Bodies that grow weary, that make mistakes, bodies that gather new potentrals from these, which in turn press upon and contınually modulate the futurity of the performance are restricted to the listener's side of things by recordings In addition to the saturation of the acoustic sensorium that mechanization has remaindered, and the escape of sound from sight's ordering habits, automation that $i s$ playback introduces a further degree of indifference that helps the listener abandon his/her traditional respect for the form or content of music in a way that gives attention permission to wander|wonder about its other interests while the musical sounds continue to act on the body, disciplining its fidgets and twitches Muzak's evil|genius was not that it sought to manipulate attention using music, but that it recognized, radicalized, industralized, and of course capitalized on what recorded music encourages - the eviction of music from its relatively recent status as fine art into the spins and stalls of everyday life

What I mean by this is that the habitual reception of musical sounds is an effect of the way music has, as a consequence of its mediatization, become an agentless feature of the environment such that it comes to be heard the way that street cars outside my apartment are-always to the side of another activity The consequences of this are both profound and curious In becoming a part of everyday life, music loses something - namely, its form, that principle of integrity so necessary for its membership into the fine arts What it gains by losing its distinctness, however, is a stickıness or emotional valence Theonst Ian Cross calls this property of music its "floatıng intentionality," a drıftıng aboutness that refers to the way it "can be thought of as gathering meaning from the contexts within which it happens and in turn contributing meaning to those contexts "106a While for Cross this ambiguity is something essential to all music, for me it specifies something about the way music has different effects according to how its realized by the attention 1t is given

106a Ian Cross, "Music and Meaning, Ambiguity and Evolution," in Musical Communication

(Oxford Oxford University Press, 2005), 30 
receive its call in a state of distraction. What this means is that part of Burrow's strangeness derives from the fact that we've been taught already how to listen "rhizomatically," how "any point [of listening] can be connected to anything other, and must be"; how listening "may be broken, shattered at a given spot, but it will start up again on one of its old lines, or on new lines." ${ }^{907}$ Because listenıng to music through recordings is central to contemporary industrial culture at large, this culture already pays "in-attention" to music in general so that the parts, the "lines of segmentarity," 108 that it tunes in and out of when "listening" to Burrow never form a complete image of the piece by which it might orient what it hears as a genre, a process, or as Arnold might say, a face "where an interpretation will be fixed, where it will be judged, approved or disapproved in the black hole of his eyes." ${ }^{109}$ In a sense, Burrow borrows from distracted culture its ramifying logic and its sleight of hand effects, but transposes these techniques into a more static context (that is, the context of listening through headphones) where perception undergoes a process of "fractal deformation," a process in which listening lives on bites of "increasingly fragmented gestures, features, images, that never add up, never amount to a whole body," $" 10$ to a form, an identity.

\section{Capture and Escape}

Every awareness begins in a shift. We think of ourselves as directing the shifts in our attention. But if you pay attention to paying attention, you quickly sense that rather than you directing your attention, your attention is directing you. It pulls you into your coming perception, which dawns on you as attention's next-effect.

\footnotetext{
${ }^{107}$ Deleuze and Guattar1, A Thousand Plateaus, 7,9

${ }^{108}$ Ibid , 9

${ }^{109}$ Alfonso Lingis, "Language and Persecution," in Between Deleuze and Derrida, ed Paul Patton and John Protevi (London, New York Contınuum, 2003), 177

${ }^{110}$ Mann, Masocriticism, 154
} 
Attention is the perception automatism that consists in tagging a change in the perceptual field as potentially important and building awareness on that change. ${ }^{111}$

There are a number of things to understand about distraction, but perhaps the most important to keep in mind is that it is coterminous with attention. Said another way, distraction and attention are different expressions of the same event much as buying and selling describe two sides of the same transaction. What determines the expression of one over the other is therefore a matter of context, how the affect of said event becomes effective. "Surfing" (the web), for example, is read as a distracting event if its effects are seen to interfere with one's productive capacity, such as the effect of memory loss or diminished analytical powers. Something like reading closely or listening intently will be taken as an attentive event to the extent that something productive comes of it: edification or emotional management. But as these examples suggest, what counts as "productive," and therefore what counts as an expression of distraction or attention, is highly contextual and circumscribed by a host of constantly shifting cultural norms.

The volatility of distraction|attention and its link to technology has become in the past ten years a hotly debated topic. Journalists Maggie Jackson and Nicholas Carr have each recently published books aimed at diagnosing contemporary distraction, and both see the powers of attention waning in light of the hegemonic role that communication technologies play in determining the priorities of life. ${ }^{112}$ Drawing similar conclusions, they argue that a network culture is a twilight culture and distraction the new moon of thought. But distraction is not entirely a symptom of recent technologies. Diversions have

\footnotetext{
${ }^{111}$ Brian Massumı, "Perception Attack Brief on War Time," Theory and Event 13, no 3 (2010)

${ }^{112}$ Maggle Jackson, Distracted The Eroston of Attention and the Coming Dark Age (Amherst, NY Prometheus Books, 2008), Nicholas Carr, The Shallows What the Internet Is Doing to Our Brains (New York, London W W Norton and Company, 2010)
} 
always been indicted as signs of potential degeneracy. The difference now is that the apparent surfeit of mass produced distractions seem poised to substitute their feints for the lunge. Siegfried Kracauer in "Cult of Distraction" (1926) and Walter Benjamin in "The Work of Art in the Age of Mechanical Productıon" (1935) each analyzed the condition of distraction in relation to an emerging mass culture. Both writers perceive distraction as a consequence of industrialization and take its filmic expression in particular to reflect something of the way modern culture represents and reproduces itself in and as "[a] fragmented sequence of splendid sense impressions." 113 While both applaud distraction's capacity to contaminate the pretense of aesthetıc modernism, rendering the notion of art's hallowed nature and the expression of an inward otherworldliness irrelevant to popular culture, they draw different conclusions regarding its ultimate role in the expression of dialectical materialism. For Kracauer, distraction was a means of both repressing and mirrornng the external conditions of mass culture, while for Benjamin distraction articulates a politics in that the cinematic manipulation of images on the one hand serve to distract-where close-ups expand space and slow motion extends movement--while on the other they convey the experience of reality's "constructedness" and thereby have the effect of teaching people to perceive "reality" as a plastic phenomenon. ${ }^{114}$

Benjamin and Kracauer's critiques, however, take place during the infancy of mass

\footnotetext{
${ }^{113}$ Siegfried Kracauer, "The Cult of Distraction On Berlın's Pleasure Palaces," in The Mass Ornament Weimar Essays, ed Thomas Y Levin (Cambridge, MA Harvard Unıversity Press, 1995), 326

${ }^{114}$ Adorno, however, critıcized Benjamin's revolutionary potentiation of distraction in his 1938 essay "On the Fetısh-Character in Music and the Regression of Listening" Where Benjamin argues that film lends itself to a distracted apperception of its whole that ultimately endows one with a kind of incidental power of critıque, Adorno, shifting the terms from cinematic vision to "easy listening" music, points out that "deconcentrated listening makes the perception of the whole impossible" and furnishes the listener, or viewer, with nothing but the charm of a "particular sensory pleasure " Adorno, "On the Fetısh-Character in Musıc," 305, 06
} 
culture and its proliferation of distractions, a time when distraction still referred chiefly to a form of "amusement," a time before distraction became a "burden." A more recent study by Joseph Urgo, which reflects on the cost of relieving the body of its labour, suggests that industrialized societies have unwittingly intensified the cognitive demands of their subjects by not only multiplying the things for consideration but converting these things into a supple form called "information." Urgo argues that because processing information has become its own form of satisfaction, it has become nearly indistinguishable from entertainment, and as information has become increasingly disembodied, virtual and ubiquitous, it has mutated from a "recipient- and source-bound phenomenon to independent, agentless phenomenon to environment." ${ }^{\text {115 }}$ But distraction is not solely cognitive; it has a material and affective logic that William Bogard refers to as a logic of escape and capture. "To distract something," he writes, "is to elude its clutches; but also, as a consequence, to now clutch it, secretly and from behind." $" 116$ Distraction is not simply a state of consciousness but a patterning, a way "to control movement, order desire and belief, and translate them into habits. ${ }^{, 117}$ In this sense, distraction is a way to describe a singularity, a metaphysical surface that refers to "a process of bifurcation" where two lines, one of capture another of escape, pull "in different directions at the same time."118 For Bogard, "in an age where simulation has become a dominant strategy of social control" distraction plays out culturally "by organizing [a body's] flows at a molecular level, at the interface of the cellular structure

\footnotetext{
115 Joseph Urgo, In the Age of Distraction (Jackson Unıversity Press of Mississıppı, 2000), 49.

116 William Bogard, "Distraction and Digital Culture," ctheory, 2000, http //www ctheory net/articles aspx?1d=131

117 Ibid

$118 \mathrm{Ib} 1 \mathrm{~d}$
} 
of the organism and the system of information." ${ }^{119}$ Here Bogard brings us back to the idea that distraction and attention are flip sides of an event. Which side gets expressed has to do with factors of speed and the way "differential flows of matter and energy" selforganize into "abstract machines" that "impart form to variable flows, or again, break their form apart and down.",120

Although looking at distraction in Bogard's quasi-materialist way opens distraction to other conceptual rhythms, I want to return to Benjamin's idea that mechanical reproduction and the distraction of cinematic effects desensitizes a public to the cult status of the art in a way that makes them "absentminded examiners." ${ }^{121}$ Basically, Benjamin is positing that through distraction the absentminded are able to incidentally (re)activate the powers of apperception. He argues in particular that film's expressive assemblage can be grasped in the same way that one's spatial surroundings are appropriated unconsciously, or "tactilely." As such, Benjamin contends, "Distraction as provided by art presents a covert control of the extent to which new tasks have become soluble by apperception." 22 This is to say that distraction possesses a homeopathic power to the extent that it produces an unconscious assemblage from disparate phenomena, or what philosopher Alphonso Lingis would call "a practicable field - a layout of means and ends, of paths, obstacles, and goals."

Art historian Christine Ross, whose work I drew on in the previous chapter, mobilizes the idea of distraction's homeopathic potential in relation to Rosemarie

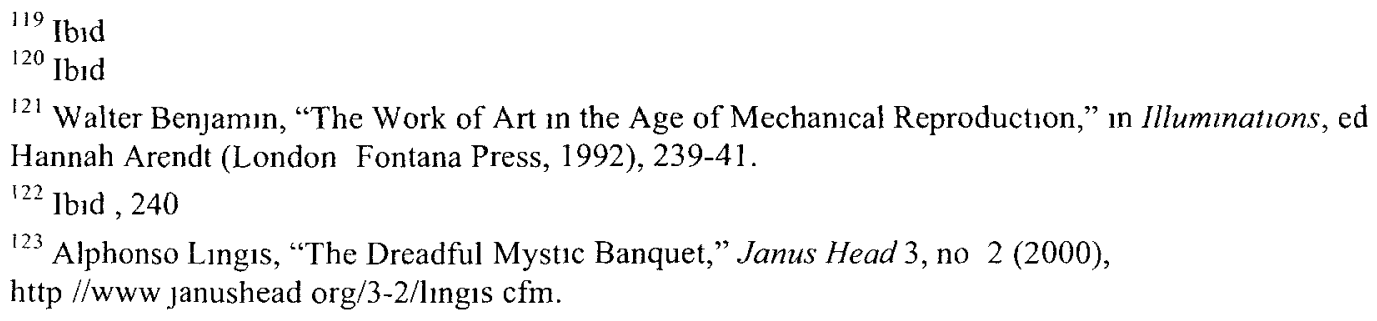


Trockel's 1999 Venice Biennale triptych-Eye, Kinderspielplatz and Sleepingpill. These three video installations-Eye, a large projection of a close-up human eye;

Kinderspielplatz, a slow-motion projection of a children's playground filmed between dawn and twilight; and Sleepingpill, another slow-motion video, which documents the quasi-event of sleep that takes place in a public mobile dormitory-revolve around what Ross calls "an activity of somnolent attention." 124 Ross argues that in these videos the anodyne of "entertaining" distraction is troped by staging and/or inducing the gloominess of a "weary" distraction. ${ }^{125}$ "The need for sleep," writes Ross, "is both a symptom of depressed fatigue and a means to regenerate the subject." ${ }^{126}$ The irresistible need for sleep has a kind of unmitigated power to disengage the most obsessive info-junkies from the choked and compulsive space of media distraction. Awake, we suffer the cancers of bright shiny things and murky blunt stuff. Asleep, we enjoy a nocturnal remission. For Ross then, Trockel's imagery of sleep and listlessness point to the regenerative powers of slumber and suggest that distraction's homeopathic properties offer a "cure" for the subject's failing faculties to the extent that the correspondences between disparities remains unconscious. ${ }^{127}$

While dreaming may indeed be a kind of absentminded escape/capture that in principle revitalizes one's deteriorated critical faculties, the sensory weirdness of being constantly distracted that describes our daily life suggests that the woolgathering of dreams are no longer entirely the office of sleep. The multi-perspective purview and

\footnotetext{
${ }^{124}$ Christine Ross, The Aesthetics of Disengagement Contemporary Art and Depression (Minneapolis University of Minnesota Press, 2006), 157

${ }^{125}$ Ibld , 178

126 Ibid

${ }^{127}$ Ibid
} 


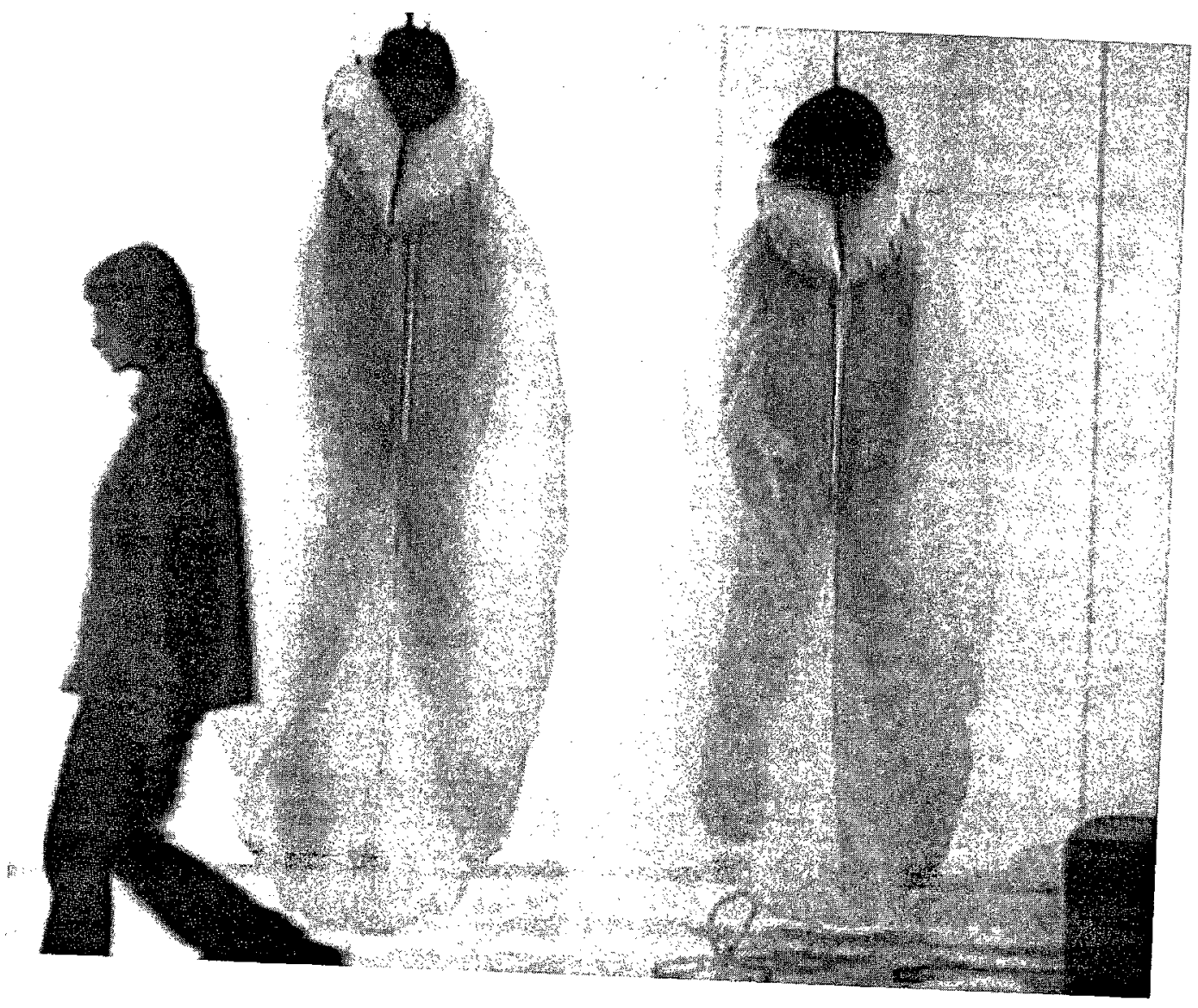

Sleepingpill (1999)

Rosemarie Trockel 
strange coeval omniscience/ignorance that describes the lived economy of dreams, an economy where the dreamer is also the dreamed and the dreaming, has seeped into wakıng life. In the same way that an industry decision to include original artıst recordings in their soundtrack along with their schmaltzy renditions blurred the lines between background and foreground musıc, ${ }^{128}$ but also owing to the ubiquity of audio playback devices that allows us to background our own tastes, the line between dream and quotidian logic has blurred. The "lateral vistas of information that stretch endlessly in every direction" ${ }^{\prime 29}$ describe the mechanics of both dreams and networked culture. And furthermore, the vaporous possibilities of dreams are matched in waking life by what Brian Massumi calls the "fog of potential" of contemporary culture's "threatenvironment," an ecology of dread in which a constellation of "effects, swirling into complex relation, give any number of competing logics and alternative presidings a chance." 130 Here then (again) is Baudrillard's "hyperreality," where simulacra orbit one another, "substituting the signs of the real for the real."131 Hyperreality, writes Bogard, "is our current mode of distraction, and our current mode of capture." 132 If a dream is the dream of another dream and by dreaming a dream is to dream a dream dreaming then dreaming dreams that dream dreams is to dream the dreaming of dreams dreaming.

\footnotetext{
${ }^{128}$ As an industry terms, foreground music is strictly speakıng, "music programming that consısts of songs in their original form, as recorded by the original artist "Jonathan Sterne adds that this music "operates at the levels of taste and distinction, differentiation and association," and rather than being organized around style, they way background music organizes its playlists, foreground music is organized "according to marketıng categories like 'top 40' or 'adult contemporary' "Sterne, "Sounds Like the Mall of Amenca," 31-32

${ }^{129}$ Sven Birkerts, The Gutenberg Elegtes The Fate of Reading in an Electronic Age (Boston Faber and Faber, 1994)

${ }^{130}$ This quotation is taken from a draft version of an essay that appears in Massumı's forthcomıng work, from MIT Press titled, Semblance and Event Arts of Experience, Politics of Expression

131 Jean Baudrillard, Simulaci a and Simulation, trans Sheıla Glaser (Ann Arbor University of Michrgan Press, 1995), 2

${ }^{132}$ Bogard, "Distraction and Digital Culture"
} 


\section{Lull ))) ))) )))}

Sleep is perhaps not the potent remedy for distraction that Ross sees in Trockel's videos. The little death that sleep gives to thinking is inaccessible because we keep waking up in dreams. But these dreams are not only optical, they are also acoustic.

Following Marshall McLuhan, who insists that humankind dwelled in an acoustic world before writing modulated the ratio of sensorium towards the visual, Paul Hegarty argues that after writing, "Our eye becomes ear... as we can no longer close it-images surround us acoustically."133 "The total visualization of culture," he writes, "frees the image from its grounding in representational meaning." 134 Similarly, music becomes increasingly transparent (invisible actually) with each layer of mediation, to the point that it becomes "a pure medium of itself." 135 This is how dreams work. As the protagonist in the 2010 film Inception says: "Dreams feel real while we're in them. It's only when we wake up that we realize that something was strange." Acoustic space is all around us and in us, and as Steve Goodman contends, this makes sound a primary vehicle for shaping reality: "Vibration research ensures a ubiquitous media environment in which any surface

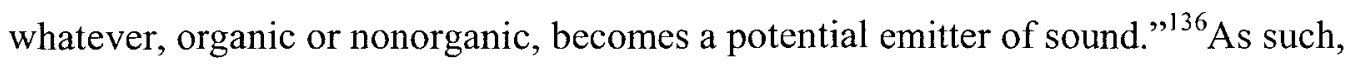
"Muzak preempted our submersion into a generalized surround sound culture, the insidious purr of control and the digital modulation of affective tonality that smoothes the

\footnotetext{
${ }^{133}$ Paul Hegarty, Notse/Music A History (New York Contınuum, 2007), 135

${ }^{134} \mathrm{Ibld}$.

${ }^{135} \mathrm{Ib} 1 \mathrm{~d}$

${ }^{136}$ Goodman, Sonic Warfare, 143
} 
experience of the ecology of fear." ${ }^{\text {337 }}$ Perhaps then it's better said that after writing, where the purr of acoustic control is the closest thing to a ground in an "unstoppable, directionless, sound world," 138 we don't sleep. Instead, we "lull." We linger in a state between dreaming and waking.

This in-between state, depending on whether you're waking up or falling asleep, is called hypnopompia or hypnagogia, respectively, and is characterized by the onset of sensory aberrations and hallucinations ranging from evanescent things like sparkling or spinning threads of light, whispered voices, the feeling of falling ("hypnic jerk"), and wafts of partially heard melodies, to more elaborate and dramatic scenarios such as being beheaded. ${ }^{139}$ The spectral nature of this state gives its expressions a valence that lends descriptions of it to the poetic. But also, because partially heard fragments of music figure regularly in these hallucinations, this between state has found its way into music. The recently nominated genres of Hauntology and the apt (but kind of silly) Hypnagogic Pop are perhaps overt examples of how music expresses a cultural lull. Both styles refer chiefly to a retro electronic music steeped in a sensibility for the fictional, or (keeping with the apparitional signifiers) the "spectral" nature of nostalgia. Specifically, groups

${ }^{137}$ Ibıd , 143, 44.

${ }^{138}$ Hegarty, Notse/Music, 135

${ }^{139}$ See Andreas Mavromatıs, Hypnagogia The Unique State of Consciousness between Wakefulness and Sleep (London Routledge, 1987), and Jeff Warren, "The Hypnopomprc," in The Head Trip Adventures on the Wheel of Consciousness (New York Random House, 2007). Prior to their scientific investigation beginning in the $19^{\text {th }}$ century, these oneirogogic images and percepts were elaborated in fantastic terms, often interpreted in a culture's terms of the supernatural The description of falling asleep given by the narrator in book one of Proust's Remembrance of Things Past is a classic illustration of hypnogogia

For a long tıme I used to go to bed early Sometımes, when I had put out my candle, my eyes would close so quickly that I had not even time to say to myself "I'm fallıng asleep And half an hour later the thought that it was time to go to sleep would awaken me, I would make as if to put away the book which I ımagıned was stıll in my hands, and to blow out the light; I had gone on thınkıng, whıle I was asleep, about what I had just been readıng, but these thoughts had taken a rather peculiar turn, it seemed to me that I myself was the immediate subject of my book a church, a quartet, the rivalry between Françoıs I and Charles V 
like Mordant Music and Pocahaunted mine the past for sounds that act the way Frederic Jameson suggests signifiers in a postmodern age do: they serve as codes for the affections of an era's style that can be "cannibalized" and made into "a field of stylistic and discursive heterogeneity without a norm." "140 While perhaps no different from other postmodern "neo-isms" that follow a logic of pastiche, what gives these haunted musics their peculiarity is a sensibility for what music critic David Keenan calls "wasteland 1980s cultural signifiers." 141 Appearing in often drone-heavy and noise-inclined music as samples or raw material whose deformation embodies the musical logic of the work, it is these signifiers that give the work their spectral identity, or as musician and writer Emilie Friedlander puts it, the sound of this "lo-fi post-noise psychedelia" that blends outmoded media's high noise to signal ration with an affected anti-virtuosity, aims to perform what is now the clichéd "deconstruction-of-the original" trick that supposedly "acknowledges pop's hold over us while using it to build an alternative to that reality.", 42

A similar sensibility and fondness for the effects generated by "trailing-edge" technology and non-virtuosity is also realized in contemporary composition; however, the points of nostalgic reference are not quite the same. Rather than sampling 80 s pop culture with contemporary technology, one can hear composers recycling the tropes of experimental art music from the 1950s and 70s, tropes that Michael Nyman compiled and categorized as "indeterminacy," "process," "ephemerality," and the "non-identity" of a work. But we can also hear the debt to conceptual art and free jazz that helped evolve experimental music in the 1970 s into sound art, something that Hauntology and

\footnotetext{
${ }^{140}$ Fredric Jameson, Postmodernism, or, the Cultural Logic of Late Capitalism (Durham, NC Duke Unıversity Press, 1991), 17.

${ }^{141}$ David Keenan, "Hypnagogıc Pop," The Wire, August 2009, 29

${ }^{142}$ Emilie Friedlander, "Horizons What, If Any, Are the Politıcs of Hypnagogic Pop?," Visitatıon Rites (2009)
} 
Hypnagogic Pop don't exhibit owing to the rock and dance background of their practitioners. Most importantly, though their aesthetic sensibilities diverge in many ways, this kind of composition shares with Hauntology and Hypnagogic Pop a kind of sadness and a desire to construct an alternative reality by lulling the listener with a shower of charms. By coaxing attention away from the depths of the music and scrambling the customary relationship between its formal object and aural symptoms, a strange, alluring apparition appears that "brings objects directly into play by invoking them as dark agents at work beneath those qualities [that express it]." ${ }^{\prime 43}$ This skewing of the object and its qualities is the condition of "charm," and charm's schızogenesis is the condition for the invention of a point, of a singular reality that revolves around its own fiction. And this happens not strictly as a matter of pastiche, but also as an effect of one's being continually distracted by the murmuring qualities that these musics bathe us in.

Bangkok-based composer Hugh Peaker writes music that lulls. Species of Space \#16 (2009), for instance, hallucinates a world of continuous deformation in which perception twists around its own processes, becoming alternately distracted and attentive in a way that articulates the extremely pliable and supple space of musicalized sound. A slow moving work (11') with a uniformly soft dynamic throughout and marked by understated but highly intoxicating glissandi in all the non-keyboard instruments, SoS\#16 is scored for a typically contemporary ensemble that mixes classical with electrified instruments characteristic of jazz, 70s pop and early synth music. ${ }^{144}$ But unlike Arnold's Burrow Music, which appeals to the habits of listening to recordings in order to make an ambient distraction effective, SoS\#16's strategy for leading listening into distraction is to

\footnotetext{
${ }^{143}$ Harman, Guerrlla Metaphystcs, 50

${ }^{144}$ Specifically flute, Fender Rhodes, Wurlıtzer EP203W Cası PT30 Organ, Amplified Fretless 'Jazz' Guitar, Violın, or Viola, or Cello (harmonics only), Cello, and Fretless Electric Bass
} 


\section{Hugh Peaker, Species of Space \#16 (2009) excerpt}

- Flute tunes a quarter tone flat Intonation may be treated as ornamental Slight glissandi are indicated by lines - Guitar, Cello, and Bass ghissandi are indicated by lines Where there is no indication, glissandi are to be played with an upward slide not greater than a major 2 nd As with the flute, glissandi are to be played in an improvisatory manner

Species of Space (\#16)
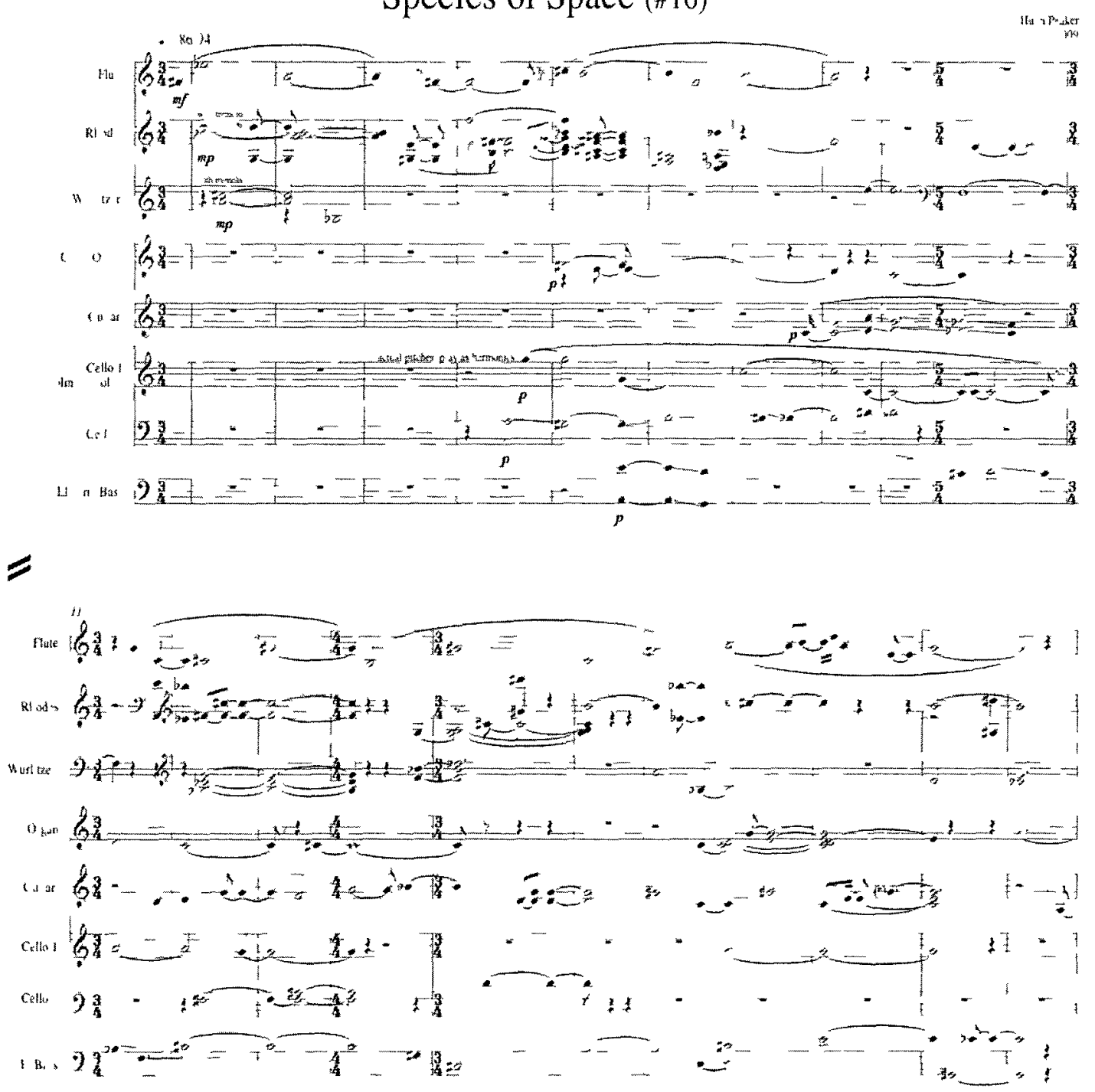
simulate some of the conditions of background music within the fixed space of the concert hall.

What is notable, or rather, un-notable about background music of the Muzak variety is the way that it conceals itself. Muzak is hidden not simply by its relatively low volume, but by its constant presence. That 1s, Muzak's continuous broadcast makes it become like the sound of the ocean or freeway traffic that over time is filtered from conscious awareness owing to a process of sensory adaptation, selective attention and sensory gating. ${ }^{145}$ The sounds don't go away or cease to have an effect on you, but are instead tempered and modulated, appropriated to the wider ecology of one's behaviour, as for instance when one habitually raises his or her voice when coming home from the quiet of the office. But to subtly thwart the deadening effects of these psycho-biological automata while still relying on them to prevent sensory overload, Muzak arrangers employ a technique that helps convey a sense of continuty without the music having to go anywhere. Piggybacking on the already naturalızed and therefore invisible design of a broadly recognized pop-music repertoire, continuity is simulated by varying the mostly uniform texture of the work using the simple but effective trick of re-orchestrating the same material. ${ }^{146}$ Though SoS\#16 doesn't exactly follow this technique, it employs its principle of variation of the same ${ }^{147}$ by shuffling nearly-similar gestures of non-

\footnotetext{
${ }^{145}$ For a brief overview of these functions see Dennis Coon, Psychology A Journey (Toronto Nelson Thomson Learning, 2009), 154-57

146 a technıque also much used by Morton Feldman to the same effect

${ }^{147}$ Repetition of the same difference refers to Deleuze's weird reworking of Nietzsche's "eternal return" where the only thing that returns is difference, an endless proliferation of "first times" that accumulate Identity effects (sameness) as each moment relays its singularity to the other As Leonard Meyers argues, variations of the same difference have an effect on listening that disturbs or muddles habits of expectation in a way that confounds rather than obliterates attention's reflex to buld awareness on a perceived change As such, attention is frustrated not to the point where there is no point - that would be the nirvanic ideal of minimalism-but to the point where its call to action and reaction is deflected towards other "manifestations," manifestations that are not necessarlly "musical" or even acoustic See Meyer, Emotion
} 
functional harmony and directionless melodic fragments among and between the instruments. Although minimalism's trance effects are well-noted precedents to the kind of listening that this sets up, the languid and a-metrical (floating) undulations of SoS\#16 dispose attention to a listening that is characteristic of Morton Feldman's music, especially his later works like Coptic Light (1985) and For Samuel Beckett (1987). ${ }^{148}$

\section{Listening to SoS\#16's Lull )))))}

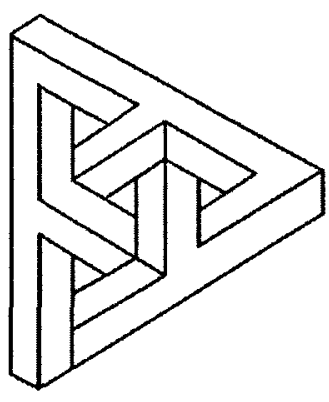

At first, listening is taken by the surface strangeness of the collective glissandi and the way the rich instrumental colours interact with the sundry sonic artefacts to weave the sonorous equivalent of an impossible figure whose parts achieve coherency but whose whole does not. In this state listening is lulled by the glissandi's tendency to keep attention "on," to keep it poised and in a diffused state of autonomic readiness. Then it twists, dopplering the accumulated sensations (many of which are not sonic: knitting a brow, bladder pressure) that transpire around its points of interest, listening leans into the next moment, surrounded by a halo of inchoate perceptions-half-formed melodies, intimated harmonies, and budding intensities - a vagueness thickens and focus blurs. Eventually, a fog of incipience suffused with a hazy sense of "felt moreness"149 grows around attention, blanketing it in a garden of forking paths. Distraction. Why am I thinking about my holiday at the ocean? My back is aching. The hydro bill is due

\footnotetext{
and Meaning in Music

${ }^{148}$ Hegarty writes that noise music also participates in this economy of variation on the same difference, suggestıng that, "Ears get used to a fixed level of sound, however loud, so alteration, and continual shifts in tones, rather than a mess of white noise is how the "noismess' is assured " Hegarty, "General Ecology of Sound"

${ }^{149}$ Massumı, Parables for the Virtual, 141
} 
tomorrow. I miss her... Listening turns inside out and away from the music without ever crossing an edge-lulled.

The wanders of attention, which is to say, the proliferation of distractions that compose the heard surface of SoS\#16, mimic the experience of "surfing" the web. "Surfing," writes Brian Massumi, "sets up a rhythm of attention and distraction."150 With each click, as with each pulse of concentration we direct at the warbly surface of SoS\#16, we "serially experience effects, accumulating them in an unprogrammed way, in a way that intensifies, creating resonances and interference patterns moving through the successive linked appearances."151 “Link after link," Massumi continues, "we click our way into a lull.", 152 And this lull is the expression of what he calls a "transductive momentum," the strange allure of potentiated relays that compel attention despite "the meagerness of the constituent links on the level of formal inventiveness, or uniqueness of content. $" 153$ SoS\#16 too displays a meagerness of formal inventiveness. Enter at any point and be carried along, up, down, side-to-side, by the same wobbling rhythm. Turn attention "here," where the different glissandi swivel around a middle $\mathrm{C},{ }^{154}$ and find it seconds later over "there" when a cool night air ruffles the hair on my arms while I wait for a street car. In both surfing and listening to SoS\#16, attention pivots on the strangely active immobility of the body. For as with any restrained activity, such as reading a book, listening to a record, or clicking links, the motor tendencies to act in some way on sensations that become a work's intensive field and its emotional gestures are "reduced to

\footnotetext{
${ }^{150}$ Ibid , 139

${ }^{151}$ Ibid, 138

152 Ibid , 139

153 Ibid, 141

${ }^{154}$ See, for example, the cello and electnc bass parts in excerpt at mm. 9-11
} 
a minimum and short-circuited by being turned in on the body." ${ }^{155}$ Incipience. The body at rest is only actually so.

Through letters [or in this case, through vibrations] we directly experience fleeting vision-like sensations, inklings of sound, faint brushes of movement. The turning in on itself of the body, its self-referential short-circuiting of outwardprojected activity, gives free rein to these incipient actions. ${ }^{156}$

Listening, distractedly even, is full of lively wrinkles and the "living change of nonactuality." 157 But for Massumi, the vague and "impending moreness" that characterizes internet surfing, as it did television before, occasionally "sharpen[s] into a selective perceptual focus or a clarity of thought that strikes the foreground consciousness in a flash of sudden interest or even revelation." 158 For Species, however, attention mostly lulls and takes the fog of incipient perceptions as a substance animated by a withdrawn but lurking object. Species lingers in a cloud of "inklings" that don't so much sharpen into focus or clarity as much as they undergo a homeomorphic deformation that turns them inside out, that performs a convulsive set of operations between doing and un-doing which continuously redefines and recontextualizes its own hesitations.

\section{(((((Listening Away))))))}

The act of listening away that realizes music as a background phenomenon is closely tied to the nineteenth-century ideal of autonomous concert music. This may seem counterintuitive and historically anachronistic since the concert form premises itself on an explicit act of listening to music and is preceded by other types of incidental music

\footnotetext{
${ }^{155}$ Massumi, Parables for the Virtual, 277, n 10

${ }^{156}$ Ibrd , 139

${ }^{157}$ Ibid , 277, n 10

${ }^{158}$ Ibıd, 140
} 
(e.g. tafelmusik). But if you think about the circumstances of a concert you can

understand it as an enchantment ritual whose way of conjuring its daemon requires spells to dampen the affectivity of the body's non-aural senses, ${ }^{159}$ but also spells to turn attention away from the rebarbative din of everyday life. To realize this musical superstition requires that the participant listen away from the "accompanying circumstances of the concert institution that contradıcts its idea." 160 That is, to realize music as an autonomous actıvity, an activity wholly separated from the heterogeneous interests of life's clamorous desires and strident demands, one has to actively exercise a practice that "excludes or annuls the "un-artistic," or more reasonably, "makes it relative." 161 The concert does this of course through its ideological summons, but is aided by a spatıal design that enforces the separation between the site of music production and the site of its consumption, and a self-consciousness performed through non-acting actsacts of shutting-up, and staying still. This formula for listening to the acoustic spectacle is therefore also a formula for listening away from the noise of necessity, away from the racket of socio-economic complexities that both underwrites the concert's autonomy and contradict its ideals.

\footnotetext{
${ }^{159}$ The body is what reminds us that we are utterly dependent creatures and it is what we need to be able to experience sound as music in the first place The body is where our capacity to respond is located. In fact, it could be argued that the body is itself constituted as a site of responses, a nexus of capacities that become focused and directed according to what sets upon it. Bergson makes this point in Matter and Memory when alluding to contemporaneous discoveries of the human nervous system

"If we cast a glance at the minute structure of the nervous system as recent discoveries have revealed it to us, we see everywhere conducting lines, nowhere any centers Threads placed end to end, of which the extremities probably touch when the current passes this is all that is seen And perhaps this is all there is, if it be true that "the body is only a place of meetıng and transfer, where stımulations recesved result in movements accomplished "-Henn Bergson, Matter and Memory, trans Nancy M Paul and W Scott Palmer (London, New York G Allen \& Co and The MacMillan Co , 1912), 227

${ }^{160}$ Hanns-Werner Hesster, "Music in Concert and Music in the Background Two Poles of Musical Realization," in Companton to Contemporary Musical Thought, ed John Paynter (London Routledge, 1992), 51

${ }^{161} \mathrm{Ib} 1 \mathrm{~d}$
} 
There are two points to be taken from this observation: the first is that the act of "listening away," which in its concert mode realizes musical sound as an autonomous aesthetic object to be listened to, also (negatively) realizes background music in that what is being "listened away to" is not the din but the "musicky" bit. The second, though it needs to be explained still, is that both concert music and background music treat Music as something autonomous, owing to their mutual belief in what Hanns-Werner Heister calls the "secular defunctionalization of music." 162 Despite the seeming remoteness of these two modes of realization, they are genetically related by virtue of their faith in music's "emancipation from its particular aims and usage."

But whereas concert music (CM) realizes this by raising itself to the level of its culture's ideology of equanimity and fraternity, background music (BGM) effaces those processes that would belie the ideal character of its object through the mediations introduced by the technical reproduction of music. Though these two "autonomies" have different effects that are exploited to different ends---aesthetic and commercial respectively - both concert music and background music revolve around the same virtual object that is free from the gluey and murky affections of social and historical mores. However, whereas concert music orients listening away from the bodies that produce it and towards the effects that flicker over the surface of these bodies, background music reverses this and pitches listening away from the virtuality that recordings effect and towards the interaction of bodies. Said another way, CM listening is centripetal; it gathers attention around the way sounds can be perceived heard unfolding a series of internal relays while dampening the affect of other sensations that occur alongside it so that things

\footnotetext{
162 Ibid., 55.

163 Ibid.
} 
like "feeling" are converted into so many weeds in the sound garden. BGM's listening on the other hand is centrifugal; it scatters attention and distributes the vitality embedded in sound among the host of co-present sensations in a way that modulates their relevance.

While both CM and BGM can be understood as different expressions of an idealized sense of musical autonomy, only recorded music wholly excuses Music from the specificities of its occasion. That is, recordings allow for musical sounds to sound without concern for what else is taking place around them, so much so that their eidetic autonomy is maintained across even the most dramatic change of events. A recording can continue sounding Sinatra's soothing croon throughout a gun fight that leaves a heap of bodies on the street. Film has actually used this property of recording, its radical decoupling of performance and listening space, to great effect, particularly in its capacity to express irony (as in the opening scene of David Lynch's Blue Velvet, in which a schmaltzy pop song expressing the tranquility and continuity of the suburbs ignores the sudden death of a man watering his lawn). It's not that recording technology accesses a hitherto inaccessible dimension of music ${ }^{164}$ inasmuch as it isolates an underdeveloped capacity for music to be realized as a purely affective accessory. The "isolated, dull and unidentified biogenic moments... of 'atmosphere,' charm and feeling", ${ }^{165}$ that concert music's emphasis on formal relations remainders are, for recorded music, shuttled to the background as absolute content.

\footnotetext{
${ }^{164}$ Tafelmusık (table music), which was traditionally performed durıng or after meals was, for instance, in some respects a precursor to Muzak insofar as it was perceived affectively, in the way musical sounds were taken account of for the mood they conjured rather than for their internal formal relationships

${ }^{165}$ Heister, "Music in Concert and Music in the Background," 58
} 


\section{Muzak's Way ${ }^{166}$ of Dreaming Ubiquitously ))))}

${ }^{166}$ Notes on Muzak

"Over stımulated, individuals can no longer be affected by increases in data alone" "166a Muzak used to rely on what the company called a "stimulus progression," a fifteen-minute segment of adjusted musical energies that would alternate with fifteen minutes of silence († See "quantum modulation.") Intended to "offset the decreases in worker efficiency during mid-mornıng and afternoon slumps,"166b Muzak's sensual caress, like preindustrial "musick," presumed to give the flux of things a temporal fix that could be modulated so as to affect one's mood that would counteract the workday's lethargic trajectory So more than simply pleasing background musıc, Muzak, writes Ronald Radano, "aıms to portray itself as "a psychologically active, sonic accompaniment, carefully designed to remain below the threshold of common attention "166c In addition to its bio-physiological effects, when Muzak was programming its own denuded versions of popular songs, it presumed a psychic/symbolic consensus of Western culture "because it massifies symbolism in which not few but all can participate "166d But this consensus was not a conspicuous one, for "The net effect is an anonymous sound field seemingly devoid of directly perceivable musical meanıng "166e As such, the shared meanıng of Muzak is something that one can only dream, an anonymous reverie to keep those "pre-cognitive 'corporeal techniques' that register a concern for the body" distracted- $-1 \mathrm{~m} /$ pre-pet sonal concerns like those which appear in repetitive jobs "an arm lowered at the wrong tıme, a slower step, a second's ırregularity, an awkward gesture, gettıng ahead, slıppıng back "166g

For Muzak these organısmic irruptions are what its refrains aim to discipline, or to opıate Yet uronically, Muzak's incessancy and the low-level intensity that is intended to tranquilize these signs of Iffe in revolt, life striving for novelty, actually have the effect of multiplying them, but onlv in their incipiency By producing conventionally arranged versions of familiar tunes whose unabashed transparency "minimizes the introduction of new musical stımulı, and by "broadcastıng continually and quietly below the dynamic level of normal speech, [which] 'hides' [its sound] from the listener," Muzak creates what Radano calls "a framework for simple being " "The language of Muzak," of consensus music-our shared reverie - he says, "establishes [a] sonic order, [that] induces the individual, alone or in a group, to let the mind wander where it pleases, to respond to stımuli in a multitude of ways "In other words, the anarchy of sensation is taken care of, managed, so that, "the individual is free to think, to rhapsodize, to create, to worry, to wonder "166h The mind supposedly comes to life here because it's been relieved of the burden of its corporeal engulfment However, the nature of these thoughts is such that they remain undetermined Like a dream in which one experiences only a series of fleetıng visions and sensations-impressions whose possibilities remain bundled in potential--our responses are pinched at the moment of emergence As noted above, Massumı writes that these are inciptent perceptions, "a turnıng in on itself of the body's activity, so that the activity is not extended toward an object but knots at its point of emergence "1661 So while Muzak "places the responsibility for creating a meaningful expenience in the realm of the recerver," ${ }^{66 j}$ it only lets him dream these experiences rather than live them

${ }_{166 a}$ Robert Sumrell and Kazys Varnelıs, Blue Monday Stones of Absurd Realttes and Natural Philosophes (Barcelona Actar Editorial, 2007), 124

${ }^{166 \mathrm{~b}}$ Sumrell and Varnelis, Blue Monday, 115

${ }^{166 c}$ Radano, "Interpretıng Muzak," 450

${ }^{166 \mathrm{~d}}$ Dr James Keenen, Chaırman of Muzak's Board of Scientıfic Advisors, quoted in Sumrell and Varnelıs, Blue Monday, 118

166e Radano, "Interpretıng Muzak," 450

${ }^{166 f}$ Ben Anderson, "Time-Stılled Space-Slowed How Boredom Matters," Geoforum 35 (2004) 749

${ }^{166 g}$ Robert Linhart quoted in Ben Highmore, Everyday Life and Cultural Theory An Introduction (London, New York Routledge, 2002), 160

${ }^{166 \mathrm{~h}}$ Radano, "Interpreting Muzak," 451, 452, 457

${ }^{1661}$ Massum1, Parables for the Virtual, 139

${ }^{166 j}$ Radano, "Interpreting Muzak," 457

\section{$\uparrow$ Quantum Modulation}

Durnng the early 1990s, Muzak developed a programming logic in order to differentiate their original artıst recording soundtrack from common radıo playlısts Unlıke the stımulus progression, whose logic revolved around manıpulatıng an individual's mood over an extended period of time by gradually introducing more energetic music, quantum modulation focuses on the production of contınuity and "maintainıng a flow that 
does not vary in 'intensity' "†a Whereas the stımulus progression might be thought of as creating a wave of musical energies on which a person's affectivity rides, quantum modulation can be understood as generatıng homeostasis by virtue of the way some songs share an intensive affinity In a sense, quantum modulation was Muzak's response to the way in which it posited that contemporary listeners were more commonly listening to music the way they would read traffic signs-namely, in passing In general, people don't stay with music long enough to be affected (their movements or mood) by gradual or progressive changes in tempo, melody, rhythm Modulation now comes in discrete packets, in "quanta "What happens, specifically from Muzak's point of view, is that listening in packets "primes" precepion, that is, the listener's hearing and forthcoming attention-and presumably desire - are conditioned by the nonconscious rehearsal and potentiation of perception during what psychologists call "attentional blink "Here, the micro-events that populate this fractional pause in awareness have the capacity to modulate the formation of a coming perception Brian Massumı's examination of this phenomenon distınguishes "priming" from the more famuliar notion of subliminal influence Writing that priming "conditions emergent awareness rather that causing a response (reproducing a preexisting model) it implies complex thought-lıke processes occurring as a nonconscious dimension of emergent perception "tb In other words, priming describes an unconscious and creative preparation by the nervous system that modifies, indeterminately, the intensity and significance of a coming perception Thus, insofar as "attentional blink" arıses "between successive changes in the perceptual field," ${ }^{\circ}$ and musical sounds literally constitute such a field, the act of hearing music is rife with primes This is doubly so both in the way that change immanent to a musical field-1 e change in harmony, tempo, orchestration-develops its own series of "blinks" that "prime" the series of perceptions which compose what is called "the music itself," and in the way that musical sound--as a medium whose materiality implicates itself in the processes of awareness that are had through $1 t^{\text {" }}$ - introduces a change in the larger perceptual field of haptic, osmic, and interioproprioceptive sensations that constitutes yet another series of blinks and primes that modulate the way a perception and desire will emerge

As such, for music to affect perception in a culture where attention is more commonly defined by its division and switchiness, it (music) has not to cut so deeply into the already scored fabric of dally awareness, but to cut quickly and decisively Musical sound has to introduce a change that will open a gap in a rapidly shıftıng and only partially active attention where its structures can be "pre-rehearsed on the nonconscious level in the form of emergent patterns" " interpellated into the dimensions of priming, music disposes perception to the peculiarties of the way it acts as structured and structuring medium, peculiarties that Shepherd and Wicke argue are particular to how musical sounds are materially involved in callıng forth and bindıng with states of awareness, especially affective states Thus, musical priming has a different effect from other sensory phenomena in that it conditions perception to develop or advance along lines that elaborate the isomorphic relation that musical sounds have with affective states This is essentially Susanne Langer's theory of "semblance," but nuanced to encompass the everyday rather than the concerted interactions that one may have with musical sound

The affectıve semblance between musical sounds and states of awareness is something that is constantly sought out, cultivated and negotıated by listeners in everyday life A more delıberate and exacting example that makes attempts to harness the way musical sounds condition perception to incline along an affective serıes is Muzak's technique of "Atmosphencs "Shıftıng from their outmoded "stımulus progression" that posits long-term histening, where one's mood is gradually modulated by slowly increasing the intensity of the music on the playlist, Muzak developed a way to qualify a retail space by quantifying various musical criteria like "rhythm, tempo, title, artist, era, genre, instrumentation, and popularity " $\rightarrow \mathrm{f}$ By indexing these values and compositing a playlsst where "the same intensity can be maintained even as the music appears to have changed," "†g Muzak's sol-disant "Sonic Architects" devised a way to infect space with "an absolutely consistent identity and unchanging mood "th The unıform intensity and sly cross-fading that seamlessly connects different songs while giving the impression of change, serves to prime perception in a way that inclines the affections of the itinerant and intermittent listener towards the affections that the retaler imagines their products can induce The important thing to take from this is that quantum modulation aims to modulate the interests that guide perception by introducing a discrete change in the perceptual field-from the general din of mall traffic to the focused drive of a techno beat-that will condition the way attention may unfold 
Through the disarticulating effects and utter ubiquity of sound technologies that permit music, any music, to be everywhere and nowhere, one is able to effortlessly fold its refrains into the routines of everyday life. And like so much of everyday life, we've learned how to forget it, how to unlisten to music, or rather, how to apprehend it through the vapors of distraction. Anahid Kassabian has commented on the situation of musical omnipresence and proposed the notion of "ubiquitous listening",167 as a way to conceptualize how contemporary subjects have been conditioned to in-attend to musical sounds. Basically, "ubiquitous listening" refers to how being continuous exposure to music breeds a mode of audition that "tak[es] place without calling conscious attention to itself as an activity in itself." 168 This listening is done most often on those occasions when "we listen 'alongside' or simultaneous with other activities"169 such as when we cook, shop, shower, drive, type, take a commercial break, or walt in line for a coffee. ${ }^{170}$ Here music becomes a simulated vitality keeping company with the drought of routine and the irritation of being between things rather than an art.

But ubiquitization isn't new. Music recordings and other audio technology have been around for a long time disarticulating listening from its conditions of production.

\footnotetext{
${ }^{165 a}$ Sterne, "Sounds Like the Mall of America," 32

${ }^{165 b}$ Massumı, Massumı, "Perception Attack," n 3.

$165 \mathrm{c}$ Ibid

${ }^{165 d}$ John Shepherd and Peter Wicke, Music and Cultural Theory (Cambridge Polity Press, 1997), 108-24

${ }^{165 e}$ Massum, "Perception Attack," n 3

${ }^{165 f}$ Sterne, "Sounds Like the Mall of America," 32

${ }^{165 g}$ Goodman, Sonic Warfare, 144

${ }^{165 \mathrm{~h}}$ Sterne, "Sounds Like the Mall of Amenca," 32

167 See Kassabıan, "Ubiquitous Listenıng and Networked Subjectivity"

${ }^{168}$ Ibid.

169 Ibid

${ }^{170}$ Kassabian has recently applied the notion of inattentive listening and ubiquitous subjectivity to so-called "world music" whose conspicuous placement in coffeeshops articulates what she calls "distributed tourısm " See Anahid Kassabian, "Would You Like Some World Music with Your Latte? Starbucks, Putumayo, and Distributed Tourism," Twentieth Century Music 2, no 1 (2004)
} 
This has not only made music a commodity by giving it a form that can be exchanged (LP, CD, cassette, Mp3 file), but has had the effect of making music something increasingly sourceless and thereby dismissible or easily ignored. Neither the form nor the content here matters. Only volume does. All styles and genres function equally well as background, easing the daily hell of other people and filling out the liminal spaces that make up more of life than we care to admit. Music's ubiquity has turned its sounds into a "form of phatic communication [whose] purpose is to keep the lines of communication open for that lumpy deployment of dense nodes of knowledge/power we call selves."171 Sounds that work to keep our tongues moist and our sociality lubricated. But as Baudrillard reminds us that "the medium and the real are now in a single nebula whose truth is indecipherable,"172 there's no longer a discernable difference between background and foreground, between phatic expressions and informative ones. So if neither background nor foreground, then music, in its ubiquitous phase, is more like a membrane or affective film that cleaves the desires of our private realities and public worlds to one another. From room to room, home to work, office to concert, lobby to pub, taxi to bed, we pass dreamily through several skins of musical "hellos."

\section{We don't (((listen))) anymore}

Or at least we don't pay the kind of attention to musical sound that (it's been suggested) we used to. The evidence of this might be the rise of $\mathrm{AD}(\mathrm{H}) \mathrm{D}$ (attention-deficit hyperactivity disorder) and strangely, the increasing prevalence of time-based art. We can't, however, as the patrons of "good taste" or defenders against false consciousness

\footnotetext{
${ }^{171}$ Kassabian, "Ubiquitous Listening and Networked Subjectıvity"

${ }^{172}$ Baudrillard, Stmulacra and Simulation, 83
} 
do, blame this on Muzak. While most people have little compunction in turning their iPods off in the middle of a song that its playing, there's an almost punishing guilt for leaving a concert performance, or worse (if you can imagine this), putting headphones on while the musicians are still sweating away onstage, commanding our attention with all the powers that any sovereign in his court would assume. Contrary to what Nick Groom writes, Muzak is not a "sleight of hand." The honey it drips into our ears is not directly responsible for the reversal of figure and ground that "displaces attention from music's manifest content to...the more "surreal' latent content." ${ }^{, 73}$ The whole condition of recorded music is responsible for this.

So while Muzak enjoys a depreciated status among critics and musicians, programmed music is in fact a more fully developed expression of musical autonomy in that it unhinges music's occasion absolutely from any specific or special time and/or place as well as from any particular use or meaning. The iPod (among other sundry audio devices) realizes this potential just as well and differs from Muzak only insofar as the latter wears its commercial interests and capital letters $\left({ }^{\mathrm{TM}}\right)$ a little higher on its sleeve. What bothers people about the BGM industry - though really "those people" are mostly musicians and music critics who are threatened by the way musical taste develops in relation to MTV, video games and more recently, internet radio's algorithmic "recommender systems" that predict musical preferences based on user profiles and past selections - is that it spoils their perception of music's capacity to "move" them. It's not the liquefaction of all those "personal, idiosyncratic, and human qualities of authenticity, of originality" ${ }^{\prime 174}$ that disturbs people - entire sub-cultures have developed around the

\footnotetext{
${ }^{173}$ Nick Groom, "The Condition of Muzak," Popular Music and Society 20, no 3 (1996) 3

${ }^{174}$ Radano, "Interpretıng Muzak," 452
} 
elimination of intimacy's mystifying qualities (Yes, I'm referring to the promiscuous spasms of Disco, ${ }^{175}$ but I could also be speaking about the sweaty anonymity of the ecstasy-charged Rave culture of the late-1980s/early-90s) — it's that the specifically affective potential realized by music's withdrawal from the foreground and its sinking into shadow makes it feel at like an anonymous sonic matter that is free for our personal investments, but that once invested it should not to be defamed by making it anonymous.

Essentially an extension and transfiguration of McLuhan's speculations on how media affect the ratıo of our senses and how sound technology promises to recover something of the auditory and haptic space anesthetized by print media, ${ }^{176}$ Kassabian proposes that our musically saturated environment teaches us to listen ubiquitously. This way of listenıng, however, is difficult to track down in perception for it obscures its own operations by drawing attention to aspects of a situation that are not it (music) but are in fact partially given by the way musical sounds, like an architectural array, modulate the conditions of perception. ${ }^{177}$ Listening ubiquitously is in some sense not exactly something that is done but something that is "undone" so that music can behave as "a quality of the

\footnotetext{
175 "The Disco Decade is one of glitter and gloss, without substance, subtlety or more than surface sexuality The Disco Decade is the era when intımacy and close personal connections are to be avoided even with the self In the $1960 \mathrm{~s}$, of course, Americans would have given anything for somethıng as mindless and impersonal as disco, an escape hatch from the social responsibilities, from the shouting and shoving in the streets Now we have found the answer All we have to do is blow dry our protein-enriched hair, anoint ourselves with musk oll, snort another line of cocaine and turn up the volume After the lofty expectations, passions and disappointments of the 1960's, we have the passive resignation and glitzy paroxysms of the Disco 1970's After the poetry of the Beatles comes the monotonous bass-pedal bombardment of Donna Summer" Robert Vare, "Discophob1a," New York Times, 10 July 1979 ${ }^{176}$ See Marshall Mcluhan, Understanding Media The Extensions of Man (New York McGraw-Hill, 1964)

${ }^{177}$ Michel Chion theorizes this effect in the phenomenon he calls synchresis, "the spontaneous and 1rresistible weld produced between a particular auditory phenomenon and visual phenomenon when they occur at the same time" Michel Chion, Audio-Vision Sound on Screen, trans Claudia Gorbman (New York Columbia Unıversity Press, 1994), 63
} 
environment," appears so due to the way conscious perception comes only after we've attuned to the various lure of things that populate our field of perception and blend with our memories. In this sense, ubiquitous listening makes music virtually imperceptible. As such, any music is welcomed, for so long as they satisfy a mood musical sounds escape the capture of genre- the habits of form - and become instead an affective residue that thurifies the affairs of the occasion. But curiously, to listen ubiquitously is to habituate hearing, and because habits are what bind us to a particular set of behaviours and thereby to specific orders of class and moral aptitude, ubiquitous listening has the effect of formalizing its formlessness. But (again), and more curiously, in becoming habitually ubiquitous, listening forgets its own form like breathing forgets air, and thereby regains something of the formlessness of its operation. What Kassabian wants to say then is that we've contracted a habit.

\section{The (((Sound))) of Habits}

Paul Harrison suggests that habits are an individual's and culture's "enunciative frame," an armature of capacities "defin[ing] what it is possible to see and to say." "179 Habits are eminently enabling, they respond to the task of becoming that we might think is what an organism is-namely, they are the ways for life to be accomplished, to be effective. Yet at the same time, while habits enable, the field of action and meaning they organize diminishes "the potential, or virtuality, of the body to do things otherwise." ${ }^{180}$ Habit

\footnotetext{
${ }^{178}$ Kassabian, "Ubiquitous Listenıng and Networked Subjectıvity"

${ }^{179}$ Paul Harrıson, "Makıng Sense Embodıment and the Sensibılitıes of the Everyday," Environment and Planning D Society and Space 18, no 4 (2000) 506

${ }^{180} \mathrm{Ib}$,d
} 
seems to make life possible but at the cost of restricting the range of the life that can be lived. But Gail Weiss, drawing on the work of Deleuze and Merleau-Ponty, suggests that habits are expressions of our capacity to connect inventively with the world. "Habits," she writes,

do not mire human beings in the world or even in its given habitus; rather, they allow...new syntheses to be established between the body and its world, syntheses that are passive to the extent that they express a dynamic engagement with the world. ${ }^{181}$

But it's also the nature of habit, the habit of habit, to disappear in its contraction. Indeed, to contract a habit is already to be dwelling within a field of sense. The pathways in which out actions cleave to the world merge with the gestures and forms of conduct that express habit's occasion. In a sense, the behaviors that manifest the contraction of habit make habit illegible as such. Only in interruption or the ill fit of its actions to a situation can we read the lines of a behaviour as habit. Indeed, Deleuze argues that we are composed most of molecularized habits and that "We speak of our 'self' only in virtue of these thousands of little witnesses which contemplate within us." ${ }^{\text {182 }}$ However, despite habit's illegibility it continues to affect behaviour by suggesting, indeed prompting, ways to in-habit the world. In other words, habits modalize reality and may be understood as invisible ways of seizing the world, infra-legible ways of taking account of the expressive profiles that are given to us in the contraction of difference over time. Habits then are expressive drifts in the delirium of an abstract potential. I write "drift" because habits, while promoting a certain kind of sedimentation that grows things like styles and

\footnotetext{
${ }^{181}$ Gall Weiss, Refiguring the Ordinary (Bloomington Indiana University Press, 2008), 90

${ }^{182}$ Gilles Deleuze, Difference and Repetition (New York. Columbia University Press, 1994), 74
} 
institutions, draw their power (affect) and their efficacy from the very difference that they, as delimiting forms, contemplate. In other words, habits also changc.

It of course is its own kind of habit to say that we use music to "make us feel" a certain way, or to understand how to feel feelings. ${ }^{183}$ This is to say that it is a cliché to take the intensities of music and in-fold them into our bodies (without organs) as habits, affective habits. But even habits have to be maintained and the repetition that breeds habits also exhausts them. Deleuze is clear about this, stating that difference inhabits repetition and that "habit draws something new from repetition-namely difference." 184 Thus while habits are contracted by circumscribing a difference internal to repetition, a difference that makes a difference effective, the same force of repetition attenuates this same habit's enablement. Every occasion in which habit would contract a certain range of actions introduces another difference that gradually dislocates the efficacy of that habit. Habit, if we recall Weiss's thought, is the expression of a power to connect with a world of difference and to draw effective relays from it. Habit is therefore a veritable force of consistency that operationalizes delirium.

Ubiquitous listening is a contemporary habit that is unconsciously exhibited and reinforced by contemporary (un)listeners. And like any habit, its subliminal modifications make it a skill for negotiating the swerves of difference that its very forgetting remainders. The fidgets, twitches, cramps, yawns, and partial awareness that accompany ubiquitous listening are reminders of a vital capacity, reminders that cultural geographer Ben Anderson calls "pre-cognitive "corporeal techniques" which "register a concern for

${ }^{183}$ See Jo Tacchi, "Radıo Texture Between Self and Others," in Material Cultures Why Some Things Matter, ed Daniel Miller (Chicago University of Chicago Press, 1998); T1a DeNora, Music in Everyday Life (Cambridge and New York Cambridge University Press, 2000), Michael Bull, Sounding out the City Personal Stereos and the Management of Everyday Life (London Berg, 2000).

${ }^{184}$ Deleuze, Difference and Repetition, 73 
the body in action and consequently act to make the present moment, the 'now' of lived experience, habitual once-again "185 Accordingly, ubiquitous listenıng can perhaps be thought of as the contemporary subject's "task" to contract habits of listening to difference, not the kind of difference that rolls out themes and variations, but the differences that are co-present with these, differences-like a growing fatigue or filling bladder - that are usually backgrounded when listenıng attentıvely but which overflow awareness when listenıng distractedly Puttıng listenıng asıde is how one listens to difference as such

\section{Sound-Effects}

In addition to the modal and polyphonic character of Martin Arnold's music is an obscure timbral richness, a murky intensity that we might qualify as "noisy" owing to the way the score elicits "sound-effects" from an unusual orchestration of parts and/or the way the work is crafted to emphasize the overlooked dimensions of sound production and/or the odd way that Arnold combines relatively consonant elements to draw an occulted discord between them Take his string quartet Contact, Vault (1997) The texture is unabashed modal, a homophony (modulatıng here and there) that stumbles along like a friendly drunk after closing time But the individual parts are executed with each performer employıng a string technique whose delicate nature has a high yıeld of unintentional sounds For example, the first violn part plays col legno tratto, the second violin pizzıcato, and the cello col legno battuto throughout The viola plays with a standard bow technique, however, its tone is heavily affected by a metal practice mute which produces a thin "nasal" quality that is in keeping with the way this string quartet is denied the

${ }^{185}$ Anderson, "Time Stılled Space Slowed," 749 

occasional ornament) unless otherwise instructed
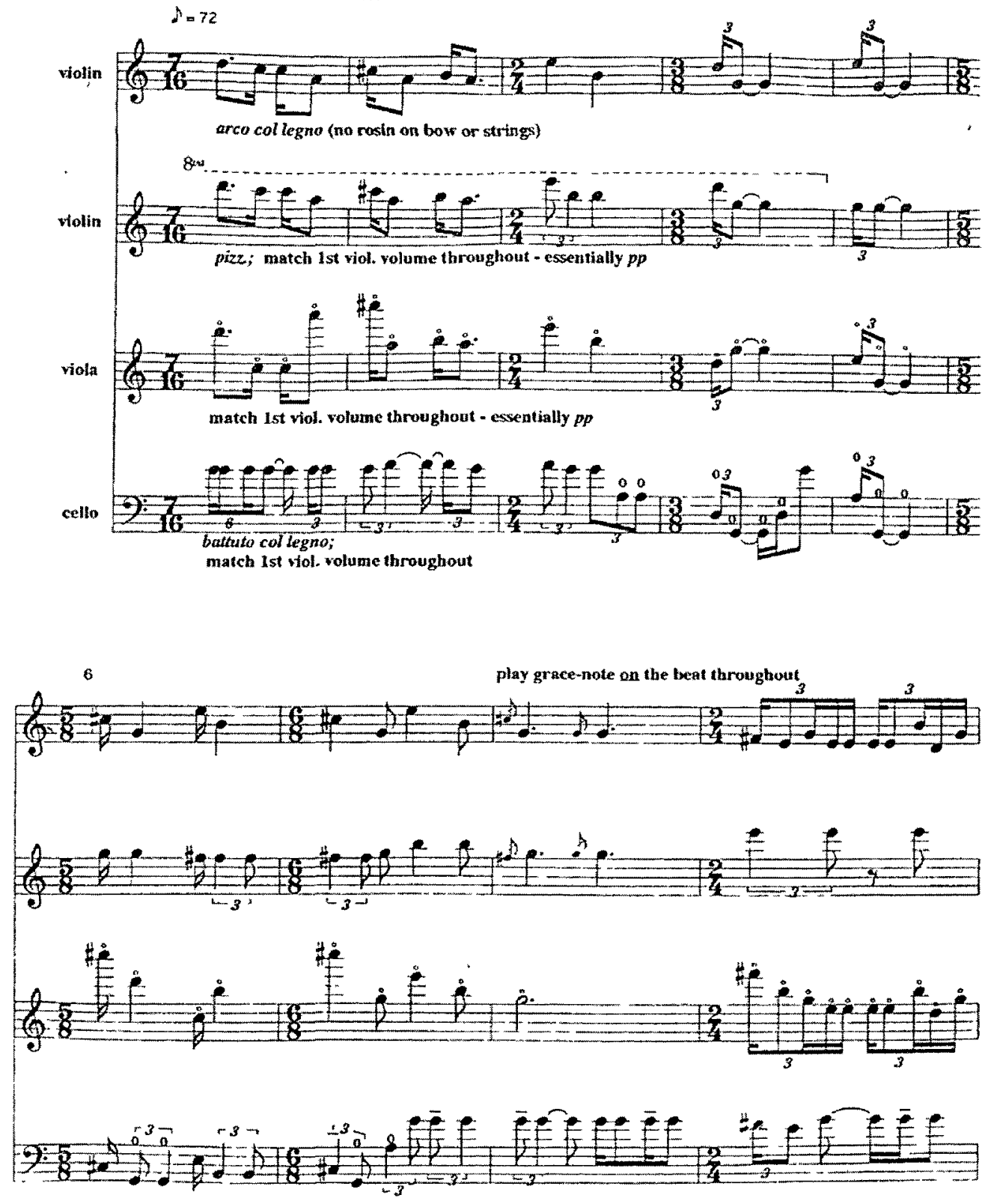
Romantic residues that still cling to its contemporary form. These gauzy sounds, composed of an almost equal amount of non-pitch as pitch, are not, however, structurally salient. Instead, their noise-character freights the sensuous aspects of the work that give Contact; Vault its charming colour.

These "sound-effects," though their cause can be precisely stipulated, possess a degree of unruliness that edges them towards the category of noise. Though harmonically interesting, without these effects Contact; Vault would lack the singularity that makes it stand out from within a very traditional concert form. Furthermore, the way Arnold plays musical and non-musical (i.e. noisy) sounds off each other results in something that is difficult to describe as anything but exquisite. There's an elegance here that refuses to allow the scratchiness of the col lengo tratto violin or the nasal whine of the viola to disturb the musical scene that it helps create. In fact, if we take this from the side of avant-garde norms, these noises are integral to the music and cannot be categorized as noise. ${ }^{186}$ However, when listening to the piece these two "sides" of the musical surface never fully unite; instead, their profiles alternate the way the figures in Wittgenstein's famous duck-rabbit image do.

The reason for this dithering is that Western musical culture as a whole has become more interested in the "sound of sound" owing to the way recorded music allows the listener to escape the fictions of closure invented by the sentence of the concert hall and in turn to be captured, "dazzled," by the immediate caress of vibratory complexes (i.e. cool-sounding sounds). Although "technology has liberated listeners from the

\footnotetext{
${ }^{186}$ This is the fundamental anthropomorphism that Douglas Kahn argues contamınates the avant-garde's claims to a sonic universality Where the noise of the universe can be appropriated to music, it is no longer noise but music, just music with an expanded palette See Douglas Kahn, Nolse, Water, Meat A History of Sound in the Arts (Cambridge, MA. MIT Press, 1999), 74
} 
completeness of form, ${ }^{, 187}$ in a way that affects every listener living in an industrialized society, it finds a particularly acute expression in the avant-garde's "moment time" or "vertical time," a nonhierarchical duration exemplified by works such as Stockhausen's aptly titled Momente (1962-64/69), or in a more mysterious way (because of the use of traditional musical devices), Stravinsky's Symphony of Wind Instruments (1920) or Czech-Canadian composer Rudolf Komorous' Tango (1986). Recalling that the “perception of the sound is more important than consideration of the 'composition' as an entity in and of itself," 188 listening, as Adorno radiated, has become "atomized." "All that is realized," writes Adorno,

is what the spotlight falls on-striking melodic intervals, unsettling modulations, intentional or unintentional mistakes, or whatever condenses itself into a formula by an especially intimate merging of melody and text. ${ }^{189}$

For Adorno, the undisputable soporific effect of atomized listening is likened to a regression of listening and the dilution of social consciousness. But for those of us whose "fundamental experience of listening to music was through recording," the "diversion of interest from the whole...to the charm of color" ${ }^{190}$ is a misconception, for under the light of our "acousticized" world, a world of complete electric definition, the "whole" is just as much a simulation as the individual sensory pleasure of isolated charms are. As such, the soporific effect - the lull — that arises from the experience of serialized perceptual charms, like surfing the Internet, is not an expression of false consciousness but a veridical one, a fact. Or at least it is for us Lotus-Eaters.

\footnotetext{
187 Jonathan Kramer, The Time of Music New Meanings, New Temporalities, New Listening Strategies (New York Schrimer, 1988), 69.

${ }^{188}$ Hosokawa, The Aesthetics of Recorded Sound, 8

${ }^{189}$ Adorno, "On the Fetish-Character in Music," 305

${ }^{190}$ Ibid, 306
} 
From his perspective, Contact; Vault expresses a metaphysical ambiguity that inheres between music-to-be-listened-to and music-to-be-heard (through-distraction). By staging itself as concert music, and therefore as a music-to-be-listened-to, yet drawing itself around "striking melodic intervals, unsettling modulations, intentional or unintentional mistakes"-charms_Contact; Vault vacillates between being heard as music-to-be-listened-to and being not heard as music-not-to-be-listened-to. Noise as a stable category in this enterprise disappears from the scene, but so, too, does music. Each category instead lives tactically and momentarily in the other's field and takes turns becoming the other's theme. When sound starts to behave like both a foreground and background, when the glitter of ornaments become the premise of form, musicologist Ronald Radano suggests that "it might best be thought of not as music but as a sonic form standing at the nexus of music and noise." 191

While conforming to harmonic logic it encourages non-reflective, non-intentional listening. Traditional forms of musical reception are disrupted, producing a lowlevel cognitive response. [It] becomes a shadow-a likeness of music-for which the formalist arguments of value and quality are simply irrelevant. In virtually all cases the receivers do not scrutinize and examine [it] as an art object; most barely even know it is there. The trouble with calling [it] music is that for the listener it hardly exists; its effect, while powerful, is largely subliminal - beneath the level of critical discourse. ${ }^{192}$

Although this describes the kind of listening that Contact; Vault invites, the "it" that Radano refers to here is actually Muzak.

Like Muzak infra-legible phenomena, Contact; Vault doesn't negate the internal purposiveness (purposiveness without [external] purpose) of its form, but simply makes it irrelevant. Contact; Vault's almost inaudible quality of an explicitly tuneful and timbrally

\footnotetext{
${ }^{191}$ Radano, "Interpreting Muzak," 457.

192 Ibid.
} 
rich melodic texture is reminiscent of Muzak's subliminal schmaltz: lush orchestration of popular melodies buzzing just loudly enough to be heard but not listened This "buzzing" draws attention away from the formal and reflexive design of the work by incessantly returning awareness to the particular sensory pleasure of its sound. However, in a sense Contact; Vault has a privative beauty. Unlike Muzak whose anonymity and technologically elaborated everydayness simply opts out of the musically beautiful, Contact; Vault clutches it from behind. Beauty is skewed rather than negated by a strangeness that breaks on the familiar, by the charm in staging a failure to be beautiful in order to be what it is.

\section{))))) Charm and Dissatisfaction}

Lest it seem that a love of charm is all there is to this music, I want to consider how these charms, which in the atomized listening that contemporary culture's addiction to the now constitutes as ephemeral and irregular phenomena, articulate a kind of dissatisfaction.

While the disinclination for Contact; Vault to make its formal properties important is indicative of informe, a disinclination that also makes the work "exist as if it were music and at the same time as if it were noise," 193 its intensity is not negatively valenced in the way expressions of informe usually are. As I suggested, Contact; Vault is charming; its disturbance is veiled and understated. As such, it implies a different kind of listening desire that works to invent a perceptual space adjacent to the burdens of taste by declining to endorse the presumed inevitability of perceptions that present themselves as though they were the necessary result of contingent historical processes. Refusing to

\footnotetext{
${ }^{193}$ Hegarty, "General Ecology of Sound."
} 
endorse the inevitability of certain perceptions in terms of "form," conveys dissatisfaction with the perceptions of the world as it has bee received, especially as those perceptions that are rendered as "fact" This dissatisfaction revolves around the premise that perceptions are not neutral but are possessed of a kind of rhetorical force which places pressure on the perceiver to endorse or affirm their reality In the case of "fact perception," this pressure is particularly intense, for "facts" are tied to epistemes in which their givenness is normatıve, "normatıve not only of actions, but of likes and dislikes, thoughts and feelıngs "194 The attempt to escape from this pressure, if only for a moment, by looking away from the world as it is given and cultıvating an attraction towards "perceptions that seem below or marginal to normal appearance,"195 constitutes a practice that Rer Terada names "phenomenophilıa"

Phenomenophilia, which draws on "the romantıc and post-romantic discourse of mere appearance," 196 is neither confrontational in the sense elaborated by modernism's avant-gardes, nor alternatively beautıful, but rather a kind of "queer desire," a desire that reflects a solipsistic appetite for perceptual experience that "no one can be imagined to share, approprate, benefit from, or push one to endorse "197 "The beauty of phenomenophilia," writes Terada, "1s the mirror image of Kant's proto-communitarian beauty," a somewhat a-social beauty that contrasts with the traditional and coercive notion that "the perceiver must feel as though everyone should agree that the object of contemplation is beautiful "198 Phenomenophilia therefore consists in flırtıng with "off-

\footnotetext{
${ }^{194}$ Terada, Looking Away, 3

${ }^{195}$ Ibld

${ }^{196}$ Ibid , 4

${ }^{197}$ Ibld , 6

${ }^{198}$ Ibid , 23
} 
beat perceptions" and a quasi-beauty that can't be shared, or if it has to, a beauty that someone else doesn't have to share But phenomenophilia is also characterized by a feeling of guilt or shame, a feeling that one shouldn't be or doesn't have the right to be fascinated with these a-social percepts The artistic costs, which is to say the Kantian communitarianism of aesthetic expenence, are decisive, for insofar as the normative prescriptions of "art" rely on the objectificatıon and, in principle, the shareability of a thıng's aesthetıc propertıes, lookıng or listenıng away from shared perceptions exempts the off-beat from becoming "art" One's toy involvements may be aesthetic, but their hermet1c nature precules them from being "art"

Though rife with such off-beat impressions that would make it a prime example of phenomenophilia, Contact, Vault is perhaps so explicit in its discontent with the given world of the string quartet that it misses phenomenophilia's distinctive diffidence Indeed, while Amold asserts that in Contact, Vault "all kınds of lines-of-flight can erupt and spill out delirious associatıons and speculations," he also writes, "I've tried to reinvent the string quartet, to turn it into a strange collection of quiet, insidious, and hopefully wonderful, discrete instruments" "As Terada notes, "Unlıke straightforward derogations of the given world that believers in another reality feel free to express," phenomenophilic dissatisfaction "insinuates a reservation it never articulates "200 Arbold is not reserved He wants to reinvent the strıng quartet. What distınguıshes phenomenophilia from the more famıliar avant-garde gesture that Contact, Vault is guilty of is an attitude that fails to either affirm or deny (which is to negatıvely assert) the world as given, but simply aims, without any sense of a right to, "to be relieved of fact

\footnotetext{
${ }^{199}$ Martın Arnold, Author's notes "Contact, Vault"

${ }^{200}$ Terada, Looking Away, 24
} 
perception's demand and the normative concepts that go with it."201 This tactic of withdrawal is crucial for it articulates a dissatisfaction that one feels no right to express and so can only insinuate it. Terada argues, "In looking away there is neither a perceived right nor an imperative to negation, only an awkward silence suspending negation and affirmation." 202 This means that music aiming to create phenomenophilic effects is in a sense flummoxed and discomposed by its own hopes of being (non)music, for (non)music is itself a thing, a reification of certain facts about sound and listening that cannot help but oblige an endorsement from the listener. To step outside this process of reification and the pressure of facts is, however, impossible. But Terada remarks that the "very desire to withdraw from what [one] perceives is worthy of respect, and this desire does not need to be linked to any future possibility." ${ }^{203}$ Phenomenophilia relinquishes the will to art: "Looking away rests content with evanescent perception that cannot be shared, and lets the chance at art go." 204 This is something that Paul Hegarty echoes throughout Noise $\mid$ Music, but makes explicit when writing about the ecstatic aspirations of a certain species of free jazz. He suggests that "the 'freeing up' that comes out fleetingly in the experience of 'freeing up' music" indicates an attempt to surpass the limits of individual or collective expression. ${ }^{205}$ This is self-defeatingly premised on "the gain of subjectivity," but it can still, Hegarty continues, "signal the limits of the mundane world [of fact] in trying to leave that world behind. ${ }^{, 206}$ Thus "its failure is a sovereign one, a

\footnotetext{
${ }^{201}$ Ibld., 187.

202 Ibid., 188

${ }^{203}$ Ibid , 29

${ }^{204}$ Ib1d , 174

${ }^{205}$ Crowley and Hegarty, Formless, 47

206 Ibid
} 
worthwhile one that remains impossible to quantify or value."207

However, Terada notes, "artists are always pulling phenomenophilic tricks"208 and so their work might be thought of as exciting perceptions that take place alongside the unavoidable affirmation of their art. That is, composers like Arnold and many of the others discussed in this chapter try to invent occasions of charm from within the coercive gaze of art, ways of perceiving or side-perceiving that are "aesthetic without being artistic." 209 Though the perceptions seen/heard by looking/listening away can never be "art" without compromising their "unfactive" and thus non-coercive nature, they can occur as a background of quasi-perceptions surrounding art's optimally resolved forms. To speak then of an aesthetic that belongs to the "listened away to" is to summon the image of a divided attention where one half-visits the shapes and forms that crystallize in and as art's sensuous object, while the other cavorts with the ambient affections and "clouds of qualities surrounding such an object. ${ }^{, 210}$ In a sense, an aesthetics of listening away is an aesthetics of distraction, for you can never listen directly to(wards) a work's charm, to what Graham Harman describes as "a black noise of muffled objects hovering at the fringes of our attention," 211 you can only listen to the side of it, to the form (object) that it is not, where your satisfactions flourish, illegitimately, behind your back.

So while Arnold's defamiliarization of the string quartet certainly evokes the kind of divided listening that, in its dissection, makes the things that happen to the side of it shine a little brighter, it lacks the hesitancy and internalized intolerance that marks the

\footnotetext{
${ }^{207}$ Ibid.

${ }^{208}$ Terada, Lookıng Away, 174.

209 Ibid.

${ }^{210}$ Harman, Guerrilla Metaphysics, 183.

211 Ibid.
} 
phenomenophile's conviction that he has "“no right'...to his dissatisfaction." 212 In Arnold's work, charm seems always in usufruct to concert music's traditional role as an autonomous object and is thereby entitled to its culturally and historically accumulated transports. This makes Contact; Vault perhaps too confident of its diversions and marvels so as to disqualify its strangeness from articulating the self-sensed intolerance that the phenomenophile has for being "attracted to the way things appear to him, to his own awareness that they appear to him.",213

A better example of this phenomenophilic diffidence can be heard in the work of Toronto composer John Mark Sherlock. Informed by the same experimentalist sensibilities that pervade Arnold's and Peaker's music (though displaying a stronger commitment to the abstractions and almost anti-melodic tendencies that characterize Morton Feldman's brand of experimentalism), Sherlock's work exhibits a palpable compunction or even contrition that is arguably connected to the cultural malaise that I described in the first chapter. However, there is something more dour than resignation in his work, something almost rueful that he hints at in an interview: "After things were completely dismantled by the music of the 1950 s and ' 60 s, we don' $t$ have much left to work with without treading over the same ground: post-modernism? I'm just holding on to the floating detritus; the flotsam remaining after it all went down." 214 one more day in the empire (2006), like many of Sherlock's compositions, is scored for variable instrumentation. And like many more of his works, it stages its own failure. In essence, Sherlock's compositions are recipes for disaster. But they're strangely harmless disasters.

\footnotetext{
212 Terada, Looking Away, 24

${ }^{213}$ Ibid , 22, my emphasis

${ }^{214}$ John Mark Sherlock, Interview with Otıno Corsano, ARTPOST info - The Art Information Portal for Galleries and Art Buyers, 2006
} 
Almost all of his pieces are deceptively innocuous looking a single time signature (usually $3 / 4$ ), a grand staff, eighth-notes, quarter-notes and grace-notes, rests, and no dynamic markıngs The instructıons, however, complicate this

1 Players may play any, all or none of the notes

2 Although the tempo should be close to that marked, precise alignment of various instruments in time is not necessary If one player is still playing after the others finish, that player should play out to the end

3 Players need not rehearse together even of they choose to rehearse on their own 4 Any instrument may play - and it would be desirable that they do so - any note as a harmonic either at pitch or in a different octave, ad libitum, with some restraint 5 Please do not improvise pitches or durations Grace notes going to nowhere can be treated as light staccatı or tenutı

6 Dynamics are free but should not exceed mezzoforte

7 Ema1l sherlock@neithernor com for further clarıfication There 1s a chance that you may not receive a response In that case proceed as you would with a dead composer ${ }^{215}$

The result is almost always the same Usually the musicians are confused Their part $\iota s$ the score itself, which invariably has too many pitches for any one instrument to play (some of which occasionally extend beyond even the most generous instrument's range), entails a supremely awkward execution, or both Additionally, even though the instructions stıpulate that "precise alignment of various instruments in time is not necessary" and that "players need not rehearse together" (or at all), often the ensembles that have performed his works attempt to do both of these, and both they do badly For a variety of reasons one more day in the empire usually ends up being the combined result of self-doubt, hesitation, tentativeness, imprudence, impatience and simple bewilderment. The product, or rather the by-product of these scores is a musical impulse that revolves around the exploitation of confounded competencies In the recorded version of this work the clarınet, Fender Rhodes, Clavinet, Wurlitzer, and e-bowed electric guitar parade all of these affections While a transcription of the pitch and rhythmical deviations from the

\footnotetext{
${ }^{215}$ John Sherlock, Performance Notes, One More Day in the Emprre 2006,
} http //www nethernor com/sherlock 1 1/ 
John Mark Sherlock, one more day in the empire (2006)_-Original"

one more day in the empire

3718040606

sherlock
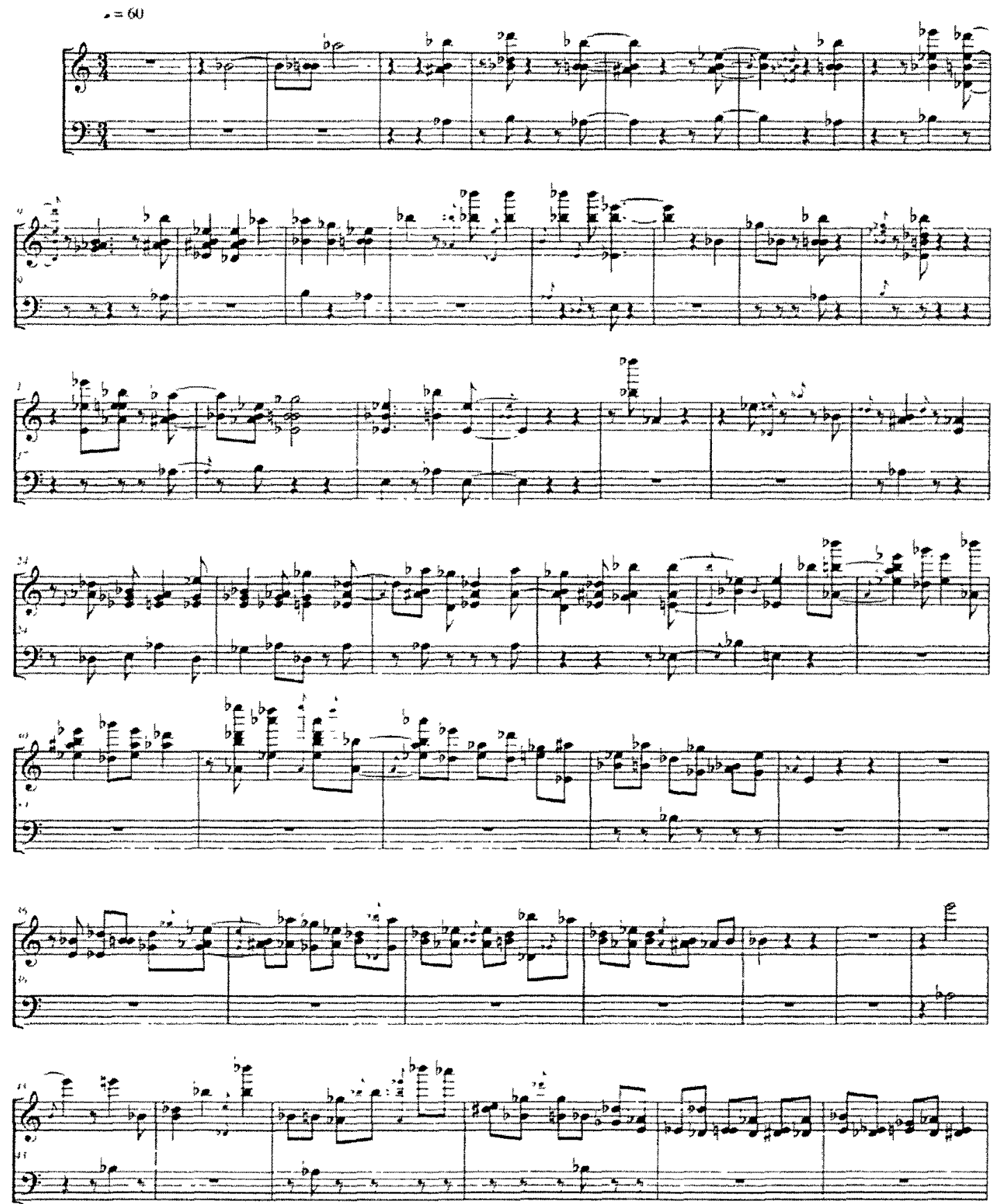
original score would represent an aspect of the work's fortuity, it wouldn't get at the way these embodied perplexes and intensive failures are received in listening. For one thing, the versioned score would just be another score of one more day in the empire, though one tremendously more complex. As an indeterminate work, one more day... is not compromised but realized by its deviations, and so any rendering of any one performance will in principle simply be-one more day in the empire. Secondly, the listener (almost) never sees the score and more often than not hears the piece only once ${ }^{216}$ and so cannot even participate in the effect of expectations and inhıbitions that deviations are supposed to excite. A better sense of one more day...'s charm can be more easily and effectively imagined with a more "impressionistic" rendering by virtue of the way the strangeness of the illustration (over page) is meant to discompose your looking at it.

Like Contact; Vault, one more day in the empire exudes charm. Both pieces have rather conventional looking scores that belie the works' aural deformations and underrepresent the extraordinary musical weirdness and incidental complexity that emerges from applying unusual playing techniques to a standard notation (Contact; Vault), or sabotaging the interpretive capacities of performers (one more day). But while Contact; Vault's charm is an expression of the way Arnold skews his own acute awareness of Western art music's common forms, the charm that spark off one more day in the empire's self-fulfilling failure is almost ashamed. The charm in Sherlock's work comes across as illegitimate or alien (as in illegal alien). As though misbegotten, one more day's bastardization of musical competence and good aesthetic sense spoils the rightful

\footnotetext{
${ }^{216}$ Repeat performances of experimental music are extremely rare Cunously though, this culture wherein ensembles receive funding for and gain credibilıty by commissioning and performing new rather than older works, gives contemporary musıc a new sense of ephemerality Then again, the ubiquity of sound recording devices, which seem to be always on, ensures that these new singularities will be heard again, at least by one person-mostly likely the composer
} 
John Mark Sherlock, one more day in the empire (2006)_-Versioned"

one more day in the empre

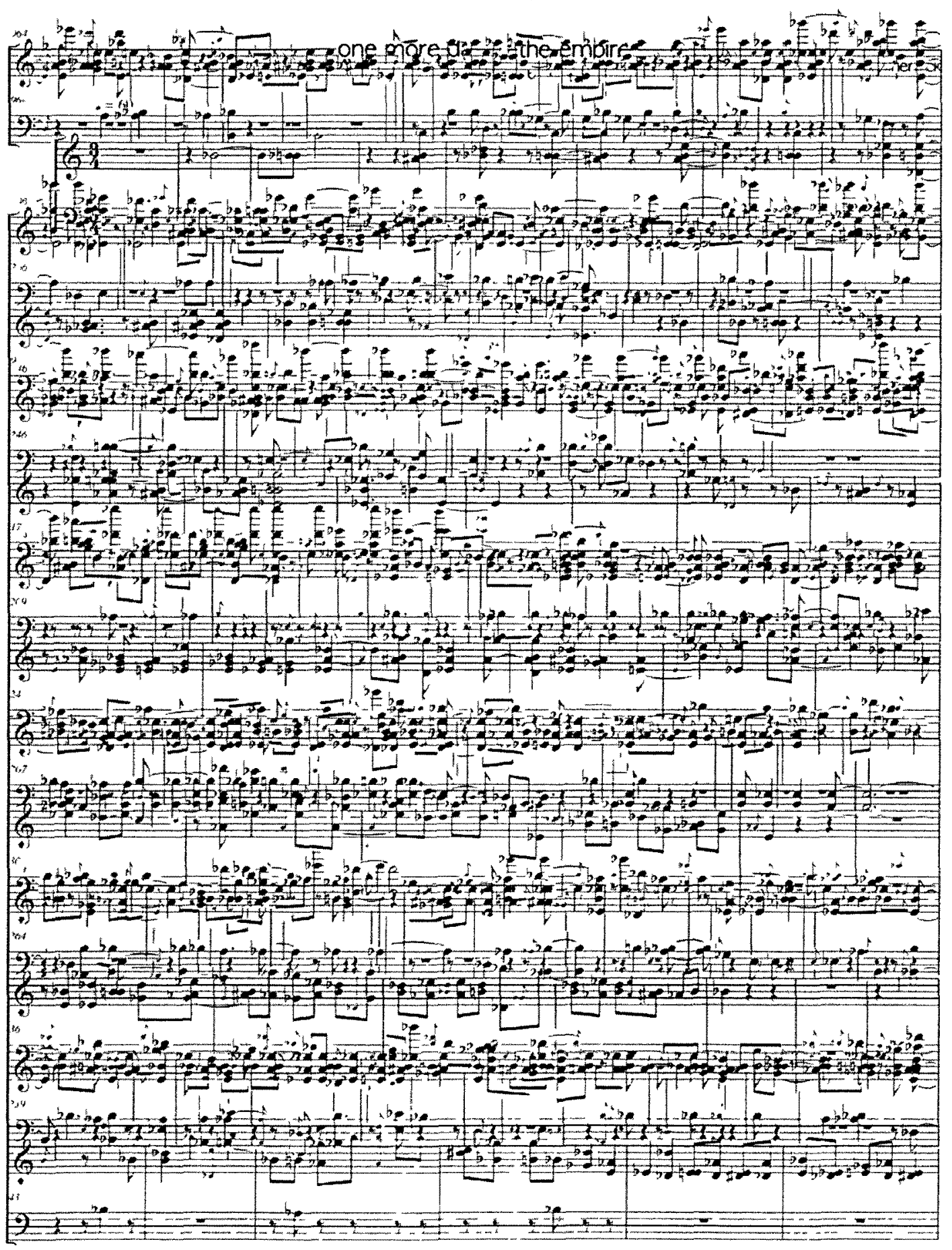


sovereignty of proper "composition" with a flimsy and undeserved allure. Why? Though one more day in the empire is composed of familiar musical notes-a quasi-minor modality, distinct moments of homophony, sumptuous instrumental timbres, silences, and shifts in musical density - it makes little attempt to render these in experimental terms or give them an expressivity that would, at least by proxy, make them minorly musical and so justify their failure to be radical or even conventionally musical. For inviting background habits into the territory of music-to-be-listened-to, one more day...is perhaps "sorry" in a way that Arnold's Burrow Music isn't. But this is not because one more day... messes with what ought-not-to-be-messed-with. Rather, one more day...'s shame is that the effects of distraction, and what sociologist Erving Goffman calls "toy involvements," a kind of secret and "inward emigration" from the collective scene (i.e., a concert) towards a "playlike world in which [one] alone participates," 217 feel anti-social. More than noise music's aggressive denial of the internal necessity of its becoming "not music," Helmut Lachenmann's sophisticated deconstruction of tradition, or even Cage's imprisonment of silence, the assembly of different incompetencies that is one more day in the empire transposes into a private reality what exists illegitimately within the main event of the concert. But smuggling private perceptions through the public doors of music comes at a cost, for lingering in the charms of incompetence reads as a kind of failure to respect the fact of music's sociality. And this failure, while sheltering perception from the pressure of musical "facts," endures the guilt that Terada associates with phenomenophilia's lack of desire for genuine sociality or critical

\footnotetext{
${ }^{217}$ Erving Goffman, Behavior in Public Places Notes on the Social Organization of Gatherings (New York Free Press, 1963), 69.
} 
perspicuity, ${ }^{218}$ a guilt that is intensified in one more day... by its proximity to art's

pledge to be beautiful, that is, its implicit promise to be had by everyone.

\section{Last)))))}

When I played parades we would be going down Canal Street and at each intersection people would hear just the fragment I happened to be playing and it would fade as I went farther down Canal. They would not be there to hear the end of phrases.... I wanted them to be able to come in where they pleased and leave when they pleased and somehow hear the germs of the start and all the possible endings at whatever point in the music that I had reached then. Like your radio without the beginnings or endings. The right ending is an open door you can't see too far out of. It can mean exactly the opposite of what you are thinking.

Michael Ondaatje Coming Through Slaughter

The passage above, spoken in the fictional voice of the New Orleans jazz musician Buddy Bolden, tells us something about the way listening can move sideways; or rather, the way it can sidle along what's being heard so that, in a sense, it listens in many directions at once. I'm suggesting that listening has habituated to the dim and partial perceptions encouraged by the way music is "more often heard now in fragments than completely," that "listening to a piece of music from beginning to end is...the exception rather than the rule. ${ }^{219}$

Here, what Bolden calls a "fragment" is something like what Alfred Whitehead or Gilles Deleuze would call an occasion or an event, a singularity around which listening is organized and which emits a virtual polyphony of musical adventures that give a qualitative background continuity to what's actually being heard. ${ }^{220}$ The fragment, in all

\footnotetext{
${ }^{218}$ Terada, Looktng Away, 29.

${ }^{219}$ Frith, Performing Rites, 242, 43

${ }^{220}$ Essentrally, this qualıtatıve background contınuıty desıgnates the feeling-thought that carries over from one lived, singular moment to the next Brian Massumı argues that this carry-over is the "affective tonality" of an occasion, and stems from the fact that every situation is festooned with "non-sensuously lived microintervals filled only qualitatively and abstractly by affect" From moment to moment, these micro-intervals
} 
its affective iridescence, can be thought to possess an internal difference that if it were given time, that is, somehow protracted, would as William James suggests, "be made to show new aspects of itself. ${ }^{, 221}$ However, it's rare that a fragment has time to itself. More often, a fragment is just another moment of our generally tessellated experience of the everyday, a domain that Ben Highmore calls "the realm of loosely held together contradıctions and...low-resolution ideology.,222

But there are occasions when a fragment does have its own time, when it can be stretched out and the bundled romances that it keeps to itself drawn apart. These occasions are taken now in the familiar concert settıng, only they are taken from behınd, buggered by a habit that smuggles Bolden's parade route-- the intersections--into the concert hall: listening comes in where it pleases and leaves when it pleases. But it's not that the musical surface is itself fragmented or splintered. Mahler's skin is just as wounded as John Zorn's. P1ggybacking on our relatıvely newly wired "google-brain," which has transformed the body from a complex abyss of desires, reasons, and feelings into "simple-processing units, quickly shepherding information into consciousness and then back out again," 223 we've unintentionally smuggled our habit of smuggling background sounds across the threshold of attention into the middle of a ritual designed precisely to keep the diversions out. We must now invert T.S. Eliot's line from Four Quartets because no longer are we "distracted from distraction by distraction" but are distracted by distraction from distraction. Musıc doesn't divert our minds from our daily

are hike vanıshing points, that while never actually in a situation, impose a sense ( $1 \mathrm{e}$, "depth") upon the words, gestures, hesitatıons that hover around therr virtuality See Brian Massumı, "The Thinkıng-Feeling of What Happens," Inflexions 1, no 1 (2008) 23-24

221 James, Talks to Teachers on Psychology, 7

${ }^{222}$ Ben Highmore, "Unprocessed Data Everyday Life in the Singular," 2005, http //www daytodaydata com/benhighmore html ${ }^{223}$ Carr, The Shallows, 119 
interruptions Music is now one of many daily interruptions, and this holds even as it crosses the threshold from public commotion to private chambers

Specifically, distraction affects the way concert music is listened to in that it violates or corrupts the intentionality that constitutes the magical object conjured by spells of silence and bodily restraint Music, in effect, shatters, it breaks apart on the backsıde of listenıng where a melodic "lift" and rhythmıc "push," or a tuneful impression and an infectious groove is had incidentally by listening aside Composers can be heard responding to cultures of distraction not by emulating the expressions of these as television programmes have tried to ape the speed and associatıve logic of advertısing's montage-effects, but in how their music fails to manıfest a set of traditional cues that "begets or intensıfies expectatıon, including the expectation of sheer contınuity" "224

More than any rhetorical refusal to deny the internal necessity of its unfolding (which is nothing less than the imperative of structural listening), we can take the protracted self-similarities of Sherlock's one more day tn the empire, Arnold's Burrow Musıc, or Peaker's Species of Spaces as fortuitous couplings with our involuntary sensibility to only partially and occasionally pay attention to musical phenomena In a sense, this music invites distraction, but always in a way that draws distraction across the work, giving it a chance to skırt aesthetıc borders and trade its sound-effects on the black market of the unconscious

Under these circumstances, the fragments that distraction isolates and scatters across listenıng create an ongoing series of incipits, the openıng lines of a story or a musical work, hterally, "here begins" "It was a dark and stormy night " In his novel If

\footnotetext{
${ }^{224}$ Susanne Langer, Feeling and Form (New York Charles Scribner's Sons, 1953), 129
} 
on a winter's night a traveler Italo Calvino describes the incipit as "the promise of a tıme of reading that extends before us and can comprise all possible developments $" 225 \mathrm{~A}$ book, or a piece of music for that matter, that is only an incipit would be a work that "maintains for its whole duration the potentiality of the beginning, the expectation still not focused on an object ${ }^{2,26}$ As a structuring force, the incipit possesses a commanding form, a veritable time signature that paces and organizes the way actions unfold over tıme Incipits are a kınd of cusp or a threshold, a metaphysical boundary dividing differing realities Call me Ishmael For a long time, I went to bed early A screaming comes across the sky Three worlds side-by-side Here, the fragment gets its time, extending itself in potential along the whole of the work But placed in series as Calvino does in If on a winter's night a traveler , the incipit returns each pulse of attention each tıme to another begınnıng_ Mrs Dalloway sald she would buy the flowers herself I am an invisible man It was the day my grandmother exploded The fragment doesn't have tıme for itself but gives it to the next moment, a moment that is just another fragment, another incipit, another unfocused object A veritable "distraction span" But an accumulation of incipits does not a text or a music make Or it does And it would be an exceptionally odd book, or a really weird song, one made of loose threads and a heap of beginnings that fail again and again to become their own possibilities The world as a multitude of nexts each moment a span of attentıon in abeyance, another singularity, another pinch point shorting out the interest of glımpse after glımpse after glimpse

\footnotetext{
${ }^{225}$ Italo Calvino, If on a Winter s Night a Traveler, trans Willam Weaver (New York Harcourt Brace Jovanovich, 1981), 177

${ }^{226}$ Ibid
} 
Another Again

Once upon a time... 


\section{Three: Nonsense}

A human being unwillingly deprived of the society of his peers descends into madness as the fine structures of percelved reality, maintained and reinforced by the rhetorical bombardments of others' truths (and his own, reflected back), rapidly unwind without constant reinforcement What I tell you three times is true What I tell you three million times is civiluzation

Mark Pesce

Bullshit is unavoidable whenever curcumstances require someone to talk without knowing what he is talking about

Harry Frankfurt

\section{(Voodoo}

In a study on difference and power in music, John Shepherd identifies a paradox that is fundamental to human sociality and is articulated by the tension expressed "between the malıenable potential for artifice and the inescapability of the material [world] "1 That is, the symbolic processes allowing us to manıpulate the material environment exhibit a certain independence from the material world while at the same time remaining indissolubly linked to material conditions Shepherd makes this point, however, not to celebrate it, but in order to expose how the largely male project of industrial capitalism tries to disguise this tension by appropriating the power of language's symbol system to 1gnore "the inherent characteristics of sounds from those of the objects on which they operate,",2 a power that is only amplified with the emergence and dissemination of print technology whose system of visual signs and phonetic literacy promote an even greater separation between the sound's characteristics and meanıng This power of language to disartıculate meanıng from a thıng's material features 1s, Shepherd argues, what drives the development of societies However, language and the sense it makes come at the cost

\footnotetext{
' John Shepherd, "Difference and Power in Music," in Musicology and Difference, ed Ruth A Solie (Berkeley, Los Angeles University of Calıforma Press, 1993), 57

${ }^{2}$ Ibıd , 54
} 
of sacrificing the relational and fluid presence that sound evokes and demands The consequences of this are twofold and mutually reinforcing First, "if the sounds of an utterance are not homologously bound or limited in their configuration by the inherent configurations of the objects to which they refer, then they can be open-endedly manipulated in relation to those objects and more easily prescribe their future manıpulation in tıme and space "3 Second, as a culture becomes literate and takes its literary expressions, in the widest sense of the term, as its central point of definition, the "system of visual signs that are quite arbitrary in their cross-sensory relation to the sounds they represent can, in principle, take on a life of its own in relation to the sounds of the language it notates "4 Thus, the number of utterances and what can be said about something is unlimited and it is not restricted to fact or morphological correspondence Unmoored like thıs, we can, in effect, bullshit all we want

For a "something" like music, whose non-denotative nature gives it a rich connotative potential, this virtually open-ended process of ascription confers on its expressions a mythical status in the sense that what music "says" is unfalsifiable (1maginary) As such, insofar as the society and culture of industrial capitalism is built on the analytic tendencies of language that promote a myth of objectivization and the concomitant belief that the world is susceptible to control, music is a problematic category As a construct of a discursive culture that categorizes musical sounds into pitch, rhythm, harmony, as well as form, genre, style, classical, and popular, the sense of integration, coexistence, and fluid interaction that sound gives rise to makes music paradoxically something that "reaffirms the flux and concreteness of the social world,"

\footnotetext{
${ }^{3}$ Ibid

${ }^{4}$ Ibld , 55
} 
but also something that reifies it. ${ }^{5}$ The idea of "Music" therefore locates a something where opposites coincide. In a sense, the category of "Music" is a stranger to the very culture that animates it, but a productive stranger whose paradoxical status excites the inconsistencies and contradictions that industrial capitalism's reckoning of the world produces in abundance. This trafficking in contradictions is also what makes music a myth, for like myth, which may be considered an unconscious expression of a society's internal discrepancies, the matrix of relations that is reflexively and outwardly connoted by "Music" holds oppositions together within the same event.

As a stranger and a myth, music functions in industrial capitalist cultures as a form of nonsense, what Susan Stewart calls a residual category, which like "Chance," "Accident," or even "etc.," "gives us a place to store any mysterious gaps in our system of order." ${ }^{, 6}$ Nonsense so defined is a conceptual stop-gap that accommodates what an order does not tolerate by marking its own limit. As such, nonsense is an inalienable "aid to sense making" without which "sense would not be 'measured' [but] would itself threaten infinity and regression." In the context of industrial capitalist society, music exists as a kind of nonsense where the inconsistencies of manipulating and defining a material reality through symbolic processes can accumulate and be provisionally managed. As nonsense, we might see "Music" functioning where "sound ceases to be a mediating presence," ${ }^{\prime 8}$ where the suppleness of its material, which cannot help but "reaffirm the present existence of the individual, and reaffirm it with a concreteness and

\footnotetext{
${ }^{5}$ lbid.

${ }^{6}$ Susan Stewart, Nonsense. Aspects of Intertextuality in Folklore and Literature (Baltimore: Johns Hopkins University Press, 1979), 5.

${ }^{7}$ Ibid.

${ }^{8}$ Shepherd, "Difference and Power in Music," 50.
} 
directness not required for reaffirmation through the sounds of language," is expurgated from the proper map of abstractions and absences that coordinate everyday life. The sticky and messy matter of music is displaced in a way that its symptomatic appearance in the form of "emotions" or "feelings" makes it a stranger to the measure of sense with which its strangeness is conterminous.

But this does not essentialize music. Or rather, it essentializes the discursive construction of "Music." But then again, what is it to say, write, or think of music or "Music" apart from its discursive constructions? Indeed, it is the basic position of poststructuralism that there is no outside, no immaculate reality apart from the discursively formulated social realities that a culture presents to itself as objective and true. Which is to say (which is already to say too much), there is no music or language, or noise, for that matter, as such. "Music" and "Language" are terms of sense that express the signifying inclination immanent to those sonic practices which discourse gathers up and disseminates in its bid for knowledge. The null- or "myth-space" of the "etcetera," which is the same as "Blah blah blah," is the closest one can come to music or language "as such." The effort to encircle the "outside" of music with something like Cage's chance operations would appear then to be the most effective way of bringing out the "blah-blah" essence of music. However, chance doesn't make music any less artificial, any less constructed, it just makes chance less chancy and more planned. But all this is old hat.

What is really interesting about all of this is not that "Music" plays out the contradictions and inconsistencies of our industrial society but how it does this. While all "Music" is subject to the discursive economy that constitutes it as "Music" and not as

\footnotetext{
${ }^{9}$ John Shepherd and Peter Wicke, Music and Cultural Theory (Cambridge Polity Press, 1997), 164
} 
sound, speech, or noise, it would seem that the more self-aware practices clustering under its sign would make an issue of it in a way that allies it to the practice of "metafiction," which as Patricia Waugh suggests is a way of writing that "self-consciously and systematically draws attention to its status as an artefact in order to pose questions about the relationship between fiction and reality." ${ }^{10}$ And indeed, the latter half of the twentieth century is dotted with musical works that embody varying degrees of self-reflexivity and formal instability that evoke comparison to the work of authors such as John Barth or Thomas Pynchon." The third movement of Berio's Sinfonia (1968-69) for instance, and Mauricio Kagel's aptly titled Metapiece (1961), too, and of course 4'33', are works that self-consciously draw attention to their artifice. But perhaps more exemplary of the way metafictions interrogate "a theory of fiction through the practice of writing fiction,", is the more recent work of composer/theorist Claus-Steffen Mahnkopf, who takes the lessons of post-structuralism and the dialectical contortions of Adorno's philosophical project as an aesthetic end to be mannered by an equally, but intentionally, clumsy "complexificationizing" of the art music tradition. But the meta-musical theatre of Mahnkopf, like so many metafictions, undermines its own disturbance by maintaining a transcendental reserve; the delirium which reflexivity courts is held off by keeping the supplementary dimension of the author in play. At most what this brand of meta-music

\footnotetext{
${ }^{10}$ Patricia Waugh, Metafiction The Theory and Practice of Self-Conscious Fiction (London, New York: Methuen, 1984), 2

${ }^{11}$ Noted, the practice of self-reflexivity appears quaint if you consider the history of European art music which is, among other things, the art of self-referent1ality. (See Ruth Katz, A Language of Its Own Sense and Meaning in the Making of Western Art Music [Chicago Unıversity of Chicago Press, 2009].) However, Waugh is writing in the early 1980 s and commenting on a trend in literature that "reflects a greater awareness within contemporary culture of the function of language in constructing and maintaining our sense of everyday 'realıty" "Waugh, Metafictıon, 3 Whıle Brahms' Symphony no 2 certainly indulges a high degree of self-referential symbolism, the discourse which constitutes it as "absolute music" excuses its signs from having to addiess the phenomenal world and so exempts the meta operations of the work from the complex and highly problematic issue of representation that make metafiction so disonenting

12 Waugh, Metafiction, 2
} 
accomplishes is a hyper-awareness of its own artifice that merely sanctions the use of a beleaguered rhetoric of aesthetic negativity (which unlike Barth is no fun to read) that gives the impression of being enlightened and insightful. Yet, in the spirit of the barren dialectic with which Mahnkopf is enthralled, this is exactly what the music stresses.

But there are other contemporary practices that take a different tack. Fully aware of the way music is discursively constituted and how the representations of its events not only have a way of becoming a part of their unfolding, of bleeding into other constructs such as gender, race, and class, there are practices that pursue a form of sovereignty which is had, paradoxically, by bullshitting. These practices flirt with Paul Mann's "stupid undergrounds" by partaking of the same asymptotic mannerisms that express the vertiginous passions of hyperreality. However, what distinguishes, for example, Irish composer Jennifer Walshe's fictive sound art collective Grúpat, or Toronto-based intermedia artist Marc Couroux's necromantic re-visioning of The Carpenters and 1970s American politics from the modernist refrains of Mahnkopf and the suicidal impulses of the stupid underground, is their conviction to explore, if I may borrow a phrase from the crypto-metaphysician Donald Rumsfeld, "unknown unknowns." In other words, a kind of radical doubt underwrites the intentions of Walshe and Couroux in a way that decentres rather than negates the problem of reflection. The effect of doubt is not to reach a higher "truth," but to make room for a little "voodoo."

This means is that Walshe and Couroux have left what Bush administration insiders have called "the reality-based community," a community defined by people who believe 
that solutions or results can "emerge from a judicious study of discernible reality ${ }^{13}$

Walshe and Couroux no longer (1f they ever did) carry out their actions with respect to an empırıcal aesthetıcs - a verifiable aesthetıcs whose effects are observable - but instead act at the level of potential where aesthetic effects recursively grow into new artistic realities As the Bush people might say, when they act, they create their own reality ${ }^{14}$ Or as Brian Massumı does say, "[T] oday's world is not objectıve It is potentıal "15 Our world of unknown unknowns is a world that is "unexpungeable because its potentiahty belongs to the objective conditions of life today "16 As such, "truth" or "fact" or "beauty" even, is self-fulfilling, for in taking unknown unknowns objectively one stokes the objectively indeterminate potential of uncertainty and encourage it to take an actual shape by "actıng to make present a future cause that sets a self-perpetuatıng movement into operation $" 17$

And is this not voodoo? Is not acting to make present a future cause exactly what the "hougan" or "bokor"" does when they wish luck or misfortune on someone, acting on the unprovables of a belief system to short circuit doubt and compensate "for the absence of an actual cause by producing an actual effect in its place? ${ }^{\text {,19 }}$ Effects as cause, as quası-cause A jinx makes itself actual by correlatıng the ordınarıly unspecified points of fallure and intensities of defeat that co-exist "in a state of actual indistınction from

\footnotetext{
${ }^{13}$ These are words that New York Times writer Ron Suskind attributes to a senior Bush advisor Ron Suskind, "Without a Doubt," New York Times Magazme, 14 October 2004, http //www ronsuskind com/articles/000106 html

${ }^{14}$ Brian Massumı, "Potentral Politics and the Primacy of Preemption," Theory and Event 10, no 2 (2007) par 17

${ }^{15}$ Ibid

${ }^{16} \mathrm{Ib} 1 \mathrm{~d}$, par 14

${ }^{17}$ Ibid , par 22

18 "Hougan" and "bokor" are the Haitıan terms for male and female voodoo priests, respectively

${ }^{19}$ Massumı, "Potentıal Polıtıcs and the Primacy of Preemption," par 23
} 
each other." Obscured failures "actively fused, in dynamic superposition."20 But this is not superstition. It is "hyperstition," a fiction that makes itself real by insinuation, by gut reactions that contaminate the nervous system with the intensity of an unbelief, a prepersonal conviction, that cannot help but register as the "reality" of a situation. In fact, Marcel Mauss describes something very close to this when he qualifies the operative logic of magic as an effort to induce belief in hopes of achieving "the adherence of all men to an idea, and consequently to a state of feeling, an act of will, and at the same time a phenomenon of ideation."21 But what Mauss misses in this characterization of magic is that one first summons an intensity, an affective quality, that is only then followed by an adherence to an idea, etcetera, for an intensity is the registering of a difference that belief represents, a sliver of felt nonsense that circuits through a constellation of symptoms, binding them in coincidence through a quasi-causality of expressive correspondences.

Hyperstition is thus like an occult technology or an "abstract machine" that (quasi)causes change to occur and events to take place in alliance with the immanent and impersonal will of a situation that cannot but express itself as a series of coincidences. In a way, hyperstition does resemble superstition. A spell is cast, a person dies; I'm wearing green socks and no planes fall from the sky. Two events connected by coincidence (expressive correspondence-voodoo) but real-ized (made effective) to the extent that their alliance shocks the system and "disconnects the body from the ongoing flow of its activities, ${ }^{, 22}$ readying it for a restart along a new path where green socks and falling planes share the same destiny. Properly speaking, this is superstition. However, when

\footnotetext{
${ }^{20}$ Brian Massumi, "Fear (the Spectrum Sand)," Positions 13, no. 1 (2005): 45.

${ }^{21}$ Marcel Mauss, A General Theory of Magic, trans. Robert Brain (London, New York· Routledge, 2001), 119.

${ }^{22}$ Massumı, "Fear (the Spectrum Sald)," 36.
} 
coincidences spread, as they do in flagrante on the nightly news (and more subtly, when people speak to one another), when the exceptions that coincidence expresses become models they generate "a real without origin or reality: a hyperreal" ${ }^{23}$ - when effects become causes and "indissociable dimensions of the same event" 24 -this is hyperstition.

But what exactly does it mean to be hyperstitious? What does it mean to have faith in the fabrication of coincidences? In short, it means that you bullshit, that you make things up. This, however, does not mean that being hyperstitious makes you a liar. As Harry Frankfurt argues, liars retain a certain respect for truth in their aim to deceive, ${ }^{25}$ which is impossible for the hyperstitious person to have because "truth" supposes a perspective from which the exception of an event can be demonstrated as unexceptional. When you see the world as a series of exceptions and happenstance, as the hyperstitious person does, the ruse of metaphysics that makes us "believe in the true" is supplanted by the superior ruse of "pataphysics which "lets us pretend to be untrue." ${ }^{26}$ In this respect, to be hyperstitious is to bluff, to feign, not in order to be false, for that would suppose a truth, but to be effective. And being effective has no concern with truth-values.

Walshe and Couroux's hyperstitions can be regarded as a hyper-fiction more than a meta-fiction, as a form of royal bullshittnng in the sense that they do not "insert a particular falsehood at a specific point in a set or system of beliefs",27 (as lying does), but instead circulate slivers of nonsense that contaminate the constellation of conventions and

\footnotetext{
${ }^{23}$ Jean Baudrillard, Simulacra and Simulation, trans She1la Glaser (Ann Arbor University of Michigan Press, 1995), 1

${ }^{24}$ Massum1, "Fear (the Spectrum Sa1d)," 36

${ }^{25}$ See Harry Frankfurt, On Bullshit (Princeton, NJ Princeton University Press, 2005)

${ }^{26}$ Christian Bok, 'Pataphysıcs The Poetıcs of an Imaginary Scıence (Chicago Northwestern University Press, 2002), 12

${ }^{27}$ Frankfurt, On Bullshit, 51
} 
assumptions which produces the appearance of an intelligible, orderly world. To this extent, the text that follows, the text that reviews their work, becomes a part of their hyperstitions. What I write about their work constitutes an aspect of the very bullshit that I am studying. Thus, the very words that I have written and which you are reading circulate a misrepresentation so that more than explaining their bullshit, it stirs it.

\section{((Metareferentiality, Metamusic and Hypermusic}

If we understand "Music" as a discursive formation, then in a sense it is always already a kind of fictum, a falsehood, for its expression as "art" entails an awareness of its "artifice," its relation to a "real" as a fiction, a "quasi-real." Like all fictions, it should be subject to various meta-processes, processes that spur "an awareness of the medial status of the work or system under consideration." ${ }^{28}$ However, a musical fictum, as opposed to a fictio whose metareferentiality is accomplished solely by producing an awareness of the sense of medality, is subject to metareferential reflection not only when its artifice is made apparent but when it elicits a comparison to a reality that it is (supposedly) not, as happens with musical works that trigger a response like: "That's not music!" This statement (negatively) describes a musical fictum for it expresses a two-fold metareference in that saying something is not music draws attention to the specific behaviour of the sonic medium while at the same time brings to mind the relationship that this medium is supposed to have with reality-namely, that music is an artifice and what is being heard as "not music" is not complying with the fictionality, the artificiality, that music is supposed to adhere to. That said, there is an even more interesting consequence

\footnotetext{
${ }^{28}$ Werner Wolf, "Metafiction and Metamusic Exploring the Limits of Metareference," in Self-Reference in the Media, ed. Winifried Noth and Nina Bishar (Berlın, New York Mouton de Gruyter, 2007), 307
} 
to draw from this kind of meta-multiple. In declaring something to be "not music," and thereby calling attention to the medium and producing a conceptual awareness of the kind that structures the difference between "fiction" and "reality," one is remaindering something whose ontological and epistemological status is radically indeterminate. If not "music," not a musical artifice, then what is "it" that remains? If "it" is not acting as an agent through which processes of expression and communication can take place (i.e. medium), then "it" is more matter than idea. And if "it" is not, so to speak, feigning a world of impending death such as Mahler's 9th does, then "it” is not even imaginary. Paradoxically then, it, this "unmusic," this acoustic matter impinging on my time and space, is something of a black hole and much closer to music as such than Chopin's Nocturnes could ever hope to be.

Unmusic, as "something" on just the other side of discourse, is a species of metamusic in the sense of its being ulterior to "Music." This departs slightly from the idea of metamusic as a practice analogous to metafiction, for this modified definition of metamusic as unmusic is characterized more by a failure than by an explicit reflexivity. While an understanding of metamusic that is analogous to metafiction typifies the operations of a signifying practice that "elicits a cognitive process or reflection on itself, on other elements of the system or on the system as a whole, ${ }^{, 29}$ my sense of metamusic is based on a failure to be musical (to act as an expressive acoustic medium) and to be "Music" (to be an object of contemplation, exchange, or study). Thus, what I am calling "unmusic" is a failed event. And as sociologist Susan Stewart notes, a failed event is nonsense. "Like a 'fiasco'," writes Stewart, "nonsense is a failed event, an event without

\footnotetext{
${ }^{29}$ Ibid., 305.
} 
proper consequences." "Not being musical" (or if you're of the avant-garde persuasion, "not being 'anti-musical") is a fiasco to the listener who expects to hear sounds behaving musically, behaving as "Music" (or the inverse). Yet, as I'm suggesting, an event with "improper" consequences is an event nevertheless. While the failed event may not comply with the conventions or context in which it is situated, even if those conventions stipulate the fictionality (artificiality) of what the event expresses, it still has effects, and these effects impinge on and influence the sense of other events despite its being cut out of the discourse that articulates the sense proper to the situation (being accomplished by and through the discourse). As such, the effects that express the sense of the fiasco that this "unmusic" is are effects of a certain failure.

But this leaves a question about how we can even study "unmusic," for how does one stage a fiasco? How does one intentionally fail? In other words, how does one make unmusic? The short and paradoxical answer is that you unmake it. The long and much more circuitous answer, which requires a major detour through the way in which meaning in music and language is generated, and how the category of "Music" can only be understood as a discursive construct such that it is impossible to think of "Music" apart from language, is that you fake it. While this is perhaps not a very satisfying answer, I'd suggest that satisfaction is already out of step with failure, for failure isn't about satisfaction but quite the opposite. Failure is about an engagement with the potential of potential rather a satisfaction of a potential's ideal. Thus to fake failure is and is not to fail to fail, for failing to fail is a success of sorts whose accomplishment is itself a type of failure (which is a success that is a failure...). And as the previous sentence demonstrates

\footnotetext{
${ }^{30}$ Stewart, Nonsense, 4.
} 
w1th its convoluted (though mercifully curtailed) recursive logic, to fail is to make nonsense, and to make nonsense is to traffic in contradictions, which is, in a sense, to unmake sense.

This redoubling of contradictions is in fact close to Adorno's formulation of modern art, which he believes is condemned to the task of expressing its alienation from the spirit of its time, to express its incapacity to adequately express itself. However, unlike the Sisyphean predicament that Adorno sees modern art suffering, unmusic finds some traction in that its being nonsense relieves its event from being "art." But the cessation of art is something that can only be accomplished when art disappears into the occasion of its own excess. And that occasion, according to Baudrillard, has already happened. In fact, "art" disappeared a while back (When? Sometime in the 1970s, probably when information technologies were electrified and the became dominant way in which Western culture mediated its self-expressions), and its sublimation into the everyday order of simulation was overlooked. ${ }^{31}$ Too busy watching reruns of I Dream of Jeanne or Bewitched I suppose. What is call "art" now is itself a continuous rerun, a rerun of the image of its own disappearance. ${ }^{32}$ But said another way, which I'm sure some would rather it be said (though it makes no difference), "art" is everywhere one and the same with the image of the everyday, if not actually, then potentially. ${ }^{33}$ Under these circumstances, because art and the reality that is supposed to set its aesthetic properties off have lost their operational difference, unmusic is everywhere "Music" is not. However, according to the logic of simulation, "Music" is everywhere so unmusic is

\footnotetext{
${ }^{31}$ See Jean Baudrillard, Symbollc Exchange and Death, trans Ian Hamilton Grant (London. Sage, 1993)

${ }^{32}$ Jean Baudrillard, The Conspiracy of Art Manifestos, Interviews, Essays, trans Sylvère Lotringer, Semıotext(e) Foreign Agents Series (New York Semıtext(e), 2005)

${ }^{33}$ But what's the difference between "actual" and "potential" if their effects and possibilities are already encoded into the range of experience?
} 
nowhere. Yet being everywhere is the same as being nowhere, therefore "Music" is nowhere, which makes unmusic everywhere. But this is hyperreality and hyperreality trucks no difference between the real and the unreal (artifice), the musical and unmusical. Thus unmusic eschews Adorno's dialectical impasse to the extent that it is total nonsense, a byproduct of the hyperreal that supervenes a discourse of contradictions and paradoxes where everything is coming up signs.

In this sense we would be better to call unmusic "hypermusic," for the failure that expresses a nonsensical "unmusic," is not outside of discourse so much as it radicalizes the powers of discourse. This process of failure would be an instance of what literary theorist Mark Fisher calls the "intense amplification of the processes of immanentization." 34 That is, the failure which constitutes "hypermusic" does not mark a breach in discourse but a doubling over of it that subtracts the need for, and indeed, the possibility of adding any supplementary dimensions - like sound — to its expressions.

"Hypermusic" is therefore no less discursively constituted than "Music" is. However, the discourse of "Music" circulates a respect for a simulated difference between real and artifice, sound and symbol, in a way that the discourse of "hypermusic" does not. And so, it is this "not" around which hypermusic revolves, a not that folds discourse back on itself making a knot that threads the nonsense of "not Music" through the sense of "Music."

In essence, hypermusic subsists here, between and among these words and your reading them, as the expression of a discourse whose mimetic devices are not just simulations - as DeLillo's photographed "barn" is in White Noise--but the theories of

\footnotetext{
${ }^{34}$ Mark Fisher, "Flatlıne Constructs Gothic Materialism and Cybernetic Theory-Fictıon" (PhD, University of Warwick, 1999), http //www cinestatıc com/trans-mat/Fisher/FC4s7 htm
} 
simulation. In other words, the map no longer precedes the territory: the manual on mapmaking now precedes the map that precedes the territory. As this means "we" are all only fictions, hypermusic, too, is revealed as just another fiction, but a certain kind of "theoryfiction" born of an insight into the depths of reflexivity, or as Fisher describes, the registering of a "cybernetic account of subjectivity, a sense that the self can no longer be properly distinguished from the multiplicity of circuits that traverse it." ${ }^{\text {"35 }}$ Hypermusic and the nonsense that it circulates (and vice-versa) is therefore an expression of my "psychedelic giddiness" which results not simply as Baudrillard suggests, "from multiple or successive connections and disconnections" ${ }^{, 36}$ that make me schizoid, but from the coincident hallucinogenic conviction that the schizonoia of hyperreality induces in me.

\section{(((Grúpat and Pseudonymity}

But I'm not the only one who feels this way. Take for instance the work of Irish composer and artist Jennifer Walshe. In an interview with James Saunders, Walshe describes the varieties of sounds that she likes to work with. In addition to what she describes as "dirty" sounds, biographically significant sounds, sounds that are byproducts of physical situations, and sensuously articulate sounds, are sounds that she says are "at times imaginary, sounds which function as conceptual descriptions"37-unreal sounds. Walshe continues:

The performer, for example, might be required to imagine the inside of their body as the interior of a mountain full of mines, feel the blood moving through their veins as tiny carts carrying diamonds to and fro through a tunnel system, and then tip these

\footnotetext{
35 Ib1d

${ }^{36}$ Jean Baudrillard, Seduction, trans Brian Singer (New York St Martın's Press, 1990), 162.

${ }^{37}$ James Saunders, The Ashgate Research Compamon to Experimental Musıc (Burlıngton, VT Ashgate, 2009), 344
} 
tiny imaginary diamonds into their lungs to prepare for creating a sound. The audience of course can't "see" the performer creating blasts of white light in their lungs to pulverize the diamonds they just tipped into them. But my intention is that all this preparation and delicate attention means that when the performer emits a vocal sound which atomizes the diamond dust, creating a crystalline mist through the air, there's a quality to the sound which comes from these imaginings. ${ }^{38}$

Although Walshe is here describing the details of a specific imaginative exercise, the fictional dimension of finding her way into a sound underwrites the principle of her imaginary South Dublin arts collective Grúpat "whose roots can be traced to 1999, when Bulletin M, The Parks Service, Turf Boon and other artists met at a rave at the Hellfire Club on Montpelier Hill, in the Dublin Mountains. ${ }^{39}$ Grúpat, to put it simply, is a project in which Walshe acts as commissioner and curator for a group of fictional composerartists whose identities and aesthetic sensibilitıes she adopts. By developing elaborate backstories and planting expressions of her pseudonyms in different media, such as the review in the May 2006 issue of The Wire of a work by Grúpat member The Parks Service, penned by Walshe under the name "Jonathan Vanns," and by performing a piece by another Grúpat member, Ukeoirn O'Connor, whom Walshe "commissioned" for the 2007 Kilkenny Arts Festival (which was subsequently reviewed in the Irish Times (Aug $21,2007)$, Walshe produces her own kind of hyper(fictional) music that harnesses the amplified immanence of the hyperreal. In addition to generating an excess of aesthetic objects and events (and perhaps more interestingly), by commissioning, installing, and performing works that she created under the names of "The Parks Service," "Turf Boon," and "Flor Hartigan" (among others), but more significantly, by documenting, reviewing

\footnotetext{
38 lbid

${ }^{39}$ A history of Grúpat can be found on Ireland's Contemporary Music Centre website and is attributed to Stuart Fresh This entry, however, was almost certainly written by Walshe and is an example of the way Walshe exploits the scattering potential of varıous media that in turn generates reality-effects See Stuart Fresh, "A Short History of Grúpat," http //www cmc te/articles/articlel799 html
} 
and giving interviews about these, ${ }^{40}$ Walshe repeats the gestures and logics of the contemporary art world that make work as obscure as hers, real. In doing this she not only multiplies her persona and aesthetic referents, she replicates the logic of hyperreality.

However, it might be argued that because it's now known that it is Walshe who realizes the different projects imagined by her Grúpat personas, she loses something of the hyper-ness of the work. From the perspective of a reality that still respects the issues and orders of representation, it is true, she does lose that liquid purpose which dissolves the cords of intention that bind the identities of Grúpat to her. In a sense, her actualizing the hypermusic of The Parks Service or Turf Boon converts it into just "music." In a world where one knows that it is Walshe who is Grúpat, to keep The Parks Service or Turf Boon's work hypermusic would require her, paradoxically, to have not realized the music, to leave it entirely virtual. But from the perspective of hyperreality, which is where Walshe would like us to dwell, there is no meaningful difference or delay between the fictional and the real, a point that is echoed by Fisher in an example he makes by drawing attention to the way the film Toy Story (1995), a film about fictional toys, and the toys of the toys in Toy Story, are released simultaneously so that "the film functions as an advertisement for the toys, which function as an advertisement for it, in an evertightening spiral. The fictional is immediately real, in the most palpable sense: it can be bought." ${ }^{41}$ In hyperreality, Walshe, Grúpat, and the "Music" are given together in an achronistic and diffracted media-time that, rather than attenuate the reality of the art and these figures, makes them abstract facets of the same hyperreal plane.

\footnotetext{
40 .and having someone devote a portion of a dissertation chapter to

${ }^{41}$ Fisher, "Flatlıne Constructs"
} 
A question then: What does the music of Turf Boon, Flor Hartigan, and Ukeorin O'Connor sound like ${ }^{42}$ Or for that matter, what does Jennifer Walshe's music sound like? It's hard to say, for even if one could tell the musics apart, to which identity should one ascribe it? Walshe does. But if she can shuffle these fictions around why can't we? More importantly, we might ask whether it matters what the "Music" sounds like. The splendid art catalogue that I'm looking at, published by The Project Arts Centre in Dublin, with its velvet-black cover adorned with monochromatic doodles, cradling highgloss colour photos of installations, score excerpts, reviews, post-cards, as well as the requisite copyright notice(s) and catalogue essay by a legit scholar, ${ }^{43}$ suggest that maybe it hardly matters. That I'm writing about Boon-Hartigan-O'Connor-Walsh seems to be what matters, or at least writing about this figment and whether it matters whether the sound of the music matters seems to matter just as much as the putative music does. For Paul Mann, who argues that radical art lives on the discourse of its own death, all of our actions, expressions and desires are occasions that maintain what he calls the "white economy of discourse." 44

It matters only that words and ideas about art are exchanged. That is to say, Grúpat is as real and as meaningful as Thomas Mann's Adrian Leverkühn insofar as the respective fictional quantities of each excite (incite) discourse in a bid to capture some kind of difference - the currency of exchange. And counting the words up to this point I would say that Grúpat is about...5700 words real and meaningful.

\footnotetext{
${ }^{42}$ You can find out by visiting http //www myspace com/ukeornoconnor and http //www myspace com/turfboon

${ }^{43}$ Bob Gilmore, Lecturer in music at Brunel University

${ }^{44}$ Paul Mann, The Theory-Death of the Avant-Garde (Bloomington Indiana University Press, 1991 ), 141.
} 


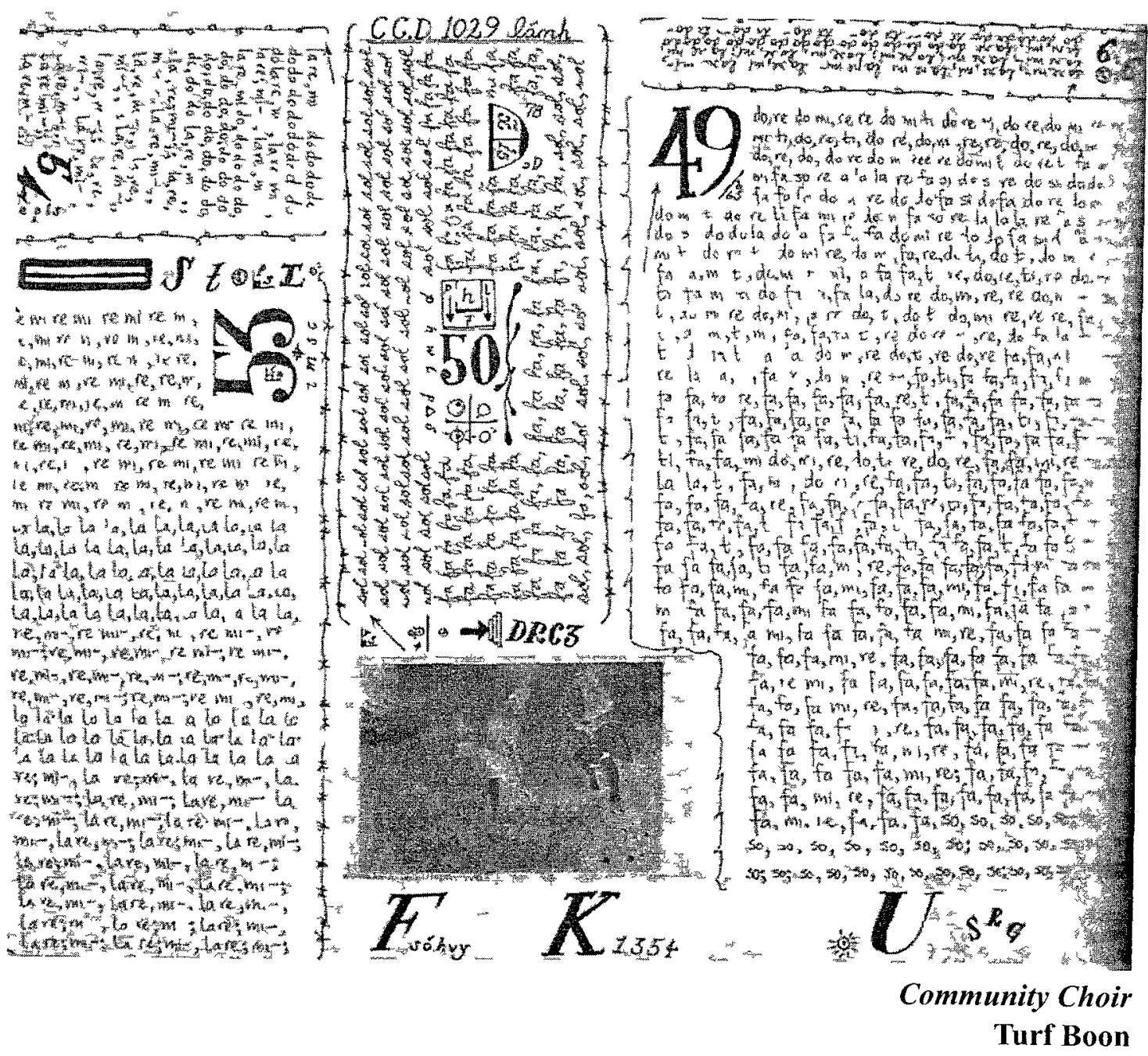



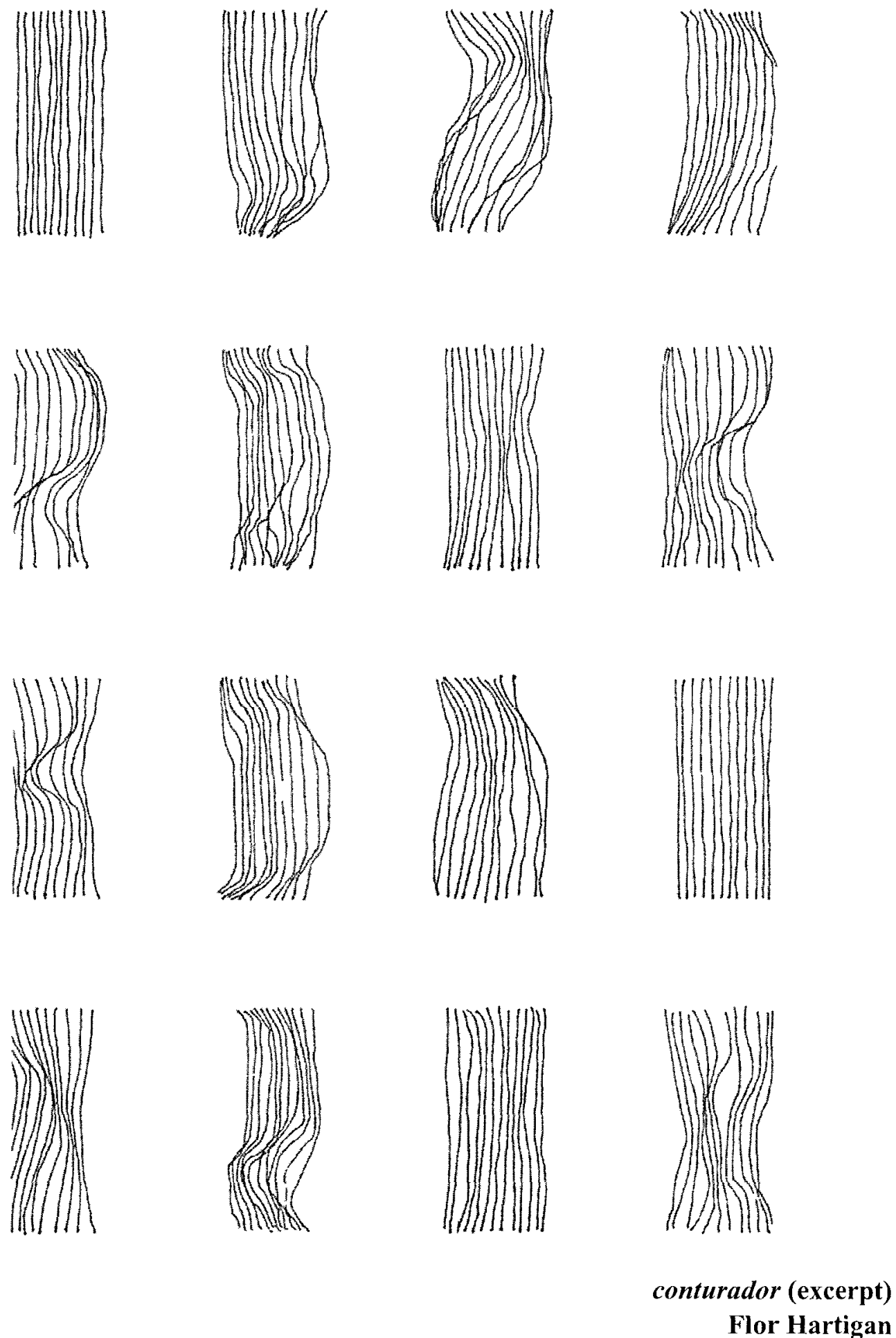


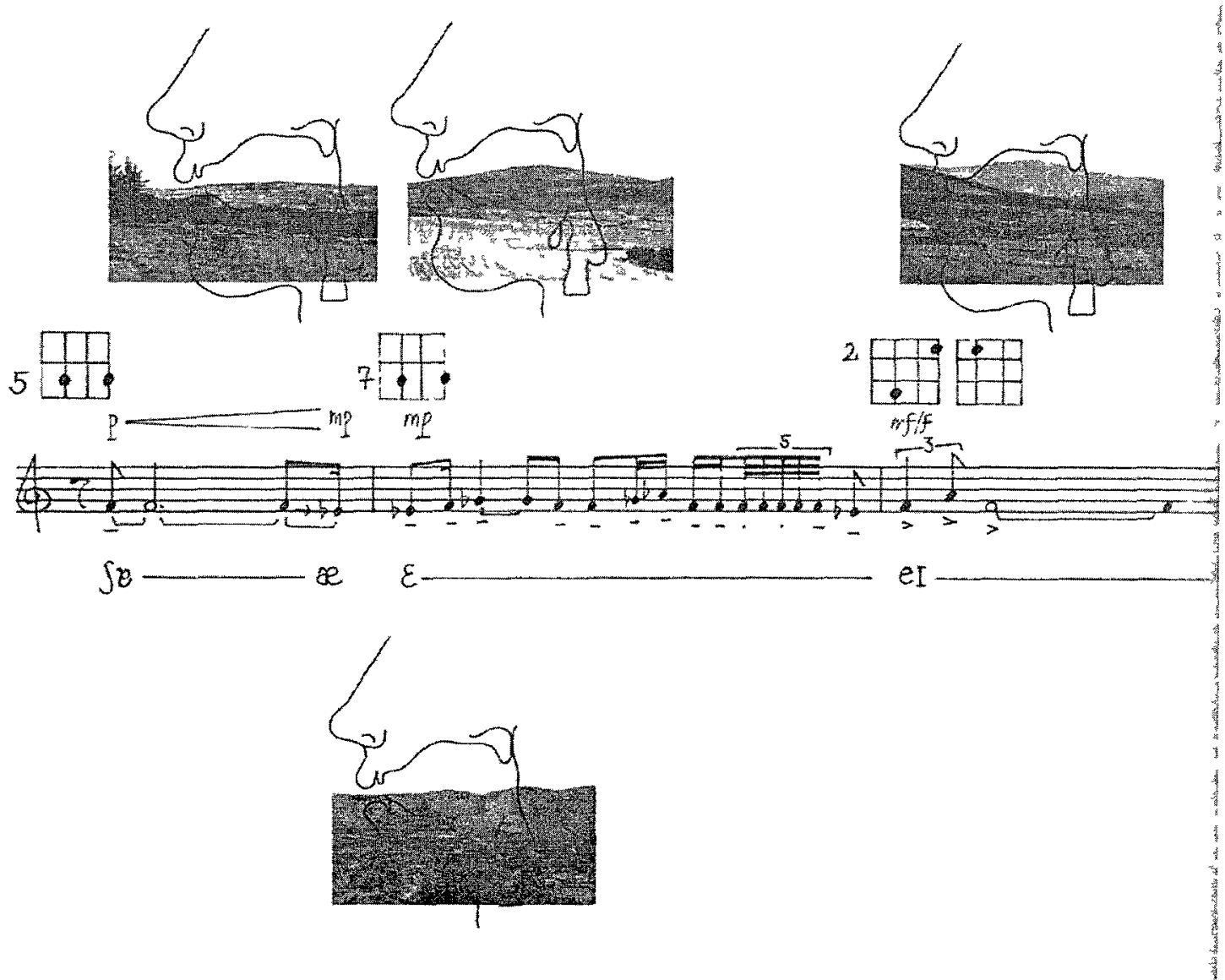

Three Songs (excerpt) Ukeoirn O'Connor 
But Walshe's Grupat is not unique in its pseudonymous venture. The history of literature is, for example, extremely familiar with the nom de plume, and in our media-saturated society it is de rigueur for anyone with a degree of electronic literacy to have at least one digital persona whose informational identity substitutes more and more for an embodied individuality. ${ }^{45}$ But what makes Grúpat different and ultimately effectıve is not its pseudonymity but the fact that Walshe executes it in the realm of Western art music, a realm conspicuously hostile to pseudonymity for the obfuscation of identity intimates an anonymity that brings its objects into unsettling proximity with "folk" and oral traditions that either have no concept of music as "art" or dilute the individual signature accomplice to the Western sense of art in a collective bath of idiosyncrasies. Furthermore, Walshe makes the fiction of Grúpat plausible by exploiting the way media superficies both distort the verity of the reality they report on and circulate this distortion as a reality to effect a feedback relationship between the orders of fiction and the real. As such, Grúpat approaches the condition of what Fisher calls "hyperfiction," a situation where "what is crucial is not the representation of reality, but the feedback between fiction and the

\footnotetext{
${ }^{45}$ Well known pseudonyms in literature are Lewis Carroll (Charles Dodgson), George Orwell (Eric Arthur Blarr) and Mark Twain (Samuel Clemens) However, the Portuguese poet and writer Fernando Pessoa is perhaps the most interesting case, for his incredibly rich body of work was written under multiple "heteronyms," a term he preferred for the way it characterized how names name distinct attributes that express different aspects of reality rather than merely act as alıases Scholar Richard Zenith suggests that Pessoa had as many as seventy-two heteronyms, however, his most important persona were Alberto Caeıro, Álvaro de Campos, and Ricardo Reis $\uparrow$ A more recent but inverted example of pseudonymic identity is "Luther Blissett Project" Blisset is the name of a 1980s Afro-Caribbean Britısh footballer that in the summer of 1994 was adopted by European artısts/activists/pranksters as an identity of "open reputation" under which a variety of critical hoaxes were carried out, such as the 1998-99 "Darko Maver" performance This "performance" is typically taken to be an elaborate manipulation of the culture industry by the art group 0100101110101101 ORG who fabulated an identity and artwork that they attributed to the fictional Serbian artsst named Darko Maver Through the prolfferation of forged documents, including press releases, self-authored theorization of Maver's artworks, news of the artist's imprisonment, and the exhibition of images of Maver's work at the 1999 Venice Biennale, the "Darko Maver" ruse demonstrates the mythopoeic potential of media environments, and at the same time exposes the perviousness of identity, fact and sense $\ddagger$

$\dagger$ Fernando Pessoa, The Book of Disquiet, trans Richard Zenith (London Penguin Classics, 2002)

+ See http //0100101110101101 org/home/darko_maver/mdex html for more detalls
} 
Real."46 The circularity between Grúpat as an enigmatic Irish art collective writing works that Walshe commissions-curates-performs-writes about elaborates the way contemporary culture's "fictional systems...emerge together, in a loop," so that "Where once there was a serial trajectory [of concerts, recordings, reviews, and critical essays] now [concerts, recordings, reviews, and critıcal essays] are issued simultaneously." 47 Like media distortion, Walshe's self-authored pseudonymous reviews of Grúpat works (which she performs) short-circuit the difference between fiction and reality and so subtract some of the supplementary dimensions that would falsify the experience. However, because Walshe still has a special role in telling Grúpat's story-she is the author who transcends its fiction—Grúpat never quite rises above the condition of metafiction.

The American composer Karen Eliot, on the other hand, is just such a hyperfiction, ${ }^{48}$ for neither the story nor the author plays any special role in the telling of her works. Yet, the author that I am referring to is not exactly "Karen Eliot," and the story is only apparently hers. In fact, Karen Eliot is a multiple-use name ${ }^{49}$ that composers and artists David Chokroun, Aydem Azmikara, Marc Couroux, Engram Knots, and Vanessa Grey use to gather the figments of their collective imagination under one appellation. Unlike Grúpat, which is a fiction that Walshe created to express the schizonoia of her artistıc interests, "Eliot" belongs to nobody and is no one. Sometimes

\footnotetext{
${ }^{46}$ Fisher, "Flatline Constructs"

47 Ibid

${ }^{48}$ The concepts in the music are avallable in the writing, each expression an advertisement for the other

${ }^{49}$ Multiple-use names are what art critıc Stewart Home defines as "'tags' that the avant-garde of the seventies and eighties proposed for serial use" (http //www stewarthomesociety org/sp/multı htm) Ideally, anyone can adopt a multiple-use name for some artistıc and/or subversive purpose

${ }^{50}$ Though largely created by Walshe in The Wire 321, she states that she has since invited individuals who've discovered what Grupat is (what she was up to) to participate and collaborate in the project
} 
referred to as an "open identity," multiple-use names like Karen Eliot are always several, and, according to culture critic Stuart Home, often "connected to radical theories of play [where] the idea is to create an 'open situation' for which no one in particular is responsible." ${ }^{, 51}$ In this case, "Karen Eliot" (the collective) is ir-responsible for the way her name functions as a point through which each of these five composers' identities pass.

That is, these composers use each others' names when "declaring" the nonpseudonymous authorship of a work; however, they do so according to a scheme whereby there will always be at least two possible attributors and so no way of determining who actually wrote the work. The scheme looks something like this
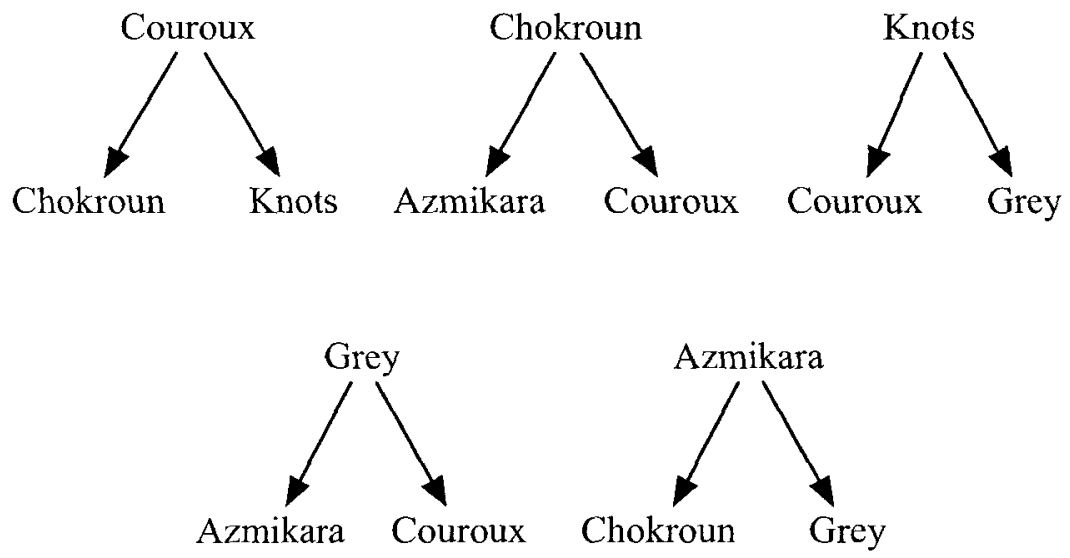

but may be more easily represented by this diagramme:

\footnotetext{
${ }^{s 1} \mathrm{http} . / / \mathrm{www}$.stewarthomesociety org/sp/multı htm
} 


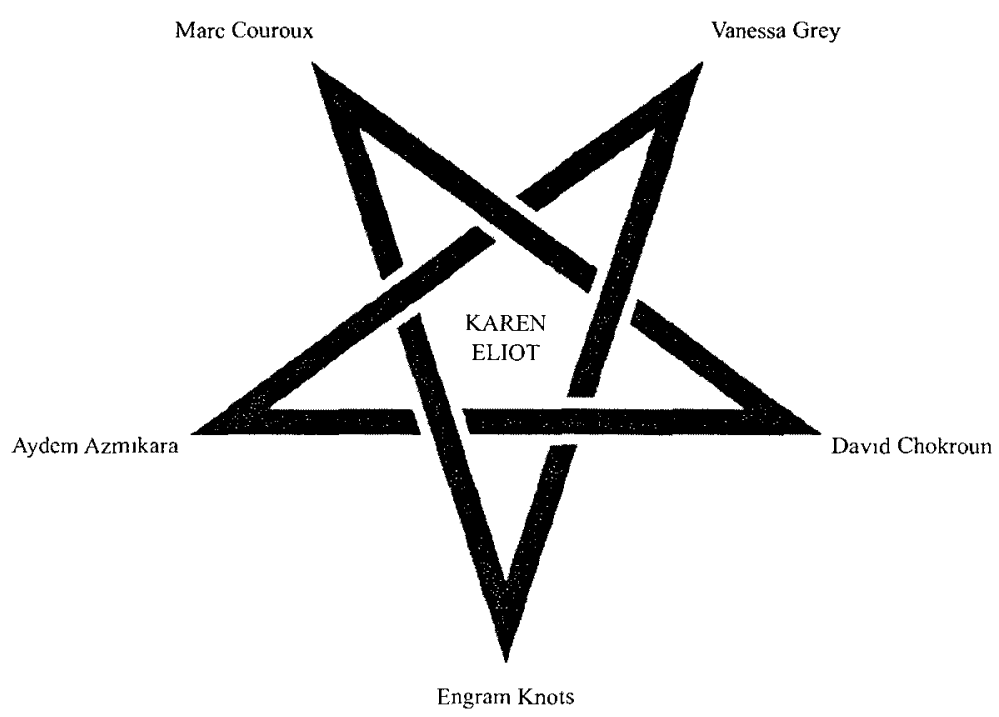

So, for example, as specified by this scheme, either David Chokroun or Engram Knots will have penned a piece by "Karen Eliot" that is attributed to Marc Couroux. Karen Eliot functions here as a pivot by which these composers appropriate each other's identity by writing about compositions that the other has written under the pseudonym of Eliot. We never know who the author is as he or she is always twice removed form the assignation of the work. In a way, this many-to-one inversion of the one-to-many Grúpat complex is not anti-identity but ante-identity. While corrupting the logic of signatures that establishes legible hierarchies of persona it nonetheless continues to traverse between levels of abstraction that permit one to communicate a sense of intention and agency that typically locates an identity. Only in this case intention and agency are always skewed and out of joint.

This has similar effects to Grúpat in terms of the way it confuses the restrictions that both define and delimit individual identity. However, Eliot is more mangy and mongrel in character than Grúpat is, for as noted, her five "collaborators" are always making it both unclear who has written what as "Eliot" and changing details, such as 
biographical particulars, that are usually considered indispensible in securing the signature of an individual. For example, the fabulated pedigrees that Eliot is given by her collaborators, who tend to portray her as an American composer working in the late twentieth century under the influence of Futurism, Dada, Fluxus, and Punk, are often switched around or reconfigured to reflect the situation in which "she" participates. For instance, the biographical details of "Eliot" that appear in a review written by Vancouver composer David Chokroun of Seattle-based Vanessa Grey's Muzak-opera Stimulus Progression (2004) - an opera in which performers follow a group of shoppers through a mall with dictaphones playing a prerecorded performance of their instrumental part-tells us when comparing Grey's work to Eliot's, that the latter is a transgender who served as a reserve in the national guard during the early nineties while studying composition privately with Barbara Monk Feldman in Santa Fe. However, another description of Eliot that appears in a programme note for her piano solo attributed to Grey who submitted the work to a women composers' competition-a work that asks the pianist to suspend two 18-inch concert marching cymbals millimeters above piano strings for as long as possible -notes that Eliot hails from Santa Fe and that it was Barbara Monk Feldman who studied with her before she (Eliot) took a job in Seattle doing arrangements and orchestrations for MUZAK Inc. In contrast to Grúpat, whose internal aesthetic dissonances and fictional reality become conceptually harmonized and somewhat spoiled by Walshe's consistent presence and relation to the group, ${ }^{52}$ the collective nature and schematic indirection of Karen Eliot circulates contradictions and inconsistencies in a way that keeps doubt and her reality in play.

\footnotetext{
${ }^{52}$ Not to mention that a feature story on her play with multiple identities in the November 2010 The Wire gave the game away See Phıllıp Clark, "Misshapen Identıes," The Wire, November 2010
} 
((((Symptoms, Syndromes and Hyperfiction

It would seem that the perplexity generated by Eliot's character would dissolve her persona into a field of nonsense. But as a form of radical play her hyperfiction does not dissolve so much as the operational difference between fiction and reality does. As Fisher notes, hyperfiction does not particupate in the kind of "imploded transcendence" that constitutes metafiction and its "interminable process by which supplementary dimensions are continually being produced but are immediately and of necessity themselves obsolesced at the very moment of their production." ${ }^{\text {53 }}$ Instead, hyperfiction elaborates processes "in which the product of any process is also one of its founding presuppositions." ${ }^{54}$ Agrippa's Trilemma writ large. ${ }^{55}$ As hyperfiction, Karen Eliot evades the "tangled herarchy" proper names of her collaborators to the point where even she proposes that Chokroun, Azmikara, Couroux, Parks, and Grey are her fabulations: "I'm a knot, nothing but a point! In fact, I'm a pointless space through which other voices pass." ${ }^{, 57}$ Neither the chicken nor the egg precedes the other; each is a relational term describing the path of a strange loop or the chiral symmetry_-"handedness"—of poultry. Names are circular and relative in hyperfiction so that "Eliot" and "Couroux," for example, are the handednesses

\footnotetext{
${ }^{53}$ Fisher, "Flatline Constructs "Fisher calls this condition of excessive meta-izing "Metanora"

${ }^{54}$ Ibid

55 Agrippa's Trilemma refers to the Greek sceptic's "conclusion" that it is impossible to prove any truth for we have either a circular argument where the premise and conclusion support each other, a regressive argument which entals that each proof requires another proof, or an axiomatic argument that acts on unproven precepts Of course the radical form of this trilemma would include its own position of this impossible situation in its formula

${ }^{56}$ This is Douglas Hofstadter's term for the way recursive processes search for supplementary dimensions to ground their propositions See Douglas Hofstadter, Godel, Escher, Bach An Eternal Golden Brald (New York Basic Books, 1979)

${ }^{57}$ eldritch Priest, "Bormg, Formless, Nonsense The Aestetıcs of Fallure in Contemporary Experımental Music” (PhD, Carleton Unıversity, 2011)
} 
of an event the way "Alice" and the "Queen" are in the chess-event of Through the

Looking Glass. And insofar as these names are constantly being exchanged—Chokroun

becomes Eliot becomes Couroux, etcetera-none receives the actions of things that

grounds the drama of the event. Indeed, as Deleuze notes, this is what happens to Alice in

her wonderland adventures:

The loss of the proper name is the adventure which is repeated throughout all of Alice's adventures. For the proper or singular name is guaranteed by the permanence of savoir [a known]. The latter is embodied in general names designating pauses and rests, in substantives and adjectives, with which the proper name maintains a constant connection [rapport constant]. Thus the personal self requires God and the world in general. But when substantives and adjectives begin to dissolve, when the names of pause and rest are carried away by the verbs of pure becoming and slide into the language of events [as they do in case of wordplay], all identity disappears from the self, the world, and God. ${ }^{58}$

By constantly swapping proper names, the field of singular symptoms that gather under its designation lose their sense, for a proper name marks a gathering point in a structure of coincidence - the syndrome of event - between a multiplicity of effects that otherwise remain impassive and inexpressive. Only a "pawn" can express the event of promotion. And when all pawns become queens, chess becomes checkers. The uncertainty that arises in shuffling proper names is not alien to the processes which naming names, but, argues Deleuze, is "an objective structure of the event itself." For example, the circulation of symptoms within a body give no sense of an illness until they are parsed and parroted as a syndrome that is designated by the proper name of the clinician who is proxy for the practice and accomplishments of "medicine," the supplementary dimension of diagnosis, treatment, and prevention of disease. And insofar as this uncertainty "moves in two directions at once," where symptoms become symptoms with reference to a syndrome

\footnotetext{
${ }^{58}$ Gilles Deleuze, The Logic of Sense (New York Columbıa Unıversity Press, 1990), 3

${ }^{59} \mathrm{Ib} 1 \mathrm{~d}$.
} 
that only becomes a syndrome with reference to symptoms, "it fragments the subject following this double direction." 60 Shuffling the identity of "Karen Eliot" doesn't exhibit or critique the framing structures that metafiction believes in and suffers from; instead, she simply makes a continuous effort to connect a multiplicity of effects that a proper name pinches with other multiplicities, such as "the sub prime mortgage crisis" or the excessively multiple "war on terror." In a sense "Karen Eliot"- the project-is like LeviStrauss" "floating signifier," an expression that is "in itself void of sense and thus susceptible of taking on any sense." ${ }^{61}$ Unlike Grúpat, Karen Eliot has no fixed referent, no identifiable set of symptoms apart from the nonsense she circulates, a nonsense that Deleuze notes, with reference to the differential play that underwrites the spatium of sense that structuralism tried to elaborate, "has no particular sense, but is opposed to the absence of sense rather than to the sense that it produces in excess. ${ }^{, 62}$ In a way, Karen Eliot is more like an esoteric word, like "snark" or "fruminous," or even "it," for without "denot[ing] real objects, manifest[ing] the beliefs and desires of real persons, or signify[ing] meaningful concepts, ${ }^{, 63}$ Eliot conveys the open sense of nothing in particular that in turn demands a continuous apprenticeship in the fundamental exercise of sense.

Eliot's esoteric apprenticeship in (non)sense is thus exemplified in the way she thematizes her nonsense as a hyperfiction that writes itself into being as someone suffering from depersonalization disorder (DPD) ${ }^{64}$ Eliot, who is several, describes her

\footnotetext{
${ }^{60} \mathrm{Ibid}$

${ }^{61}$ Claude Lévi-Strauss, "Introduction à l'oeuvre de Marcel Mauss," in Mauss, sociologie et anthropologie (Pans. PUF, 1950), 48-49, quoted in Deleuze, Logic of Sense, 50

${ }^{62}$ Deleuze, Logic of Sense, 71

${ }^{63}$ Charles Strvale, Gilles Deleuze Key Concepts (Montreal: McGill-Queen's University Press, 2005), 68

${ }^{64}$ The DSM-IV defines depersonalization disorder as a condition that can be identified by symptoms such as feelings of unreality, that one's body does not belong to you, or that one is constantly in a dreamlike state http.//allpsych com/disorders/dissocsative/depersonalization html
} 
nonsense in the prolegomena to her The Pinocchio Syndrome by writing that she suffers recurring episodes of feeling as though she is completely artificial or invented. "There are times," she writes, "where I feel to be little more than the empty spaces between the words you're reading, which is to say that I am as much and as little as a blank page." Having read Kendall Walton's self-help book Mimesis as Make-Believe (1990) while in grad school at the University of Michigan, a work in which Walton argues that art is an elaborate game of make believe and that the world and objects (rules and things) adumbrated by fictional statements-- propositions that are "to be imagined to be true" are to be taken as props that direct and organize our affective and emotional investment in the imagined reality, Eliot developed a strategy for coping with her condition. She writes, "I write fictions, what others might call little 'reality machines,' about music that I have not in fact written or listened to." From her perspective as a work of fiction herself, "reality machines" are props that make her real, or as she puts it, "at the very least they make everything as a fictional as I am." That is, Eliot's fictions are not only like Walton's props, wherein the act of saying "Say this is that" marks the event around which sense can be made, but resembles Deleuze and Guattari's abstract machines in that her "sayings" place "variables of content and expression in continuity," which is to say, in metaphysical-speak, that her fictions have a way of binding differences and making them resonate to produce a temporary reality zone or assemblage of sincerity. But Eliot's "reality machines" are actually no different from the more familiar notion of "discourse,"

\footnotetext{
${ }^{65}$ Kendall Walton, "Précts of Mimests as Make-Believe," Phllosophy and Phenomenological Research, 51, no 2 (1991) 380 See also Walton, Mimesis as Make-Belleve On the Foundations of the Representational Arts (Cambridge, MA. Harvard University Press, 1990)

${ }^{66}$ Gilles Deleuze and Felix Guattar1, A Thousand Plateaus Capıallsm and Schizophrenı, trans Brian Massumı (Minneapolıs Unıversıty of Minnesota Press, 1987), 511
} 
which also corrals difference into consistent realties, except that her realities spin out of musical props and, for the most part, she keeps her fascism to herself.

While Eliot's form of "therapy" may be somewhat deluded, what is interesting about her fictions is that they take on many different styles and are often self-reflexive interrogations on the constellation of voices that her proper name circulates. These machinic props may take the shape of a concert programme note (or may simply refer to biographical notes as I did above), conventional short stories, newspaper articles, blog entries, a series of emails or even dissertation chapters. Some of the more curious machines, however, are those that resemble JG Ballard's "invisible literature," writings that simulate the canon-less history of classified ads, car manuals, telephone books, and weather reports. "Her" work, In a Sedimental Mood (2010), for example, is like a compilation of classified ads about a work that explores how, under certain conditions, perception might be unhinged from its morphological habits to lose track of its expressions of attention and distraction. This prop, however, also alludes to a tendency in contemporary art to exemplify the paradoxical sense of stasis and unfinishedness that prolonged duration evokes, a sense that art theorist Terry Smith identifies as "the taking up of a viewer's time before the artwork provides enough information about itself for its point to become apparent. ${ }^{67}$

\footnotetext{
${ }^{67}$ Terry Smıth, What Is Contemporary Art? (Chicago University Of Chicago Press, 2009), 194
} 
(((((In a Sedimental Mood

\section{CONSTRUCTED BY} INDEPENDENTLY RECORDED LAYERS of differmng specifics (pitch, harmony) but same general affect/gesture Music as a Gradual Process

\section{CONVENTIONAL} SOUNDING SURFACE

made to function unconventionally

(experımentally) over tıme

\section{'REPOINTING'-}

listening attention keeps moving around-a lot of "signposts" clamouring for central focus Hinting at stylistic categories but never fully going there (eccentric hybridity)

\section{THAT MOMENT IN THE FILM \\ PERFORMANCE (1970)}

when background music suddenly becomes foregrounded-when the head gangster draws attention to it ("I like this part") and asks that the apparatus be turned up It also signals a move from an extra-narrative situation (background music / soundtrack) to a material (immanent) subject within the narratıve itself Many werrd perversions of this type occur in the last few scenes of Edgar G Ulmer's Detour (1945)
THE MUSIC IS CONSTANTLY DE- AND RE-CENTERING YOU, giving you an illusion of diversity, meanwhile indoctrinatıng you deeper into the system Always transposing, always standing stıll (similar actions carried out in different layers cancel each other out) Total variety $=$ total strictness

\section{EACH LINE HAS ITS OWN SET OF BOUNDARIES}

Descending piano lines (cocktail), rhythmic piano and detuned Rhodes (The French Connection), Bacharach chordal progressions, static single guitar lines, light virtuosic organ, arch-pseudo-Baroque harpsichord (late 60s soundtracks) Depending on the relative clarity of any given moment (how many lines are happening at once), the moment-tomoment stylistic profile will change Each line was recorded separately without listening to the other (simultaneous) lines A kind of "deaf" recording (vs blınd drawıngs)

Moreover, EACH OF THE 84 VERSIONS OF THE SAME LINE WAS RECORDED CONSECUTIVELY (1 e every line of descending plano recorded in a row, one after the other) Then, the second lines were recorded in their 84 incarnations (without listening to line 1) etc What you end up getting is a process which extends (exhausts) itself horizontally, has a definite linear timeline, but also has vertical consequences which cannot be predicted (deaf recording) In other words, recording 84 versions of the same contour/gesture/affect consecutively takes its toll because of the relative simplicity of each line, boredom sets in quickly when recording

\section{HOW TO BE}

INVENTIVE AFTER

ITERATION 64 did I

play that one already? And does it matter, in the end? [T] he boundaries within which formal cohesion is enacted exert a centrifugal retreat from the necessities of local choice This or that descending line, this or that chord, makes little difference when the overall texture is self- similar from iteration to iteration A selfenclosed system

\section{THE THING IS "MODULATING" from} one iteration to another (they aren't really iterations though), but each one is still cut from the same cloth (Moving while staying in place) Or it's like coming across the same object over and over again, but never in the same location 
HARMONY AND MELODY INTERSECT IN THE MIND OF THE LISTENER. FADE OUTS ARE IMMEDIATE RETROSPECTIVIZERS (formally). Fade outs usually happen over redundant materials-not so here Gettıng used to something over timethrough repeats that aren't repeats. Normalization

\section{OVER TIME THE FORM OF THE COMPOSITES BECOMES CLEAR}

even as content remaıns inscrutable. Foreign (noisy) elements are suddenly "justıfied" by the bifurcation to a more compatible context.
CONSONANCE/DISSON ANCE-SIGNAL/NOISE. The signal of one context becomes the norse (interference) to the next context (which "arrives" without you knowing it, Móbius-style). Your signal is my noise / your noise is my signal

\section{OSCILLATION} BETWEEN PERCEPTION OF OBJECT (FOCUSED ON) TO PERCEPTION OF SPACE, the environment in which this "background music" is playing .Fades into the background even when it's being actively listened to in the foreground

\section{NON-REPETITIVE} REPETITION: your ears are momentarily retuned, then the music fades into the background again (without undergoing any kind of shift in volume). Compare the physical fade outs at the end of each event with the mental "fade outs" occurring when attention drifts towards other shores...Dares you not to histen to it -much like wallpaper begs you not to look at it

\section{CONTINUOUS} REFOCUSING OF PERSPECTIVES when recognizable entities emerge out of chaotic layering.

\section{ONCE A "THINGNESS"}

has been established (through duration, repetition), then perceptions of variation can become more acute and specific. Where that "flup" happens depends on the individual listener. The "thingness" of the thing is established by cranking out variations which reinforce (paradoxically) their sameness.

This unauthonzed versioning of Eliot's fictionalizations (apparently) by Toronto intermedia artist Marc Couroux, is Eliot's machine (which is Couroux's fiction (which is our discourse)) describing a kaleidoscopic reality composed of multiple surfaces bleeding into each other's ground and staining each other's figures. In a Sedimental Mood, like any good piece of fiction, draws a map to its world. It does this by evoking the affects coded through musical works of 1960 s and 70 s popular culture as noted in the passage where Eliot describes the stylistic constraints of the instrumental voices-_Descending 
piano lines (cockta1l), rhythmic prano and detuned Rhodes (The French Connection), Bacharach chordal progressions, statıc single guitar lines, light virtuosic organ, archpseudo-Baroque harpsichord (late 60s soundtracks)" Essentually, Elıot is exploiting what Muzak "audio architects" refer to as a song's "topology,"- "the cultural and temporal associations that it [the song] carries with it, like a hidden refrain" ${ }^{\prime 6}$ - to create a polyphony of affects that articulate the baroque nature of late-capitalist culture's polytemporality, one that Smith argues " 1 s characterized by the insistent presentness of multiple, often incompatible temporalities accompanied by the failure of all candidates that seek to provide the overriding temporal framework" "69 "We might also say," continues Smith, "that time is moving in many different directions backward, forward trending, sideways sliding, in suspension, stilled, bent warped, or repeated "70 To the extent that the disparate lines of In a Sedimental Mood juxtapose musical layers that slow down, speed up, antıcıpate, and induce a sıckly nostalgıa, they present a way of hearing the multıfarıous present that Smith describes (and therefore to presence the feeling of it as well since duration and affect are inalıenable) Additionally, insofar as this tangle of durations and affective codes model something of the present imbroglio, the fiction of In a Sedimental Mood diagnoses the symptoms of contemporaneity, which has the paradoxical effect of realizing its fiction

\footnotetext{
${ }^{68}$ David Owen, "The Soundtrack of Your Life," The New Yorker, 10 April 2006, http //www newyorker com/archive/2006/04/10/060410fa_fact\#1Xzz16vOqbKnW

${ }^{69}$ Smith, What Is Contemporary Art? 196

${ }^{70}$ Ibid
} 
((((((Hyperstition, Magick and Nonsense

If you recall from the introduction to this chapter, the idea of fiction ${ }^{71}$ realizing itself is a form of hyperstition. And hyperstition, as it is characterized not by an insuperable belief that restricts belief to one kind of reality as superstition does, but by unbelief--which is to say that unbelief is a belief in the effects of belef-is linked to the modern occult practice of Chaos Magick. ${ }^{72}$ As Chaos Magick's initial expounder, Peter Carroll defines it, Chaos Magick is a practical and experımental art in developing "magical thinking,",73 a meta-belief in the efficacy of belief for achieving effects. ${ }^{74}$ Like Chaos Magick, which aims to access "the "thing' responsible for the origin and contınued action of events" hijacking the symbols and discipline of belief structures, hyperstition manipulates the real. But "The Real" that hyperstition manipulates is of course the realm of effects, a realm of expressive correspondences that represents the commingling of virtual and actual entities as they mutually alter and modulate each other's territory; in other words, the constructed world. But what distinguishes hyperstition from Chaos Magick is less the

\footnotetext{
${ }^{71}$ (aka "bullshıt")

${ }^{72}$ The " $k$ " at the end of magick is a practice initıated by Aleister Crowley who introduced the archaic form of the word to distinguish the occult practice and esoteric wisdom he was teaching from stage magic However, in the introduction to Crowley's work Magick (1973), John Symonds and Kenneth Grant argue that the spelling has an occult significance
}

The Anglo-Saxon $k$ in Magick, like most of Crowley's conceits, is a means of indicating the kind of magic which he performed $K$ is the eleventh letter of several alphabets, and eleven is the principal number of magick, because it is the number attributed to the Qliphoth-the underworld of demonic and chaotic forces that have to be conquered before magick can be performed $\mathrm{K}$ has other magical implications it corresponds to the power or shakt aspect of creative energy, for $\mathrm{k}$ is the ancient Egyptian khu, the magical power Specifically, it stands for ktets (vagina), the complement to the wand (or phallus) which is used by the Magician in certain aspects of the Great Work "---Aleıster Crowley, Magick, ed Symonds John and Kenneth Grant (London Routledge, 1973), xv1

${ }^{73}$ This is not to be confused with the psychoanalytic notion of "magical thinkıng" as a primitive form of naive anımism, but a kind of non-rational (which may include unconscious form as well as drug or meditation induced alternatıve states) thinking that particıpates in the manipulation of reality

${ }^{74}$ See Peter Carroll, "Chaoısm and Chaos Magic, A Personal View," avalable all over the Internet but here's a link http //Www chaosmatrix org/library/chaos/texts/chaosm html

${ }^{75}$ Peter Carroll, Liber Null \& Psychonaut An Introduction to Chaos Magic (York Beach We1ser Books, 1987), 28 
fact of reality manipulation and more the location of agency and intention. From the side of Chaos Magick, and most occult philosophies which subscribe to some form of Jakob Böhme's theory of the "doctrine of signatures" wherein "Everything is a signature, pointing beyond itself to an ultimate and interior reality,"76 agency is explicitly located in the individual who, as an expression (or a "mode" to use Spinoza's terminology) of divine impulse, possesses an innate capacity to realize his/her nature as an actor in the shaping of reality by way of appropriating the energy harnessing disciplines of various belief systems. Here, the Chaos magician's intent and non-attachment to any specific belief is a thing to be practiced and cultivated, the way, for instance, a studio musician aims to develop a technique and musicality that is adaptable to any style or genre. Hyperfiction, however, as it entails unbelief, surrenders agency to the differential and impersonal workıngs of things such as language, economy, and affect, the power of which is manipulated indirectly by communication technologies and a vast media apparatus whose dissemination of information has a way of taking on a life of its own. Take, for example, the phenomenon of "hype." What "hype" describes is a process in which statements about a future effect are peremptorily circulated in various media and intensified by an excitement embodied in the present as a "buzz" which eventually brings about the anticipated reality in the form of interest. Call it an unintentional incantation,

\footnotetext{
${ }^{76}$ Brian Gibbons, Spirituality and the Occult (London, New York Routledge, 2001), 7 Prior to its expression in occult terms, the doctrine of signatures referred chiefly to a herbalist practice in which an identıfied homology between various herbs and certain human body parts is thought to express the medicinal effects the herb will have on that part For example, the value of "bloodroot" in treating blood diseases was believed to be "written" in its orange-red colour More 1ikely, though, the doctrine of signatures was a mnemonic device and way of dissemınating medical information See Bradley Bennett, "Doctrine of Signatures An Explanation of Medicinal Plant Discovery or Dissemination of Knowledge?," Journal of the New York Botanical Garden 61, no 3 (2007)
} 
one that deputizes the effect before it happens. ${ }^{77}$ The important point here is that Chaos Magick is a practice and it intends what Peter Carroll calls "psychological anarchy...[where] the aim is to produce inspiration and enlightenment through disordering our belief structures," effect arising in feedback systems that continually self-adjust to and compensate the reality that they produce (like capitalism) ${ }^{79}$ In a sense, hyperstition is what the Chaos Magician tries to create: an abstract machine re-punctuating the real with virtual entities that pinch, fold, bend, and twist the hardware of actual bodies to form new circuits of behaviour and desire.

Drawing on thıs distınction we can consider another of Eliot's schizo-fictions, “Becoming Karen et al, a Real-Time Hyperstition as of March 30, 2007," to be a blending of Chaos Magıck and hyperstition in the way it aims to shape the reality of a musical experience by treating its own narrative as a cryptic symbolization of the meanngs and intents of the music she writes about. This is a process known in occult circles as "sigılızatıon," a technıque derived from the English artist Austin Osman

\footnotetext{
${ }^{77}$ The financial fallout known as the sub-prime mortgage crisis of 2008 is another example of hyperstitional processes in that the events leading up to the collapse of the reality known as "the market" unfolded through a series of greed driven symbolic investments made on the credit ratings provided by hedge funds and other entities of the shadow banking system $\uparrow$ No one person or secret cabal manipulated this reality with esoteric spells to effect a change in wealth, rather, it was a series of adjustments in financial policy, the misapplication of risk models and financial engineering, and a dubious faith in the market's ability to self-correct +

$\uparrow$ For an incredibly detalled overvew and summary (with nifty graphics and flowcharts) see the Wikipedia entry on the Subprime mortgage crisıs at http //en wikıpedia org/wikı/Subprıme_mortgage_crisis

$\$$ Paul Volcker goes into these conditions in more detall in "The Time We Have Is Growing Short," The New York Review of Books, 24 June 2010, http //www nybooks com/articles/archives/2010/jun/24/time-we-havegrowing-short/

${ }^{78}$ Carroll, Liber Null \& Psychonaut, 115

${ }^{79}$ For an exegesis on how capitalism breeds and lives on hyperfictıons see Mark Fisher, Caputalist Realism Is There No Alternatrve? (London Zero Books, 2009)
} 
Spare's practice of reducing statements of intent to illegible glyphs (something looking sufficiently witchy like this:

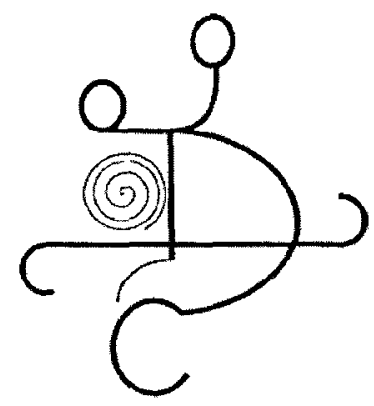

For Spare and the Chaos mage,

Sigils are monograms of thought... a mathematical means of symbolizing desire and giving it form that has the virtue of preventing any thought and association on that particular desire (at the magical time), escaping the detection of the Ego, so that it does not restrain or attach such desire to its own transitory images, memories and worries, but allows it free passage to the sub-consciousness. ${ }^{80}$

The practice of sigilization is thus a way of accessing the repressed forces of the unconscious, and indeed occult author Frater U $\therefore$ D $\therefore$ calls Spare's sigilization a form of "controlled repression" and a means of "reversely using" (i.e. de-pathologizing) this psychological mechanism. He writes that Spare's rationale can be summarized as follows:

If the psyche represses certain impulses, desires, fears, and so on, and these then have the power to become so effective that they can mold or even determine entirely the entire conscious personality of a person right down to the most subtle detail, this means nothing more than the fact that through repression ("forgetting") many impulses, desires, etc. have the ability to create a reality to which they are denied access as long as they are either kept alive in the conscious mind or recalled into it. Under certain conditions, that which is repressed can become even more powerful than that which is held in the conscious mind. ${ }^{81}$

For Chaos Magick, sigilization accomplishes a magical action by enciphering desire and is therefore a technique that "takes advantage of the psychological fulfillment automatism

\footnotetext{
${ }^{80}$ Austin Osman Spare, The Book of Pleasure (Sioux Falls, SD NuVision Publications, 2007), 91.

${ }^{81}$ Frater U $\therefore$ D. , High Magic Theory \& Practice (St Paul, MN. Llewellyn Publications, 2005), 134
} 
and forces the subconscious to bring about the desired effect against the potential resistance of the conscious mind and censor. ${ }^{\prime 82}$ Basically, the idea of using sigils is to bypass the ego's editing mechanisms and implant desires and directions for drives at the level of the unconscious where their workings may go unnoticed and un-bowdlerized. In this respect, Eliot herself might be a sigil in that her name functions as a glyph for a hyperstition that manifests a fictional desire which she, and the composers who become her, share. We may say then that to become Karen is to pretend to repress desire "in order to make it capable of being fulfilled." 83

But if this is the case, if Karen Eliot is a sigil that has effects by being written and read, which itself is enciphering fictional desires, then she resembles what writer Grant Morrison calls a "hypersigil," "a dynamic miniature model of the magician's universe, a hologram, microcosm or 'voodoo doll' which can be manipulated in real time to produce changes in the macrocosmic environment of "real' life." monogram of thought that one symbolizes and then forgets (i.e. represses). ${ }^{85}$ But as Morrison explains, a "hypersigil" is not static; it is "a sigil extended through the fourth dimension" and "can take the form of a poem, a story, a song, a dance or any other extended artistic activity you wish to try." unlike ordinary sigils, the hypersigil "is a dynamic miniature model of the magician's

\footnotetext{
82 Ib1d, 135.

${ }^{83}$ Ibid

${ }^{84}$ Grant Morrison, "Pop Magic'," in Book of Lies The Disinformation Gulde to Magick and the Occult (Being an Alchemical Formula to Rip a Hole in the Fabric of Realtty), ed. Richard Metzger (New York The Disinformation Company, 2003), 21

${ }^{85}$ This process of "forgetting" is usually referred to as "charging" the sigil and is ideally accomplished by holding the sigil before oneself or in mind during moments of intensity arising through concentration, fear or even lust, and then promptly abandons Because mediation can take years and moments of surprise are out of one's control, Morrison suggests masturbation as an expedient (and fun) way of sigil-charging

${ }^{86}$ Morrison, "Pop Magic'," 21
} 
universe... [that] can be manipulated in real time to produce changes in the macrocosmic environment of 'real' life." ${ }^{97}$ Morrison calls his own comic series, The Invisibles (19942000), a hypersigil, describing it as "a six year long sigil in the form of an occult adventure story which consumed and recreated my life during the period of its composition and execution." ${ }^{, 88}$ In this sense, Karen Eliot, too, is a hypersigil in that the composition and execution of her fiction not only (re)creates her life and the composers who pass through her, but mine and yours as well. And she does this not by simply consuming writing/reading hours, but by the way her stories shuttle desires to the unconscious where they form a "complex" of ideas and affect, an affectively charged fictional quantity that functions independently of conscious thought while striving towards its own satisfaction. ${ }^{89}$

If this is too esoteric sounding, let's for a moment reframe it in more academic terms. For those scholars who approach change and reality in terms of sublimated material relations and the textual production of difference, hypersigils may be likened not to objects but the variations that play across objects, across the serial moments of writing or reading a book, of composing, of performing or of listening to music, of being arrested, or even those liminal moments such as commuting to work. As such, a hypersigil embodied is change, and what change explicates is an implicated difference, a difference that from one direction seems to induce the process that actualizes it in terms of ordinary sense experience, but from another, is an expression, a symptom, of that process. Deleuze-Sorcerer Supreme of Difference — notes that this process of becoming

\footnotetext{
${ }^{87}$ Ibld

${ }^{88}$ Ibld

${ }^{89} \mathrm{U} \therefore \mathrm{D} \therefore$, High Magic, 135
} 
always eludes the present, that change moves and pulls in both directions at once as Alice does when she grows taller than she was and smaller than she will be. ${ }^{90}$ Change taken in this way is in fact very close to Deleuze's understanding of "sense" as a dimension that establishes the expressive potential of a proposition or an event so that, for example, we can say "to grow" has the sense of "younger" and "older," "faster" and "slower," or to use Deleuze's example, "a tree greens" is the sense, the pure variation of an arborific becoming. Employing the figure of the phantasm to describe how sense is connected to thinking, Deleuze writes, the phantasm "is a machine for the extraction of a little thought, for the distribution of a difference of potential at the edges of the crack [in the flow of becoming], and for the polarization of the cerebral field." change, a virtual fold or pleat that introduces "value or significance into neutral system." It is the genetic condition of thought in that it grounds the possible ways we may refer to an external state of affairs, manifest a desire or belief, or signify another concept. ${ }^{93}$ Yet sense is a paradoxical dimension in that it changes with each expression of it so that while the pure variation of "to thirst" which marks an expressive potential does not change, how one thirsts is always being refigured. "Intensities of relations change in the realm of sense, but the relations themselves are eternal." $" 94$ What sense traces then are variations of variations, a spiraling differential intensity that flickers across things as an abstract line of development, a line of creative flight. Deleuze's own The Logic of Sense,

\footnotetext{
${ }^{90}$ See Deleuze, The Logtc of Sense, 1-3

${ }^{91}$ Ibid , 220

92 James Williams, Gilles Deleuze's Logic of Sense A Crittcal Introduction and Guide (Edinburgh Edinburgh University Press, 2008), 3

${ }^{93}$ Deleuze indicates these as three types of relations (dımensions) of a proposition denotation, manifestation, and signification But sense is the fourth dimension of the proposition and only it relates a proposition to an event, to a becoming See "Third Series of the Proposition," in The Logic of Sense, 12-22 ${ }^{94}$ Williams, Gilles Deleuze's Logic of Sense, 3
} 
composed of multıdimensional sentences ${ }^{95}$ and mind-bending figurations of sense, is itself a hypersigil in that its experimental form and series of series creates the sense of sense which is that sense is creatıve, always being made and changing. While this makes for a nearly impenetrable read, by implicating its own expressions into its explication, it nevertheless conveys something of the nature of sense not by simply telling us what it is but by becoming what it is. Thus, like all sigils, The Logic of Sense ferries something to the unconscious where its ideas are repressed and allowed to work in the reader at a level where there are no contradictıons and insight is a lateral rather than linear event

Returning to the discussion of Eliot's fiction, "Becoming Karen et al, a Real-Time Hyperstition as of March 30, 2007," I want to suggest that it is like The Logic of Sense in that it tries to convey what it describes by becoming it. This piece, which is (supposedly) penned by Montreal-based composer Aydem Azmıkara ${ }^{96}$ - a Chaos magician, incidentally, who composes music by stealing the signature elements of other composers' works, first by making a transcription of the thoughts he had while listening to or performing another's work, and then turning this transcription into a sigil-takes the form of a journal entry in which "Eliot" recounts her own experience and thoughts of listening to Marc Couroux's Carpenters et al., Downey musical holdings, a real-time

\footnotetext{
95 James Williams insists that Deleuze's writing style in The Logic of Sense is deliberately composed to "prompt" something in the reader for sense is "not in what is said, but what readers allow it to trigger" Ibid, 21 To provoke the agitation of sense Deleuze writes so that "each sentence is a mixture of philosophical demonstrations and conceptual innovations, with literary and artistic references, with accessible images, with terms form many other disciplınes, (mathematics, psychoanalysis, literature, structuralism ), with condensed physical metaphors and extremely varied analogies " Ib1d, 20

${ }^{96}$ Aydem Azmıkara 1s, lıke Karen Elıot, a multıple use name However, this name is designed to express the ideal anonymity inherent to cyberspace Type this name into a search engine and you'll find a blog explainıng that "Aydem Azmıkara" is "an anonymous distributed identity project," a name that can be used by anyone as an anonymous "signature" and therefore impersonally gain access to a range of potentual transactions avallable online Further down the page, the significance of the name is revealed, reading "'arakımza Medya' means 'stolen sıgnature media' which becomes 'Aydem Azmıkara,' when read backwards" http //arakımzaMedya blogspot com
} 
social system as of March 29,2007. In this entry, she suggests that the concept of media "spin," which Couroux's work purports to simulate, recasts the occult principle of reality manipulation in a way that suggests both "spin" and "magick" exploit the paradox that affirms sense as not only pliable metaphysical surface but a creative obscenity.

\section{((()((Becoming Karen et al, a Real-Time Hyperstition as of March 30, 2007}

By Karen Eliot

Last night I went to hear my friend Aydem perform in Marc Couroux's piece Carpenters

et al., Downey musical holdings, a real-time social system as of March 29, 2007 at the

Queen West Arts Centre with Neither/Nor. ${ }^{97}$ I've been to some of Neither/Nor's shows before and found them to be, how can I put it, weird. The shows and the music are for the most part unassuming; they're staged in small theatres or, as their so called "obscurity" festival was back in 2005, in a room in the Darling Building, ${ }^{98}$ and presented like any concert is, with the musicians and audience divided by that invisible line of concert convention. But the music is strange. It's strange not in the way that Lachenmann's instrumentale musique concrete or Russolo's intonarumori orchestra might be considered strange, but strange in the way that it's so sincere. Now, I know that all of Neither/Nor's members are savvy in some regard to the idea of the social construction of reality, so this sincerity doesn't strike me as naïve. Rather, it's more like the idea of reality's constructedness is taken for granted so that art becomes less a hammer for smashing

\footnotetext{
${ }^{97}$ Neither/Nor is a Toronto-based experimental music collective, of which I am co-artistic director 98 The Darlıng Building is one of many buldings located in downtown Toronto that rents suites to individuals and business For several years, the majority of occupants were artists who used the suites as studio space (and occasionally living quarters), however, with rent rising in response to the re-urbanization of Toronto's central core, most of the studios and galleries that once occupied the Darling Buildıng have left
} 
mirrors, or a monad reflecting the internal conflicts of sociohistorlcal processes, and more a technique for generating affect, for producing the thing that makes thoughts sticky and, ultimately, effective. So, in going to listen to Aydem, I anticipated that I would be similarly affected, that in listening to this music I would, in a sense, be changed. And from the moment I stepped into the space, I suppose I was. Let me explain.

Unlike the studio space that obseurity took place in, this series of shows that Neither/Nor produced-titled "(fallure)" by the way-were being staged at what is essentially a rehearsal hall for amateur theatre and dance. Located just up the street from the Centre for Addiction and Health, on the second floor of a rundown bulding, the performance space, a dance hall, was filled with mirrors and ballet bars lining the walls. There was some attempt to cover these with huge swathes of kraft paper But thankfully, this material (whose colour always strikes me as a vomity shade of ecru brown) was modulated towards a more tolerable shade of ochre by a rather charming display of bare incandescent bulbs strung around the exposed rafters. In my opinion, the place was a dump.

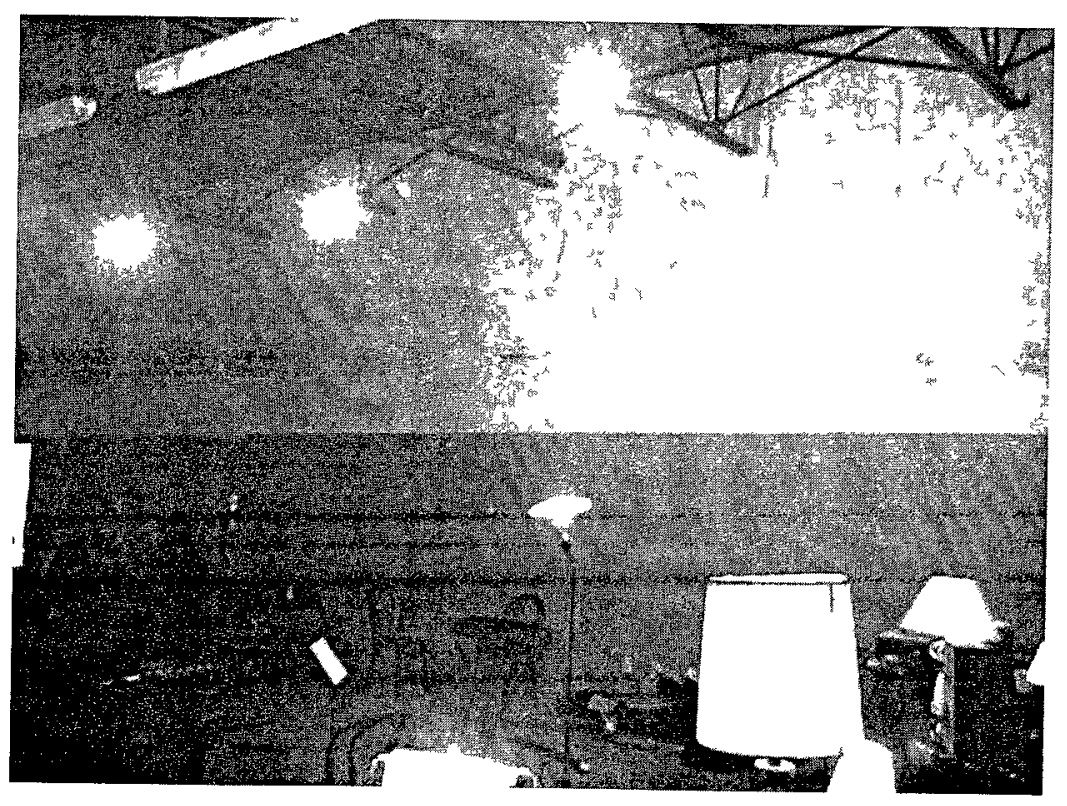


Before Couroux's piece were a couple of other small chamber works, the most interesting of which was a minimal solo violin piece by Los Angles composer-performer Eric km Clark that consisted of him quietly bowing harmonics and occasionally plucking a string on what he calls a 'simplified violin' (a violin whose strings are all tuned to E). What made this work interesting were the artefacts generated by his bowing and the instrument's inability to hold the tuning. (I should think about this piece some more.) But Clark's brief and austere sound world, which came off as someone trying to figure out a tune in their head by whistling it out loud, was the opposite of Carpenters et al. 's forty minute din.

Carpenters et al., whose concept can be summarized as a set of instructions for a performer to learn Carpenters songs on the spot, has no specific instrumentation; however, in this case the piece was realized by eight musicians, divided into three groups. What I learned only after talking with Aydem was that Couroux split the ensemble to represent three dimensions of what he (Couroux) refers to as the process of "spin," as in media spin.

I'll try to describe how this worked: The first "dimension" of spin, which was Couroux on piano and visual artist Juliana Pivato on vocals, was positioned near the back of the stage-area. Both Couroux and Pivato were wearing headphones and listening to a set of three or four randomly selected fragments of Carpenters songs. ${ }^{99}$ As they listened, they would try to learn the fragments one by one, then smear them together to form a kind of "hook" (which had the effect of them playing excerpts from "The

\footnotetext{
${ }^{99}$ For this piece, Couroux used a patch that he wrote for the ubiquitous interactive music software MAX/MSP to randomly select two to five second samples of Carpenters repertorre Importantly, these samples are taken from anywhere in a track so that their start and stop points cut across phrases and vocal lines to further dismember and decontextualize the melodic sense of the original piece
} 
Carpenters Greatest Hits that never were"), and start the process over again. The second dimension of spin was composed of two electric guitars (one of whom was Aydem). These musicians were asked to listen to the spun (smeared) melodies of the first dimension and try to reproduce what they heard, to replicate the hesitation and errors, the inaccuracies and fudging, which would turn into its own kind of smear. The third dimension of violin, trombone, electric guitar and contrabass, had each player listening through headphones to the original fragments that were the source for the first group (piano and voice). But unlike the first group, these musicians were trying to "recover" the Carpenters shavings as accurately as possible while at the same time being impinged on by the spins of both the first and second dimensions. The result, if you can imagine it, was something like those hidden 3D pictures-"stereograms" I believe they're called-popular in the 90 s where, if you can unfocus on the place of coloured dots, a phantasmatic image will appear to float over the noise of the picture.

Hyperstition as of March 31, 2007

I've heard Couroux do something like this in an earlier piece called Watergating (2007). In that work there were only two performers learning and building a repertoire from similarly randomized fragments of the Carpenters. But unlike Carpenters et al., Watergating isn't reflexive about the creative distortion of spin. That is, Watergating simply exploits the logic of spin to create another, if somewhat twisted, reality from a heap of cultural debris, while Carpenters et al. seems to linger in and palpate the nonsense that a sound bite must pass through in order to be spun, to make sense. But there is something obscene about both of these works. Basically, the musicians are instructed to use their musicianship to "smooth-over" the jagged edges and 
discontinuities of the fragments they hear. In other words, they are asked to put a spin on the nonsense expressed by the continual circulation of decontextualized shards of music. What makes this perverse is that the musician has to expose him or herself to an ongoing series of what are effectively puzzle pieces that never actually form a complete picture but instead keep making nonsense-fractalizing nonsense-and thus creating an unpredictable situation that dislocates the performer from his/her intentions to play well, to not suck, which forces them to either play with their pants down and fondle their musical junk in front of people, or fake it and make it look/sound like they know what they're doing. The listener, too, is caught in the pinches and pulls of spin, for they are also dislocated from their intentions, their intentions to hear a piece of "Music" and not a rehearsal. And to this extent, the listener can either hear the failure as it is-as nonsense-or become an implicated voyeur. Admittedly, I stared a lot.

Hyperstition as of April 1, 2007

I've been thinking, perhaps even more perverse, however, is the startling intimacy that this shared exposure to nonsense creates. Last night, I asked Aydem to do that thing he does where he makes a transcription of his thought-impression as he was playing

Carpenters et al., and this is what he wrote:

Start. Stop. Start again. Listen again. What was that? Did it go like this? No, more like this, but a little slower. Okay, now what's that? Up a step...down a third...down another thi-No, wait...Up a step... down a minor third, down a step. What's next? I can't hear what--too short. Try again. That's awkward. Okay. Like this...then like this... and like-again... Where are we? Right. Back h...e-r--e again. Up, down, down..."-_, uh-uh-uh. There's that voice part: “...e've only just begu..." Again. Up, down, down..."-", uhuhuh... "e've only just begu." Now it's coming together... Up/down/down "-" dadada-e've only just beguUpDownDown-dadada e've only just begu-la lalala laaa...shit, now it's changed again...

Now, what's startling is that I did the same and this is what I wrote: 
Start. Stop. Start. Listen. What's that? I think it was...No, it's like that but a little slower. Okay, what's this? A litter higher...now lower...down again-No, wait...what's she singing?... down even lower. What's next? It's getting noisy-what was that? Listen again. That's strange, but okay. Ahh, I like that... and that....and yes-again... Wait, where are we? Okay. Back...there-again. Da, duh, duh..."-_", uhhhhh. Right, that voice: “...e've only just begu..." Again. Da, duh, duh..."-”, uhhhhh... "e've only just begu." Now I think I hear it... Da/duh/duh ".." whhhhh-e've only just begu...Da/duh/duh-uhhhhh e've only just begu-_la lalala laaa...what!@? it changed...

In a way, maybe what's obscene about Couroux's work is that it's not clear where performing ends and listening begins. It stands to reason that if both Aydem and I were enduring the same nonsense, that is, if he and I were suffering the same perpetually undone (incomplete) event, then how could we be said to be "we." Because Carpenters et al. is nothing but the exhibition of process itself, then it has no particular sense by which to fix the clamour of its happening. All that it's producing are relations that it has yet to determine, to actualize. That is, it makes the sense from which "before" and "after," "performer" and "listener," "Aydem" and "Karen" can be specified. And until someone (like me) begins selecting a series of relations, emphasizing one direction of this sense over the other as my explication (unfolding) is doing right now, beforelafter, performer/listener, Aydem/Karen are simply implicated in the event-expressible but not-yet-expressed.

But is this nonsense really obscene, or is it more like the kind of mystical experience that Aydem tells me occult practices, such as alchemy and Kabbalah, refer to as coincidentia oppositorum. ${ }^{100}$ To linger at the edge of spin, an edge that is constantly

\footnotetext{
${ }^{100}$ This expression onginates with the fifteenth-century cardinal Nicholas de Cusa who reasons that from the perspective of the infinite-1 e God-opposites coincide, for the infinite by definition must include all categories of things, even what it is not For de Cusa, this was a way of showing how the faculty of reason, while limited, is (paradoxically) capable of conceptualızing the un-conceptualizable (the infinite) in the form of paradox (hence the title of his treatise De Docta Ignorantia). While de Cusa's work is the first to use the expression, Dennis McCort argues that the theme of coincidentia oppositorum is "everywhere in cultural expression," for life is constituted by an ineradicably tension between difference and identity,
} 
advancing and so continually displacing itself in Carpenters et al. is not to stall in a nothingness but to ride a surface, a surface that is relation as such. Yet sound bites are never heard "as such"; they come with a residue of context-finger streaks on a pane of glass. Hence there is always an "It sounds like... "But by the same token, to "sound like" is also "to not sound like," for it is by this same relation (and not by a relation to the same) that the sound bite becomes either. To spin is therefore to manipulate a surface that stretches along the length of a sound event...so had he "a rose by any other name" Lazarus might still be dead. In a way, the perpetual spin of Carpenters et al. is obscene, for its continuous decentring of intention resembles the depth created by two mirrors endlessly displacing each other's surface to create the effect of depth. However, on the other hand, its way of promoting action on fragments that spread effects across the surface of the work smacks of occult sympathies in that it articulates the basic magical principle of the law of contiguity or cosmic isotropy whereby to affect a part has effects on the whole. ${ }^{101}$ To this end, the way Carpenters et al. summons performance habits and forces the performer to confront and change them is a form of auto-affection, one that generates local effects which radiate outwards, inf(l)ecting a musical reality in which Carpenters et al. is itself but a part. Quod est inferius est sicut quod est superius, et quod est superius est sicut quod est inferius. ${ }^{102}$

transcendence and immanence See Dennis McCort, Going Beyond the Pairs The Coincidence of Opposites in German Romanticism, Zen, and Deconstruction (Albany. State University of New York Press, 2001)

${ }^{101}$ See Mauss, A General Theory of Magzc, 79-86

${ }^{102}$ This is the classic formulation of occult metaphysics as rendered by the legendary figure Hermes Trismegistus in the Emerald Tablet, an ancient book of insights that reveals a "spiritual technology" for self-transformation and the sublimation of the species into higher spiritual states This passage reads. "That which is below is as that which is above, and that which is above is as that which is below." 
Hyperstition as of April 2, 2007

More to mock his beliefs then to make a serious point, I told Aydem that maybe

Carpenters et al. was this esoteric ritual Couroux devised in order to ward off the demons

and specters of media However, to my surprise he responded qute sincerely, saying

something like

Yeah, Couroux is a closet magician. "Spin" is just a way for him to mask his occult predilections. In fact, his notion of spin just riffs on Genesis P-Orridge's idea of the sound byte as a "splinter," a hologrammatic fragment refracting the whole of a reality it helped compose ${ }^{103}$ The whole lot of them [neither/nor], they're all repressed sorcerers They all practlce magic but don't see how their music making, especially the concerty part, is an occult practice for summoning affective egregores. ${ }^{104}$ Forget his rhetoric about the work being a metaphor for the way pop culture absorbs the subtle and complex elements of a given situation ${ }^{105} \mathrm{No}$, Carpenters et al. is a hypersigil. Its cryptic circulation of

${ }^{103}$ Azmikara's summary of P-Orndge's "splınters" is a little shallow in that it doesn't convey what POrridge sees as the splinter's dynamic and non-linear topography

No matter how short, or apparently unrecognizable a 'sample' might be in linear time perception, I beheve it must, inevitably, contain withın it (and accessible through it), the sum total of absolutely everything its original context represented, communicated, or touched in any way, on top of this, it must implicitly also include the sum total of every individual in any way connected with its introduction and construction within the original (host) culture, and every subsequent (mutated or engineered) culture it in any way, means of form, has contact with forever.

Genesis P-Orridge, "Thee Splinter Test," in Book of Lies The Disinformation Guide to Magick and the Occult (Being an Alchemical Formula to Rip a Hole in the Fabric of Reality), ed Richard Metzger (New York The Disinformation Company, 2003), 32

104 "Egregore" is a term in occult practices referring to a symbiotic entity that arises as the (psychic) expression of collective will While wholly virtual, an egregore has the habit of affecting the thoughts and desires not only of those who occasioned it, but those who, as occultist Gaetan Delaforgem writes, "consciously come together for a common purpose" which "has the characteristic of having an effectiveness greater than the mere sum of its individual members "Importantly, an egregore is not a mere figment of group imagination, but a werd, quasi-autonomous affect in that "It continuously interacts with its members, influencing them and being influenced by them," and as such, "It will stimulate both individually and collectively all those faculties in the group which will permit the realization of the objectives of its original program "Perhaps the most striking thing about the egregore is that it needn't be intentionally realızed to emerge and if contınually invested and invoked, "will take on a kind of lıfe of its own, and can become so strong that even if all its members should die, it would continue to exist on the inner dimensions and can be contacted even centurnes later by a group of people prepared to live the lives of the original founders, particularly if they are willing to provide the initial input of energy to get it going again "In Gaetan Delaforgem, "The Templar Tradition Yesterday and Today," Gnosis 1987,

http //www masontcworld com/education/files/artjun02/TEMPTRAD htm Examples of popular egregores would be Santa Claus, Uncle Sam, and the Boogeyman But, also, because of the mythical status they have attained, we might include The Beatles and Beethoven as types of egregore, as well as Ronald McDonald and maybe even Jean Baudrillard

${ }^{105}$ Marc Couroux, Programme note, Carpenters et al, Downey Musical Holdings, a Real-Time Social System as of March 29,2007, 2010, http //couroux org/"page_1d=48 
Carpenters tunes is his way of sigilizing an intent. I'm not sure what exactly that intent is, but the egregore its withering melodies evoke is some kind of golemic Karen. It's necromancy in my opinion. But more to the point, what really makes this work function as magic is the way it attempts to affect the larger phenomenon of "spin" by directing the individual to change his or her own relationship to sense, to the very relation by which one thing comes to mean one thing and/or then another. And how one performs this sorcerous act of autoplastic adaptation is by doing what any magick practitioner does to get results-they exercise a belief.

I asked Aydem what "belief" was being exercised by Carpenters et al., and he replied that it was a belief in nonsense, nonsense as a kind of immanent blind-spot that keeps possibilities open and so never fully under control. What I take him to mean is that Carpenters et al. invests energies in the belief that the fitful distribution of Carpenters fragments is something like an "it" that indicates not a truth or a real real, but a sliver of nonsense, an " $x$ " that circulates among the fragments causing them to communicate and making it possible to think about things like truth. "It" can therefore only be elaborated, which is to say, ornamented and so in a sense occluded or obscured. Thus, "Carpenters et al." may be thought of as an esoteric word, a name for what this circulating and hidden element is "called," which is, paradoxically, what Carpenters et al is. As such, the performance, what the musicians do, is the summoning of an elemental or immanent nonsense that once present plays across the capacities of each performer, causing them to communicate with and modulate each others' expressions to form the refrain of a constant spin. 
(((()((O) Lies

Lies are sufficient to breed opinion, and opinion brings on substance.

Francis Bacon

But lies are a complicated thing. No more than truths, their expressions are composed of symbols that cannot but present something as being some way. "The sky is blue." "It's raining." Which is true, which is false? Or is it even a matter of truth and falsity? Before around the age of four, children don't appreciate the difference between factual or counterfactual statements for their ability to manipulate belief or to deceive. Instead, they treat ether expression as a representation of the way the world is, and so compare the world of a statement with a state of affairs in terms of consonance or dissonance, not verity or deceit. ${ }^{106}$ What is interesting about this is that counterfactuals can in a sense be lived, lived in terms of the sense they make of a state of affairs. Strictly speaking, it doesn't matter whether what I experience is true or false, factual or counterfactual, so long as the sense expressed allows one to form an opinion, which as the epigraph above contends, brings on substance insofar as it provides a way into the consensual hallucination that "we" calls "reality"--or in other words, everybody else's lies.

This can be linked again to Deleuze's idea of sense in the way it refers not to meaning but to the condition of meaning-relationality. As Paul Patton explains, sense, which is another way to describe an event independent of its particular expression-a "pure" event—is made insofar as "the manner in which a given occurrence is described or 'represented' within a given social context determines it as a particular kind of event." 107 In other words, the sense of a situation precedes its truth or falsity, for "the

\footnotetext{
${ }^{106}$ See Beate Sodıan et al, "Early Deception and the Chıld's Theory of Mind False Traıls and Genuine Markers," Chld Development 62, no 3 (1991)

107 Paul Patton, "The World Seen from Withın," Theory and Event 1, no 1 (1997) par 6, my emphasis
} 
event proper or pure event is not reducible to the manner in which it appears or is incarnated in particular states of affairs." ${ }^{108}$ Being inseparable from but equally not reducible to its expression makes a sense/event strangely impassive and neither true nor false with regard to its form(s) of expression and the particular state of affairs whose sense it is. Because "events [are] not exhausted by any particular description or set of descriptions," 109 and so may be endlessly paraphrased, "there is no simple fact of the matter which enables us to say whether such redescriptions are correct or incorrect."110 Sense-Events, such as "being cut" which the statement "He was cut with a knife" expresses, cannot only be described otherwise-"'He was wounded," "On either side of the blade his flesh lay exposed," "He was initiated into the order"--but none of these expressions is more true. The sense of an occurrence is therefore not its truth, but its potentiality, a response-ability informing the way a situation may take effect so that Alice, believing herself to have grasped the sense of eating and drinking's relationship with changes in size, can ask as she nibbles the cake marked "EAT ME": "Which way? Which way?" Understood as an effect that is made actionable in the expressions that call it forth and make it effective, sense, as Deleuze writes, "is like the sphere in which I am already established in order to enact possible denotations, and even to think their conditions." "In a very real way then, sense is an occulted relational immanence that inheres in an occurrence as its set of potentials, such as those an artwork makes abstractly apart and felt in its suspension from its effects. ${ }^{112}$ As such, sense is neither latent nor

\footnotetext{
${ }^{108}$ Ibid par 6

${ }^{109}$ Ibid par 5

${ }^{110}$ Ibid par 6

111 Deleuze, The Logic of Sense, 28

${ }^{112}$ Brian Massumi argues that artworks take the dimension of a potential lived relationship to an object that is common to all perception to a higher power in that they abstract and emphasize this potential, this
} 
dormant It is made, each tıme, from moment to moment And what makıng sense establishes, without assigning a specific direction or name, are the possible ways in which one might relate to a situation

In a way, sense is a black box Or as Deleuze (with Guattarı) might put 1t, akın to a map that is "entirely oriented toward an experimentation in contact with the real [and] does not reproduce an unconscious closed in upon itself, it constructs the unconscious "113 That 1s, like a map, sense is "open and connectable in all of its dimensions, it is detachable, reversible, susceptible to constant modification "114 As a map tolerates ingression from any direction to the territory it surveys, so too does sense And that sense is coextensive with and mutually determining of a nonsense that it contınually displaces, but which nevertheless circulates endlessly and randomly throughout a state of affairs, sense-non-sense is everywhere and everywhen As such, an event, the falling towers of $9 / 11$ for example, can be expressed in any number of ways, which means that "language use is not primarily the communication of information but a matter of actıng in or upon the world event attributıons do not simply describe or report pre-existing events, they help to actualize particular events in the social field "115 And indeed, the mutability of events, their endless paraphrasing, is what makes the representation of any trauma so fraught and embattled, for the way in which an event is represented is "integral to its actualization as a certain kind of event" "116 Perhaps this is why people are so touchy about how traumatıc events are described, for events that burn

"porse" which is one's being capacitated to act, yet suspend it by keeping it in virtual quarantine See Brian Massumi, "The Thinking-Feeling of What Happens," Inflexions 1, no 1 (2008) 5

113 Patton, "The World Seen from Within," par 7

114 Deleuze and Guattarı, A Thousand Plateaus, 12

115 Patton, "The World Seen from Withın," par 8

116 Ibid 
with the fierce flame of the real, in being so mutable, so inconsistent, broach the condition of fiction.

Is not something of this dis-ease inverted when I present Eliot's fictions? That the sense of the fictitious somehow, in its being conveyed with sincerity, with scores, audio samples, and vivid description, infects the real? Like the members of the Gladney family in Don DeLillo's White Noise, who suffer the real effects of rumour and dread roused by a reported but never directly encountered "Airborne Toxic Event," you experience the vague effects of a music that never was, the sense of a music that isn't- - but may be or could be. Like the logic of preemption, which proliferates the conditional effects of an indeterminately present futurity and organizes modes of being around the presence of this future cause (i.e., "threat," or in what's to follow, "pain"), ${ }^{117}$ the sense of music affected by this world of letters spreads across your reading of "this" and eventually to your listening and thinking about other musical sounds so that eventually, when you hear things exhibiting symptoms of polytemporality and spin, they will snap into place and actualize the sense of In a Sedimental Mood or Carpenters et al.

Sense spreads like this because it does not directly affect states of affairs - the sense of "being cut" never hurts. The effects of sense affect other effects, other events, not causally or necessarily, but expressively. As Deleuze notes, the proliferation of sense entails "a relation of effects among themselves" that together constitute "an aggregate of noncausal correspondences which form a system of echoes, of resumptions and resonances, a system of signs." 118 He calls this order of expressive relations "quasi-

\footnotetext{
${ }^{117}$ For an extended discussıon of the logıc of preemptive power see Massumı, "Potential Politics and the Primacy of Preemption."

${ }^{118}$ Deleuze, The Logic of Sense, 170.
} 
causality" arguing that sense and events modulate each other's effects and the meanings that proliferate through them to the degree that they influence the intensity in which each will be (will have been) expressed. Thus the sense of "being cut" will affect the sense of "cooking dinner" in the way that being cut is expressed by losing a finger, for example, changing the future and past intensity of the relationship between the bodies-vegetables, knives and fingers - in which the sense of cooking inheres. In other words, how a senseevent is expressed affects how one responds to and expresses the sense of another state of affairs. ${ }^{119}$ Simllarly, the sense of "musicking" made by this writng will affect the sense of "listening" in the way that its expressions of occultism and hyperstition capacitate your hearing in some manner that resembles doubt. It's no wonder then that fictions, because they are essentially sense generating machines, have a way of contaminating the world beyond its expressions. And just as you can survey a map of "Glubbdubdrib," "120 so too can you orient your self to a reality with the sense made by fiction. Fictions are thus a type of spell that intervenes in the production of the real by the way its fabricated sense is cast into the "chaosmos"

Eliot's fictions, in additıon to their "therapeutic" use, should be considered "spells," quasi-causal spells that disseminate their sense across the field of musical discourse,

\footnotetext{
${ }^{119}$ Now why the relationship between events is a "quasi-causality," and why some events correspond or seem more and less compatible with each other ( $1 \mathrm{e}$, the sense of being cut has hitle impact on the sense of a tree's greening) is a complicated matter, but has mainly to do with the increases or decreases in intensity one event brings to the expression of another That is, any event may (and virtually does) correspond with any other (all others), yet only those which affect a shift in intensity are registered, or considered significant

120 "Glubbdubdnb," an island of sorcerers, is one of the lands visited by Lemeul Gulliver in his travels

${ }^{121}$ A Joycean term (Finnegan's Wake) that Philıp Kuberskı culls to describe a world of emergence as "a contınual coincidence of 'quantum weirdness' and classical determımism," or, more asyndetically, "a unitary and yet untotalized, a chiasmic concept of the world as a field of mutual and simultaneous interference and convergence, an interanimation of the subjective and objective, an endless realm of chance which nevertheless displays a tendency toward pattern and order" Philıp Kuberski, Chaosmos Literature, Sclence, and Theory (Albany State University of New York Press, 1994), 2, 3
} 
makıng use of the way the "representation of events, in television and print media [including of course academic journal and books], has become part of the unfolding of events themselves "122 To this end they speak to something about the status of contemporary compositıon that journalıst Phılıp Clark notes in his artıcle on Walshe when he writes that the Grúpat-hoax was effective owing in part to the way the discussion of new music rarely rises above the level of composers listıng off their influences and naming the festıvals and ensembles who have played their works, or superficial descriptions of how the music was put together, how it sounds (sort of), or how it "comments" on some normative aspect of a culture ${ }^{123}$ All of this makes a kind of sense of the music, but the sense it makes is a particular kind, for "the nature of the incarnate or impure event is closely bound up with the forms of its expression "124 The sense it makes is not so much gibberish as it is phatıc, a language facilitatıng social interaction more than conveying information- "Lovely weather, 1sn't it" Grúpat makes sense of this in the way Walshe hijacks and coordinates the phatıc expressions of new music to elaborate their hidden sense of simulation In other words, while there exist music and artworks that represent the efforts of Grúpat, there needn't have been Grúpat could have remained wholly fictıonal, for the sense of "Grúpat-thınk" generated by fake reviews, false interviews, misleading programme notes, or erudite dissertation chapters, is just as effective, just as "real" as any other new music event However, it could only do this at the cost of being as simulated and vaporous as the reality it expresses Thus, in order to lever itself out of this position, Walshe must, paradoxically, confess the fiction of

\footnotetext{
${ }^{122}$ Patton, "The World Seen from Withın," par 9

${ }^{123}$ See Clark, "Misshapen Identies"

${ }^{124}$ Patton, "The World Seen from Within," par 6
} 
Grúpat in order to escape the pull of the imploded immanence she is trying to manipulate. The illusion becomes effective, tensile, as an illusion, only when it's known to be a trick.

Here then is where the difference between the illusionist and illuminist becomes apparent. Grúpat is a hoax, Karen Eliot is a hex. That is, Grúpat clings to belief in a transcendental refuge ("Walshe") where it can always find itself centred and in control of its effects, while Karen Eliot has faith only in the movement of delirium, a faith that the sense of her fiction is to determine a certain type of relation between otherwise “irrational" factors. ${ }^{125}$ Eliot's fictions are not illusions, they are conjurations or performances that act to change the reality of their own discourse by gathering and circulating nonsense elements to produce sense as an effect in conformity with the will that is immanent to its own drift. This is no less than sorcery. And no more either.

I want to end this chapter with a final fiction by Eliot, a final spell or hypersigil that aims to make sense of "constant variation" in music by summoning the sense of torture and pain, which is essentially a sense that undoes sense. In this work, titled "What does music feel like? (or, 'on the refrain of pain and imagining'): Discursive Remainders from glossolalia (stress positions)" (penned by Vanessa Grey)," Eliot writes a piece in the form of an essay about her own fictional status and how she writes fictions to make herself real. In this essay she also describes things like meta-referentiality, other fictional realities, and magick, and she also gives examples of her writings, one of which is a fiction written in the form of an essay that she attributes to Engram Knots, a graduate student in cultural studies who is writing about her piece glossolalia (stress positions) and its reflection on the way the continuous expression of musical variation is like the

\footnotetext{
${ }^{125}$ Gilles Deleuze, Desert Islands and Other Texts, 1953-1974, ed David Lapoujade, trans Michael Taormına (Los Angeles; Cambrıdge, MA Semıotext(e), 2004), 262
} 
refrain of pain. Here Knots draws on a number of sources including Elaine Scarry's theory that pain and the imagination are the potentializing poles of sentience, Freud's notion of "dream-work," and (of course) Deleuze's notion of sense and repetition. Ultimately, as "Knots" unpacks the relationship between music and pain, and exposes their shared intensity, he uncovers a hidden dualism and the unconscious of music.

(((()(((What does music feel like? (or, 'on the refrain of pain and imagining'): Discursive Remainders from glossolalia (stress positions) by Engram Knots

We all know the story of Cage's visit to the anechoic chamber. He came in wondering what silence sounds like and left believing that sound would never leave him. But Cage left the anechoic chamber. He walked away and left the corporeal cacophony of his body safely behind. "There will be sounds until I die," he said. Sure. But he always had the prerogative to decide how those sounds will be heard. Sound is everywhere. How wonderful. But what if the technician who assisted Cage had locked Cage in that echoless room? What if those two sounds, "one high and one low," couldn't be turned down or shut off? How wonderful would sound be then?

This is something that composer Karen Eliot asked herself after learning in 2004 from Afghanistan war veterans (whom she met while working as lab assistant at the Alan Edwards Centre for Research on Pain at McGill University) that the American military had been using sound and music in their interrogation of detainees, particularly at a prison located on the Bagram Air Base. These veterans, whose phantom limb pain was being studied at the centre, spoke about the use of acoustic weapons, such as the 
LRAD $^{126}$ on the battlefield, and about interrogations in which prisoners were placed in small cells and submitted to a constant stream of loud and shrill music (mostly 'rap' and 'metal' music). It was this image of the prisoner, confined to a nearly featureless room and forced to endure a condition that Cage himself rassed to the level of art, that took hold of Eliot's imagination and led her to ask how the sense of this constant exposure to sound/music might be expressed differently than it was by Cage's comfortable reassurance.

But Elot took on this question in a peculiar way. Rather than conducting her test in the controlled environment of a lab, Eliot locked herself in a practice room in McGill's music department where she spent nine hours subjecting herself to a recording of John Cage's Freeman Etudes played at a nearly steady volume just over 120 decibels. In a journal entry, on the night of her sound test, Eliot wrote:

It's always struck me as slightly curious why the US army has never thought to use experimental music, that is "art" music like the kind that I am listening to right now, as a torture device. I understand how the aggressiveness of rock or metal music, or the obnoxious exhortations of "Barney's theme," might affect a detained listener by virtue of their sheer volume and/or asinine refrains, but I can't help but wonder whether the glacial pace of a piece like Leif Inge's 9 Beet Stretch (2002) or the restiveness of Michael Finnissy's five hour The History of Photography in Sound (2001), or perhaps the skull rattling buzz of Phil Niblock's Five More String Quartets (1993) might be an even more effective form of torture. In an article I read the other day, the US Army's Psychological Operations Company Sergeant, Mark Hadsell, cites "unfamiliarity" as an essential factor in how heavy metal negatively affects detainees, by which he means Arabs. But by that reasoning, experimental composition should be even more effective than metal. ${ }^{127}$

\footnotetext{
${ }^{126}$ From the company's website "LRAD ${ }^{\circledR}$ (Long Range Acoustıc Device ${ }^{\mathrm{TM}}$ ) is a breakthrough hailıng and warning, directed acoustic device designed to communicate with authonty and exceptionally high Intelligibility" (hitp //Www lradx com/site/content/view/15/110/) Although the LRAD corporation does not exphicitly refer to the device as an acoustic weapon, their description of the "LRAD $1000 X^{\text {TM" }}$ is highly suggestive of this use "Through the use of powerful voice commands and deterrent tones, large safety zones can be created while determining the intent and influencing the behavior of an intruder " (http //www lradx com/site/content/view/220/110/)

${ }^{127}$ See "Sesame Street breaks Iraq1 POWs," http $/ /$ news bbc co uk/2/h1/middle_east $/ 3042907 \mathrm{stm}$
} 
My thoughts about this "oversight" is that most Psy Op officers, or more likely, the combat soldiers who are directly involved in applying music as a torture device, are themselves so wholly unfamiliar with experimental music, that if they happened to somehow encounter such a music, say, during a summer leave at the now defunct US army garrison-Darmstadt, where he or she may have stumbled upon a concert at the Darmstadt Summer Music Workshop, they would find themselves on the other end of the proverbial waterboard and thus unwilling, or unable, to take it as a weapon of their own. Of course I'm stretching things and playing fast and loose with Sgt. Hadsell's musicological perspicuity, for as any military personnel who has received training by S.E.R.E. (Survival, Evasion, Resistance and Escape) on how to resist various coercive techniques by being subject to those same techniques will tell you, knowing what it's like to be drowned, I mean, to be drowned for pretend, gives one a certain "insight" and thus a certain "familiarity" with the experience, which by the sheer power of reason, should inoculate one to its effects. Again, I'm being somewhat facetious here, but even though we're talking about music and not things like bamboo shoots or thumbscrews, it's curious to think about how the same musical object can have different effects on different people such that in one case its affect is pleasurable while in another it is torturous.

While Eliot doesn't disclose what she experienced during those nine hours, after this experiment her music began to exhibit a certain sensibility, or appetite rather, for particular kinds of psychological effects that arise when the body is put under duress, especially the kind of duress that characterizes contemporary forms of "enhanced interrogation techniques" that isolate and amplify the body's capacity to distress itself by varying the sense/sensation of its expression. For example, a lot of the music that Eliot has written in the past few years explores the kind of repetition that Gilles Deleuze and Felix Guattari characterize as one of "intensive variation." Basically, this concept refers to a type of repetition wherein the iterations of a gesture or a phrase do not refer to one another as particulars to a universal — our familiar "theme" to "variations" — but instead serialize the connections between their singular expressions, as echoes in a chamber or waves on the ocean do. Applied to language, Deleuze and Guattari suggest that the fixed idea of a word or a proper name derives not from a pre-existing ideal category of what 
"life" or, let's say, "music" means, but is essentially an effect generated by the continual act of enunciating or doing it. "Music" is an idea remaindered-expressed--from the intensive variations of its being done over and over again, forming between each gesture, movement, work, oeuvre, an immanent "line of continuous variation." ${ }^{128}$ Each iteration of a song, or a word, or an idiom, or more locally, a melodic phrase or ornament, swerves indeterminately along a virtual continuum that expresses the sense of "the song," and this continuum itself swerves along a continuum of what we might call a style or genre. Thus the sense of "Music" or of "speech" is an effect, an expression of certain differential relations-i.e. pitch, phonemes, amplitude-articulated in sound that, following Deleuze and Guattari's notion of "the refrain" as a pattern of intensities that form alliances with other intensive periodicities, is perpetually modifying, adjusting, and disciplining its continuous variation.

In Eliot's work she tries to fabricate intensive variation through a process that ramifies the tendencies of what, musicologically speaking, we might loosely call a melodic "style." She does this by exploiting the immanent referrals of a melodic idea and intensifying those lineaments that give us the character of its refrain. That is, she manipulates the drifts that are already at play in the idea of a style by exaggerating or minimizing its sensible and conceptual regularities. This was an explicit project in an earlier chamber piece pleasure drenching... (2003-04), in which Eliot derived the pitch material for many of the instruments using a recursive algorithm invented by Per Nørgård (the infinity series ${ }^{129}$ ) and then applying the resultant pitches to one of seventeen

\footnotetext{
${ }^{128}$ See "November 20, 1923 Postulates of Linguistics," in Deleuze and Guattar1, A Thousand Plateaus, $75-110$.

${ }^{129}$ The infinity serıes is an algorithm developed by Per Nørgård in the late 1960s in response to the hierarchical system theories that emerged in the 1970s These theories are not to be understood in the
} 
rhythmic modes that she selected using the integer shuffler at the website www.random.org ${ }^{130}$ and assigning them to a specific instrument. In effect, she wove a non-repeating melodic fabric whose relative consistency, achieved through the selfsimilar pitch groupings of the infinity series and the set of rhythmic constraints, expressed what could be considered the "style" immanent to the process. Applying this procedure to six primary voices convolutes the character of the procedure to produce a kind of melodic stuttering or lyrical nonsense that resembles the linguistic weirdness found in Chrıstian Bök's poem Eunoı-a retelling of 1001 Arabian Nights whereby each of the five chapters is restricted to words that contain only one of the five English vowels. ${ }^{131}$ By exaggerating the style or manner of the variation, the cultural clichés that

oppressıve and domınatıng sense of the word hierarchy (a rıgıd system/order of rankıng and suppressing), but rather as an "open" hierarchy, or as Arthur Kestler coined 1t, "holarchy" This ordering scheme can be basically understood as greater levels of complexity and integration perceived as wholes that also function as parts of even greater wholes from the perspective of an even greater context of complexity and integration

There is no absolute top or bottom to this scheme, the contextual 'tops' can be connected to further 'tops' and seen to comprise a 'bottom' in an even 'higher' relative hierarchy The scheme can be endlessly subdivided in an upward drection The same can be sard for 'bottoms' Bottoms are also non-absolute They can be connected to other 'bottoms' and seen to be 'tops' of other lower contextual hierarchies Nørgård found in his infinity series this same type of principle and employed it as a device to organıze the fields of pitch, rhythm and harmony However, in pleasure drenching the infinity sentes is not used for its nested hierarchical properties but for the modal/tonal cells that it generates and whose self-similar, fractallike qualitıes are give the sense of an endlessly differentıatıng identıty

${ }^{130}$ To illustrate A cell from a section of the Infinity series $\quad[\mathrm{Eb} \mathrm{Bb} \mathrm{F} \mathrm{Ab} \mathrm{F]} \mathrm{Bb} \mathrm{C \#} \mathrm{C} \mathrm{Eb} \mathrm{Bb} \mathrm{Eb} \infty$, Random integer "9", which she assigned the rhythmic mode of $54 \mathrm{e}$, becomes the figure

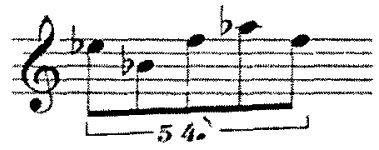

eldritch Prest, "Like Good Acid and the Residue of Pleasure Drenching " (MMus, University of Victoria, 2004), 5

131 Chapter "I" (excerpt)

Writing is inhibitıng Sighing, I sit, scribbling in ink this pidgin script I sing with nihilistic witticism, disciplıning signs with trifling gimmicks-impish hijınks which highlight stıck sigils Isn't it glib? Isn't it chic? I fit childısh insights within ngid limits, writing shtick which might instill priggish misgivings in critics blind with hindsight I dismiss nit-picking criticism which flirts with philıstınism I bitch, I kıbitz-gripıng whilst critıcızıng dimwits, snıpıng whılst indicting nitwits, dismıssing simplistıc thinkıng, in whıch philıppic wit is stıll illıcit Christian Bok, Eunoza (Toronto Coach House Books, 2001), 50 
already encrust certain melodic gestures and the internal clichés that arise within the time and space of the performance itself begin to lose their semiotic clutch and gradually increase the possibilities of a melody's referential aberration.

Like Raymond Roussel's machine texts that were generated using techniques which exploit the homophonic and connotatıve properties of both written and spoken language, Eliot's aim in pleasure drenching... was to create a music of richly distorted clichés. As Deleuze argues in his work on Francis Bacon, clichés must be destroyed in order for the construction of a new image to be possible. ${ }^{132}$ But clichés can only be curtailed, bent, turned, or rather, "troped." Because all processes of expression involve the more or less regular mixture of all types of bodies whose effect upon one another is called "sense," the more regular the mixture, the more clichéd its effects. In the case of music whose "bodies" include not only the body of pitch relations, but the body of cultural traditions, the body of styles, and the body of the auditor, its clichés are the expression of their common mixture, their "common sense." So cliché is not something that is preventable, for our very idea of music is itself a cliché that sustains the entire practice of assembling sound into expressive refrains. Instead, the musical cliché, like any process of expression, develops mutant strains that distort the common or single sense of "Music" by

${ }^{132}$ See Gilles Deleuze, Francis Bacon The Loglc of Sensation, trans Daniel W Smıth (London Contınuum, 2003). Elsewhere Deleuze writes that clichés are overcome in a moment of catastrophe. This moment must be a catastrophe for clichés are not simply repeated signs and artefacts of an external world, they "also penetrate each of us and constitute [our] internal world, so that everyone possesses only psychic clichés by which we think and feel, are thought and felt, being ourselves one chiché among others in the world that surrounds us "† The artist, argues Deleuze (with Guattar1), enacts this catastrophe by a process of "dıagrammatısm," which is a way of using nonrepresentational and nonsignifying elements-musically speakıng, these would be "licks," "grooves," or an enchanting sonority - to pllot through chaos and extract a hitle rhythm and regulanty from it ${ }^{\ddagger}$

†Glles Deleuze, Cinema 1 The Movement Image, trans Hugh Thomlınson and Barbara Haberjam (Minneapolıs University of Minnesota, 1989), 208-09

Deleuze and Guattarı, A Thousand Plateaus, 142 
configuring new relations that make new domains of musical sense. In pleasure drenching... the sing-songy row expressed in terms of an infinity series and randomized rhythmic modes never brings the melodic curve to a point of cadence or permits the material to develop any long-term architectonics that would organize pitches, key areas, or rhythmic values into relations of greater or lesser importance. Over a period of fortyfive minutes the melodic clichés that radiate from the modal polyphony-a sonority whose distribution of intensities are already more queerly diffused than the major-minor system-become tasked with the chore of justifying their ongoing nonsense. That is, lacking formal development, these impassive expressions are charged the affective burden of going nowhere for three-quarters of an hour. As such the clichés that streak across the melodic threads bend and twist under the strain of their own banality to the point where their misshapen expressions develop a new, mutant, valence. For Eliot, this is a way of writing music's continuous variation in medias res, a writing that cannot but start with a body of clichés that has to be dis-figured if its sense is to be made.

\section{((()(((((glossolalia (stress positions)}

Eliot's work, glossolalia (stress positions) (2008), however, differs from pleasure drenching... in that it concentrates more narrowly on the multiplicity of a single melodic variation. The refrain composed by glossolalia develops a line of variation not on a "theme," but on itself. This is to say that what is varied is not an object that can be isolated from the wresting and turning of the melody, but an indeterminate "idea" of the music as an ongoing variation of its own melodic sense. What this describes is a constant melodic variation, a paradoxically unstable yet invariant process of differentiation. But 
this shouldn't sound too odd, for as noted above with respect to things like "words," constants are variations of their own internal variation

In the case of glossolalıa, Eliot's "constant" derives from an imaginary variation Take the concertma part at the opening of the work (meas 1-64) What you hear the violın accompanyıng is a fake recording of a fictıonal French-Algerian musical savant named Félıx Amr in the 1970s ${ }^{133}$ Durıng the 1960s, Amr made his living playing balmusette in the Paris banlleue Chchy-sous-Bois But in 1971 he suffered a minor stroke that left him with restricted arm movements After the stroke, Amr, supported by a meager state pension, took up the smaller and more compact concertına and spent most of each day in his apartment playing the instrument without interruption For long hours, Amr would sit with his concertina at his kitchen table, decorated with the morning paper and an ashtray that would slowly fill to overflowing, playing pieces from his repertorre However, he never actually played any songs, instead, he executed extraordinarily long and florid passages that would resemble the ornamentations and transitional passages of bal-musette more than the songs themselves Curıously, durıng these musings Amr never once repeated the same phrase precisely, the melodic character of these flourishes always almost resembling itself This recording of Amr's lyrical reveries exemplifies the paradox of a musical line that is in "constant variation"

Now, whether this was intentional or simply a byproduct of Amr's condition is irrelevant, for the effect in either case is the same Though Amr died in 1984 at the age of 64 , the recording made of his playing avoids thematizing its variations in two ways one, because it doesn't exist, and two, because its endless varıatıons break apart the

\footnotetext{
${ }^{133}$ This name is Eliot's invention and comes from combining the French for "lucky" (Felix) and "find" (amr)
} 


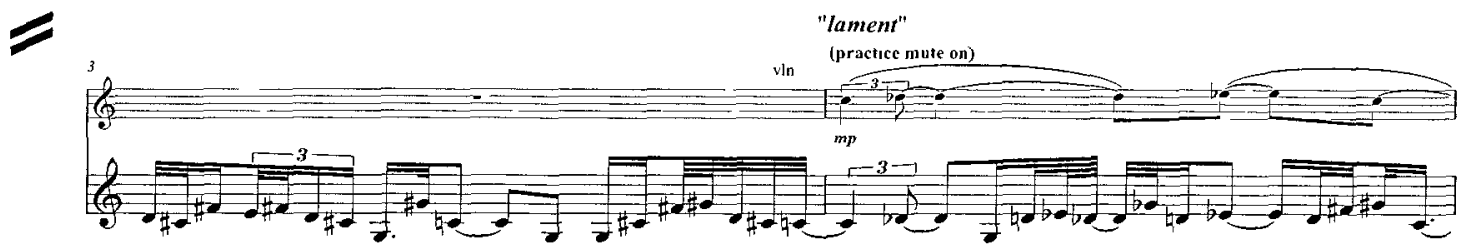

2

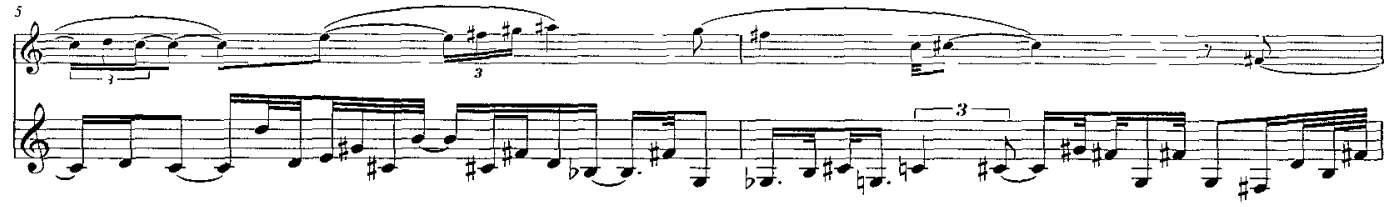

2

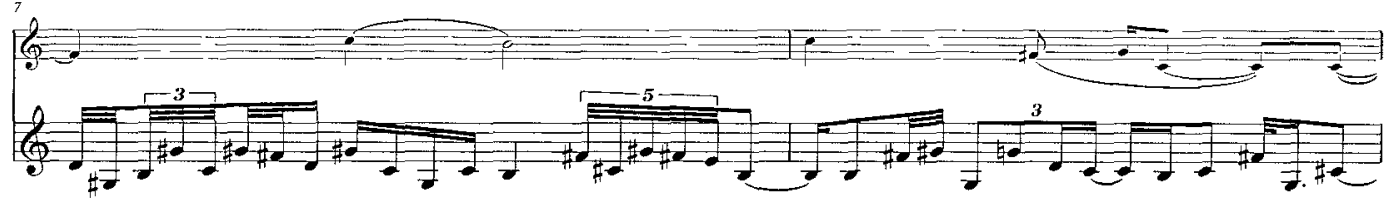

2

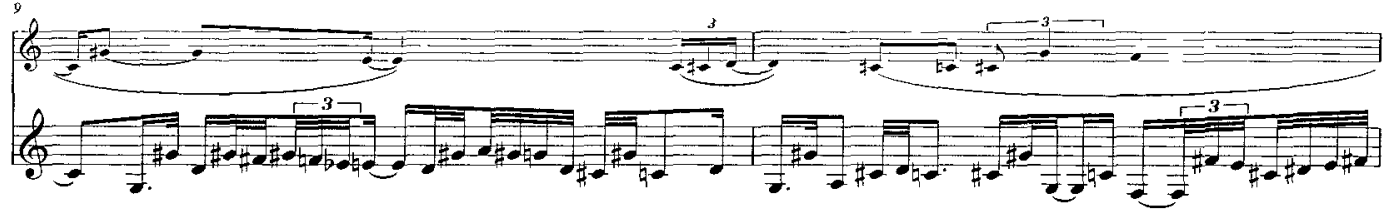

2

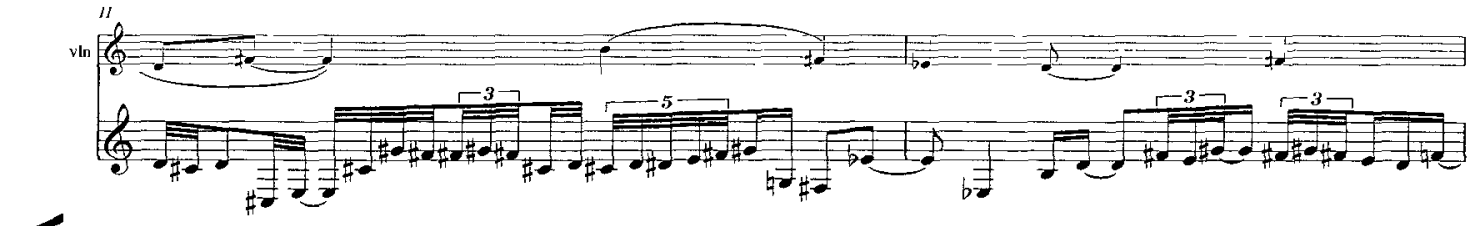

2

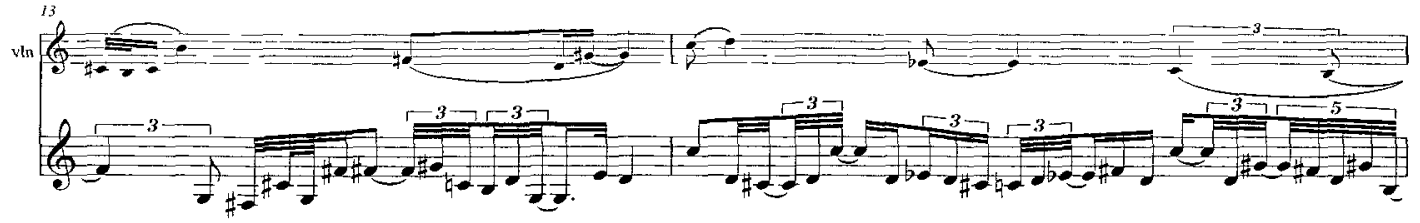


291

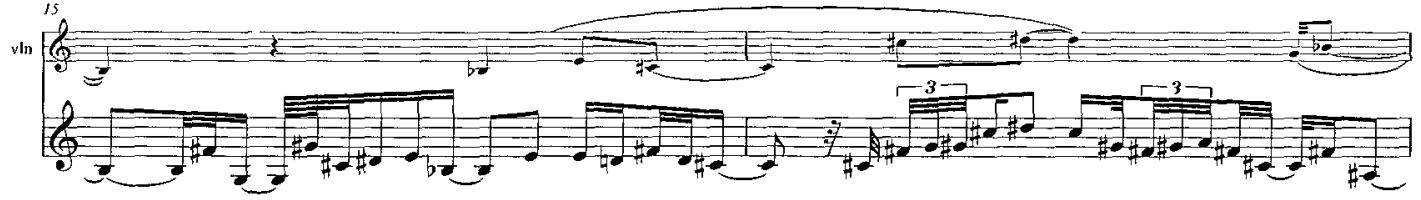

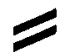

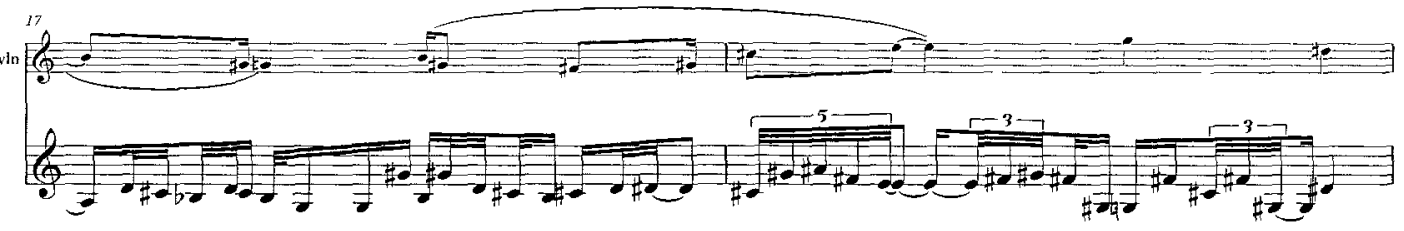

$\geqslant$

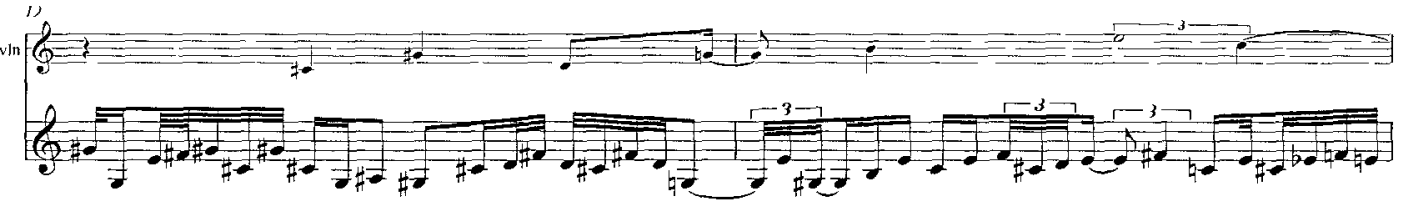

$\geqslant$

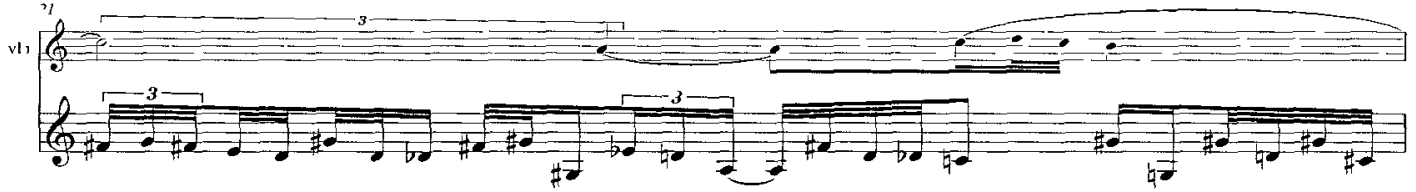

$\geqslant$

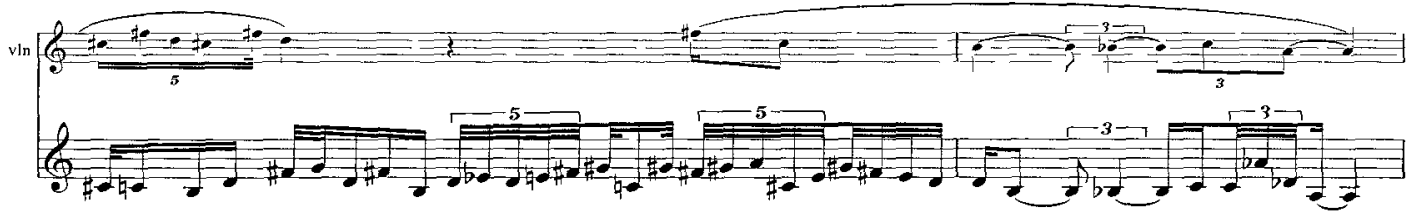

$\geqslant$

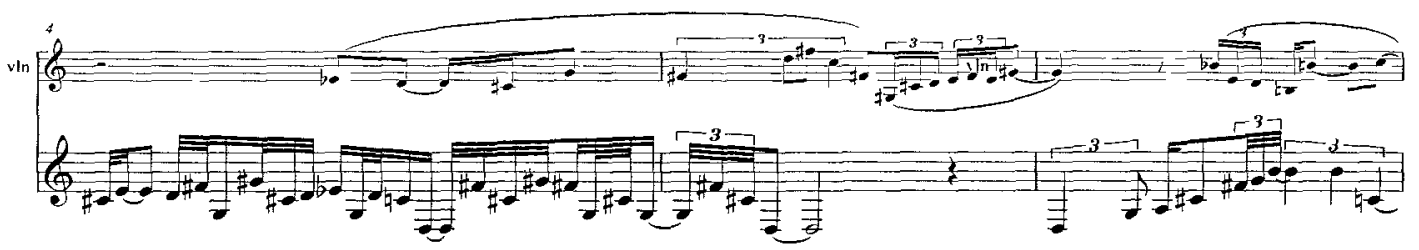

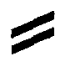

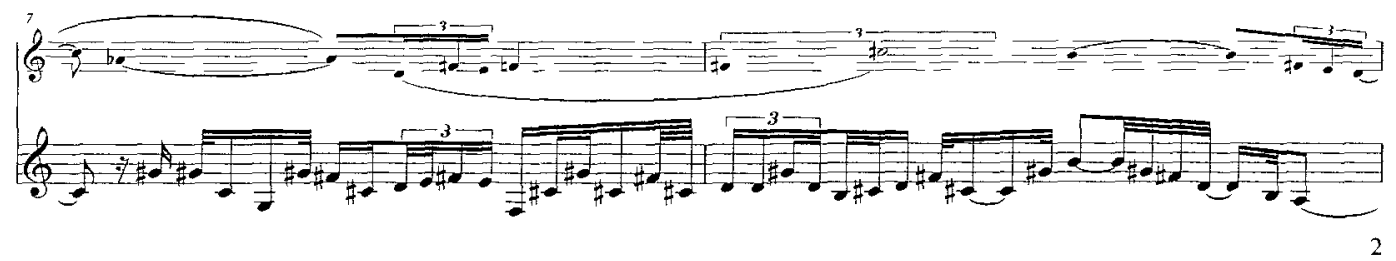




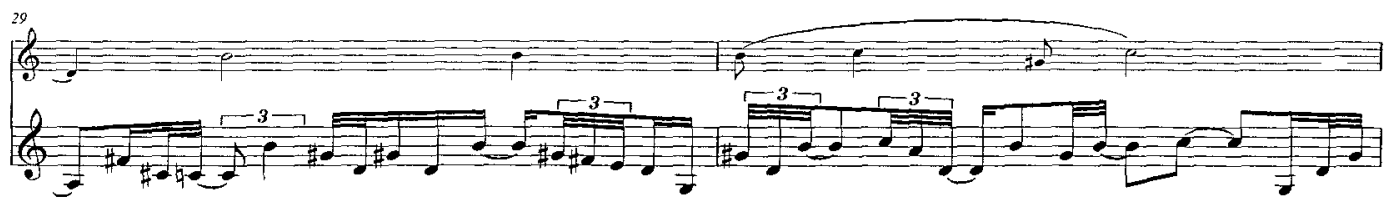

$=$

(2)

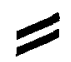

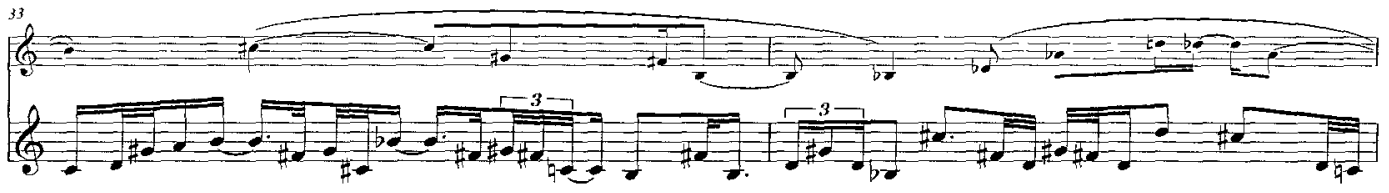

$\geqslant$

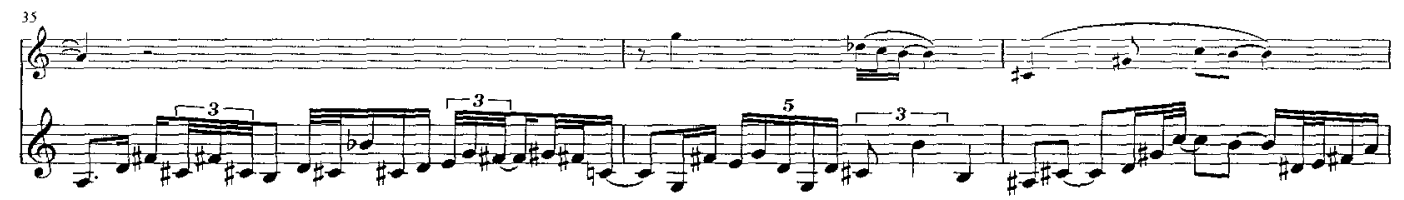

$=$

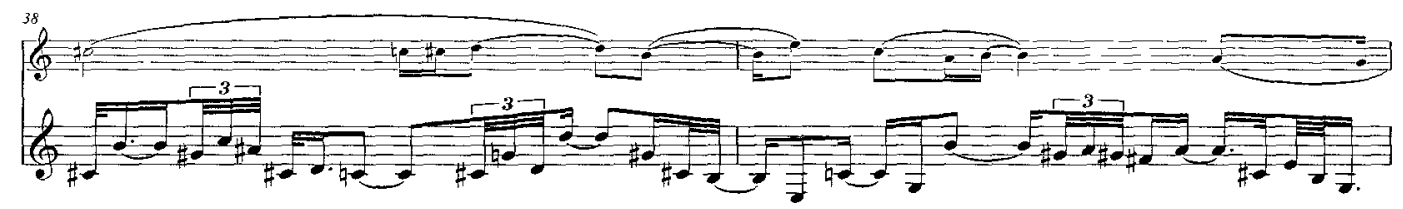

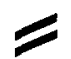

(2)

$\geqslant$

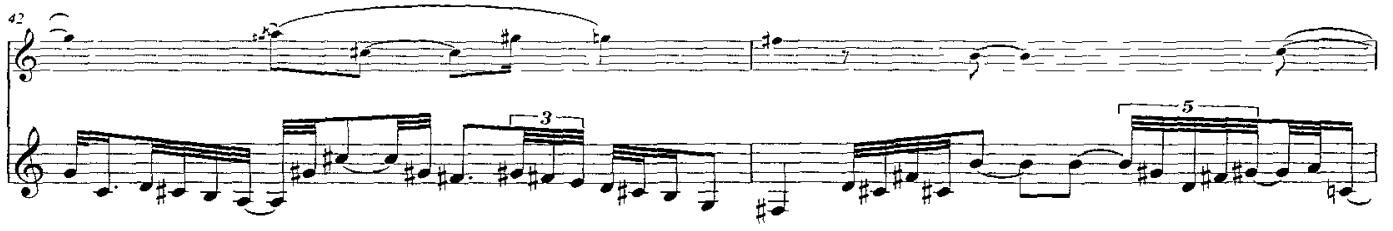


coordinates that define the fact of "Music," marking out instead only a theme-yet-tocome, or as Deleuze would say, "the possibility of fact."134 This "futural" theme, one around which the listener's flickering attention is organized, may be considered the sound of becoming itself, the sound of a perpetual differentiation of a present that is "subdivided ad infinitum into something that has just happened and something that is going to happen, always flying in both directions at once." 135

In the second part of glossolalia (stress positions), Eliot takes up this conundrum of constant change where "what will have been heard" as a futural theme begins to find its refrain (its characteristic rhythms and counterpoints) stammering and opening upon the unexpected territory of bodily anguish. We can understand how the baroque air of this part of the piece, with its sinuous coils of melodies that always seem to go on just a little too long, too indulgently, too asyndetically in a way that transposes the effect of their potential carrying on to the body by considering what Elaine Scarry writes about sentience as an embodied state framed by the contrary poles of pain and imagining.

Pain, according to Scarry, expresses a state of sentience completely empty of referential content, while imagining expresses sentience entirely as referential content. Each of these modes of experience, insofar as sentience is bound to the figure of intentionality, can thereby be theoretically conceived as each other's object/state, respectively. Yet, as Scarry notes, because an "intentional state without an object" is a contradiction in terms, pain cannot be intended, only suffered. "Pain," she writes, "only becomes an intentional state once it is brought into relation with the objectifying power

\footnotetext{
${ }^{134}$ Deleuze, Francrs Bacon, 101

${ }^{135}$ Deleuze, The Logic of Sense, 63
} 
of the imagination." ${ }^{136}$ But until then, until the fiery traces of pain diagramme a continuum of intensity through which it can create the possibility of fact into which it can pass the intentions of an individual, pain marks the boundary of sense. It is in this "framing" of sentience which Scarry ultimately justifies by observing how "the more a habitual form of perception is experienced as itself rather than its external object, the closer it lies to pain [and] conversely the more completely a state is experienced as its object, the closer it lies to imaginative self-transformation [displacement of one's "self"]," 137 that conscious experience is expressed in the movement between an aversive state of radical embodiment (pain) and a self-satisfying state of radical objectification (imaging). For her, experience is the movement of a continuum of perceptual, somatic and emotional events that are more or less passively suffered or actively invented.

Assuming one agrees with this model, that experience hovers between a sweeping physical pain and a plenary imagining and that a state without an object is painful, then it is reasonable to suppose that following or anticipating the occurrence of pain would be an impulse for one to objectify his or her experience, to pour one's self into things. The world that we all share, a world of suffering and fancy, will be said to expresses the dynamic and continuous variation of pain and imagining. However, within this dynamic inheres a paradox that cannot help but arise as perception approaches isolation. As Scarry notes, if perception becomes isolated and deprived of an object, it has the "potential for being experienced either as [feeling] state or as object." ${ }^{138}$ For Scarry this describes a fluid attribute of perception wherein it can be experienced as/in either state. For example,

\footnotetext{
${ }^{136}$ Elame Scarry, The Body in Pain The Making and Unmaking of the World (Oxford Oxford University Press, 1985), 164

${ }^{137} \mathrm{Ib}$ Id, 165

${ }^{138} \mathrm{Ibid}$
} 
at one moment you can regard the sun as a brilliant object; yet, if you stare too long at it your seeing falls into itself, it moves towards suffering the sun's blinding intensity in "the event of 'seeing' itself",139 — seeing seeing itself. Similarly, and more relevantly to this study, we can objectify the piecing chirps of the LRAD's deterrence setting as a loud sound; however, before too long hearing is pushed into the body where the sound and sensation blur in painful indistinction. The more isolated or self-implicated perception becomes, the more its feeling-thinking intends itself as its object, the more the body consumes itself. In other words, in extreme isolation or withdrawal of a perceptual object, the pain of perception can only imagine itself. But strangely, the other condition in which such isolation of sensation happens is orgasm. Thus we come upon the curious nature of intensity as an event of suffering.

Let me explain further. Ordinarily, interior states bond with "companion objects in the outside world" 140 and thus invite us into its movements and affordances. However, the state of pain or orgasm "is itself alone"; each is a passive event that is suffered and finds relief only in an imaginative "self-transformation" that supplements a disembodied or objectified state for the embodied objectless state. Focusing on the pole of pain we find a particularly acute example of this dynamic paradox at work in the "stress position." A "stress position," as outlined in the CIA's cryptonymic KUBARK, ${ }^{141}$ is an interrogation technique wherein an interrogatee is essentially made to harm himself by being forced to hold certain postures that place an inordinate amount of force on a small part of his/her

\footnotetext{
139 Ibid

${ }^{140}$ Ibid, 162

${ }^{141}$ Volume one is subtitled "Counterintelligence Interrogation," while volume 2 replaces KUBARK with the name "Human Resource Exploitation Training Manual "Each is avallable as PDF files from http //www gwu edu/ nsarchıv/NSAEBB/NSAEBB122/1ndex htm\#kubark and http //www gwu edu/\%7Ensarchıv/NSAEBB/NSAEBB122/1ndex.htm\#hre
} 
own body such that they overtax the muscles and ligaments. The effect is that pain never diminishes but is rather pushed around the body. Stress positions, such as those inflicted by the American military upon detainees at Guantanamo Bay and most famously at Abu Ghraib prison, are expressions of pain and imagining taking each as the intentional companion of the other - "pain as the imagination's intentional state and...the imagination as pain's intentional object. "142 Here, standing on a narrow surface, blindfolded, with arms outstretched, fearing threat of electrocution, the pain of holding still becomes the intentional state and the intentional object of experience. In a sense, what we are talking about here is the constant variation of pain as the refrain of torture.

\section{$((()((()(($ Occult dualism}

So how does this relate to what I have been saying about a composition that "will have been heard" as music? Insofar as the idea of a melodic singularity that Eliot sets in constant variation is a diagramme that bends and turns the sensuous refrains of "Music," opening the body to the recursive territory of pain, we are dealing with the ethical hazard of the arts. And to the extent that this work renders sonorous the consistently inconsistent patterns of a force that constantly acts upon itself, it traces a "line of flight" from its musicians and sounds, from the stage, from the concert hall, and towards the egregious exercise of power and the violation of human dignity. If we listen along this flight towards its outside, towards the screams and wails of the tortured, we will have, as Deleuze and Guattari say, "deterritorialized the refrain." 143 We will have exiled the airs and ornaments of glossolalia from their native aesthetics purchase, making instead a

\footnotetext{
${ }^{142}$ Scarry, The Body in Pain, 164.

${ }^{143}$ Deleuze and Guattari, A Thousand Plateaus, 331.
} 
music that is homeless, a music whose wandering variations light upon domains as heterogeneous as pain and imagining.

So what do these becomings of glossolalia-becoming-pain, becomingimaginary - express? It is not that the music or the cries are transformed into one another: music is torture; pain is music. Becomings are vectors, openings, modulations. What "becomes" is a dynamic "bloc" (field) of sensations, a zone of difference that effects the mutual transformation of a whimper and a soto voce. ${ }^{144}$ Neither actually becomes the other, for there is no identity in becoming; or rather, there is only differentiation and the infinite identity of both directions (too much-not enough) of sense at the same time. ${ }^{145}$ This bisection of becoming is expressive in the way that "snowflakes" are an expression of the way temperature and humidity mutually alter one another in their proximate difference: the snowflake is a new event that expresses the sense "of [a] contraction enveloping the entirety of [this] processes."146

The becoming that I'm describing is therefore like a line that extends, going in both ways at once, between music and pain. It is "a specific configuration of relative movements and affective intensities" between two expressions of force acting on, in, through the body. ${ }^{147}$ Both music and torture are disciplines that organize a body's affects. Music, traditionally at least, is a way that cultures have learned to arrange and link bodies (human, instrument, concert hall, genre, repertoire...) in order to "harness" and express forces in sound. All of these bodies somehow interact, hang together, and make sense,

\footnotetext{
${ }^{144}$ Ibid , 164

${ }^{145}$ Deleuze, The Logic of Sense, 3

${ }^{146}$ Brian Massumı, Parables for the Virtual Movement, Affect, Sensation (Durham, NC Duke Unıversity Press, 2002), 18

${ }^{147}$ Ronald Bogue, Deleuze on Music, Painting, and the Arts (London Routledge, 2003), 35
} 
make music (though more precisely, it is the regularity of these connections that we call "Music"). Torture, too, arranges bodies and the forces that act upon and through them. However, unlike the common practice of music that manners its affects into emotional circuits, torture is a mannered and disciplined way to "liberate" affects from any purposive perspective. The pain that sets the body to blaze, that annihilates the world and its theatre of symbols and artefacts, looses a spasm of intensity that subsists, insists between the soaking towel, the mouth, and the lungs... between the wrists, the twine, the overhead piping, and the pull of the fatigued body. Perhaps not so curiously, culture forms around both of these practices. We can say that "Music" forms around the domestication of intensity while "Pain" forms around its radical emancipation. From this point of view, the polarized cultivation of intensity has a strange history: music is intensity enslaved while torture is intensity set free. Thus, on the one hand the history of music is a public history of enchanting or charming intensity, a culture's masochistic zoo of affective captures. On the other hand, the history of torture is a private history of disenchanting intensity, a secret sadism that a culture performs to express the limits of its own reason.

Said another way, both music and torture make sense of what has no sense apart from the actions that express it. Each in its own way articulates "a secret dualism hidden in sensible and material bodies" that distinguishes not between the Model and copy, but the copy and simulacra. ${ }^{148}$ This, as Deleuze shows, is not a dualism between the sensible and intelligible, matter and idea, but between "limited and measured things" and "a pure

\footnotetext{
${ }^{448}$ Deleuze, The Loglc of Sense, 2.
} 
becoming without measure." ${ }^{149}$ Crudely summarized, "copies" punctuate the sense of the Idea, while "simulacra" express the movement or transformation of these. ${ }^{150}$ Yet, Deleuze insists that this dualism is not hidden but is instead distributed everywhere so that "It is no longer a question of simulacra which elude the ground and insinuate themselves everywhere, but rather a question of effects which manifest themselves and act in their [simulacra's] place."151 But these effects can also act in place of the Idea as a "Snark" does when it's a "Boojum," which is to say that effects are like Schrödinger's cat-dead, alive, or both at once. It all depends on how you look at them.

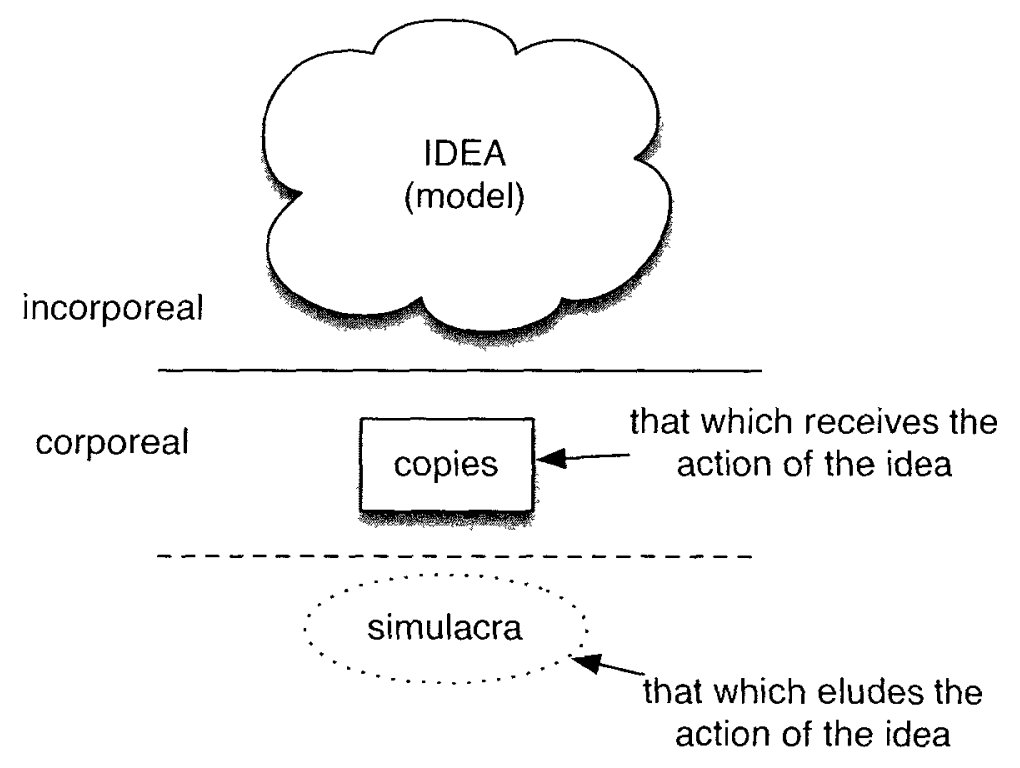

\section{((((()(((()llustrative Interlude: Practicing}

Practice. Practice. Practice. The masochist's mantra that founders on the mad becomings of their art. First up the scale, then down. Transpose to another key: up...down; again, transpose: up...down. What is this? Practice. But what is practice? It's not "Music," but

\footnotetext{
${ }^{149}$ Ib1d., 1 .

${ }^{150}$ Ibld., 2

${ }^{15 !}$ Ibjd., 7
} 
neither is it "Torture" Practicing in fact makes more sense than music does for there is no end to it, it is unlimited The intensities of slipping up, of cacking, of tentatively pıckıng one's way through a passage, of stumbling or falterıng over a phrase, of playıng a melody slower and quieter than indicated, of learning only fragments of a melody, of missing a note, of adding a beat, are all expressions of the "unlımited" that practice cırculates Practıce shuffles while "Musıc" plays games

Practice then is a becoming and the migration of simulacra that tend towards becoming more musical and less musical, making one's performance always better and worse at the same time Practicing thus has no limits, no tense, no horizon "To practice" names an infinitive You can always get better than you were and worse than you will become What 1s "Music," If not an active limiting, a superinduction of its Idea on the errors and flaws that practıce makes sense of" An Idea of "Music" does nothing to the cacophony of intensities itself, but instead simulates an order of original and copy by way of the unlimited's functioning ${ }^{152}$ A performance then is better understood as the representation, the repression, of an unlimited practice (the impossible perfection) in the effective simulation of the Idea of "Music" In other words, all our concerts or recordings regulate (limit) the beginning and end of music's Idea Interrogation, the ritual of releasing excessive affects, can also be considered a performance Interrogation simulates the Idea of "Torture" by "making the simulacrum function"153 and raising a "truth" that it throws back onto the becomıngs of burnıng, stıngıng, suffocatıng, in order to signify the sign of their limits

\footnotetext{
152 Ibıd , 262

${ }^{153}$ Ibıd, 266
} 


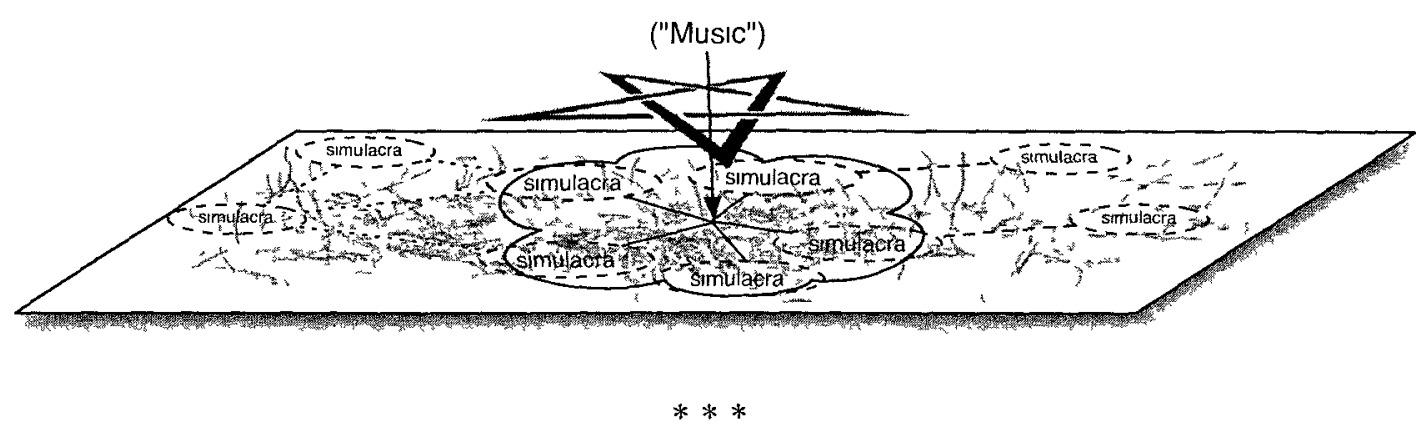

Where then does all this repetition lead us except back to constant variation, to the variable intensity and force of existing that eternal difference produces everywhere in abundance? In music, constant variation expresses the sense of a "theme," a central motıf or refrain from which the utterances simulate departure. However, in psychoanalytic terms repetition and variation are not structural elements but unconscious processes.

Off the surface of the unlimited are reflected the manıfest content of music that will be mastered and called a "theme"--a mastered prece of variation. So here we learn that Beethoven is Music's Plato. His work "simulates at once the father, the pretender, and the fiancé in a superimposition of masks," 154 a simulation we know better as the author, the performer, and the listener. The "Ode," for example, a variation on Plato's "Cave," is a master-piece, not in its formal brilliance or striking harmonies, but in the way it watches over and disciplines the wild elements that produce the phantom of its Idea. In other words, the "Ode" masters the unlimited by the very power of simulation that its simulacra remainder.

\footnotetext{
${ }^{154}$ Ib1d, 262
} 


\section{(((८((((૮(((The sleep side of music and dream-work}

Here, near the end of our discussion, is the Ideal form of the "Ode" whose simulation is the manifest content of a culture's dream that takes the echoes of its difference as the simulated essence of 1ts worth Like the irreality of a dream that we recollect only upon waking, the Idea of the "Ode" appears only when the work (the dream) is over We recall only the phantasm and not the difference that escapes its Idea We say "It sounds like "X," like "Y," like "Z", however, we know that no amount of signs will give us the "Ode" 1tself No matter how many things are sald in its name their referrals cannot express the host of symptoms that course throughout its phantasmatic body We know only intuitively, affectıvely, that beneath the "Ode's" mamifest content hes a sea of senseless turbulence, that the "affective charge associated with the phantasm is explained by [an] internal resonance whose bearers are the simulacra "155 Between what we say of the "Ode" and what we listen to, we have the dream-work of music

While we are familiar with the waking life of music in the way our favourite band and favourite song each articulate with other ideas that we have about of ourselves-all of which correspond in a network of referrals that make our world make sense--we are less certain about how the slumbering side of music behaves What does music sound like from its "sleep side" "156 The manifest content of the Ideas of "Music" c1rculate in and as the formal domain characterized by melody, harmony, pitch, rhythm, as well as the discursive realm where we describe the importance of these effects to ourselves and others But the latent content of music insinuates itself everywhere between these as sensation, feeling, and disposition The unconscious of music is where bodies affect one

\footnotetext{
${ }^{155}$ Ibid , 261

${ }^{156}$ Anne Carson, Decreation (Toronto Vintage Canada, 2006), 20
} 
another, where they meld, break and fall apart...meld, break, and fall apart, again...again... again. Because "Music's" Idea is the expression of how these bodies mingle, it can arise anywhere that its mixture can be simulated. Thus we have the Ideas of Bach's Well Tempered Clavier (WTC) performed on the modern piano, or the six cello suites performed on contrabass. Though the sounds of these works are particular to the bodies that cause them - piano and contrabass - their sense is not itself limited to such manifest content, for the latent content of the sonatas or WTC communicates modally such that we register in the cello suites performed on guitar or the WTC performed on a clarinet an intensive rather than a formal difference between the bodies (instruments and their sound) and the music's Idea. What we listen to are simulacra. However, the name "transcription" that is given these expressions of $W T C$ and the sonatas preserve the privilege of the fundamental, for the repetition of the Idea's difference that makes the work what it is obscures the way the haecceity or thisness of each "transcription" is its own original expression. But curiously, when doubles appear, each claiming the Idea of the work as its own, the simulacra cannot help but surface and infect the order of the Idea (of copy). Who remembers that Twist and Shout was first recorded by The Top Notes, that Respect is due to Otis Redding, or that the Goldberg Variations is harpsichord music. The Beatles, Aretha Franklin, and Glenn Gould each caught the Idea of a music sleeping, and entering from the sleep side, each showed us what it was dreaming.

But the musical unconscious is not, as musicologist Michael Chanan suggests, "continuous with musical consciousness" in the sense that "the conscious and subconscious map directly onto each other." ${ }^{157}$ The modes, harmonies, intervals,

\footnotetext{
${ }^{157}$ Michael Chanan, Musica Practica The Social Practice of Western Music from Gregonan Chant to Postmodernism (New York. Verso, 1994), 105
} 
rhythms, timbres, and proper names that express the sense of these symptoms and which make up the symbols of musical consciousness do not chart the unconscious, for as I've described, becomings are not limited things the way intervals, etc. are. An interval, a major third for example, is a simulated essence, a phantasm of a differential relation that is qualified in terms of space and time. The "major third" is an Idea-symbol for a movement between two differences, a movement that is not itself an Idea-symbol, but something more like a libidinal charge or pure desire before it has been coded as a "love," "affection," or "friendship." The musical unconscious therefore does not conceal itself but rather its operation is dissembled within the workings of the music's ego-its Idea of itself. The trafficking with incompatibles, the coincidence of opposites, and the desertion of rational timespace that mark the activity of the unconscious is implicated in music through the way its measurable (conscious) propaganda--harmony, melody, and rhythm-express an intensive magnitude. It is the disjunctive continuity between the expressed intensity and the expression itself that constitutes the dream-work of music.

The "dream-work" of music, however, does not lend itself to interpretation but instead operates as a matter of expression. Interpretation assumes a world or a structure of fixed terms and relations in which thought is merely a more or less adequate reflection of its general order, and in this sense interpretation is the proper approach when aimed at affirming the normative scope of an event. But expression is different; instead of extracting fantasies of order from a prescribed set of relations, expression seizes on the present, complex and contingent immediacy of things to forge new relations and new ways of becoming. Taking music's dream-work as an expressive activity rather than as distortion of an already (over)determined desired is to approach music from its sleep side 
and listen in on the pure variability of its dream. This emphasis on the creative potential over the hermeneutic prospects of dream-work is actually suggested by Freud himself in a footnote that he added twenty-five years later to The Interpretation of Dreams:

But now that analysts at least have become reconciled to replacing the manifest dream by the meaning revealed by its interpretation, many of them have become guilty of falling into another confusion which they cling to with equal obstinacy. They seek to find the essence of dreams in their latent content and in so doing they overlook the distinction between the latent dream-thoughts and the dream-work. At bottom dreams are nothing other than a particular form of thinking, made possible by the conditions of the state of sleep. It is the dream-work which creates that form, and it alone is the essence of dreaming-the explanation of its peculiar nature. ${ }^{158}$

Dream-work is creative. But it is creative in the way that Deleuze understands sense to be creative by virtue of how it expresses the fluctuating relations of intensity between heterogeneous things. Neither the manifest nor latent content is the sense of dreaming, but, as Freud writes, these are "like two versions of the same subject-matter in two different languages." "59 The sense of dreaming is not what the manifest or latent content can be interpreted to mean but the way in which displacements, condensations, representations and revisions take place. In short, the dream-work is the sense of dreams, a process that dis/articulates the manifest and latent content like the twist in the Möbius strip does the inside and outside of a surface. Said another way, dream-work is a mode of thinking that is expressed in manifest and latent terms.

Expanding on this, music's dream-work can be understood as a particularly dynamic mode of thinking, an abstract movement-thinking whose logic Deleuze characterizes, with regard to Kierkegaard's and Nietzsche's metaphysics, as relating a movement of "vibrations, rotations, whirlings, gravitations, dances or leaps which

\footnotetext{
${ }^{158}$ Sigmund Freud, The Interpretation of Dreams, trans. James Strachey (New York: Basic Books, 1955), 506-07.

${ }^{159}$ Ibid., 277.
} 
directly touch the mind." ${ }^{\prime 60}$ But as Simon Duffy notes, this logic of expression "is not an abstract logic that merely represents the movement of these affects, but the very logic by means of which these affects are expressed [made effective]." ${ }^{161}$ To be fair to Chanan, there $i s$ a continuity of sorts between music's conscious (Ideas) and unconscious (simulacra), but only insofar as this contınuity refers to a modal disjunction between two sides of the same expression, two different orders of the same process: cause and effect. Music's dream-work, its sense, is characterized then not by figures of condensation or displacement so much as it is by expression whose logic relates the unconscious and conscious according to what Duffy calls a "mutual immanence," a relation whereby "the structure of the first [unconscious] envelops the existence of the second [conscious] and inversely the existence of the second [conscious] expressor represents the structure of the first [unconsc1ous]." 162 The unconscious of music, in its striking dissimilarity to itself, is not something to be "read" or decoded, but something to be raised to the surface.

But what does it mean, "raising the unconscious to the surface"? Moreover, what is this "surface" to which the simulacra ought to be raised, and how can an unlimited becoming encroach upon a limited Idea? The short answer is that the musical unconscious is expressed by what Deleuze would say is the "immanence of expression in what expresses itself, and of what is expressed in its expression." ${ }^{\prime 63}$ The long answer, however, requires that we return to the idea of the "masterpiece" and the question of its

\footnotetext{
${ }^{160}$ Gilles Deleuze, Difference and Repetition (New York. Columbia Unıversity Press, 1994), 184 Here, Deleuze is referring specifically to the unconscious of philosophy, which he says Kierkegaard and Nietzsche were trying to bring to the surface in their writıngs

${ }^{161}$ Simon Duffy, "The Logic of Expression in Deleuze's Expressionısm in Philosophy Spinoza A Strategy of Engagement," International Journal of Philosophical Studies 12, no 1 (2004) 51

${ }^{162}$ Albert Lautman, Essal sur l'unte des sclences mathematıques dans leur développement actuel (Parıs Hermann, 1938), 31, cited in ibid, 56

${ }^{163}$ Gilles Deleuze, Expressionism in Philosophy Sptnoza, trans Martın Joughın (New York Zone Books, 1990), 180
} 
discipline, which again, but this time from below (or its "sleep side"), brings us back to the refrains of pain and imaging, and how their motıfs are expressed at the cultural level by the Idea of "Music"

What I have been discussing here and calling a "becoming" is not the 1dentification of musical experience with pain but the way in which music and pain are expressions of some body actıng upon and through another body I am stıll dealing with becoming at this point, but now with the aim to show that the process of repression, which musical simulacra inflict upon themselves in the name of "Music," 1s similar to the process that transforms pain into the imagination For instance, consider how both the singing and the screaming body are expressions of intensity Psychoanalytic theories take the intensity of pain and music as a mutual origin, suggestıng that music is essentially a transfiguration of infantıle vocalizations of pain, or more accurately, the valencing of a pre-qualified intensity In his essay "Contribution to the Psychoanalysis of Music," psychoanalyst Heınrıch Racker argues exactly thıs, writıng, "[I]n theır physıcal aspect it is already evident that scream and song are intımately related tone is a transformed scream "164 Song in this sense develops from the scream as an expression of inarticulate desires But, as is often noted, sound is something that one cannot simply exclude, or shut outvibrations impinge upon us whether one wishes them to or not Thus, to the infant who does not yet distınguish between the sounds emanatıng from insıde or outside, music develops away from or against the sounds that encroach upon its body "Music in this circumstance is presumed to result from attempts to master this kind of unpleasant

${ }^{164}$ Heınnch Racker, "Contribution to Psychoanalysıs of Musıc," American Imago 8, no 2 (1951) 142 
experience." 165 One can extrapolate from this that harnessing what cannot be wholly kept out (of the body) is another role of the dream-work of music.

While dream-work brings the unconscious to the surface it also aims to regulate and organize the intensities it disinters, to manage and harness sonorous (but also not-sosonorous) forces that assail the body by bringing its flood of sensations under the influence of an Idea. Hence, the notion of the "masterpiece" not only disciplines the field of artistic activity internally, but compels actual sound-events to pass through its ideational domains (quasi-cause) in a way that tempers or modulates one's sensitivity to the action of the idea. Although the process of dream-work can represent the dualism we spoke of earlier, between simulacra and Ideas, it also speaks to the way bodies are composed and organized by what affects them.

The musical unconscious, like a state of affairs, is separate from the expressions that make sense of its dream-work in a way that is comparable to effects taken apart from their causes. Such a situation is not, however, thinkable in itself, for the thinkable is what happens at the surface of things, the surface where things enter into various mixtures with one another. That is to say, things do not think themselves but have an affect: a thing is what it does, what effect it has on another body. A "thing" is known by its affects, by the "form" of its encounter with another body. For example, the sun is known as a thing by various abstract means, but most notably "it" is known by how it warms our body. And a song, too, though composed of notes, melodies, chords, etc., is known as a thing by how it moves one, makes one feel, dance, and think. Yet recalling Scarry's example of staring at the sun, we can see under this extreme condition the body of the sun melt away into its

\footnotetext{
${ }^{165}$ Shepherd and Wicke, Music and Cultural Theory, 59, my emphasıs
} 
own affect. In its pure form we would call this depth of bodies absolute nonsense-the noise of the body. ${ }^{166}$ Yet, following the logic of expression, even this pure nonsense is expressive, for though nonsense does not have any particular sense it is always opposed to the absence of sense ${ }^{167}$ such that the order of the musical unconscious, like pain, is an affair of the body whose expressions are given in terms of how the force of my characteristic existing is modified by what affects it. Like "pain," which is a particular idea of an effect of a body on mine that compromises or destroys a part of my characteristic (i.e. individual) relations, ${ }^{168}$ "Music" is an idea that rises to the surface from the way sounds adjust and modulate them. In the same way that "pain" connects a knife and flesh through an event that cannot be reduced to either knife or flesh but subsists at their surface as the sense of "being cut," "Music" connects bodies-fingertips, metal strings, bows, habits and reflexes (expedited bodily movements), eyes and scores, ears and vibrating air molecules - in the sense "performing," "listening" or "musicking."

So if "pain" and "Music" are both expressions of bodily affairs, one making the body howl, the other making it sing, how is it that one becomes the other? How is practicing itself a kind of stress position and a stress position a kind of practice? In other words, at what point does music become pain and pain become music? If we understand that what affects us generates Ideas and that these Ideas somehow escape and dislocate an

\footnotetext{
${ }^{166}$ Deleuze actually identifies two orders of nonsense one at the surface of things in the radical affirmation of sense that is expressed in terms of paradox (Carroll's nonsense), and another in the carnal mixture of bodies (forces) caught in an endless process of mutual impingements This latter is the nonsense of the Antonin Artaud wherem words (their sounds) are no less corporeal and thus affective than the bodies that speak them.

${ }^{167}$ Deleuze, The Logic of Sense, 71

${ }^{168}$ An expression of what compromises the whole of characteristic relation of the body would be "death" Curiously, this opens the possibility that the destruction of my "characteristic" relation enta1s the construction of another relation, though while not "characteristic" is nevertheless not a nothingness, a reincarnatıon of sorts See Gılles Deleuze, "Lecture Transcripts on Spınoza's Concept of Affect," http //www webdeleuze com/pdf/uk/Spınoza/240178 zıp
} 
intensity from the characteristic set of relations that compose a body as a bundled potential of actions, then we see a path open to an incorporeal realm of symbols "outside" the excessive becomings of the body telling us that music and pain exist along a continuum of embodiment that is either more or less disciplined, more or less receptive to the action of an idea, to incorporeal effects of the masterpiece.

Finally, where do I think Eliot's work fits into all of this? Briefly put, I think that her work is about the displacement of nonsense, the drifting circularity that "is always excentric in relation to an always decentred center." 169 That is to say, her music is a torturous involution of intensities whose sign as "Music" expresses its madness as a pattern, a "logic," of constant variation that reposes fitfully in the crowned anarchy of its Own contradiction.())))))())) ))\})

\section{Inconclusion}

Perhaps you've noticed, this writing makes a theme or a drama of the inconsistencies and discrepancies that are juggled in the first two chapters. Yet in this drama I'm not trying to resolve inconsistencies, banish paradoxes, or allay the incredulity that making sense of nonsense breeds. I'm trying instead to let nonsense speak for itself, as itself. But this means giving nonsense a voice, which, because it has no particular sense, will always be

\section{This chapter is false}

It's true. But does this make it fail? Not in any simple sense, for if it is true that this work is false then it will have succeeded in failing to be true, which in doing so will make it true and thus fail to be false. Now, call me a cretin, but is there not something interesting, something playful about this kind of circularity? Is there

${ }^{169}$ Deleuze, The Logic of Sense, 264. 
many and multiple Indeed, this is what Lewis Carroll showed, that nonsense can only "speak" when someone else is talking That is, nonsense speaks through the commotion of sense, through the contest of sense's duplicity In his work The Phllosophy of Nonsense, Jean-Jacques Lecercle explains how nonsense is expressed by making the shared sense of multiple expressions virtually apparent to one another At its most basic, "a nonsense text," he writes, "requires to be read on two levels at oncetwo incompatible levels not ' $\mathrm{x}$ means A' but ' $\mathrm{x}$ is both $\mathrm{A}$ and, incoherently, B " $" 170$ The expressions of $\mathrm{A}$ and $\mathrm{B}$ resonate at the same time with regard to the same text-_ " $\mathrm{x}$ " This multiplicity of expression is exemplıfied in Lewis Carroll's opening lines of his poem Jabberwocky

Twas brillig, and the slithy toves Did gyre and gimble in the wabe All mimsy were the borogoves, And the mome raths outgrabe

In this stanza, which is immediately unintelligible, we're asked to entertain the several not something about the way this figure, in its dizzying viciousness, makes one "relationally actıvated" and "poised for what may come," 178 even though the "what" in this case is just another fold in the expression of a paradox? In his work Man, Play, and Games (1961), Roger Carllors characterizes this kind of play as "ilinx," which is the Greek for "whırlpool" but derives from llingos (vertigo) and therefore describes the pursuit of vertigo in "an attempt to momentarily destroy the stability of perception and inflict a kind of voluptuous panic upon an otherwise lucid mind "179 While all of Ca1llors' examples of $\operatorname{ll}$ inx entail a physical assault on

\footnotetext{
${ }^{170}$ Jean Jacques Lecercle, Philosophy of Nonsense The Intuttions of Victor tan Nonsense Literature (London Routledge, 1994), 19

${ }^{178}$ Massumı, The Thinkıng Feeling of What Happens, 5

${ }^{179}$ Roger Callows Man Play and Games, trans Meyer Barash (New York Free Press of Glencoe 1961), 23
} 
possible ways in which it may be read - all at once.

Lecercle suggests that from a structural linguistic

point of view there are four possible modes: phonetic, morphology, syntax and semantic. Phonetically the passage is highly readable and seems to imitate the phonological principles of English-it moves well in the mouth. Morphologically the verse is exhibited as most written languages are--words are shown with spaces and punctuations whose morphemes can be located and parsed. Syntactically, words can be nominated as adjectives, nouns and verbs to form noun phrases (the slithy toves) and verb phrases (Did gyre and gimble in the wabe) to form syntagmata and sentences. And semantically...? Although the other levels of reading perform in a way that can easily be recognized and understood, at the semantic level we are stumped. With this piece of nonsense "all we have," says Lecercle, "is the global coherence of discourse: something is being said, only I do not know exactly what." ${ }^{\prime 11}$ After reading Jabberwocky, Alice says much the same thing, exclaiming, the integrity of the body, such as the gyrations that send whirling dervishes into ecstatic remembrances of God (dhikr), or the rushing free-fall that makes bungee jumpers shit their pants, thinking through a paradox has a similar effect, for a paradox is also an expressive form, one that isolates a fold or transformation in a system to present a semblance of nonsense. For a cretin like me, this is interesting because a semblance of nonsense does not halt thinking so much as it suspends and intensifies the potential to think this way or that. That is, the relays to "truth"/"falsity," or good sense/error, do not take place in paradox because, like a work of art whose form "poises the body for a certain set of potentials" ${ }^{\prime 180}$ but

\footnotetext{
${ }^{171}$ Ibud , 23

${ }^{180}$ Massumı, "The Thınkıng-Feelıng of What Happens," 5
} 
"Somehow it seems to fill my head with ideas-only

I don't know exactly what they are "

What "they" are, exactly, are "semantic

blanks," a veritable vacuum of meanıng that becomes

expressive because "one of the structural levels [of

language] is vo1d "172 To "draw a blank" when

reading this verse is to draw something inscrutable

from out of its otherwise well-ordered phonetic,

morphological, and syntactic levels And as Lecercle

suggests, is this not "the most striking part of the

stanza," a "contag1ous incoherence" ${ }^{\text {173 }}$ that instead of

alıenatıng, draws us along as we draw it out of each

line and subsequent stanzas? The semantic mystery

that breaks on the shores of a familıar sounding

verse-form invites us to engage with the way its

nonsense, its void, "multıplies meaning" and

encourages us to read it with an ear to its music

[T]he words sing in our ears, unexpected links are established between them, relationships of alliteration, assonance or rhyme, of potential spoonerism (why not 'the rome maths outgrabe'? After all Carroll did teach mathematıcs at one stage), of leisurely exploration of phonetic similanitıes ('mımsy' will evoke 'flımsy', 'mıme' and 'prim') The reading is no longer systematic and rational, but desultory and playful There is suspends their execution in 1ts own perception, paradox folds the sense of opposing categories into the same expression so that the relation that articulates inside-outside, buyingselling, living-dying can be thought (felt) more intensely And this is what makes things like pranks and hoaxes so much fun

As Chris Fleming and John O'Carroll characterize it, a hoax is an "artful deception, an aesthetically sophisticated act of trickery, of mimetic artistry "181 What makes a hoax "artful" is what makes any art "artful" it is wrought and presented in such as way as to persuade us to take its semblance, its illusion (Schen), seriously The difference, however, is that the artwork's semblance is quarantıned by its own form

\footnotetext{
172 Ibid

${ }^{173}$ Ibrd , 22
} 
no fixed and unique meaning or interpretation, but a proliferation of variously ambiguous partial structures. ${ }^{174}$

More important than discerning that the poem is

(somehow) about the slaying of a thing called

Jabberwocky are the linguistic adventures that it

takes us on. The sematic gaps that crowd the first

stanza of Jabberwocky are lures into the sine qua non

of language, what Lacan calls "llanguage” (lalangue)

to designate the ineradicable senseless material traces

that remain in speech and writıng but are obscured by

signification. ${ }^{175}$ To move on/at/around language at

this level is nothing less than an adventure, for

exploring the part of language that "refus[es] to be

meaningful, to efface itself before meaning," is to

explore the senselessness of "slithy," of "outgrabe" in a way that foregrounds the

virtuality of perception,

while the hoax's semblance

leaks into the instrumental

perches of the event that it

conjures. This is due to the

way hoax, unlike art, is

transparently parasitic.

Whereas art draws into itself

to highlight its internal

morphogenesis, the hoax

"draws its formal generic

features from the text-genre

of what is actually being

hoaxed" 182 so that its

expressions become

"indistınguishable from

another [event] that is

designed to produce a

\footnotetext{
${ }^{181}$ Chris Fleming and John O'Carroll, "The Art of the Hoax," Parallax 16, no 4 (2010) 45

174 Ib1d, 24

175 The term "llanguage" (the Enghish renderıng of Lacan's "lalangue") is one of several Lacanian figures designed to bring awareness to what its concept designates Strictly speaking llanguage refers to the way an alien materality emerges from a word when it is repeated over and over As such, llanguage is itself unspeakable, and, to the extent that a subject is only conscious of what can be said, formulated in language, llanguage is unconscious However, because llanguage is ineliminable it appears in language from time to tıme as symptoms (sinthomes), mostly notably in those moments "when language no longer functions in the way that consciousness requires, which is to subordinate itself to meaning "The stutter, the lisp, the cry of pain, the palindrome, anagram, or coinages such as Carroll's are symptoms of llanguage But it's important to understand that the symptoms of llanguage are not necessarily symptomatic of repression but, as Michael Lewis points out, are symptomatic of an insistent presence, the enunciator's presence or selfidentity $\ddagger$

$\dagger$ Michael Lewis, Dernda and Lacan Another Writıng (Edinburgh Edinburgh Unıversity Press, 2008), 210

+ Lew1s, Dernda and Lacan Another Writng, 210

On "lalange" see Jacques Lacan, On Feminine Sexuality, the Limits of Love and Knowledge The Seminar of Jacques Lacan, Book XX Encore 1972-1973, trans Jacques-Alain Miller (New York Norton, 1998)
} 
"borogoves"- how they sound, how they feel in the mouth, how they seduce or repel each other into or from their associations These expressive exploits are instances of how, as Lacan says, "llanguage serves purposes that are altogether different from that of communication," $" 176$ and they are worth having, if not because they are inherently meaningful, then because, at the very least, they teach us that things are not always as they are meant to be, that the world may be otherwise thugh weruld ma1-B uthrwyze

But all adventures, if they are to avoid becoming tribulations, are comforted by something In Alice's adventures it is the elusive garden and her childhood memories of the former that comfort her In Jabberwocky it is the narrative form and the syntactic and rambic coherence of the quatrains that comfort the mad ramblings of the excessive coinages But what comforts this writıng and compensates for the incoherence that it exudes?

I want to say that it is music I want to say different effect " 183 The hoax "function[s] simultaneously and sensibly" 184 both as the event that it says it is and the event that it is not It is neither truth nor falsehood but both, a duplexity that allows one to say two things at once to tell the truth by lying

But is there not something reversible about this relationship? Is there not something "hoaxful" about an artwork? Whereas a hoax has a peculiar anticipated "afterwardsness" $" 185$ to it in the eventual revelation of 1 ts mimicry, one that feeds the sincerity of the event that it pretends to be back through its fakery, the artwork, whose duplicity is transparent from the beginning, has an immediate

\footnotetext{
${ }^{182}$ Ibid 46

${ }^{176}$ Lacan, On Femmme Sexuality, 138

${ }^{183}$ Ibid 48

${ }^{184}$ Ibid 57

${ }^{185}$ Ibid 48
} 
that music here is like Alice's garden, a cynosure or guide that eases the twists and turns of this writing. But music it turns out is more like Wonderland than the garden, which is to say that music is nothing other than the scene of our adventures, a dream. Moreover, there is no music here. There is "Music," that discursively constituted field in which we've been roaming for the past several pages, but not music, not that sensuous and seductive thing that "reaffirms the flux and concreteness of the social world"177_-music was banished the moment you began turning these pages.

What comforts this writing is, paradoxically of course, llanguage. The very twisting and turning that make this a dizzying chapter are symptomatic incursions of the flux and concreteness of the world that is denied "Music." In other words, the distortion of concepts, the stretching of facts, and the general fuckedness of this writing is, in an oblique way, a concrete supplement to the excessive semantics of "music."

The llanguage that is suffocated by the beforehandness to its caricaturization that retrojects the semblance of the event that it is through its probity. In other words, where the hoax becomes less real, art becomes more real; art becomes more real by becoming more "true," which it does through the recursive truth-effect of its beforehandness. Art will have been true when its effects become the cause of itself as "Art," when thought and language, but also bodies and passions, move to displace the nonsense of artifice with the sense of fact. Just as asserting the potentiality of radicalized Islamic youth has a selfperpetuating movement that leads the US Department of Homeland Security to, in effect, sponsor that same radicalization that leads it to justify its preemptive

\footnotetext{
${ }^{177}$ Shepherd, "Difference and Power in Musıc," 59.
} 
demands of well grammar, propoer speling, and verbs agreement, is revived here by the fractured forms, the multiple voices, and the pranks that put language to work for something other than communication. This doesn't mean that communication is wholly exempt from this study so much as it means that communication is accessorized by what language's formalization sets off-intonation, stress, rate of dehvery, hesitation, and timbre. While many of these paralnguistıc factors are not actually exhibited in this work, they are implicated by virtue of how the lies and the creative play with voices make thought and understandıng leap from one register of sense to another. In effect, the text behaves virtually like the "Music" that it imagines and in doing so compensates for its resistance to be understood. arrests, ${ }^{186}$ so too do art's semblances sponsor their own programme of realization. And that is exactly what has happened here. All the names, all the diagrammes, all the descriptions, and all the references: they are all effects whose circulation generates the sense of a "truth" that has yet to come.

From the beginning "Shepherd's Paradox" is a hoax perpetrated by art, a hoax that was and will have been performed not to deceive but to say two things at once, to live the truth by lying.

\footnotetext{
${ }^{186} \mathrm{I}$ 'm referring here to Mohamed Osman Mohamud, a nineteen year old Somal1-American who was arrested 26 November 2010 for attempting to detonate what he believed was a car bomb durng a Christmas Tree lightıng ceremony in Portland, Oregon By design (the FBI's), the bomb was a fake While perhaps angry and disaffected, and maybe even disposed to havoc, Mohamud was not a jhadist, not yet But as the journalist Glenn Greenwald notes, "with months of encouragement, support and money from the FBI's own undercover agents," Mohamud became a jhadist-virtually The FBI's stıng operation was not a passive factor in Mohamud's radicalization Through a series of expressive correspondences, such as Mohamud's being placed on the United States' no-fly list which prevented him from taking a fishing job in Alaska thereby leaving him unemployed, which made him more receptive to money offered by undercover agents, this potential for radicalization was drawn forth and actuated See Glenn Greenwald, "The FBI Successfully Thwarts its Own Terronst Plot," 28 November 2010 , http //www salon com/news/opinion/glenn_greenwald/2010/11/28/fbi
} 


\section{("Disclaimer")}

As per the conventions of multiple-use names, "Karen Elıot" is a designation that "refers to an individual human being who can be anyone," especially if this anyone is used "for a senes of actions, interventions, exhibitions, texts, etc " $" 187$ In this work, Karen Eliot is used for 1 llustrative purposes only As such, many of the characters appearıng in this work as "Karen Eliot" are either fictitious, pseudonymous, or friends amenable to my portrayal of them as "Karen Eliot," and any resemblance to real or unreal persons, living or dead, while not entrely coincidental, is purely expressive of my point that wherein the symbolic processes which allow one to manipulate the objects and events of one's material environment exhibit a form of independence from said environment that makes them capable of being "open-endedly manipulated in relation to those objects [events] and more easily prescribe their future manıpulation in time and space," 188 one may say or write whatever one wants to about something, and, upon condition of certain expressive correspondences, affect how this something is (or is not) taken up and makes (non)sense

${ }^{187}$ Stuart Home, http //www stewarthomesociety org/sp/eliot htm

${ }^{188}$ Shepherd, "Difference and Power in Music," 54 


\section{Confabulation}

I am a sick man...I am a spiteful man. I am an unattractive man. I believe my liver is diseased. However, I know nothing at all about my disease, and do not know for certain what ails me. I don't consult a doctor for it, and never have, though I have a respect for medicine and doctors. Besides, I am extremely superstitious, sufficiently so to respect medicine, anyway (I am welleducated enough not to be superstitious, but I am superstitious). No, I refuse to consult a doctor from spite. That you probably will not understand. Well, I understand it, though. Of course, I can't explain who it is precisely that I am mortifying in this case by my spite: I am perfectly well aware that I cannot "pay out" the doctors by not consulting them; I know better than anyone that by all this I am only injuring myself and no one else. But still, if I don't consult a doctor it is from spite. My liver is bad, well-let it get worse!

These words, spoken by Dostoyevsky's "Underground Man" over a century ago, express something of the spirit, but also the disquiet, that runs through this study. Though less rancorous in tone, this study is its own type of note from underground. However, in this story there is no rambling monologue, no mockery of the suffering that is born from the antinomies of reason and morality. Instead there is a puzzling over the boring formless nonsense of things that a failed experimental aesthetics, with pretensions to universality and radical inclusiveness, has remaindered. More specifically, there is an attempt to work through the problems of a will to abstraction that the largely white male discourse of experimental music sustains in virtual exile from present aesthetic concerns.

For Dostoyevsky, the secular reforms a mid-nineteenth-century Russian society were fundamentally flawed in their appeal to a particular form of instrumental of procedural reason whose abstract figure of humankind estranges "living life" from its concrete predicament. The Underground Man is the voice of a conflicted subject who withdraws into the inertia of this alienation to find himself full of spite and able only to articulate the torsions of an existential stalemate. But a hundred and fifty years later, after the virtual apocalypse of the real, there are no actual incongruities, no genuine discordance that circulates beyond its own sign. As such, there 
is no real crisis or deadlock-no underground. There is only a surface of having or not having an effect: success or failure. Whereas Dostoyevsky's notes came from below, mine come from what feels like "nowhere in particular," neither above nor to the side, nor here nor there. They seem to come from this angle and that---lines, planes, and vectors that are only these after the fact, after I've gotten their drift and had their adventures. Here inertia is replaced by chaos, and spite with delirium. So what can I say about this " $n t h$-estate" that doesn't already declare its own inversion, it own reversal, its own success?

I can say this: that only a male subject with certain political and social privileges could dwell on his serial failings and be convinced of their abstract potential. Perplexed and haunted by the well-rehearsed post-structuralist/feminist argument that the masculine subject is itself an abstraction constituted by a fallacious sense of its own universality, an aesthetics of failure has to be seen as highly seductive to a masculine subject, for it promises to recover something of his former abstraction, though in a seemingly less imperious, if more ethically perverse, form of genericity, a genericity that in its exile from both mainstream and marginal Western culture enjoys a certain neglect that encourages its going to seed and getting lost in the delirium of its own perception. The problem, however, is that such a boutique abstraction not only risks political impassivity, but the very will to abstraction that drives this delirium suffers from a seemingly irresistible tendency to veer into generality insofar as its figures exhibit a kind of independence from the political, social, and economic conditions that are immanent to its expression. Indeed, the will to abstraction that animates this study often wants to be "we," and it is all that I can do to displace it, again and again and again. And this is why I am not a sick but a confused and uncertain man supremely ambivalent about his powers to pay attention, to be interested and/or interesting, or to tell the truth. 
Admittedly, this is an idiosyncratic take on failure and diverges from the recent trend in art criticism to represent failure as a form of counter-hegemonic resistance. Though I share some of the latter sentiment, it seems to me that what is wanted from failure is too irregular, too elusive, that to pin it down ultimately corrupts what failure is supposed to represent, or not represent. In this respect, failure for me is polymorphic, it is something that occurs and can be expressed in many different forms. This doesn't mean that I don't favour certain forms of failure over others; as I explained at the beginning of this study, and as my examples demonstrate, I'm tuned into a narrow frequency where failure bleeds into other expressions such as insufficiency, distraction and dissemblance.

What it does mean is that I've approached failure as an imbroglio, as an event that is entangled in its own duplicity, its doubleness as both a qualified deviation from norms, and as something unqualified, something whose intensity hasn't been seized by a culture's familiar semiotic and practical relays of meaning and function. In this sense, failure's doubleness, which confuses judgment by invoking paradox and aporia, expresses the sense of an experimental event in that its outcome is not so much "unforeseen" as it is undecidable. And in being undecidable, failure suspends the ethical tradition that conflates capacity and necessity to regain something of the abstract potential of being to advance on novelty. The advantage of failure to draw on the abstract potential of being is that it reiterates the idea of "sovereignty" against the servility of calculated or instrumentally oriented being. But, as I intimated above, the disadvantage of positing failure in this way is that every expression of it risks not only a misplaced concreteness but hazards being mistaken for a general concept that it must always fail to satisfy.

So that's failure, but why is music important to this study? And furthermore, why do I consider this music and not something like droning doom metal or Sunn O))), the sloppy refrains 
of "Jandek," or the abstract acoustic realities of sound art? Well, there are a few ways I can answer this. One response, and probably the most difficult to justify, is that I am drawn to those the kind of sonic experiences that transport me, that meddle with my expectations and modulate my mood in a way that charms rather than simply deconstructs or critically reflects the phenomenology of perception.

For me, music that retains a force, a capacity to move or seduce someone into difference, evokes a set of concerns that I think were too hastily abandoned by the Cagean gesture to include every acoustic, and non-acoustic detail for that matter, within its remit. The temporal and affective relations that certain, if nonetheless confused, sonic expressions create are worth studying for the way they articulate with and modulate other phenomena. The music in this study can be understood then to bring to light a breed of post-Cagean experimentalism that reanimates the abstract potential of musical sound to have an effect, which here are thematized according to a capacity to bore, to deform, or to make sense. Maybe this makes me old-fashioned, but the preservation of music's capacity to do something... or not, puts music, more than say the perceptual fetishes of sound art, in much closer proximity to failure.

A second response to why music is important to this study is that before I even began graduate studies, I observed the virtual disappearance of composed music from debates about contemporary experimental aesthetics. For the most part, the discourses concerning the experimental in music seemed to shift to works that explore the disparate mediations of sound: circuit bending and noise music, for example are practices that interrogate music's thresholds of distortion and audibility, while the sampling obsession that's characteristic of so-called hauntological and Hypnagogic Pop music probe the memorial promises of recorded sound.

As a self-identified experimental composer, and someone committed to the way certain 
strains of post-modern philosophy prompt a creative advance on difference, I found myself wondering why I and others would still bother to pursue a practice that is not only hopelessly out of fashion, but seems to be moving into greater fields of irrelevance and deeper depths of obscurity (and also more severe rings of poverty). But rather than plead the case and work to convince both you and I that it's in fact not the case, that experimental composition is healthy and flourishing, I imagined that it would be more interesting to ask what happens when a highly reflective tradition is set adrift and rendered discourseless, made effectively peripheral to the peripheries that it once lived on.

The value in this approach is that it avoids the hapless histrionics of the dialectic whose show of critical defiance suffers the embarrassment of being already figured, and thereby defanged, by the discourses that it claims to negate. Setting music loose on the sea of obscurity promotes a kind of experimental movement where it clutches at the infinite...not to dissipate itself but, to quote Felix Guattari, to choose its finitude. In a sense, I pushed this already teetering music off the cliff in order to ask something about what happens to its valences, its power to combine with other cultural logics and forms, to ask what its fall (exemption) from vanguardist discourses open up or close down, to question whether its exile creates new networks of signification that are otherwise inaccessible to the digital habits of current aesthetic thought, and lastly, what is its point in being music and not an "intervention in and transformation of a wider acoustic ecology?"

These were some of my guiding questions. But in keeping with the spirit of the study and its intimacy with the risk of experimentation, I have to think that I failed to answer them. Yet, before I wholly scuttle this project, and so that I might emphasize the wager that I place on aesthetic failure to express what I characterize as "sheer relation," I want to suggest that maybe 
my questions are not questions so much as they are propositions, or what Alfred North Whitehead calls "lures for feeling" that together compose "the tales that might be told about particular actualities."

You'll notice that the tone and figures change dramatically over the course of the work. From the first chapter's more carefully composed scholarly gloss of boredom and its intervention in the discourse of depression, to the second chapter's self-conscious fragmentation of form and constellation of concepts, to the final chapter's play with symbolic realities and hyperfiction, there is an increasing involvement with the matter of writing. What happens is that the writing becomes progressively self-aware and sensitive to its own rhythms and colours, to the point where it seems to talk to itself as it talks to you, thereby blurring the linguistic protocols that differentiate the text from context, the reader from writer, and the subject from object. This process entailed a certain amount of mental acrobatics and an element of risk that $I$ think is fundamental to the aesthetic realities being invented by this nomadic music.

I have to say, however, that for a long time I wasn't certain how to describe the kind of enquiry that this is. I used to think about this kind of writing as embodying a "lyrical philosophy" in the sense that it folded the poetic and affective dimensions of the medium into its expressions. But last year I was fortunate enough to be able sit in on a seminar given by Brian Massumi at Cornell University that was focused primarily on the writings of Henri Bergson, William James, Whitehead and Deleuze. In this class, there was an emphasis given to the way that their writings not only theorized the mechanics of an active and change-based reality, but made an ethics of this reality by advocating a "life-creative."

In a recent talk at McGill University, Massumi described this as characteristic of an “activist philosophy." In bringing this up I'm suggesting that this work is itself something of an 
activist philosophy that entails a thinking which expresses an appetite to change the world in order to make its propositions true. Though I don't explicitly dwell on the particulars of process philosophy, the virtual commotion produced by my use of ironic tropes, excessive footnoting, a free indirect style, and various forms of hoaxing, makes this an activist work in the sense that it attempts to invent a new kind of language of expression whose weirdness is a semblance for the musical realities on whose behalf it acts. This is probably the most difficult and challenging dimension of $m y$ project. To create a rhetoric and vernacular that expresses the sense of an experimental music (which is a matter of how failure expresses the paradoxical set of variations that play across a dynamic unity composed of performers, instruments, sounds, listeners, styles, genres, expectations, intentions, habits, hesitations, mistakes, recoveries, repetitions, repetitions repetitions, cadences) is to invent a language that simulates the abstract relational potential that musicalized sounds convoke.

To a degree, Theodor Adorno attempted to create a kind of llanguage in critical terms by contorting and warping his words to match the convulsions of an imploded sense of alienation. And more recently, Kwodo Eshun, a largely unclassifiable writer and artist, composes "sonic fictions" that embody the movement and logic of "break-beat science" that informs the music of "Jungle," "Detroit techno" and early 80 s synth hip-hop. But no one has attempted to do this with regard to the obscure arts of contemporary experimental composition. In this dissertation, the digressions, the duplicity, the fictional personae, and the proliferation of inexistent compositions should be taken as phantasms of a musical reality that, perhaps more than any score or recording could, expresses the sense of failure as an abstract potential. Recalling then what I wrote at the beginning of this afterword, if what you've just read makes me sound delirious, then my "failing cant" will have succeeded. 


\section{Bibliography}

Adorno, Theodor W. Essays on Music. Translated by Susan H. Gillespie. Edited by Richard Leppert. Berkeley: University of California Press, 2002.

_. "Form in the New Music." Music Analysis 27, no. 2-3 (2008): 201-16.

-Introduction to the Sociology of Music. Translated by E.B. Ashton. New York: Seabury Press, 1976.

- "Music in the Background." In Essays on Music, edited by Richard Leppert. Berkeley: University of California Press, 2002.

- "On the Fetish-Character in Music." In Essays on Music, edited by Richard Leppert. Berkeley: University of California Press, 2002.

Agamben, Giorgio. "Bartleby, or on Contingency." In Potentialities: Collected Essays in Philosophy, edited by Daniel Heller-Roazen. Stanford: Stanford University Press, 1993.

Anderson, Ben. "Time-Stilled Space-Slowed: How Boredom Matters." Geoforum 35 (2004): 739-54.

Anderson, Sam. "In Defense of Distraction: Twitter, Adderall, Lifehacking, Mindful Jogging, Power Browsing, Obama's Blackberry, and the Benefits of Overstimulation." New York Magazine, 17 May 2009.

Arnold, Martin. "Observations About, around and Beside "Burrow out; Burrow in; Burrow Music.” PhD, University of Victoria, 1995.

Attali, Jacques. Noise: The Political Economy of Music. Minneapolis: University of Minnesota Press, 1985.

Barone, Chedomir. Personal communication, 2009.

Barrett, G. Douglas. Personal communication, 2009.

Barrett, G. Douglas, and Michael Winter. "Livescore: Real-Time Notation in the Music of Harris Wulfson." Contemporary Music Review 29, no. 1 (2010): 55-62.

Barthes, Roland. The Neutral: Lecture Course at the Collège De France, 1977-1978.

Translated by Rosalind Krauss and Denis Hollier. New York: Columbia University Press, 2005.

Bataille, Georges. Visions of Excess. Translated by Allan Stoekl. Edited by Allan Stoekl. Minneapolis: University of Minnesota Press, 1985.

Baudelaire, Charles. Les Fleurs Du Mal. Translated by Richard Howard. Boston: David R. Godine, 1985.

Baudrillard, Jean. The Conspiracy of Art: Manifestos, Interviews, Essays. Translated by Sylvère Lotringer, Semiotext(e) Foreign Agents Series. New York: Semiotext(e), 2005.

- Seduction. Translated by Brian Singer. New York: St. Martin's Press, 1990.

- Simulacra and Simulation. Translated by Sheila Glaser. Ann Arbor: University of Michigan Press, 1995.

- Symbolic Exchange and Death. Translated by Ian Hamilton Grant. London: Sage, 1993. 
Beckett, Samuel. Worstward Ho. London: John Calder, 1983.

Bell, Clive. Art. London: Chatto and Windus, 1949.

Benjamin, Walter. Arcades Project. Translated by Kevin McLaughlin Howard Eiland. Edited by Rolf Tiedemann. Cambridge, MA: Belknap Press of Harvard University Press, 2002.

- "The Work of Art in the Age of Mechanical Reproduction." In Illuminations, edited by Hannah Arendt. London: Fontana Press, 1992.

- The Writer of Modern Life: Essays on Charles Baudelaire. Translated by Rodney Livingstone, Edmund Jephcott, and Harry Zohn. Edited by Michael W. Jennings. Cambridge, MA: Belknap Press of Harvard University Press 2006.

Bennett, Bradley. "Doctrine of Signatures: An Explanation of Medicinal Plant Discovery or Dissemination of Knowledge?" Journal of the New York Botanical Garden 61, no. 3 (2007): 246-55.

Benson, Bruce Ellis. The Improvisation of Musical Dialogue: A Phenomenology of Music. Cambridge and New York: Cambridge University Press, 2003.

Benzon, William. Beethoven's Anvil: Music in Mind and Culture. Basic Books: New York, 2001.

Bergson, Henri. The Creative Mind. Translated by Mabelle L. Andison. New York: Philosophical Library, 1946.

- Matter and Memory. Translated by Nancy M. Paul and W. Scott Palmer. London; New York: G. Allen \& Co. and MacMillan Co., 1912.

Birkerts, Sven. The Gutenberg Elegies: The Fate of Reading in an Electronic Age. Boston: Faber and Faber, 1994.

Bissell, Tom. "Cinema Crudité: The Mysterious Appeal of the Post-Camp Cult Film." Harper's Magazine, August 2010, 58-65.

Blom, Ina. "Boredom and Oblivion." In The Fluxus Reader, edited by Ken Friedman, 6390. West Sussex, UK: Academy Editions, 1998.

Bogard, William. "Distraction and Digital Culture." ctheory, 5 October 2000. http://www.ctheory.net/articles.aspx?id=131.

Bogue, Ronald. Deleuze and Guattari. London; New York: Routledge, 1989.

_ Deleuze on Music, Painting, and the Arts. London: Routledge, 2003.

Bois, Yve-Alain, and Rosalind Krauss. Formless: A User's Guide. Cambridge, MA: MIT Press, 1997.

Bök, Christian. Eunoia. Toronto: Coach House Books, 2001.

__ 'Pataphysics: The Poetics of an Imaginary Science. Chicago: Northwestern University Press, 2002.

Bull, Michael. Sounding out the City: Personal Stereos and the Management of Everyday Life. London: Berg, 2000.

Bull, Michael, and Les Back. The Auditory Culture Reader. Oxford; New York: Berg, 2003.

Burrows, David. Time and the Warm Body: A Musical Perspective on the Construction of Time. Leiden; Boston Brill, 2007. 
Burt, Warren. "DECIBEL02: Warren Burt - Another Noisy Lullaby." Interview with Julian Day, Australian Music, Australian Broadcasting Corporation, 19 April 2010. http://www.abc.net.au/classic/australianmusic/stories/s2835399.htm.

- Personal communcation, 2010.

Busoni, Ferruccio. Sketch of a New Esthetic of Music. Translated by T.H. Baker. New York: G. Schrimer, 1911.

Cage, John. Silence: Lectures and Writings. Middletown, CN: Wesleyan University Press, 1961.

Caillois, Roger. Man, Play and Games. Translated by Meyer Barash. New York: Free Press of Glencoe, 1961.

Calvino, Italo. If on a Winter's Night a Traveler. Translated by William Weaver. New York: Harcourt Brace Jovanovich, 1981.

Caplan, Arthur, and Carl Elliott. "Should We Use Technology to Be Better Than Well?" PLoS Medicine 1, no. 3 (2004).

Carr, Nicholas. The Shallows: What the Internet Is Doing to Our Brains. New York; London: W.W. Norton and Company, 2010.

Carroll, Peter. Liber Null \& Psychonaut: An Introduction to Chaos Magic. York Beach: Weiser Books, 1987.

Carson, Anne. Decreation. Toronto: Vintage Canada, 2006.

Cascone, Kim. 'The Aesthetics of Failure: 'Post-Digital' Tendencies in Contemporary Computer Music.” Computer Music Journal 24, no. 4 (2000): 12-18.

Certeau, Michel de. The Practice of Everyday Life. Translated by Steven Rendall. Berkeley: University of California Press, 1984.

Chanan, Michael. Musica Practica: The Social Practice of Western Music from Gregorian Chant to Postmodernism. New York: Verso, 1994.

Charland, Louis C. "Emotion Experience and the Indeterminacy of Valence." In Emotion and Consciousness, edited by Lisa Feldman Barrett, Paula M. Niedenthal and Piotr Winkielman, 231-54. New York: The Guilford Press, 2005.

Chion, Michel. Audio-Vision: Sound on Screen. Translated by Claudia Gorbman. New York: Columbia University Press, 1994.

Christensen, Erik. "Overt and Hidden Processes in $20^{\text {th }}$-Century Music " Axiomathes 14, no. 1-3 (2004): 97-117.

Chusid, Irwin. Songs in the Key of Z: The Curious Universe of Outsider Music. Chicago: A Cappella, 2000.

Clark, Phillip. "Misshapen Identies." The Wire, November 2010, 45-49.

Cocker, Emma. "Over and over, Again and Again." In Failure, edited by Lisa Le Feuvre, 154-63. Cambridge, MA: MIT Press, 2010.

Conklin, Jeffery. "Hypertext: An Introduction and Survey." IEEE Computer 20 (1987): $17-41$.

Coon, Dennis. Psychology: A Journey. Toronto: Nelson Thomson Learning, 2009.

Couroux, Marc. Programme note, Carpenters et al., Downey Musical Holdings, a RealTime Social System as of March 29, 2007, 2010. http://couroux.org/?page_id=48. 
Cox, Christoph, and Daniel Warner. Audio Culture: Readings in Modern Music. New York: Continuum, 2004.

Cross, Ian. "Music and Meaning, Ambiguity and Evolution." In Musical Communication, 27-44. Oxford: Oxford University Press, 2005.

-. "Music, Cognition, Culture, and Evolution." Annals of the New York Academy of Sciences 930 (2001): 28-42.

Crowley, Aleister. Magick. Edited by Symonds John and Kenneth Grant. London: Routledge, 1973.

Crowley, Patrick, and Paul Hegarty. Formless: Ways in and out of Form. Bern: Peter Lang, 2005.

Csepregi, Gabor. The Clever Body. Calgary: University of Calgary Press, 2006.

Cusick, Suzanne G. "Music as Torture/Music as Weapon." Transcultural Music Review 10 (2006). http://www.sibetrans.com/trans/trans10/cusick_eng.htm.

_ " "You Are in a Place That Is out of the World. . .: Music in the Detention Camps of the 'Global War on Terror'." Journal of the Society for American Music 2, no. 1 (2008): 1-26.

Cusick, Suzanne G., and Branden Joseph. "Across an Invisible Line: A Conversation About Music and Torture." Grey Room 42 (2011): 6-11.

Dahlhaus, Carl. Nineteenth-Century Music. Berkeley: University of California Press, 1989.

Daston, Lorraine, and Katherine Park. Wonder and the Order of Nature. New York: Zone Books, 1998.

DECIBEL Ensemble. “Tape It!” Programme notes: Warren Burt, Another Noisy Lullaby. http://decibel.waapamusic.com/concert-1-tape-it/tape-it-program-notes/.

Delaforgem, Gaetan. "The Templar Tradition: Yesterday and Today." Gnosis 6 (1987), 8-13.

Deleuze, Gilles. Cinema 1: The Movement Image. Translated by Hugh Thomlinson and Barbara Haberjam. Minneapolis: University of Minnesota, 1989.

- Desert Islands and Other Texts, 1953-1974. Translated by Michael Taormina. Edited by David Lapoujade. Los Angeles; Cambridge, MA: Semiotext(e), 2004.

__. Difference and Repetition. New York: Columbia University Press, 1994.

_- Expressionism in Philosophy: Spinoza. Translated by Martin Joughin. New York: Zone Books, 1990.

- Francis Bacon: The Logic of Sensation. Translated by Daniel W. Smith. London: Continuum, 2003.

__. "Lecture Transcripts on Spinoza's Concept of Affect," 24 January 1978. http://www.webdeleuze.com/pdf/uk/Spinoza/240178.zip.

- The Logic of Sense. New York: Columbia University Press, 1990.

Deleuze, Gilles, and Felix Guattari. A Thousand Plateaus: Capitalism and Schizophrenia. Translated by Brian Massumi. Minneapolis: University of Minnesota Press, 1987.

___ What Is Philosophy? Translated by Hugh Tomlinson and Graham Burchell. New York: Columbia University Press, 1994. 
DeNora, Tia. Music in Everyday Life. Cambridge and New York: Cambridge University Press, 2000.

Didi-Huberman, Georges. La Ressemblance informe, ou, le gai savoir visuel selon Georges Bataille. Paris: Editions Macula, 1995.

Diederichshen, Diederich. On (Surplus) Value in Art. Rotterdam: Witte de With, 2008.

Dostoevsky, Fyodor. Notes from Underground. Translated by Constance Garnett. New York: Dover Publications, 1992.

Dretske, Fred. "Meaningful Perception." In An Invitation to Cognitive Science: Visual Cognition, edited by Daniel N. Osherson, Stephen Michael Kosslyn and Lila R. Gleitman, 331-52. Cambridge, MA: The MIT PRess, 1995.

Duffy, Simon. "The Logic of Expression in Deleuze's Expressionism in Philosophy: Spinoza: A Strategy of Engagement." International Journal of Philosophical Studies 12, no. 1 (2004): 47-60.

Dworkin, Craig. Reading the Illegible. Evanston, IL: Northwestern University Press, 2003.

Ehrenberg, Alain. The Weariness of the Self: Diagnosing the History of Depression in the Contemporary Age. Montreal; Kingston: McGill-Queen's University Press, 2010.

Erlmann, Veit. Hearing Cultures: Essays on Sound, Listening, and Modernity. English ed. Oxford; New York: Berg, 2004.

Evens, Aden. Sound Ideas: Music, Machines, and Experience. Minneapolis: University of Minnesota Press, 2005.

Featherstone, Mike. Undoing Culture: Globalization, Postmoderism and Identity. London; Thousand Oaks, CA: Sage Publications, 1995.

Fink, Robert. Repeating Ourselves: American Minimal Music as Cultural Practice. Berkeley: University of California Press, 2005.

Fisher, Joel. "Judgement and Purpose." In $M / E / a / N / I / N / G$ : An Anthology of Artists" Writings, Theory, and Criticism edited by Susan Bee and Mira Schor, 155-62. Durham; London: Duke University Press, 2000.

Fisher, Mark. Capitalist Realism: Is There No Alternative? London: Zero Books, 2009.

_. "Flatline Constructs: Gothic Materialism and Cybernetic Theory-Fiction." PhD, University of Warwick, 1999.

Fisher, Philip. Wonder, the Rainbow, and the Aesthetics of Rare Experiences. Cambridge, MA: Harvard University Press, 1998.

Fleming, Chris, and John O'Carroll. “The Art of the Hoax." Parallax 16, no. 4 (2010): 45-59.

Foucault, Michel. "What Is an Author?" In The Foucault Reader edited by Paul Rabinow, 101-20. New York: Pantheon Books, 1984.

Frankfurt, Harry. On Bullshit. Princeton, NJ: Princeton University Press, 2005.

Fresh, Stuart. "A Short History of Grúpat," 2006. http://www.cmc.ie/articles/article1799.html.

Freud, Sigmund. The Interpretation of Dreams. Translated by James Strachey. New York: Basic Books, 1955. 
Friedlander, Emilie. "Horizons: What, If Any, Are the Politics of Hypnagogic Pop?," 28 September 2009. http://www.visitation-rites.com/2009/09/what-if-any-are-thepolitics-of-hynagogic-pop/.

Frith, Simon. Performing Rites: On the Value of Popular Music. Cambridge, MA: Harvard University Press, 1996.

Gibbons, Brian. Spirituality and the Occult. London; New York: Routledge, 2001.

Goehr, Lydia. The Imaginary Museum of Musical Works: An Essay in the Philosophy of Music. Oxford; New York: Clarendon Press; Oxford University Press, 1992.

Goffman, Erving. Behavior in Public Places: Notes on the Social Organization of Gatherings. New York: Free Press, 1963.

Goldman, Robert, and Stephen Papson. "Advertising in the Age of Hypersignification." Theory, Culture \& Society 11, no. 3 (1994): 23-53.

Goodman, Steve. Sonic Warfare: Sound, Affect, and the Ecology of Fear. Cambridge, MA: MIT Press, 2010.

Goodstein, Elizabeth S. Experience without Qualities: Boredom and Modernity. Stanford: Stanford University Press, 2005.

Groom, Nick. "The Condition of Muzak." Popular Music and Society 20, no. 3 (1996): 117.

Grosz, Elizabeth. Chaos, Territory, Art: Deleuze and the Framing of the Earth. New York: Columbia University Press, 2008.

Guattari, Felix. Chaosmosis: An Ethico-Aesthetic Paradigm. Translated by Paul Baines and Jullian Penfais. Innianapolis: Indiana University Press, 1995.

Harman, Graham. Guerrilla Metaphysics: Phenomenology and the Carpentry of Things. Chicago: Open Court, 2005.

Harrison, Paul. "Making Sense: Embodiment and the Sensibilities of the Everyday." Environment and Planning D: Society and Space 18, no. 4 (2000): 497-517.

Healy, Seán Desmond. Boredom, Self, and Culture. Rutherford; London: Fairleigh Dickinson University Press;, 1984.

Hedges, Chris. Death of the Liberal Class. New York: Nation Books, 2010.

Hegarty, Paul. "Formal Insistence." The Semiotic Review of Books 13, no. 2 (2003): 6-9.

___ "General Ecology of Sound: Japanese Noise Music as Low Form." In Le travail de

- Noise/Music: A History. New York: Continuum, 2007.

- - "Residue - Margin - Other: Noise as Ethics of Excess." In Argosfestival 2003, edited by Paul Willemsen and Frie Depraetere, 76-87. Brussels: Argo, 2003.

Hegel, G.W.F. Lectures on the History of Philosophy. Translated by E. S. Haldane and Frances H. Simson. Vol. 3. Lincoln: University of Nebraska Press, 1995.

Heidegger, Martin. Being and Time. Translated by John Macquarrie and Edward Robinson. Oxford: Blackwell, 1978.

- The Fundamental Concepts of Metaphysics: World, Finitude, Solitude. Translated by William McNeill and Nicholas Walker. Indianapolis: Indiana University Press, 2001. 
—_. "What Is Metaphysics?" In Basic Writings, edited by David Farrell Krell, 89-110. New York: Harper Perennial Modern Classics, 2008.

Heister, Hanns-Werner. "Music in Concert and Music in the Background: Two Poles of Musical Realization." In Companion to Contemporary Musical Thought, edited by John Paynter. London: Routledge, 1992.

Higgins, Dick. "Boredom and Danger." In Breaking the Sound Barrier: A Critical Anthology of the New Music, edited by Gregory Battcock, 20-27. New York: Dutton, 1982.

Higgins, Dick, and Hannah Higgins. "Synesthesia and Intersenses: Intermedia." Leonardo 34, no. 1 (2001): 54-55.

Highmore, Ben. Everyday Life and Cultural Theory: An Introduction. London; New York: Routledge, 2002.

_. "Unprocessed Data: Everyday Life in the Singular," 2005. http://www.daytodaydata.com/benhighmore.html.

Hofstadter, Douglas. Gödel, Escher, Bach: An Eternal Golden Braid. New York: Basic Books, 1979.

Hosokawa, Shuhei. The Aesthetics of Recorded Sound. Tokyo: Keiso Shobo, 1990.

Houellebecq, Michel. Platform. Translated by Frank Wynne. London: Heinemann, 2002.

Huebler, Douglas. "Untitled Statement." In Theories and Documents of Contemporary Art, edited by Kristine Stiles and Peter Selz. Berkeley: University of California Press, 1996.

Jackson, Maggie. Distracted: The Erosion of Attention and the Coming Dark Age. Amherst, NY: Prometheus Books, 2008.

Jakobson, Roman. "Shifters and Verbal Categories." In On Language, edited by Linda Waugh and Monique Monville-Burston, 386-92. Cambridge, MA: Harvard University Press, 1990.

James, William. Talks to Teachers on Psychology; and to Students on Some of Life's Ideals. New York: W.W. Norton, 1958.

Jameson, Fredric. Postmodernism, or, the Cultural Logic of Late Capitalism. Durham, NC: Duke University Press, 1991.

- "Theories of the Postmodern." In The Cultural Turn: Selected Writings on the Postmodern, 1983-1998, 20-32. London: Verso, 1998.

Kahn, Douglas. Noise, Water, Meat: A History of Sound in the Arts. Cambridge, MA: MIT Press, 1999.

Kant, Immanuel. Critique of Pure Reason. Translated by Paul Guyer and Allen Wood. Cambridge, MA: Cambridge University Press, 1999.

Kassabian, Anahid. "Ubiquitous Listening and Networked Subjectivity." Echo 2 (2001), http://www.echo.ucla.edu/volume3-issue2/kassabian/index.html.

- "Would You Like Some World Music with Your Latte? Starbucks, Putumayo, and Distributed Tourism." Twentieth Century Music 2, no. 1 (2004): 209-23.

Katz, Ruth. A Language of Its Own: Sense and Meaning in the Making of Western Art Music. Chicago: The University of Chicago Press, 2009. 
Keenan, David. "Hypnagogic Pop." The Wire 306 (August 2009).

Keep, Christopher, Tim McLaughlin, and Robin Parmar. "The Electronic Labyrinth," 2001. http://www2.iath.virginia.edu/elab/.

Kierkegaard, Sören. Either/Or. Translated by Howard V. Hong and Edna H. Hong. Princeton: Princeton University Press, 1988.

Klapp, Orrin. Overload and Boredom. New York: Greenwood Press, 1986.

Koopman, Colin. "Pragmatism as a Philosophy of Hope: Emerson, James, Dewey, Rorty." The Journal of Speculative Philosophy 20, no. 2 (2006): 106-16.

Kostelanetz, Richard. Conversing with Cage. New York: Routledge, 2003.

Kracauer, Siegfried. "Boredom." In The Mass Ornament: Weimar Essays, edited by Thomas Y. Levin, 331-34. Cambridge, MA: Harvard University Press, 1995.

—_. "The Cult of Distraction: On Berlin's Pleasure Palaces." In The Mass Ornament: Weimar Essays, edited by Thomas Y. Levin. Cambridge, MA: Harvard University Press, 1995.

Kramer, Jonathan. The Time of Music: New Meanings, New Temporalities, New Listening Strategies. New York: Schrimer, 1988.

Krauss, Rosalind E. "Video: The Aesthetics of Narcissism." October 1 (1976): 50-64.

Kuberski, Philip. Chaosmos: Literature, Science, and Theory. Albany: State University of New York Press, 1994.

LaBelle, Brandon. Background Noise: Perspectives on Sound Art. New York: Continuum, 2006.

Lacan, Jacques. On Feminine Sexuality, the Limits of Love and Knowledge: The Seminar of Jacques Lacan, Book XX Encore 1972-1973. Translated by Jacques-Alain Miller. New York: Norton, 1998.

Langer, Susanne. Feeling and Form. New York: Charles Scribner's Sons, 1953.

Le Feuvre, Lisa. Failure. Cambridge, MA: MIT Press, 2010.

Lecercle, Jean-Jacques. Philosophy of Nonsense: The Intuitions of Victorian Nonsense Literature. London: Routledge, 1994.

Lewis, Michael. Derrida and Lacan: Another Writing. Edinburgh: Edinburgh University Press, 2008.

Licht, Alan. Sound Art: Beyond Music, between Categories. New York, NY: Rizzoli International Publications, 2007.

Lingis, Alphonso. "Language and Persecution." In Between Deleuze and Derrida, edited by Paul Patton and John Protevi. London; New York: Continuum, 2003.

___ . "The Dreadful Mystic Banquet." Janus Head 2 (2000). http://www.janushead.org/3-2/lingis.cfm.

Lyotard, Jean-François. Discourse, Figure. Translated by Antony Hudek and Mary Lydon. Minneapolis: University of Minnesota Press, 2011.

_. Libidinal Economy. Translated by Iain Hamilton Grant. Bloomington: Indiana University Press, 1993

-. Perigrinations: Law, Form, Event. New York: Columbia University Press, 1988. 
- The Postmodern Condition: A Report on Knowledge. Translated by Geoff

Bennington and Brian Massumi. Minneapolis: University of Minnesota Press, 1984.

Mac Low, Jackson. Thing of Beauty. Edited by Anne Tardos. Berkely: University of California Press, 2009.

Mann, Paul. Masocriticism. Albany: State University of New York Press, 1999.

The Theory-Death of the Avant-Garde. Bloomington: Indiana University Press, 1991.

Marder, Michael. "Heidegger's 'Phenomenology of Failure' in Sein Und Zeit." Phillosophy Today 51, no. 1 (2007): 69-78.

Marx, Karl, and Friedrich Engels. The Communist Manifesto. Translated by Samuel Moore. London: Penguin Classics, 2002.

Massumi, Brian. "Fear (the Spectrum Said)." Positions 13, no. 1 (2005): $31-48$.

- Parables for the Virtual: Movement, Affect, Sensation. Durham, NC: Duke University Press, 2002.

—. "Perception Attack: Brief on War Time." Theory and Event 13, no. 3 (2010).

_ . "Potential Politics and the Primacy of Preemption." Theory and Event 10, no. 2 (2007).

- "The Thinking-Feeling of What Happens." Inflexions 1, no. 1 (2008).

Massumi, Brian, and Kenneth Dean. "First and Last Emperors: The Absolute State and the Body of the Despot." Brooklyn, NY: Autonomedia, 1992.

Mauceri, Frank X. "From Experimental Music to Musical Experiment." Perspectives of New Music 35, no. 1 (1997): 187-204.

Mauss, Marcel. A General Theory of Magic. Translated by Robert Brain. London; New York: Routledge, 2001.

Mavromatis, Andreas. Hypnagogia: The Unique State of Consciousness between Wakefulness and Sleep. London: Routledge, 1987.

Maxwell, Devin. Personal communication, 2009.

McClary, Susan. "Narrative Agendas in 'Absolute Music'." In Musicology and Difference: Gender and Sexuality in Music Scholarship, edited by Ruth A. Solie, 326-44. Berkeley: University of California Press 1995.

McCort, Dennis. Going Beyond the Pairs: The Coincidence of Opposites in German Romanticism, Zen, and Deconstruction. Albany: State University of New York Press, 2001.

Mcluhan, Marshall. Understanding Media: The Extensions of Man. New York: McGrawHill, 1964.

Merleau-Ponty, Maurice. The Visible and the Invisible. Translated by Alfonso Lingis. Evanston, IL: Northwestern University Press, 1968.

Menke, Christoph. The Sovereignty of Art: Aesthetic Negativity in Adorno and Derrida. Translated by Neil Solomon. Cambridge, MA: MIT Press, 1999.

Meyer, Leonard B. Emotion and Meaning in Music. Chicago: University of Chicago Press, 1956.

Midgette, Ann. "Pioneer. Composer. Psychoacoustician?" New York Times, 8 May 2005. 
Miller, Nancy K. "The Text's Heroine: A Feminist Critic and Her Fictions." Diacritics 12, no. 2 (1982): 48-53.

Monsell, Stephen, and Jon Driver, eds. Control of Cognitive Processes: Attention and Performance XVIII. Cambridge, MA: MIT Press, 2000.

Morrison, Grant. "Pop Magic!" In Book of Lies: The Disinformation Guide to Magick and the Occult (Being an Alchemical Formula to Rip a Hole in the Fabric of Reality), edited by Richard Metzger, 16-25. New York: The Disinformation Company, 2003.

Negarestani, Reza, "The Horror of Something: Commentaries on the Littered Universe and the Weird," 2008. Eliminative Culinarism (blog). http://blog.urbanomic.com/cyclon/archives/2008/06/the_weird_is_th.html

Ngai, Sianne. Ugly Feelings. Cambridge, MA: Harvard University Press, 2005.

Nietzsche, Freidrich. The Birth of Tragedy and the Case of Wagner. Translated by Walter Kaufman. New York: Vintage, 1967.

Nietzsche, Freidrich. Human, All Too Human. Translated by R. J. Hollingdale. Cambridge: Cambridge University Press, 1996.

Nyman, Michael. Experimental Music: Cage and Beyond. Cambridge; New York: Cambridge University Press, 1999.

Ondaatje, Michael. Coming Through Slaughter. Toronto: Coach House Press, 1976.

Ostergaard, Geoffrey. "Anarchism." In A Dictionary of Marxist Thought, edited by Tom Bottomore, Laurence Harris, V. G. Kiernan and Ralph Miliband, 21-23. Oxford: Blackwell Publishing, 1991.

Owen, David. "The Soundtrack of Your Life." The New Yorker, 10 April 2006.

Pape, Gerard. "Varèse the Visionary." Contemporary Music Review 23, no. 2 (2004): 1925.

Patton, Paul. "The World Seen from Within." Theory and Event 1, no. 1 (1997).

Pesce, Mark. "The Executable Dreamtime." In Book of Lies: The Disinformation Guide to Magick and the Occult (Being an Alchemical Formula to Rip a Hole in the Fabric of Reality), edited by Richard Metzger, 26-31. New York: The Disinformation Company, 2003.

Pessoa, Fernando. The Book of Disquiet. Translated by Richard Zenith. London: Penguin Classics, 2002.

Phillips, Adam. On Kissing, Tickling, and Being Bored: Psychoanalytic Essays on the Unexamined Life. Cambridge: Harvard University Press, 1993.

Pieslak, Jonathan. Sound Targets: American Soldiers and Music in the Iraq War. Bloomington: Indiana University Press, 2009.

P-Orridge, Genesis. "Thee Splinter Test." In Book of Lies: The Disinformation Guide to Magick and the Occult (Being an Alchemical Formula to Rip a Hole in the Fabric of Reality), edited by Richard Metzger, 138-48. New York: The Disinformation Company, 2003.

Priest, eldritch. "Like Good Acid and the Residue of Pleasure Drenching...." MMus, University of Victoria, 2004. 
Quinn, Dennis. Iris Exiled: A Synoptic History of Wonder. Lanham, MD: University Press of America, 2002.

Racker, Heinrich. "Contribution to Psychoanalysis of Music." American Imago 8, no. 2 (1951): 129-63.

Radano, Ronald Michael. "Interpreting Muzak: Speculations on Musical Experience in Everyday Life." American Music 7, no. 4 (1989): 448-60.

Reich, Steve. "Music as Gradual Process." In Writings on Music, 1965-2000, edited by Paul Hillier, 34-36. Oxford; New York: Oxford University Press, 2002.

Renzetti, Elizabeth, and Simon Houpt. "The All-Stars of Absurdism Face Off." The Globe and Mail, 16 May 2009.

Ross, Christine. The Aesthetics of Disengagement: Contemporary Art and Depression. Minneapolis: University of Minnesota Press, 2006.

_. "The Temporalities of Video: Extendedness Revisited." Art Journal 65, no. 3 (2006): 82-99.

Rubinstein, Joshua S., David E. Meyer, and Jeffrey E. Evans. "Executive Control of Cognitive Processes in Task Switching." Journal of Experimental Psychology: Human Perception and Performance 27, no. 4 (2001): 763-97.

Sartre, Jean-Paul. Being and Nothingness. Translated by Hazel Estella Barnes. New York: Washinton Square Press, 1984.

—_. Nausea. Translated by Lloyd Alexander. New York: New Directions Publishing, 1969.

Sass, Louis A. Madness and Modernism: Insanity in the Light of Modern Art, Literature, and Thought New York: Basic Books, 1992.

Saunders, James. The Ashgate Research Companion to Experimental Music. Burlington, VT: Ashgate, 2009.

Scarry, Elaine. The Body in Pain: The Making and Unmaking of the World. Oxford: Oxford University Press, 1985.

Schafer, R. Murray. The Soundscape: Our Sonic Environment and the Tuning of the World. Rochester, VT: Destiny Books, 1993.

Sewell, Elizabeth. The Field of Nonsense. London: Chatto and Windus, 1952.

Shepherd, John. "Difference and Power in Music." In Musicology and Difference, edited by Ruth A. Solie, 46-65. Berkeley; Los Angeles: University of California Press, 1993.

Shepherd, John, and Peter Wicke. Music and Cultural Theory. Cambridge: Polity Press, 1997.

Sigman, Mariano, and Stanislas Dehaene. "Dynamics of the Central Bottleneck: DualTask and Task Uncertainty." PLoS Biololgy 4, no. 7 (2006).

Simmel, Georg. "The Metropolis and Mental Life." In The Sociology of Georg Simmel, 409-17. New York: Free Press, 1964.

Singer, Irving. Feeling and Imagination. Lanham, MD: Rowman \& Littlefield, 2001.

Smith, Terry. What Is Contemporary Art? Chicago: University Of Chicago Press, 2009. 
Sodian, Beate, Catherine Taylor, Paul L. Harris, and Josef Perner. "Early Deception and the Child's Theory of Mind: False Trails and Genuine Markers." Child Development 62, no. 3 (1991): 468-83.

Solnit, Rebecca. A Field Guide to Getting Lost. New York: Viking, 2005.

Stagoll, Cliff. "Concepts." In The Deleuze Dictionary, edited by Adrian Parr, 50-51. Edinburgh: Edinburgh University Press, 2005.

__. "Event." In The Deleuze Dictionary, edited by Adrian Parr, 87-89. Edinburgh: Edinburgh University Press, 2005.

Steenhuisen, Paul. Sonic Mosaics: Conversations with Composers. Edmonton: University of Alberta Press, 2009.

Stein, Gertrude. The Making of Americans: Being a History of a Family's Progress. New York: Something Else Press, 1966.

Sterne, Jonathan. The Audible Past: Cultural Origins of Sound Reproduction. Durham, NC: Duke University Press, 2003.

___ "Sounds Like the Mall of America: Programmed Music and the Architectonics of Commercial Space." Ethnomusicology 41, no. 1 (1997): 22-50.

Subotnik, Rose Rosengard. "On Deconstructing Structural Listening." In Music, Culture, and Society: A Reader, edited by Derek B. Scott. Oxford; New York: Oxford University Press, 2000.

Spare, Austin Osman. The Book of Pleasure. Sioux Falls, SD: NuVision Publications, 2007.

Stewart, Susan. Nonsense: Aspects of Intertextuality in Folklore and Literature. Baltimore: Johns Hopkins University Press, 1979.

Stivale, Charles. Gilles Deleuze: Key Concepts. Montreal: McGill-Queen's University Press, 2005.

Suskind, Ron. "Without a Doubt." New York Times Magazine, 14 October 2004.

Sumrell, Robert, and Kazys Varnelis. Blue Monday: Stories of Absurd Realities and Natural Philosophies. Barcelona: Actar Editorial, 2007.

Svendsen, Lars. A Philosophy of Boredom. Translated by John Irons. London: Reaktion Books, 2005.

Tacchi, Jo. "Radio Texture: Between Self and Others." In Material Cultures: Why Some Things Matter, edited by Daniel Miller, 25-47. Chicago: University of Chicago Press, 1998.

Terada, Rei. Looking Away: Phenomenality and Dissatisfaction, Kant to Adorno. Cambridge, MA: Harvard University Press, 2009.

Théberge, Paul. Any Sound You Can Imagine: Making Music/Consuming Technology. Hanover, NH: Wesleyan University Press; University Press of New England, 1997.

Thorpe, Josh. "Here Hear: My Recent Compositions in a Context of Philosophy and $20^{\text {th }}$ Century Experimental Music." MA, York University, 2000.

Tiffany, Daniel. Infidel Poetics: Riddles, Nightlife, Substance. Chicago: University of Chicago Press, 2009.

Tigges, Wim. Explorations in the Field of Nonsense. Amsterdam: Rodopi, 1987. 
Toulmin, Stephen. Cosmopolis: The Hidden Agena of Modernity. Chicago: University of Chicago Press, 1992.

Ulmer, Gregory. Heuretics: The Logic of Invention. Baltimore; London: The Johns Hopkins University Press, 1994.

U. $\therefore$. , Frater. High Magic: Theory \& Practice. St. Paul, MN: Llewellyn Publications, 2005.

Urgo, Joseph. In the Age of Distraction. Jackson, MS: University Press of Mississippi, 2000.

Vare, Robert. "Discophobia." New York Times, 10 July 1979.

Vermeir, Koen. "The Reality of Failure: On the Interpretation of Success and Failure in (the History and Philosophy of) Science and Technology." In Variantology 2: On Deep Time Relations of Arts, Sciences and Technologies, edited by Siegfried Zielinski and David Link. Köln: Buchhandlung Walther König, 2006.

Volcker, Paul. "The Time We Have Is Growing Short." The New York Review of Books, 24 June 2010.

Wallace, David Foster. A Supposedly Fun Thing I'll Never Do Again: Essays and Arguments. Boston: Little, Brown and Co., 1997.

- "Wiggle Room." The New Yorker, 9 March 2009.

Walton, Kendall. Mimesis as Make-Believe: On the Foundations of the Representational Arts. Cambridge, MA: Harvard University Press, 1990.

—. "Précis of Mimesis as Make-Believe." Philosophy and Phenomenological Research 51, no. 2 (1991): 379-82.

Warren, Jeff. "The Hypnopompic." In The Head Trip: Adventures on the Wheel of Consciousness. New York: Random House, 2007.

Waugh, Patricia. Metafiction: The Theory and Practice of Self-Conscious Fiction. London; New York: Methuen, 1984.

Weiss, Gail. Refiguring the Ordinary. Bloomington: Indiana University Press, 2008.

Wernick, Andrew. "Bataille's Columbine: The Sacred Space of Hate." ctheory, 3 November 1999. http://www.ctheory.net/articles.aspx?id=119.

Wike, Victoria. Kant's Antinomies of Reason. Lanham, MD: University Press of America, 1982.

Williams, James. Gilles Deleuze's Logic of Sense: A Critical Introduction and Guide. Edinburgh: Edinburgh University Press, 2008.

Wolf, Werner. "Metafiction and Metamusic: Exploring the Limits of Metareference." In Self-Reference in the Media, edited by Winifried Nöth and Nina Bishar, 303-24. Berlin; New York: Mouton de Gruyter, 2007.

Wolff, Janet. "The Ideology of Autonomous Art." In Music and Society: The Politics of Composition, Performance and Reception, edited by Richard Leppert and Susan McClary, 1-12. Cambridge: Cambridge University Press, 1987. 